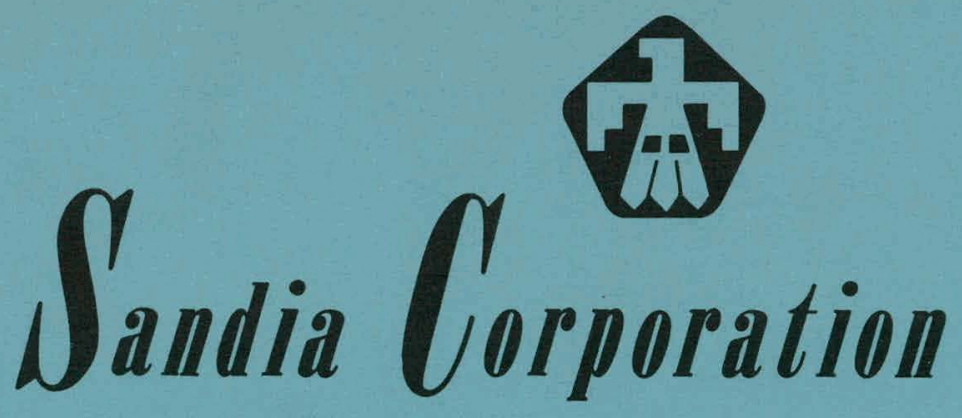

• MONOGRAPH

\title{
GRAPHS OF THE HYPERGEOMETRIC \\ O.C. AnD A.0.Q. FUnCTIONS fOR \\ LOT SIZES 10 TO 225
}

\author{
by \\ C R Clark \\ and \\ L H Koopmans
}

SEPTEmBER 1959 


\section{DISCLAIMER}

This report was prepared as an account of work sponsored by an agency of the United States Government. Neither the United States Government nor any agency Thereof, nor any of their employees, makes any warranty, express or implied, or assumes any legal liability or responsibility for the accuracy, completeness, or usefulness of any information, apparatus, product, or process disclosed, or represents that its use would not infringe privately owned rights. Reference herein to any specific commercial product, process, or service by trade name, trademark, manufacturer, or otherwise does not necessarily constitute or imply its endorsement, recommendation, or favoring by the United States Government or any agency thereof. The views and opinions of authors expressed herein do not necessarily state or reflect those of the United States Government or any agency thereof. 


\section{DISCLAIMER}

Portions of this document may be illegible in electronic image products. Images are produced from the best available original document. 


\section{LEGAL NOTICE}

This report was prepared as an account of Government sponsored work. Neither the United Slates, nor the Commission, nor any person acting on behalf of the Commission:

A. Makes any warranty or representation, expressed or implied, with respect to the accuracy, completeness, or usefulness of the information contained in this report, or that the use of any information, apparatus, method, or process disclosed in this report may not infringe privately owned rights; or

B. Assumes any liabilities with respect to the use of, or for damages resulting from the use of any information, apparatus, method, or process disclosed in this report.

As used in the above, "person acting on behalf of the Commission" includes any employee or contractor of the Cormission, or employee of such contractor, to the extent that such employee or contractor of the Commission, or employee of such contractor prepares, disseminates, or provides access to, any information pursuant to his employment or contract with the Commission, or his employment with such contractor.

Printed in USA. Price $\$ 3.00$. Available from the Office of

Technical Services, Department of Commerce

Washington 25, D. C. 
SCR -121

TID -4500 (15 th Edition)

Statistics and Quality Control

SANDIA CORPORATION MONOGRAPH

GRAPHS OF THE HYPERGEOMETRIC

O.C. AND A.O.Q. FUNCTIONS FOR

LOT SIZES 10 TO 225

by

C. R. Clark

and

L. H. Koopmans

September 1959

f

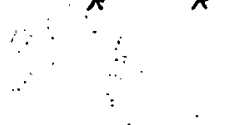




\begin{abstract}
Graphs of the hypergeometric operating characteristic (O.C.) and average outgoing quality (A.O.Q.) functions are given for lot oizco 10 : to 226 and various sample sizes.

Section.I includes graphs for acceptance numbers $0(1) 2$ and Section I I includes graphs for acceptance numbers $0(1) 3$.
\end{abstract}




\section{ACKNOW LEDGMENT}

Thanks are due to Mr. W. W. Whisler lür translating the computing program of the second author into machine code for the CRC-102A. Both authors gratefully acknowledge their appreciation to the staff assistants of Division 5125, Sandia Corporation, for their thorough and skillful checking of the data and initial plotting of the graphs. The coordination of the technical work was expertly accomplished by Mr. Max Weber, Division 5121. 


\section{GRAPHS OF THE HYPERGEOMETRIC \\ O.C. AND A.O.Q. FUNCTIONS FOR \\ LOT SIZES 10 TO 225}

Most of the existing collections of operating characteristic curves for sampling plans based on sampling without replacement have used binomial or Poisson approximations to the hypergeometric distribution. When the lot size is small, or the sample size is a significant fraction of the lot size, these curves may not be sufficiently accurate to provide the sampling economy necessary in many applications. For this reason, Wiesen (Ref. 1) has compiled a set of graphs of the operating characteristic (O.C.) and average outgoing quality (A.O.Q.) functions for single sampling plans based on the hypergeometric distribution which covers the range of large lot sizes $N$ and sample sizes $n$ (see Fig. 1, code $x)$. The present monograph extends this collection to include the additional lot sizes and sample sizes plntted in Figurc 1 (codes $\bullet, 0$, and $\Delta$ ).

As noted in Figure 1, the graphs are classified into two sections according to lot and sample size. The acceptance numbers for the curves of Section I (pp.11-50) are $a=0,1$, and 2, and those for Section II (pp.51-172) are $a=0,1,2$, and 3 .

The functions plotted are:

a. The O.C. function, $100 \mathrm{P}\left(\mathrm{D} ; \mathrm{N}, \mathrm{n}\right.$, a) versus $100 \frac{\mathrm{D}}{\mathrm{N}}$,

where*

$$
P(D ; N, n, a)=\sum_{x=0}^{a} \frac{\left(\begin{array}{l}
D \\
x
\end{array}\right)\left(\begin{array}{l}
N-D \\
n-x
\end{array}\right)}{\left(\begin{array}{l}
N \\
n
\end{array}\right)}
$$

"The binomial coefficient, $\left(\begin{array}{l}a \\ b\end{array}\right)$, is defined to be $\frac{a !}{b !(a-b) !}$ for integral values of $b$ and $a$ satisfying the inequalities $0 \leq b \leq a$ and is zero elsewhere. 


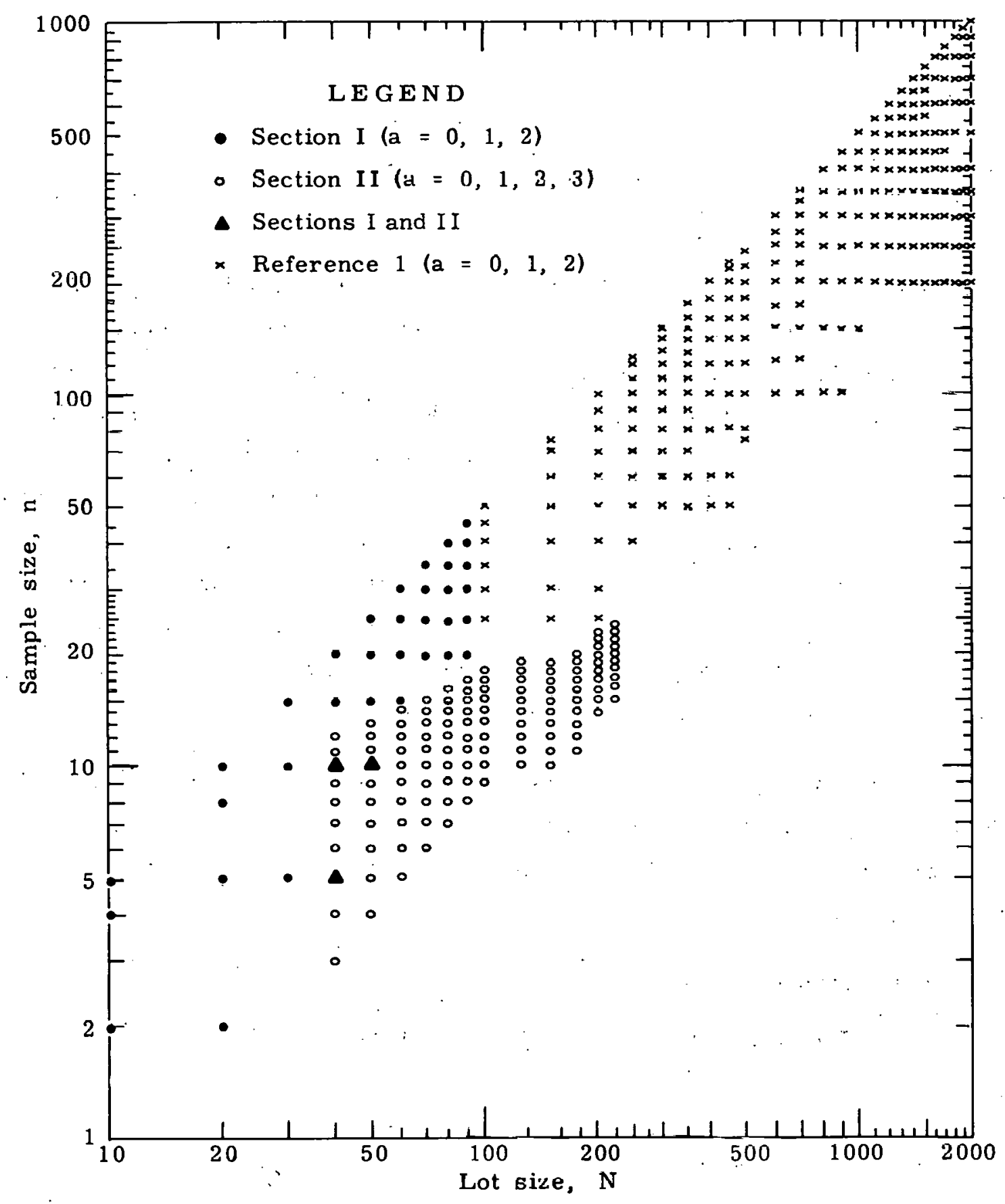

Fig. 1 -- Values of lot size $\mathrm{N}$ and sample size $\mathrm{n}$ for which graphs of the hypergeometric O.C. and A.O.Q. functions exist 
is the probability of accepting a lot of size $\mathrm{N}$ containing exactly $\mathrm{D}$ defective items based on a single sampling plan which specifies sample size $n$ and acceptance number a; and

$$
\text { b. The A.O.Q. function, } 100 \mathrm{~A}(\mathrm{D} ; \mathrm{N}, \mathrm{n}, \mathrm{a}) \text { versus } 100 \frac{\mathrm{D}}{\mathrm{N}} \text {, }
$$

where

$$
A(D ; N, n, a)=\frac{D}{N} P(D ; N, n, a)
$$

is the average proportion defective in all outgoing lots initially containing $D$ defective items when all defective items in rejected lots are replaced with good ones, and the proportion defective in accepted lots is unchanged by the sampling procedure. Although the O.C. and A.O.Q. functions are defined only for integral values of $D$, they are plotted as continuous curves to conform with past practice and to give a better visual representation of the functions.

Reference 2 contains derivations of Equations (1) and (2) along with examples illustrative of their applications. Additional theory and tables and graphs of the O.C. functions for several sampling plans based on infinite lot approximations are available in References 3,4 , and 5 .

Some recent contributions to the literature on hypergeometric sampling plans are given in References 6 and 7. Reference 6 contains graphs for determining the sample size necessary to ensure high lot reliability (maximum allow able value of $\mathrm{D} / \mathrm{N}=0.0001,0.0005,0.001,0.005)$ with various confidences $(0.50,0.90,0.95$, and 0.99$)$. The results are graphed for acceptance numbers 0 and 1.

A convenient approximation to the sample size necessary to ensure a desired lot reliability with arbitrary confidence for acceptance number 0 is given in Reference 7.

Tables of point and summed hypergeometric probabilities for small lot sizes $(1 \leq N \leq 50)$ correct to six decimal places may be obtained from Refer ence 8 .

The subdivision of the present set of graphs into two sections is motivated by the separate uses for which they were originally intended. The first author of this paper used an LGP-30 computer to compute the numbers plotted on the 
graphs contained in Section I. These graphs are to be used by the Statistics and Evaluation Division of the Reliability Department 1590, Sandia Corporation. The graphs of Section II were compiled by the second author at the request of the Quality Assurance Procedures Division of the Quality Assurance Department 5510. Figure 1 facilitates easy reference to the proper section for a given lot size and sample size. 


\section{REFERENCES}

1. Wiesen, J. M., Extension of Existing Tables of Attribute Sampling Plans, Sandia Corporation Technical $\overline{\text { Memorandum SC }} \overline{\mathrm{TM}} \overline{42-58(12)}, \overline{\text { February }} \overline{4,19} 58$.

2. Burr, I., Engineering Statistics and Quality Control, McGraw Hill, 1953.

3. Statistical Research Group, Columbia University, Sampling Inspection, McGraw Hill, 1948.

4. MIL-STD-105A, Sàmpling Procedures and Tables for Inspection by Attributes, Department of Defense, 1950.

5. Doḍge, H. F., and Romig, H. G., Sampling Inspection Tables, Wiley, 1959.

6. Barker, B. E., Attribute Sampling Plans for Assuring High Lot Reliability, Sandia Corporation Technical Memorandum SC TM 352-58(51), December 19, 1958.

7. Owen, D. B., Gilbert, E. J., Steck, G. P., and Young, D. A., A Formula for Determining Sample Size in Hypergeometric Sampling When Zero Defectives are Observed in the Sample, Sandia Corporation. Technical

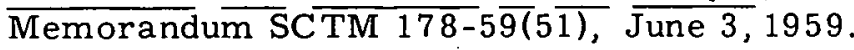

8. Owen, D. B., Tabulation of the Hypergeometric Probability Distribution for Lot Sizes Less Than or Equal to 50, Sandia Corporation Technical Memorandum SCTM $\overline{215-59(51), 1959 .}$ 


\section{SECTION I}

O.C. and A. O.Q. Curves for

$\begin{array}{ll}\frac{\mathrm{N}}{10} & \frac{1}{\mathrm{n}} \\ 20 & 2,4,5 \\ 30 & 2,5,8,10 \\ 40 & 5(5) 15 \\ 50 & 5(5) 20 \\ 60 & 10(5) 25 \\ 70 & 15(5) 30 \\ 80 & 20(5) 35 \\ 90 & 20(5) 40 \\ & 20(5) 45\end{array}$




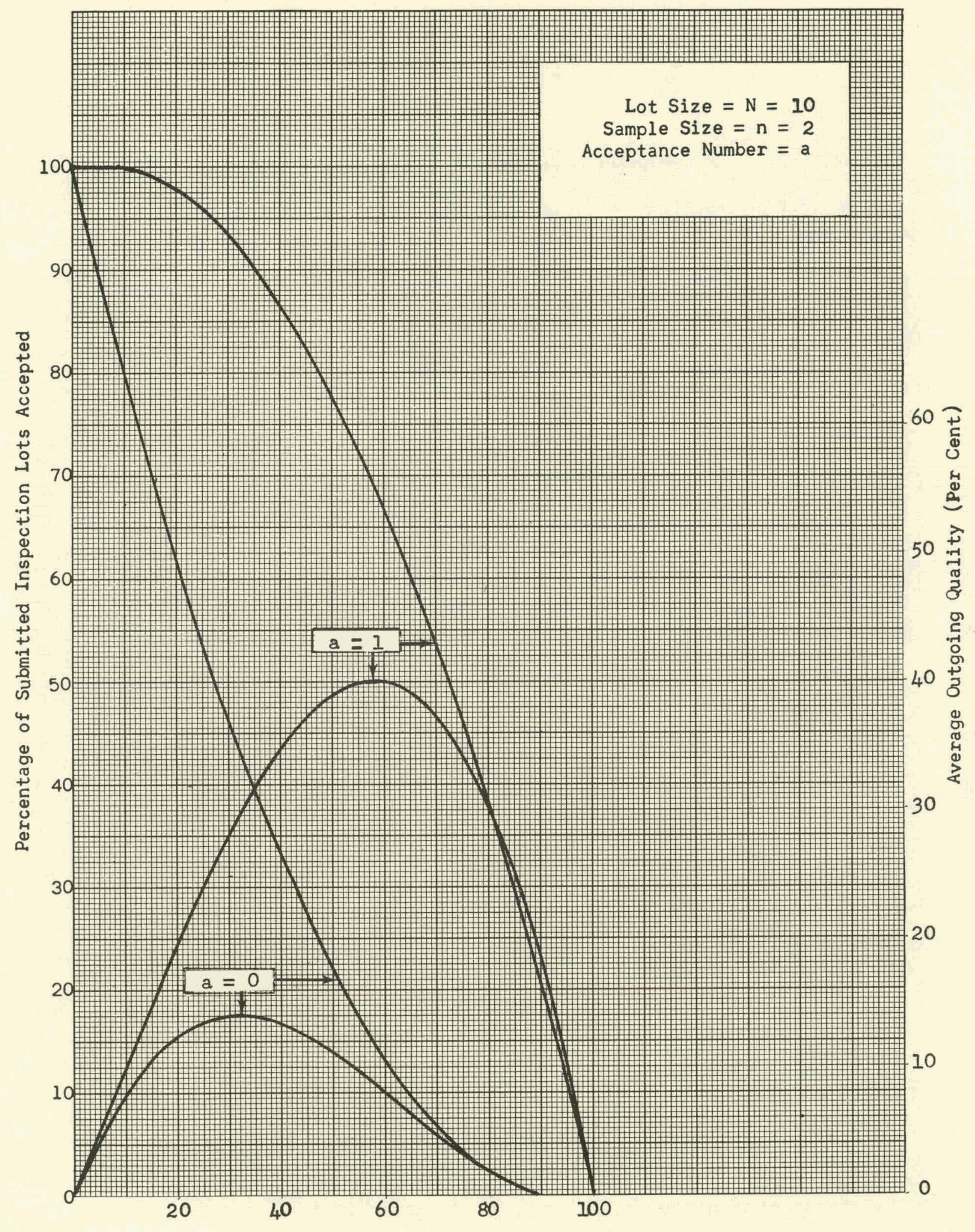

Percentage of Defective Items in Submitted Inspection Lots 


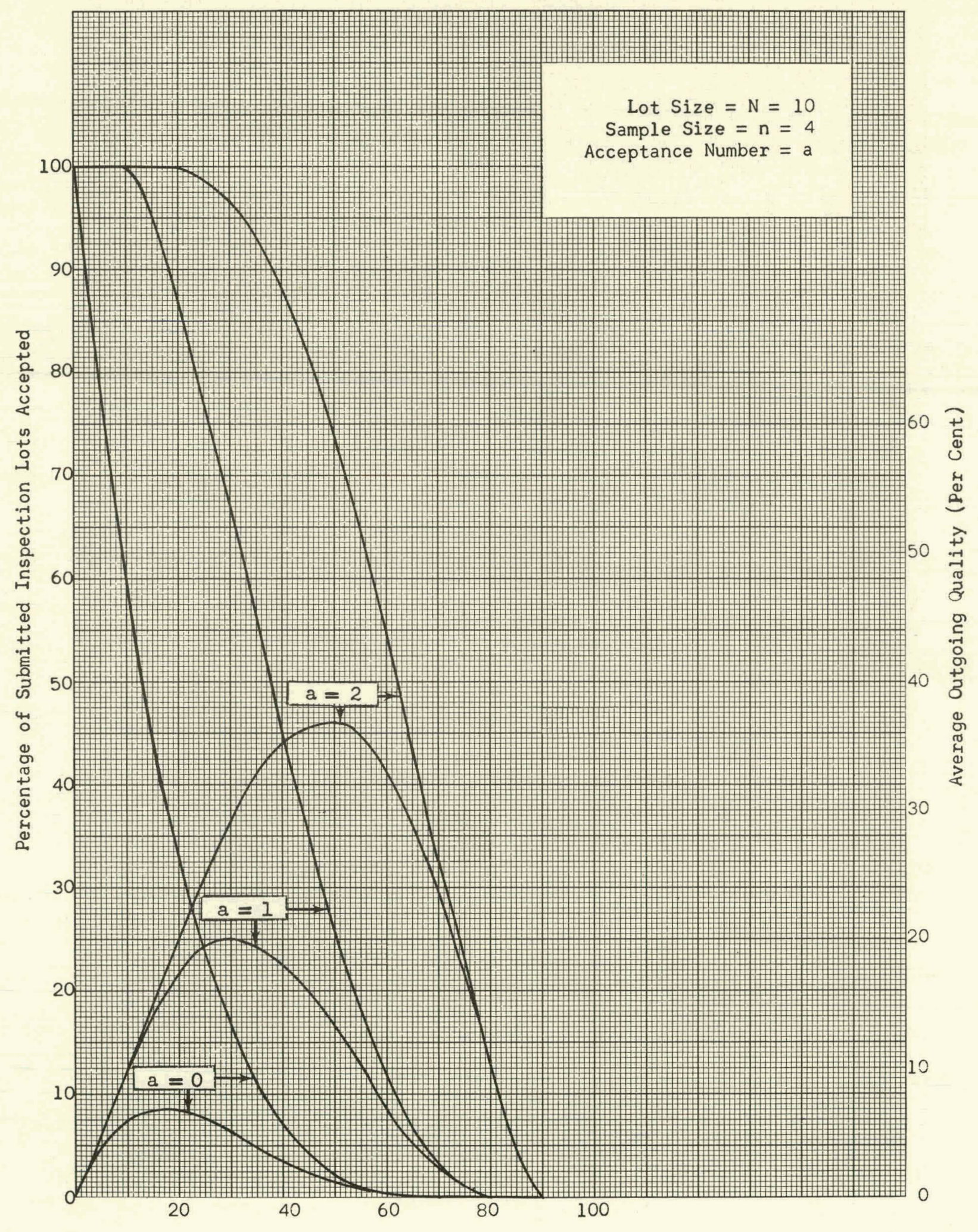

Percentage of Defective Items in Submitted Inspection Lots 


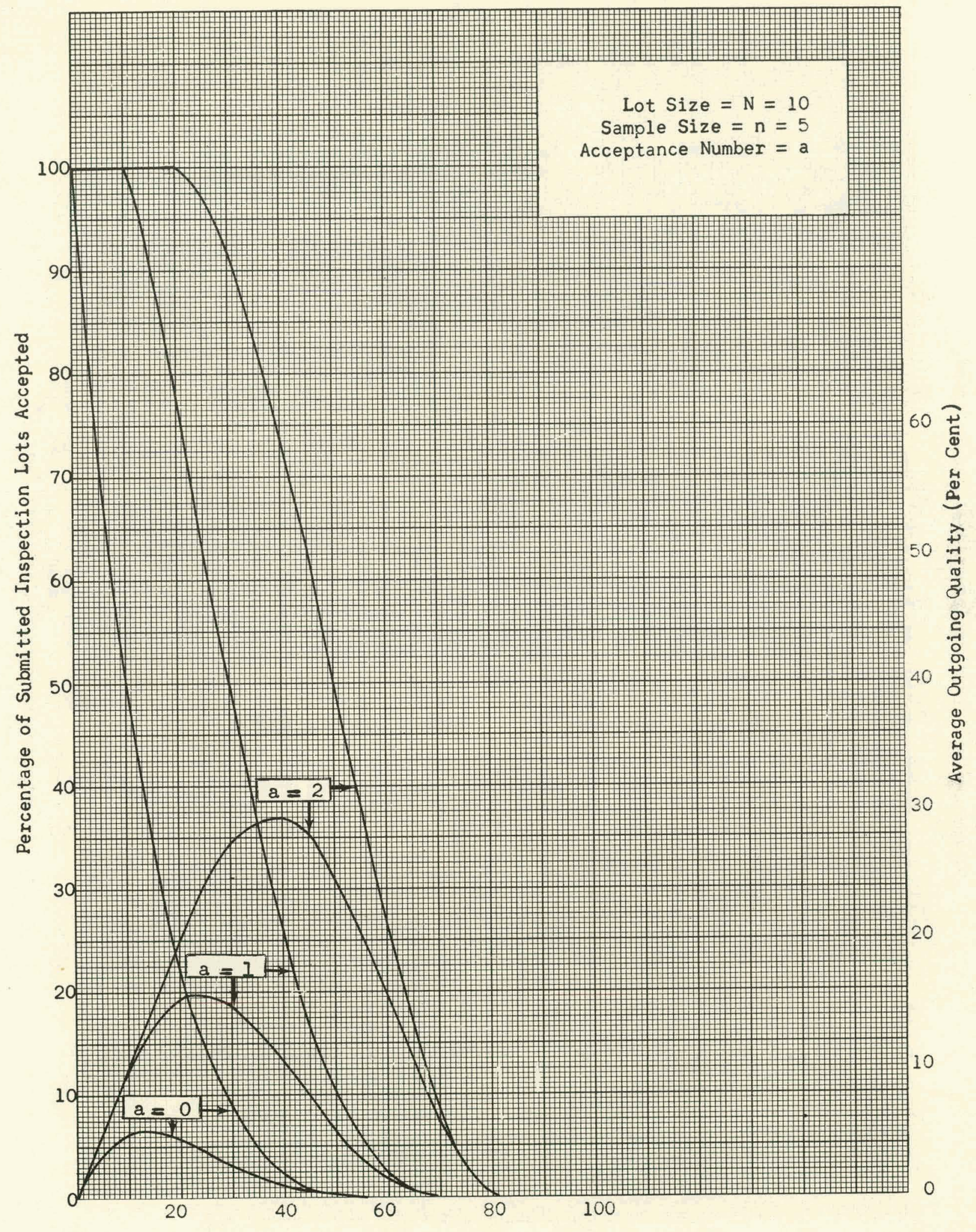

Percentage of Defective Items in Submitted Inspection Lots 


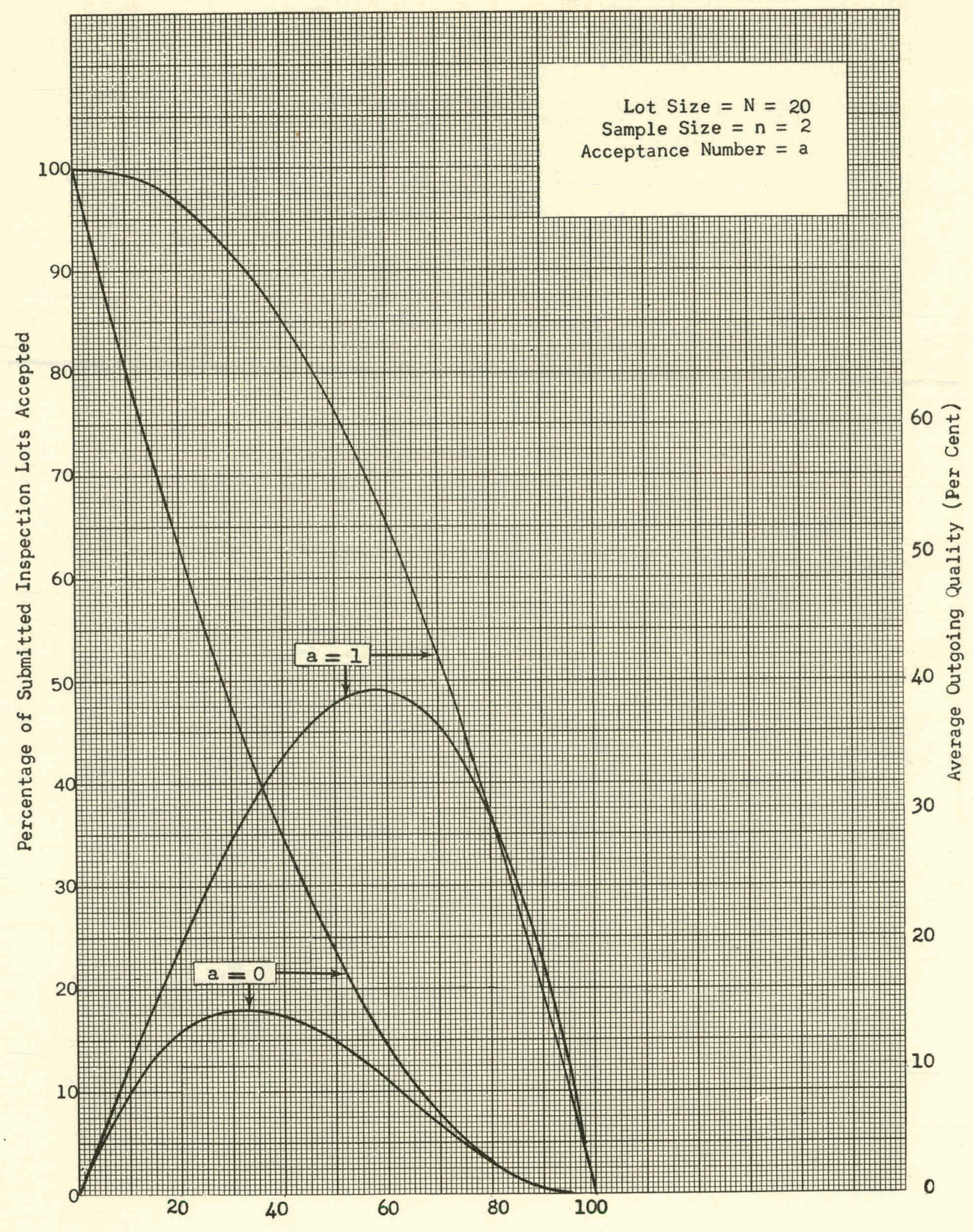

Percentage of Defective Items in Submitted Inspection Lots 


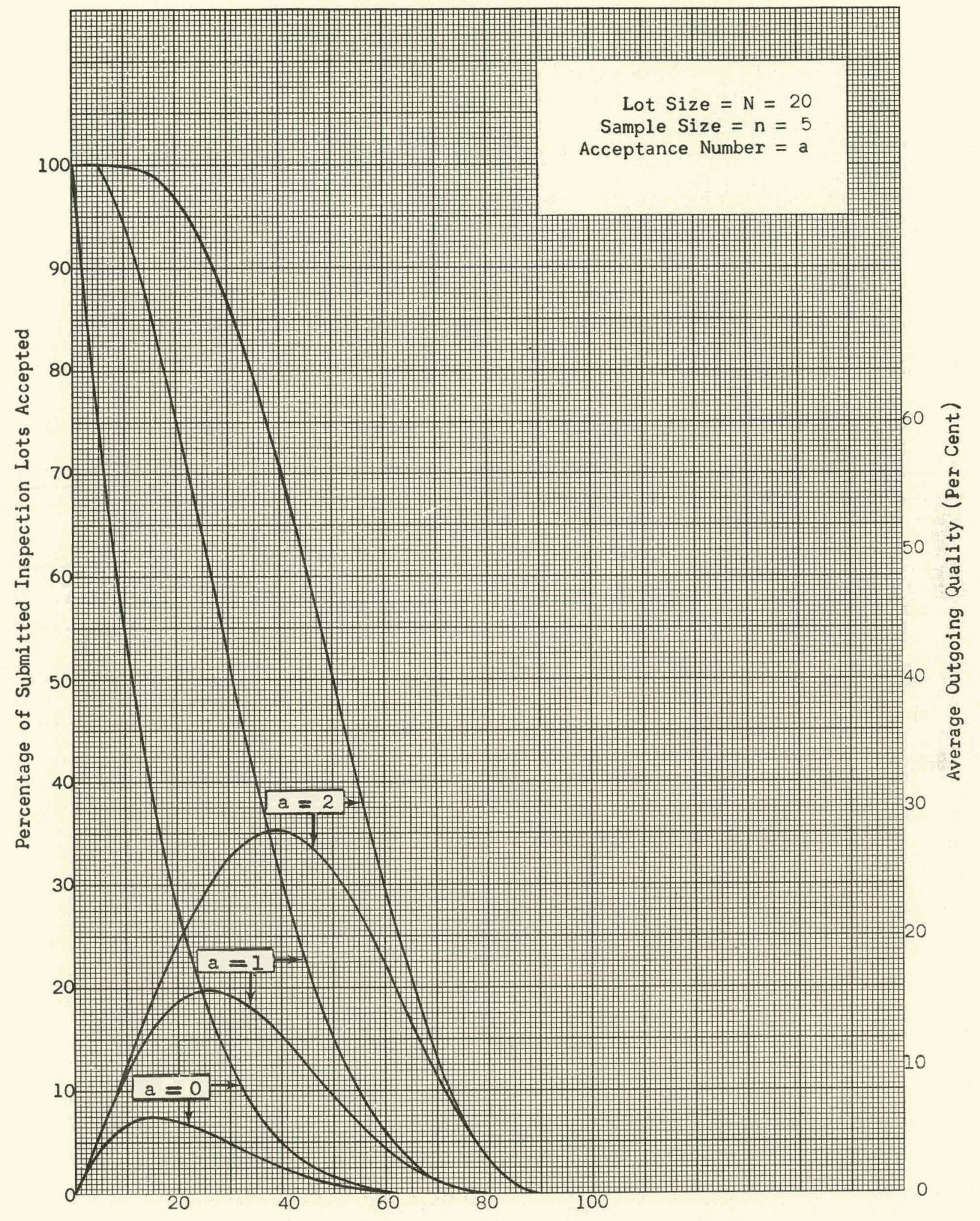

Percentage of Defective Items in Submitted Inspection Lots 


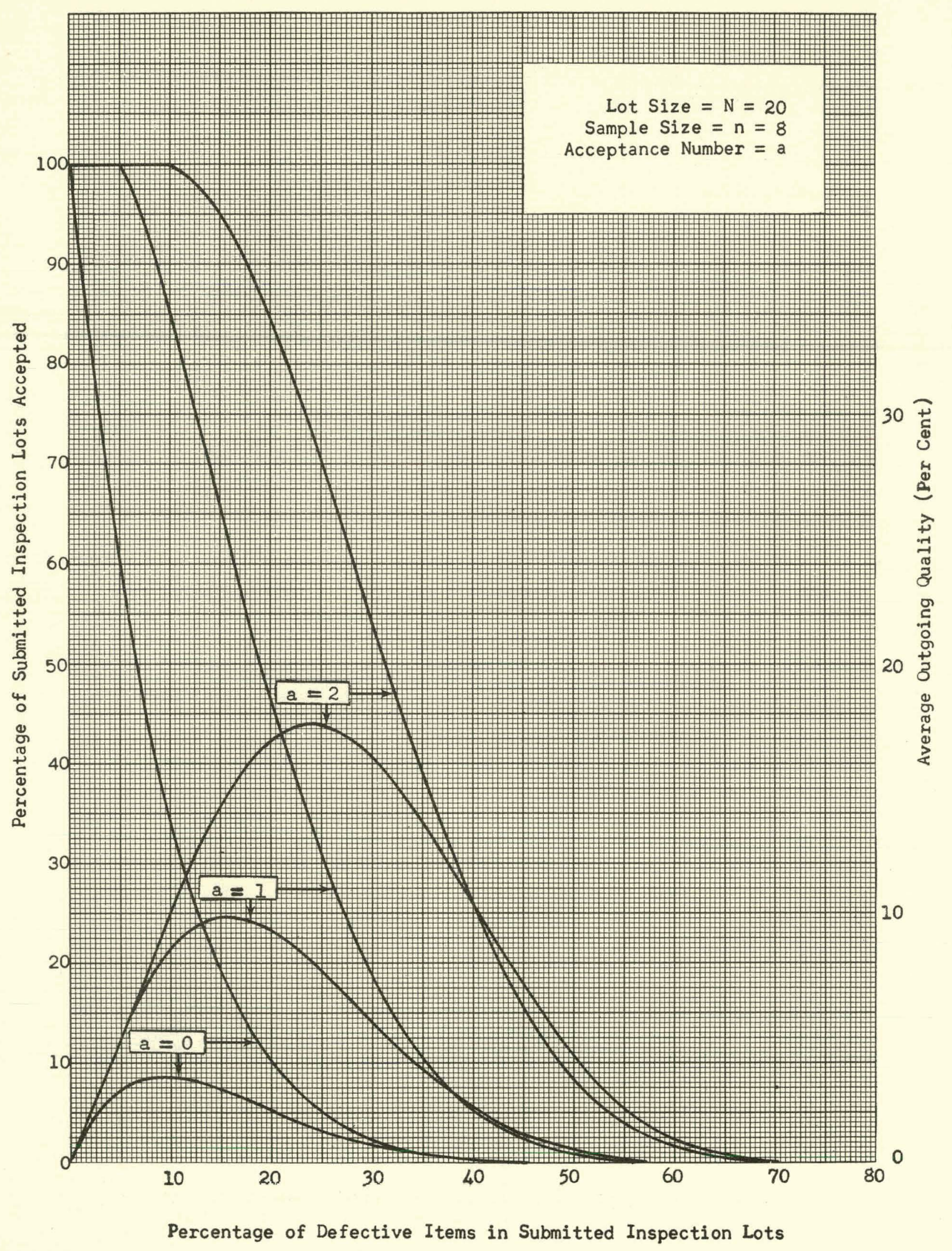




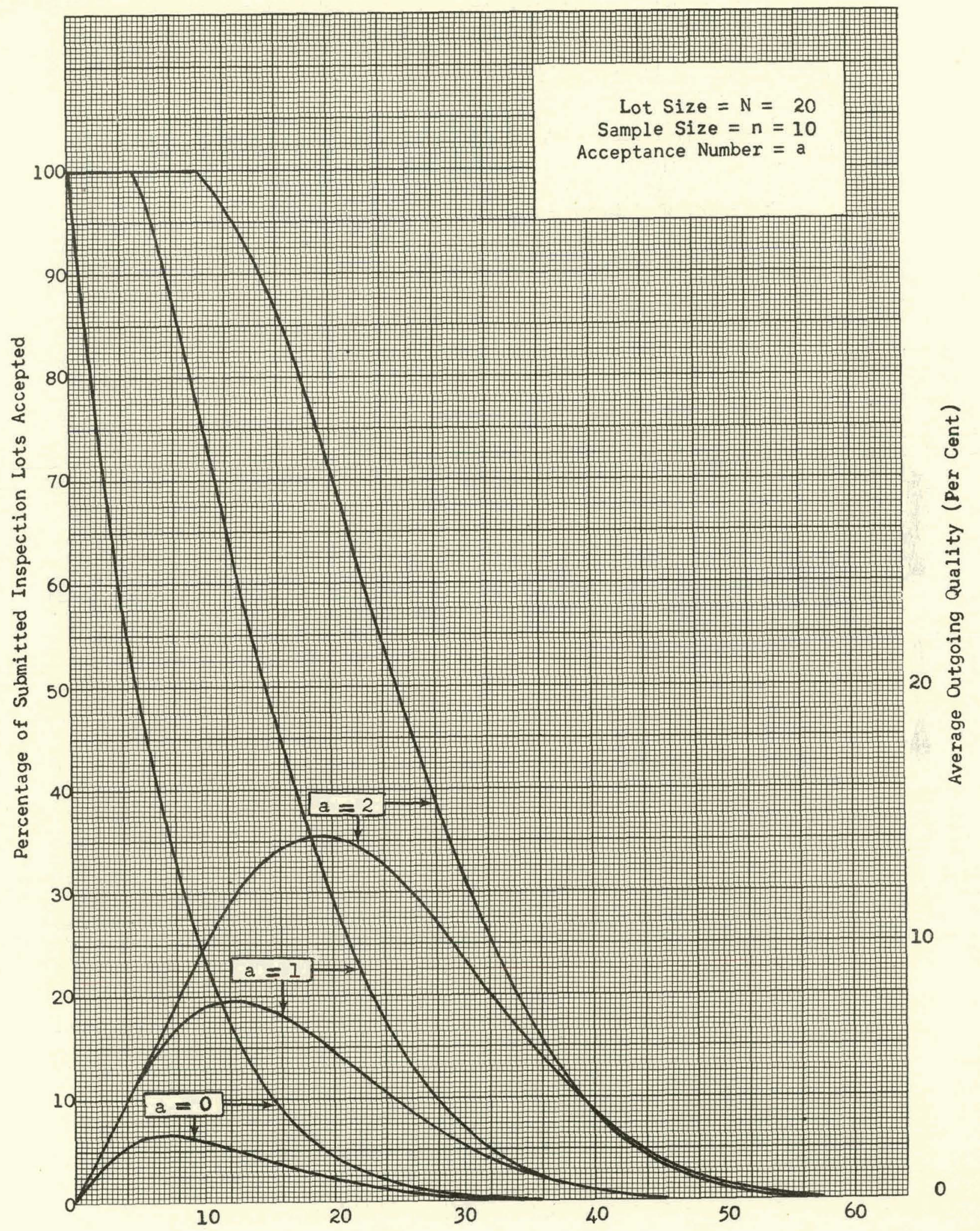

Percentage of Defective Items in Submitted Inspection Lots 


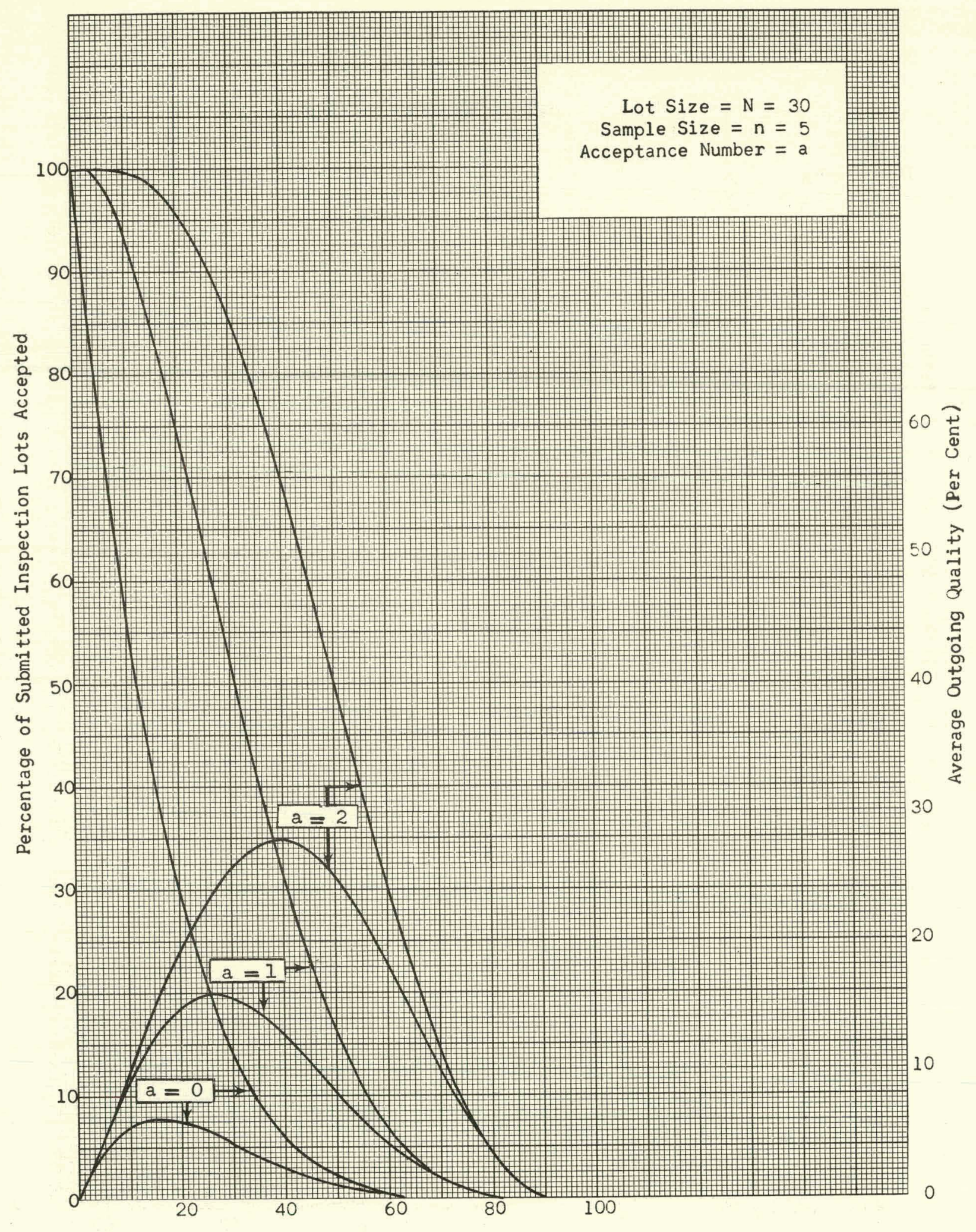

Percentage of Defective Items in Submitted Inspection Lots 


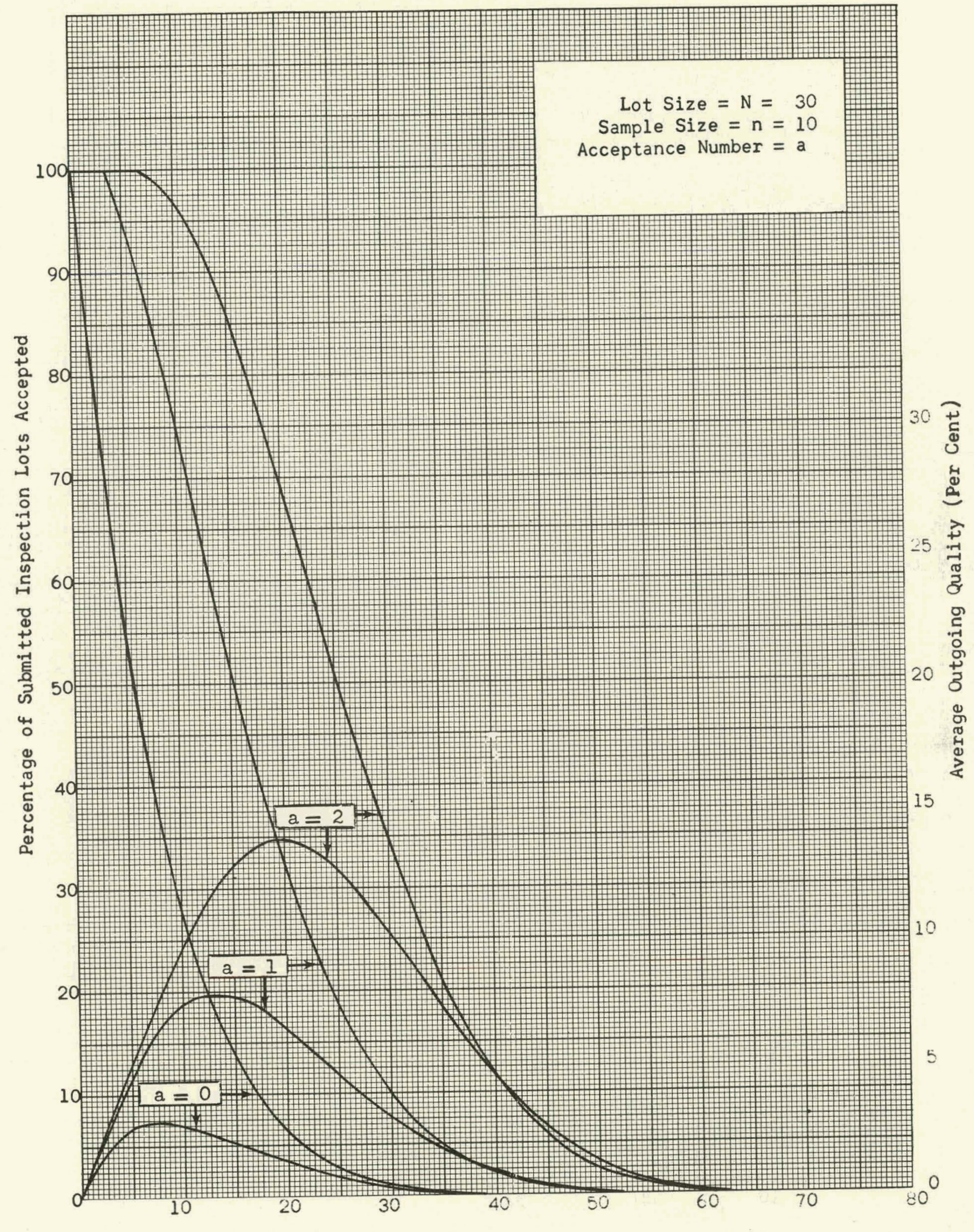

Percentage of Defective Items in Submitted Inspection Lots 


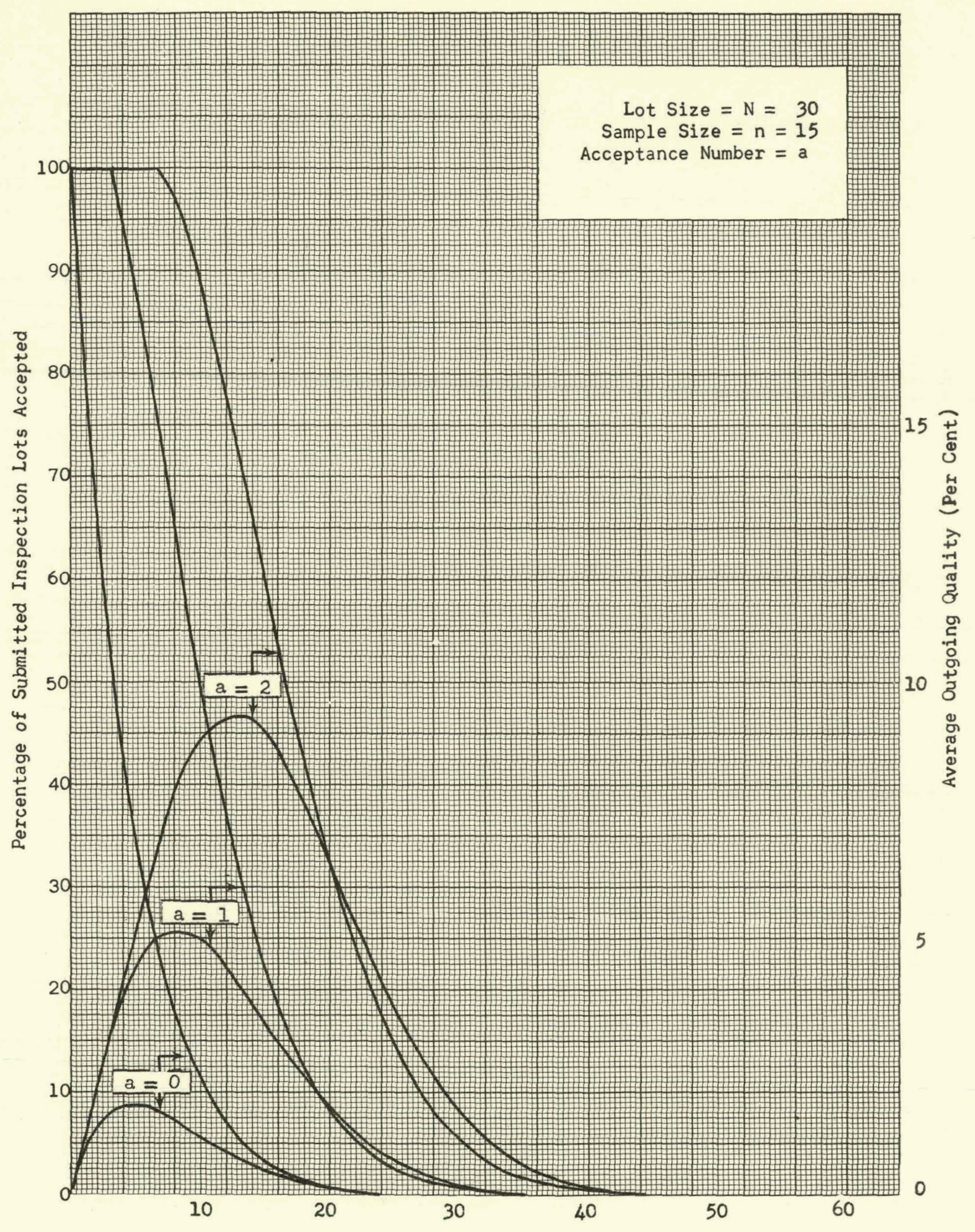

Percentage of Defective Items in Submitted Inspection Lots 


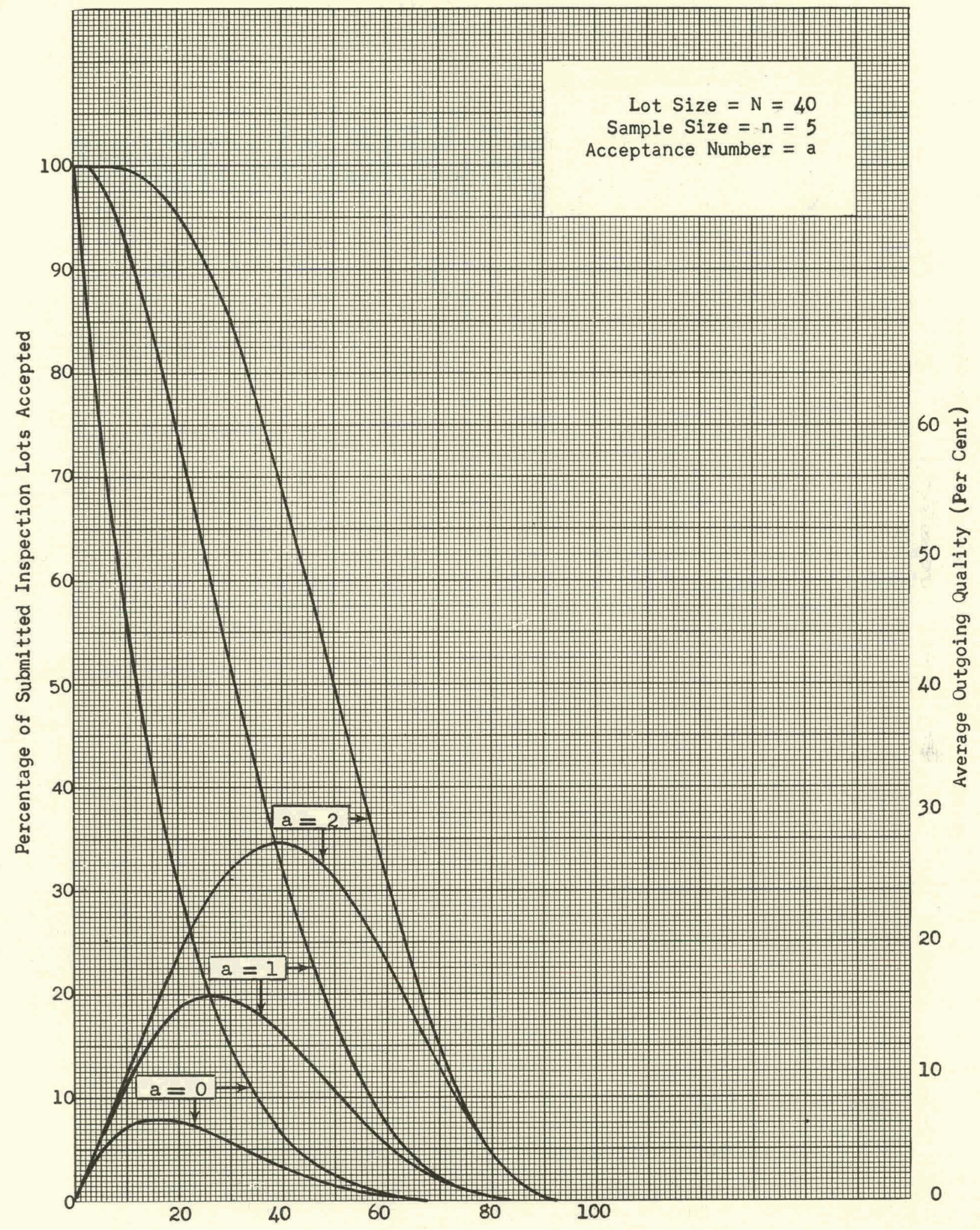

Percentage of Defective Items in Submitted Inspection Lots 


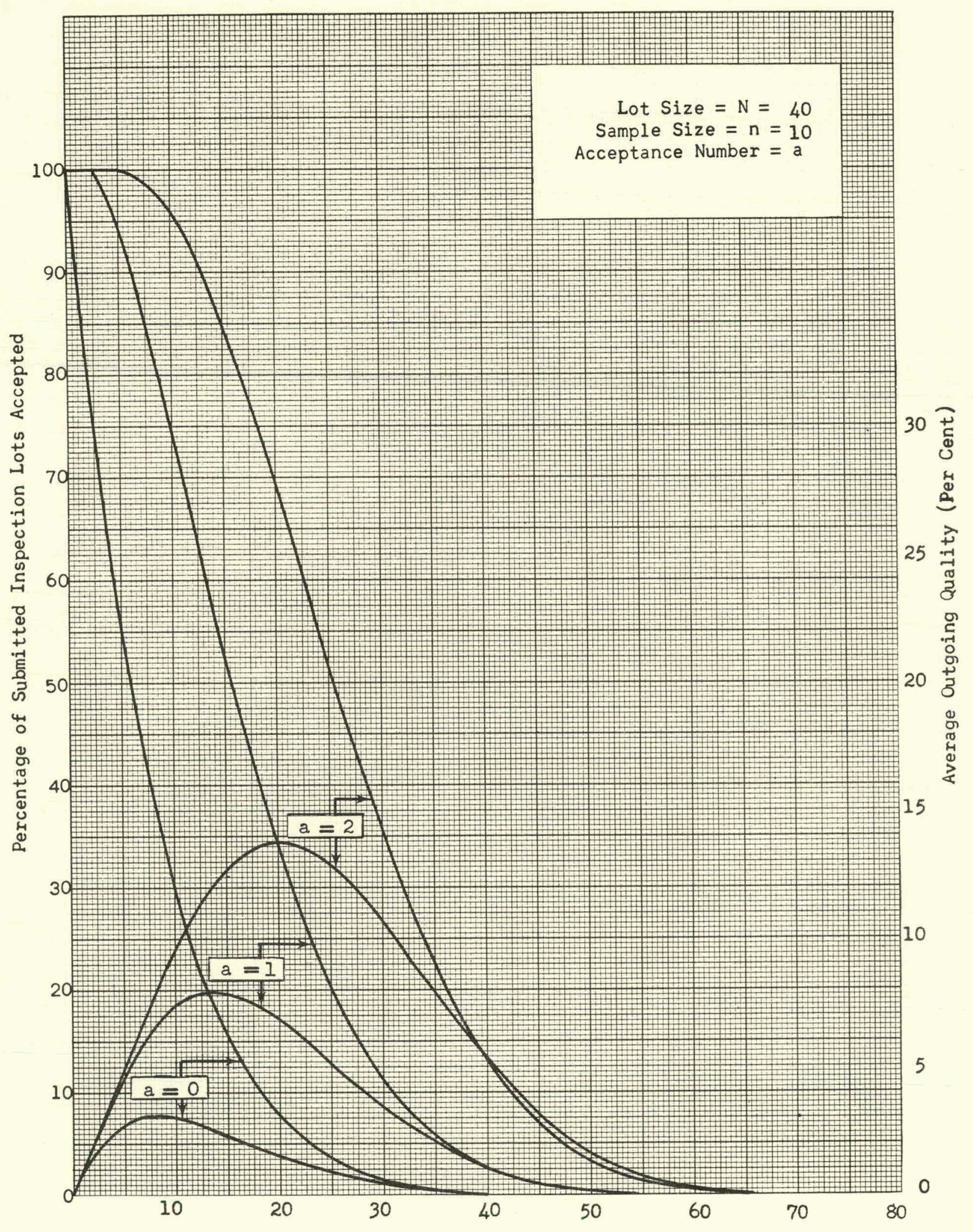

Percentage of Defective Items in Submitted Inspection Lots 


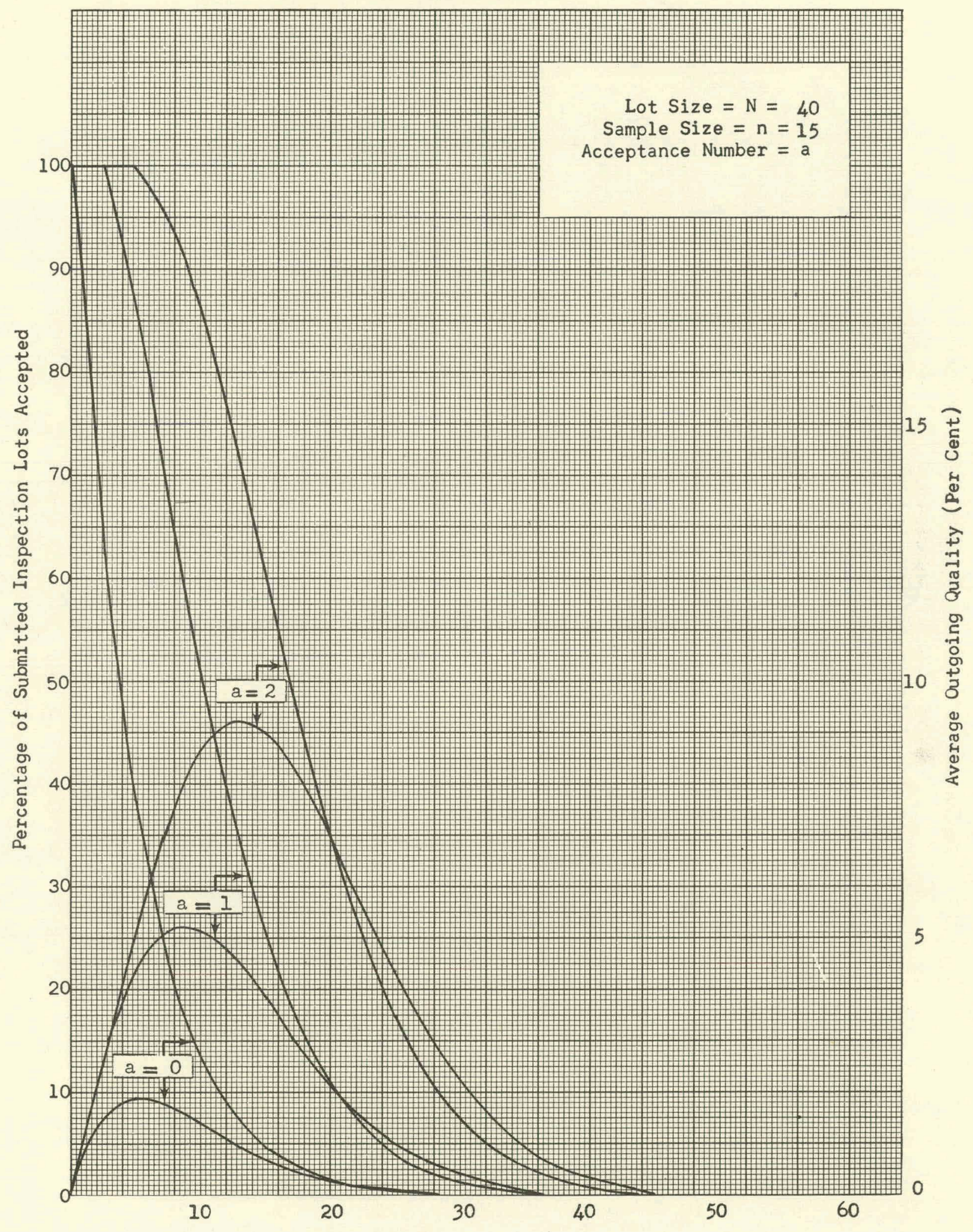

Percentage of Defective Items in Submitted Inspection Lots 


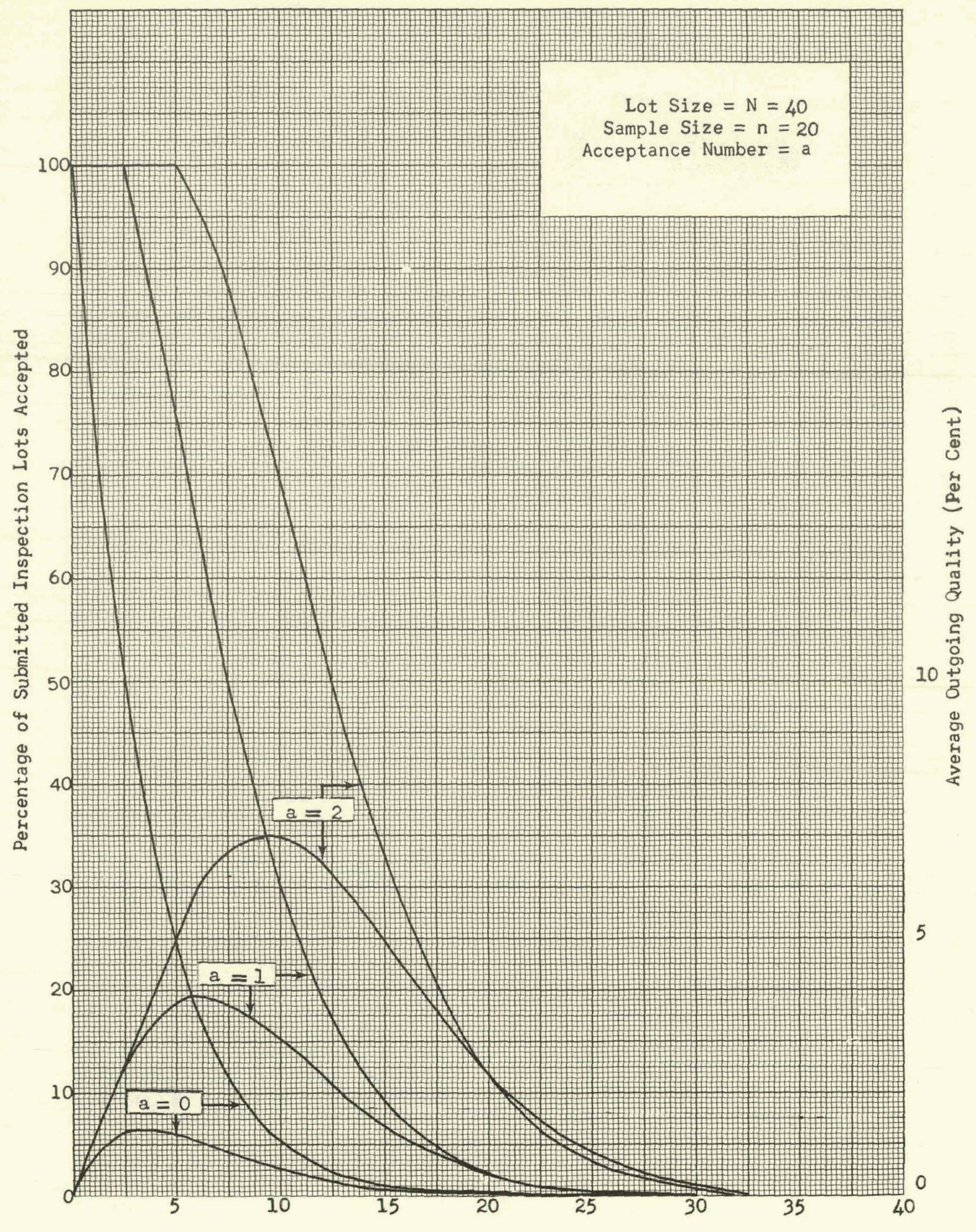

Percentage of Defective Items in Submitted Inspection Lots 


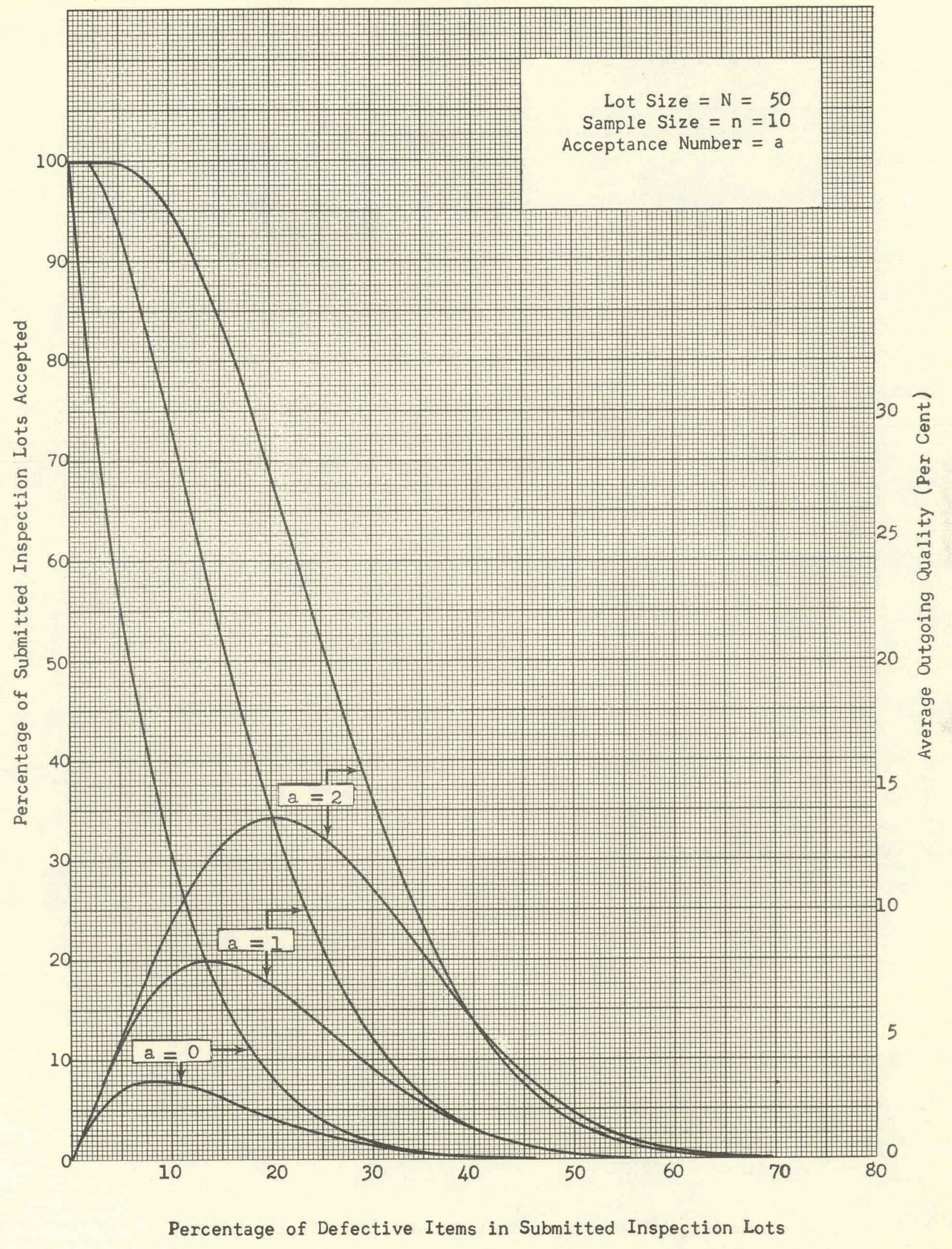




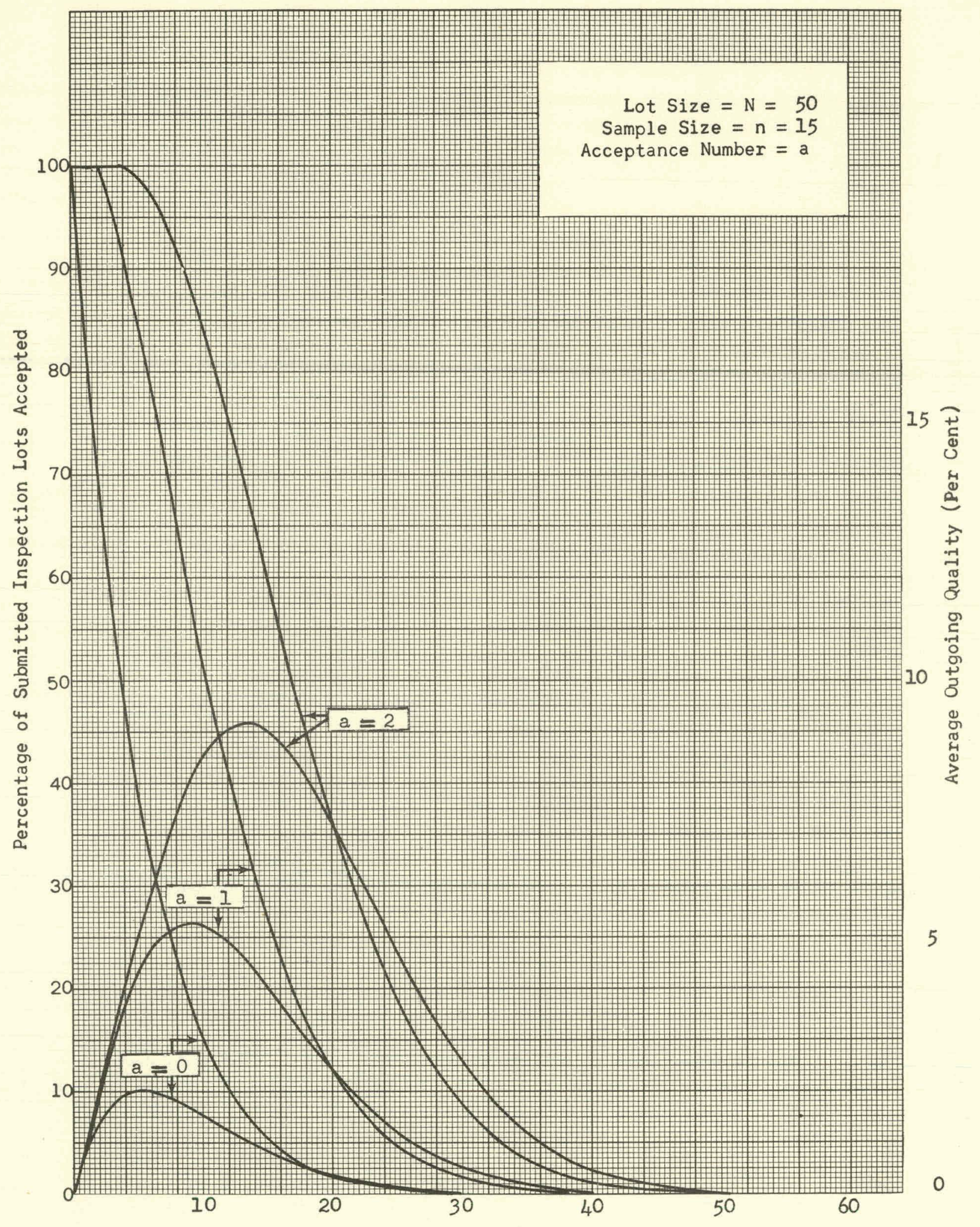

Percentage of Defective Items in Submitted Inspection Lots 


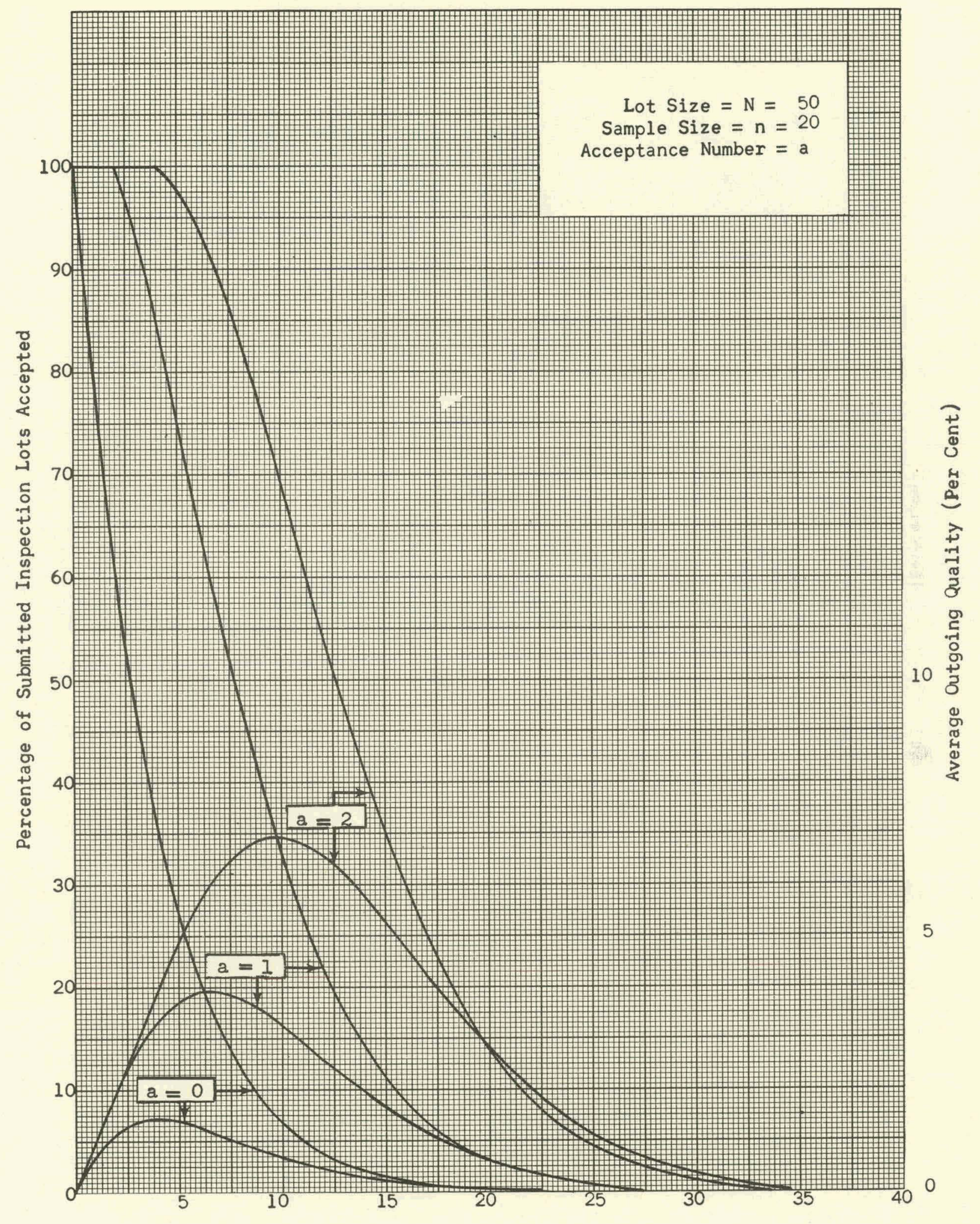

Percentage of Defective Items in Submitted Inspection Lots 


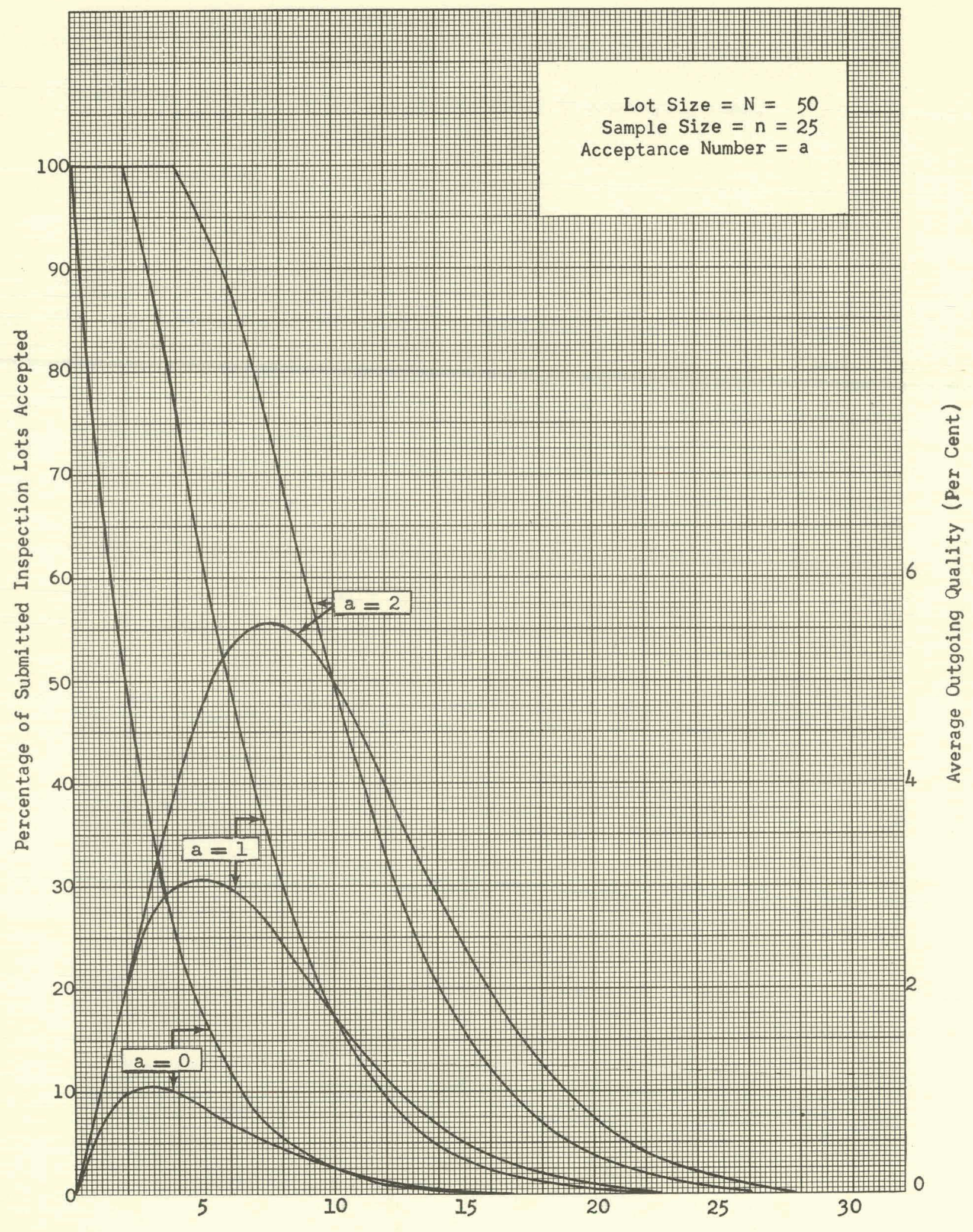

Percentage of Defective Items in Submitted Inspection Lots 


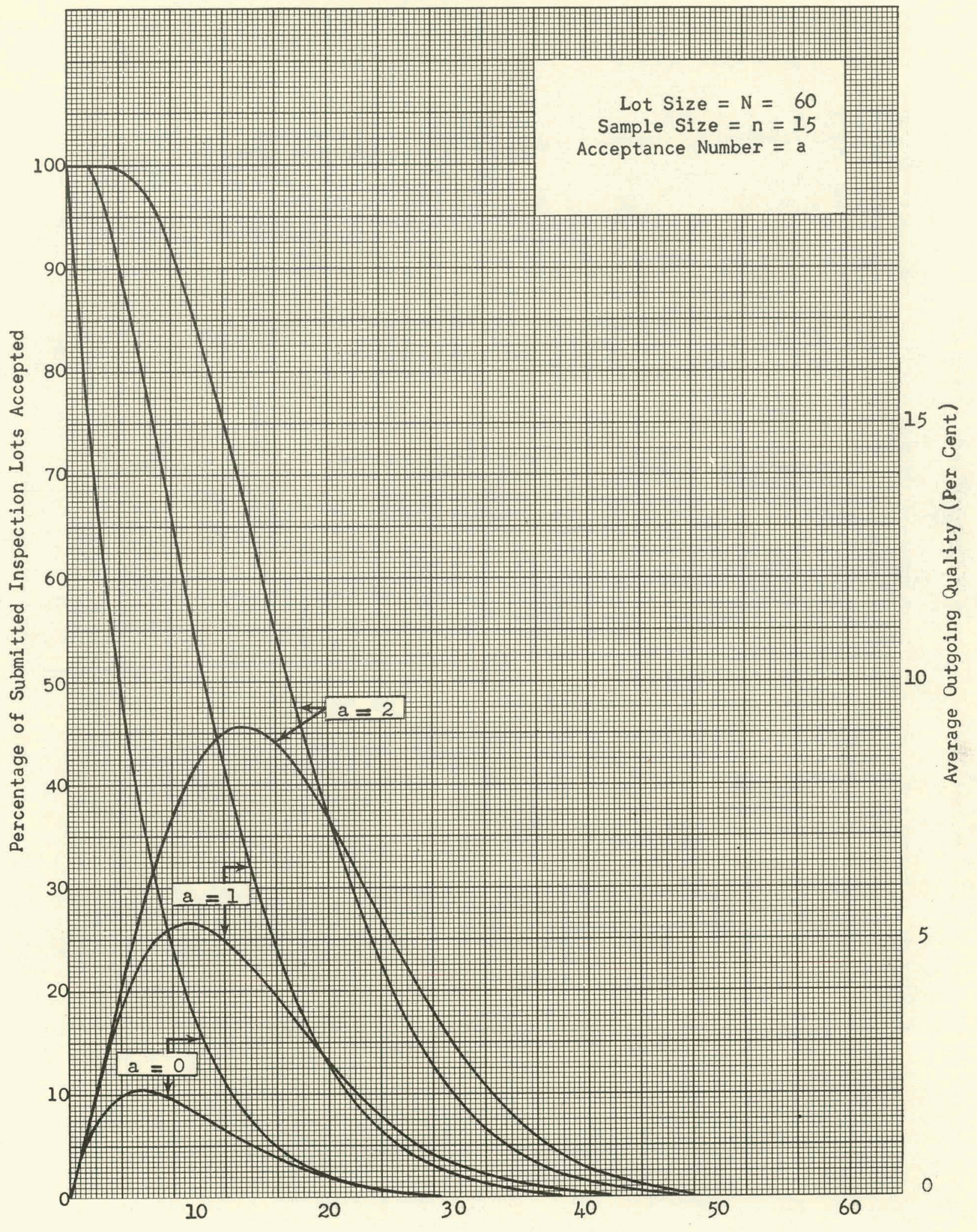

Percentage of Defective Items in Submitted Inspection Lots 


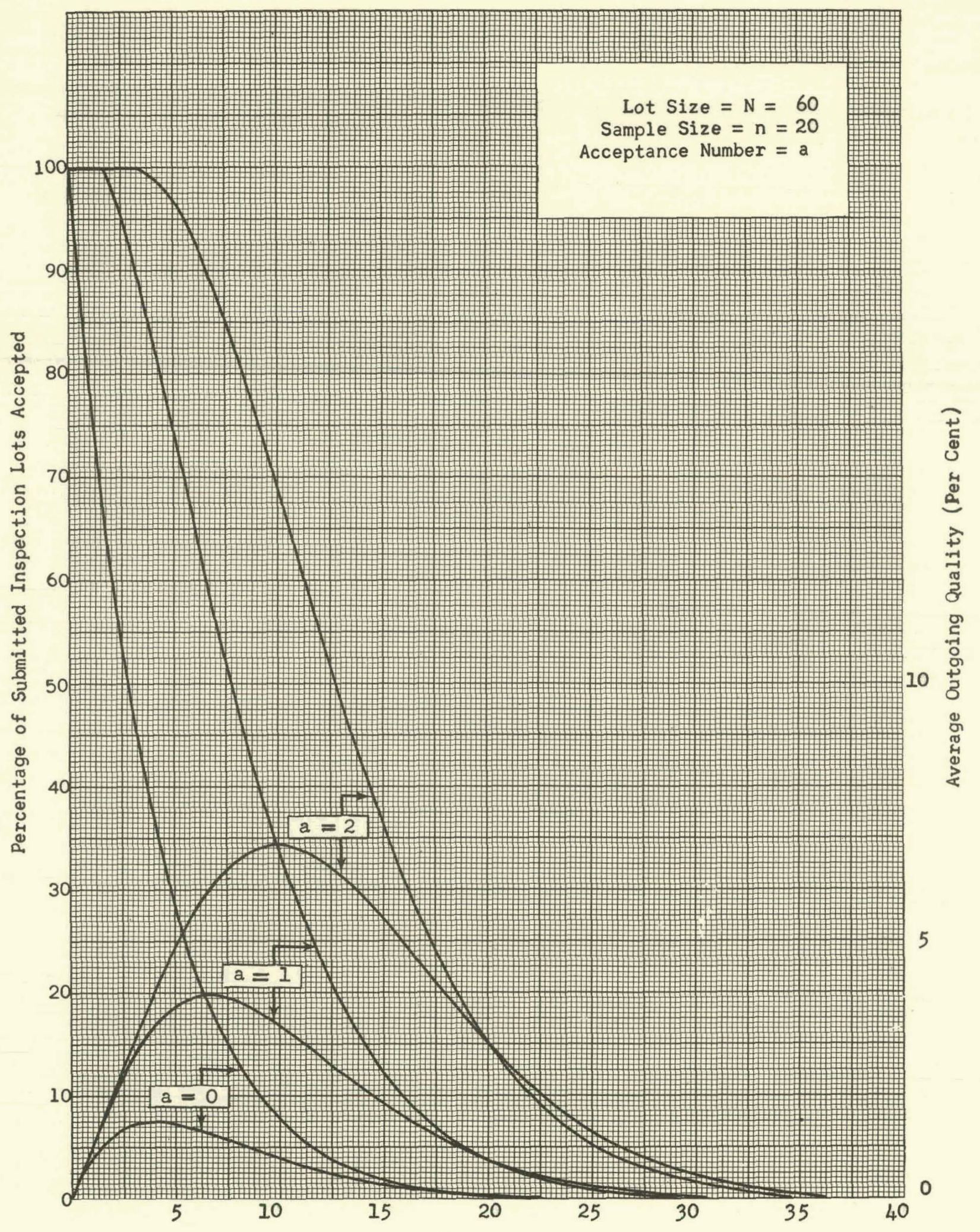

Percentage of Defective Items in Submitted Inspection Lots 


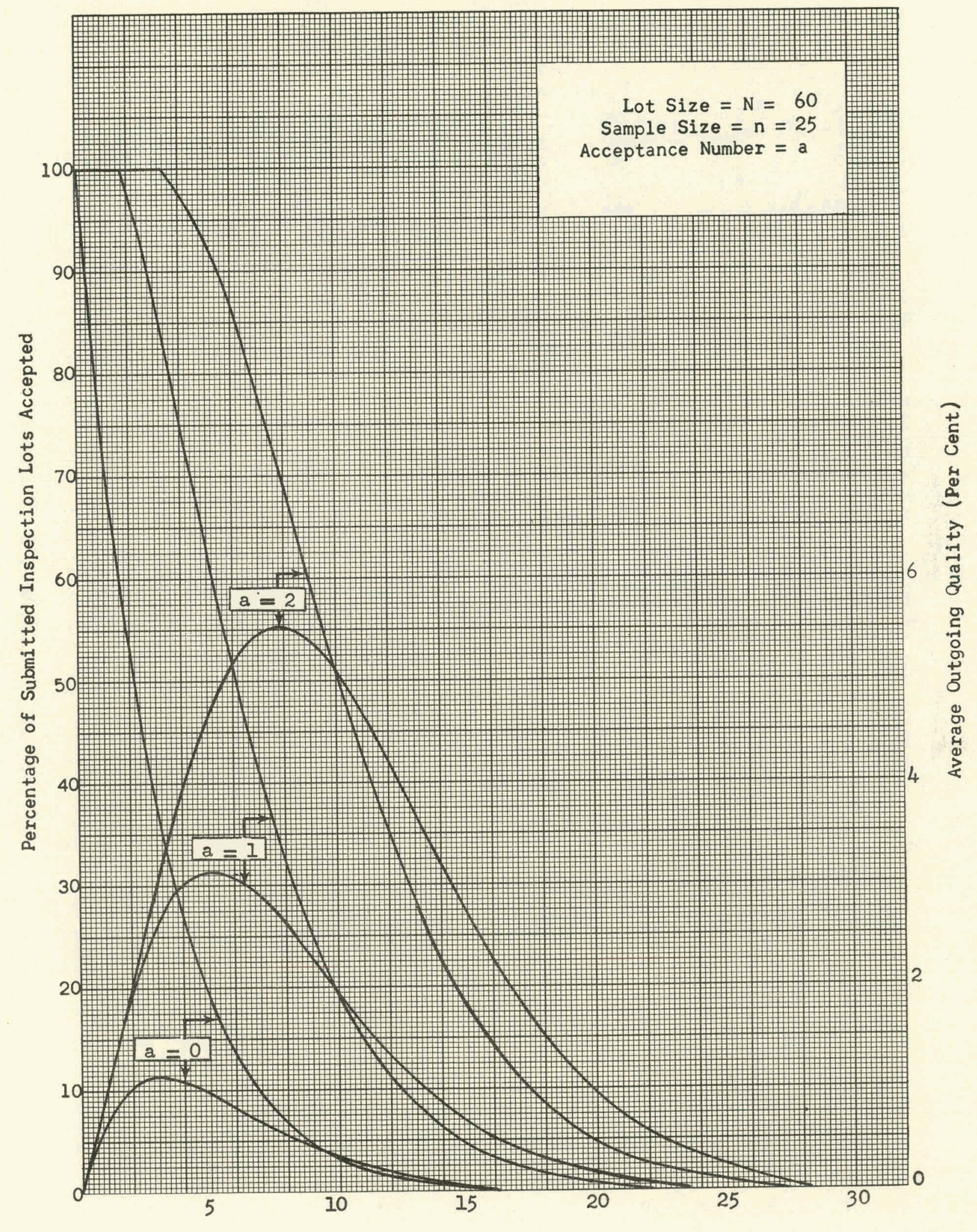

Percentage of Defective Items in Submitted Inspection Lots 


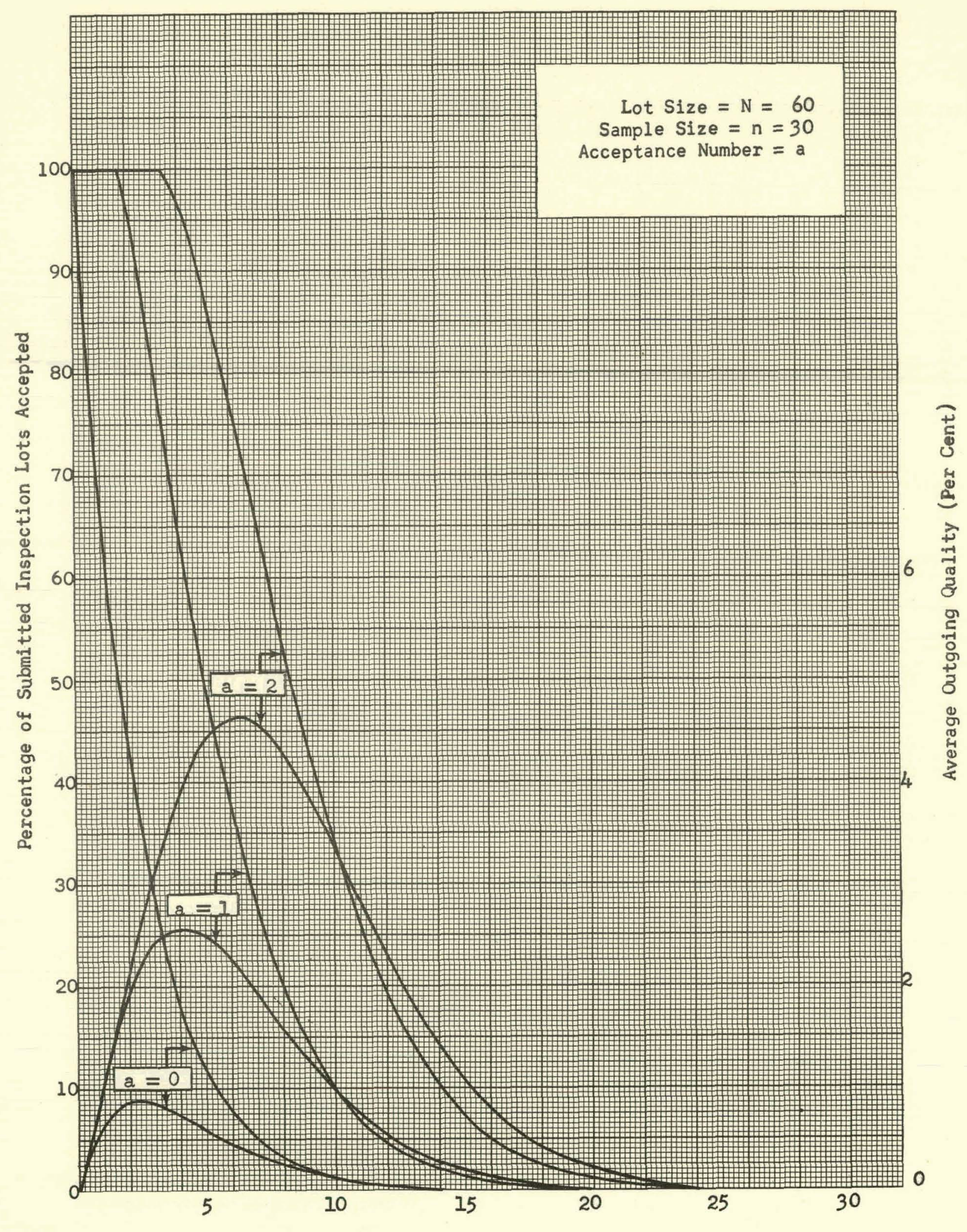

Percentage of Defective Items in Submitted Inspection Lots 


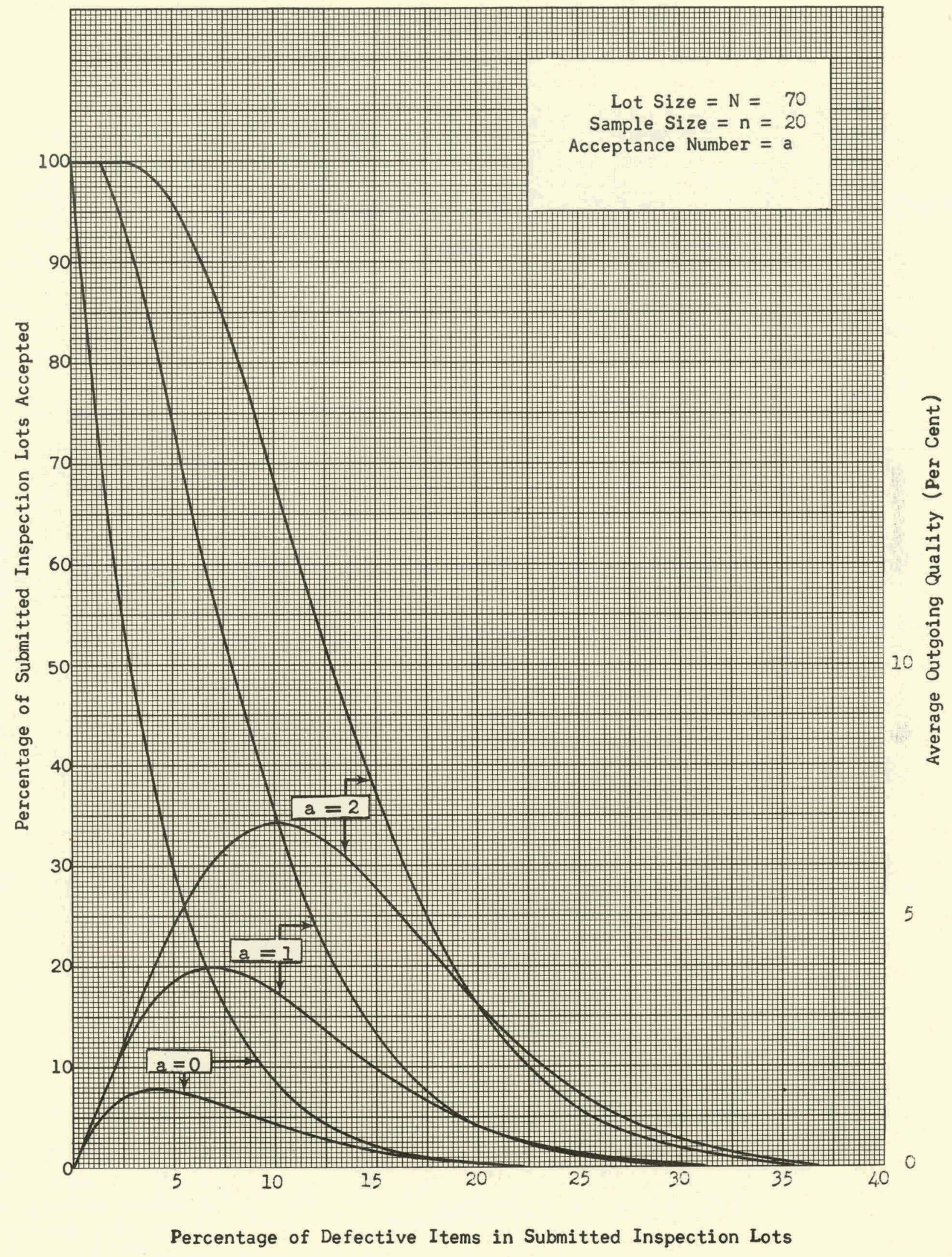




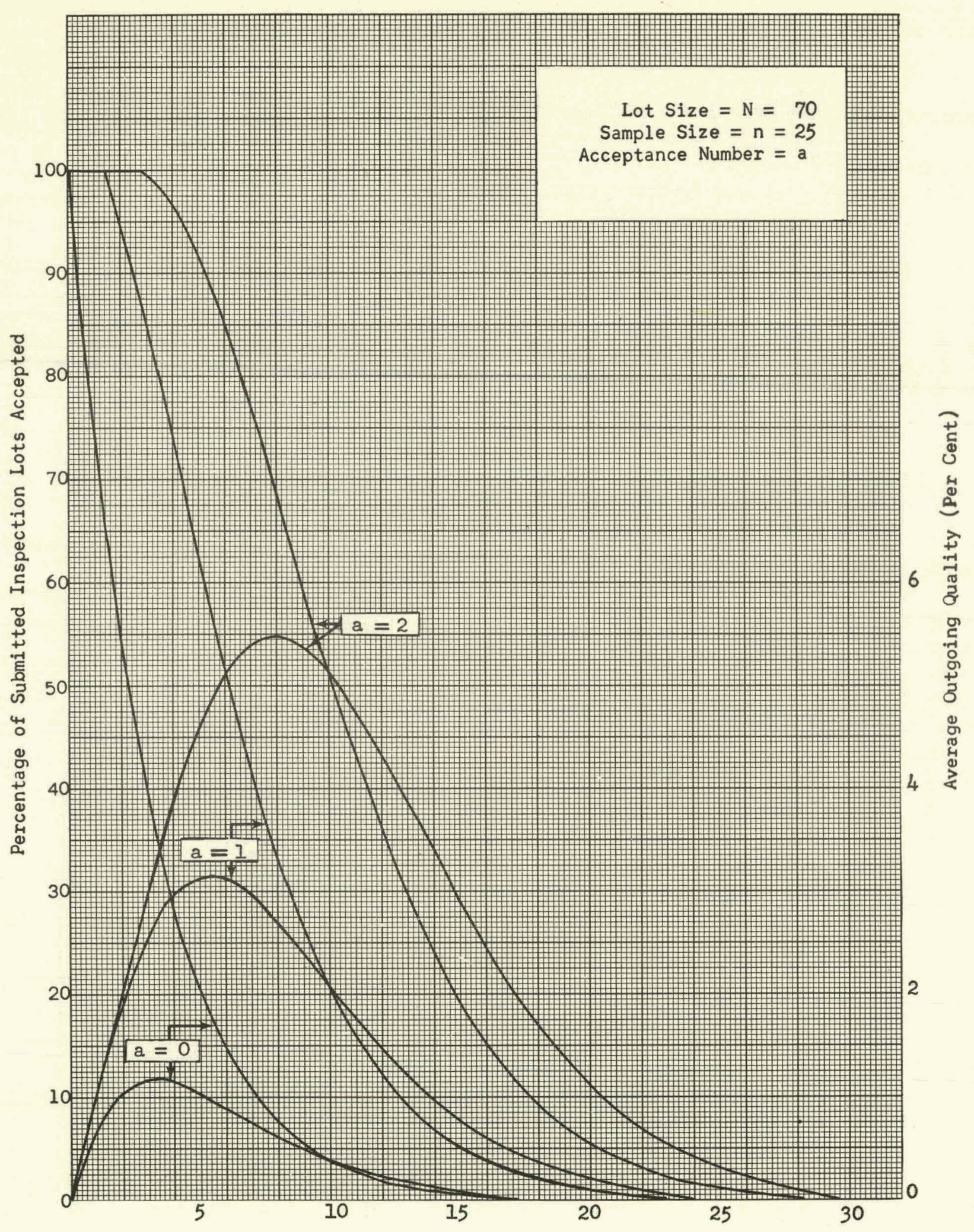

Percentage of Defective Items in Submitted Inspection Lots 


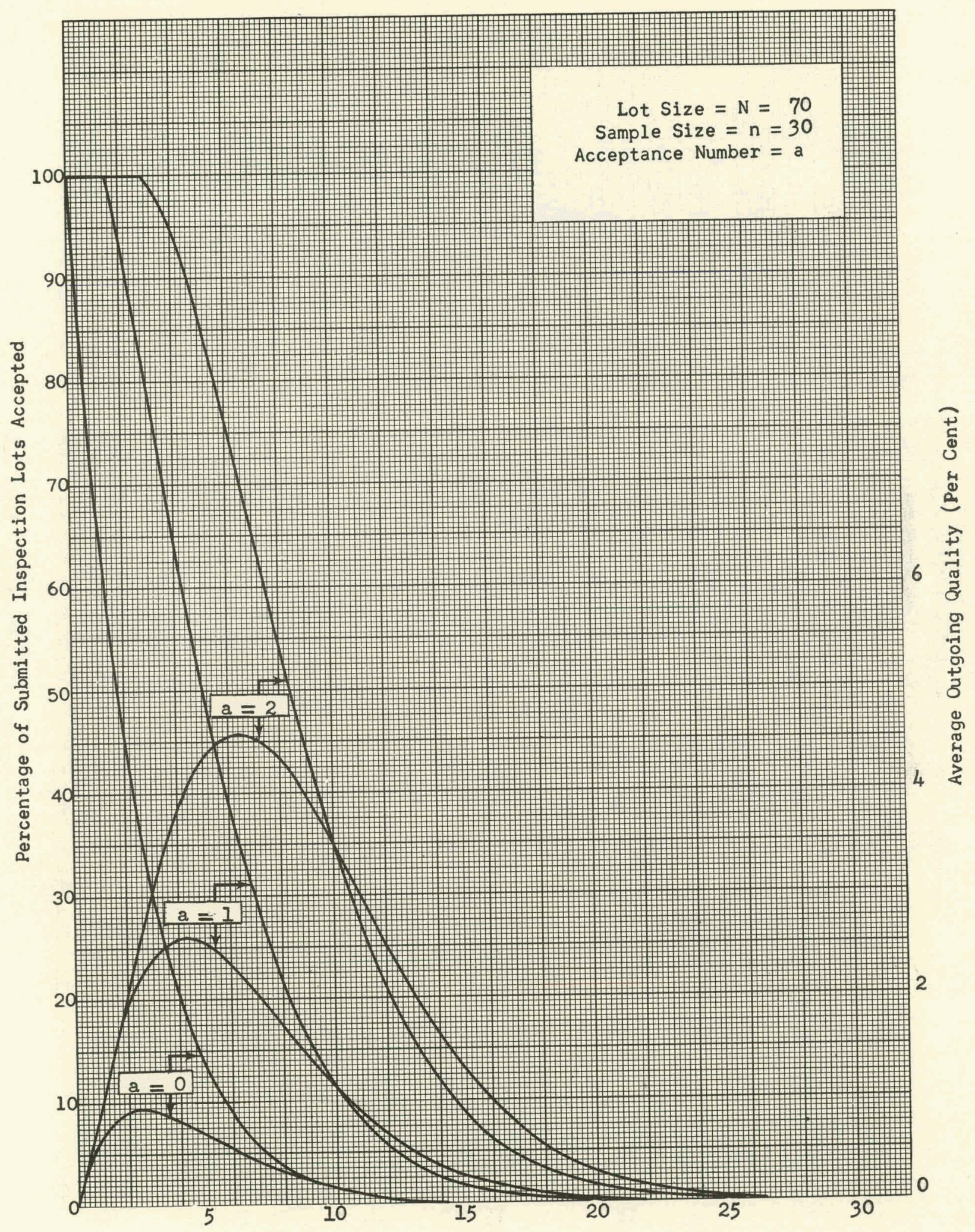

Percentage of Defective Items in Submitted Inspection Lots 


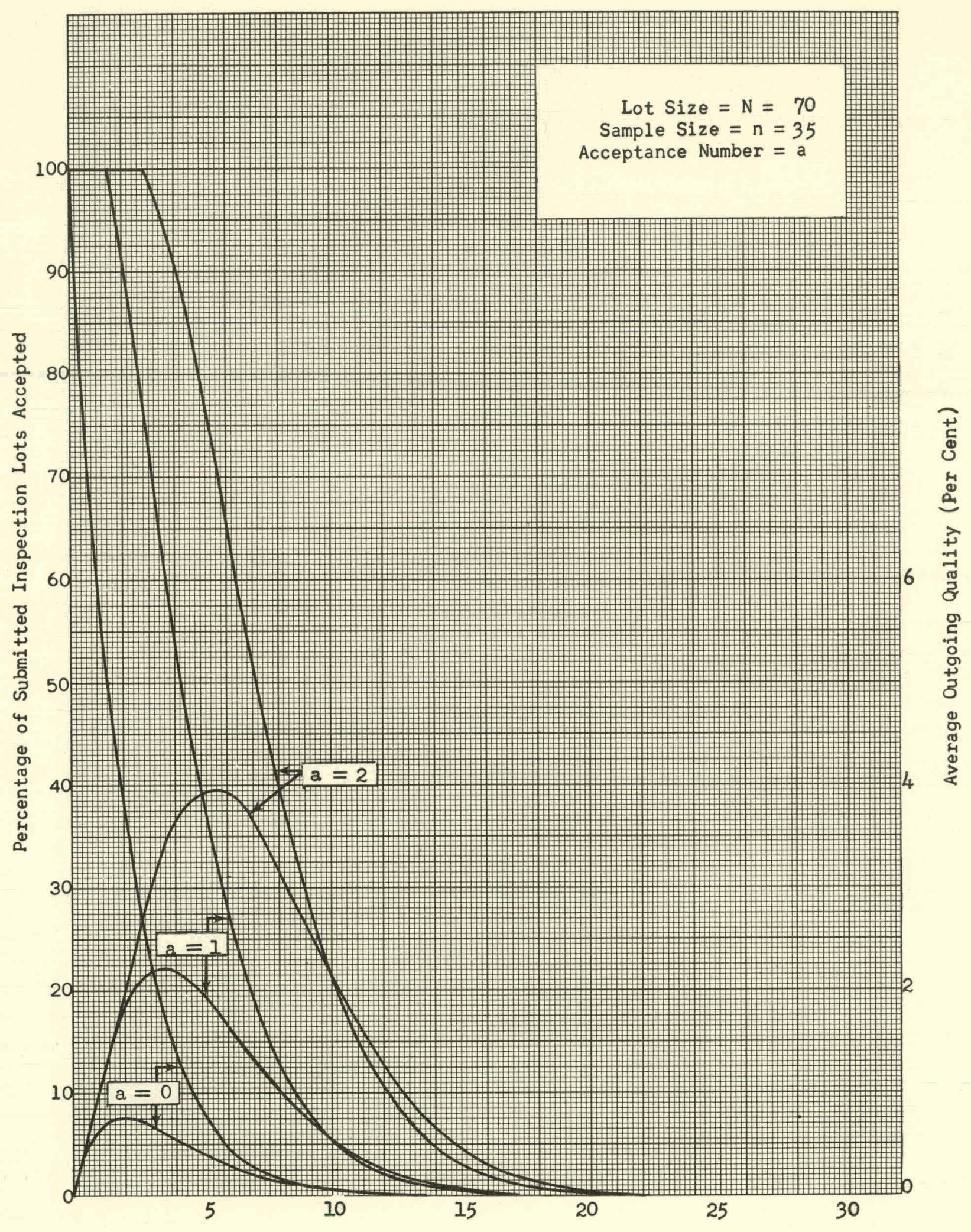

Percentage of Defective Items in Submitted Inspection Lots 


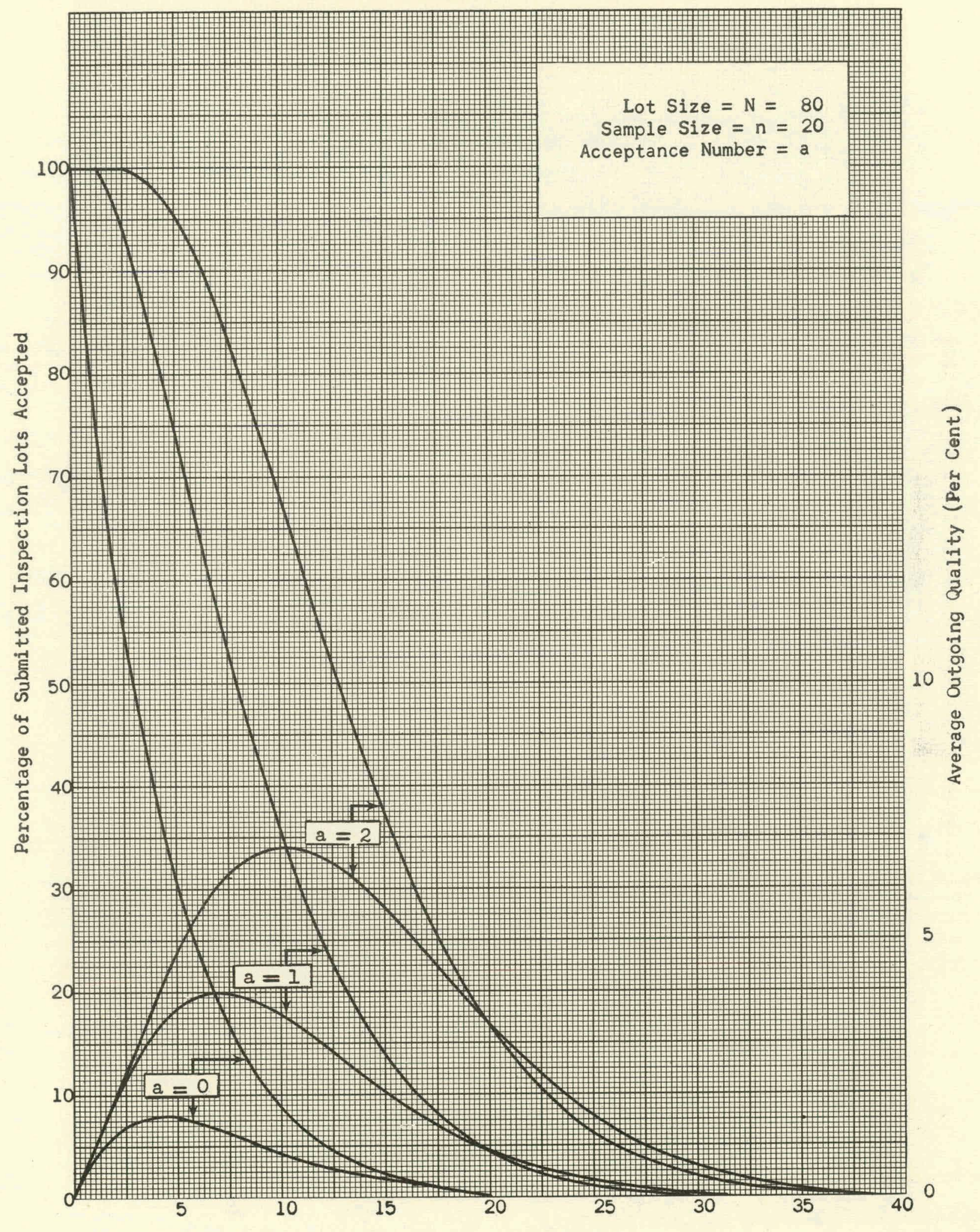

Percentage of Defective Items in Submitted Inspection Lots 


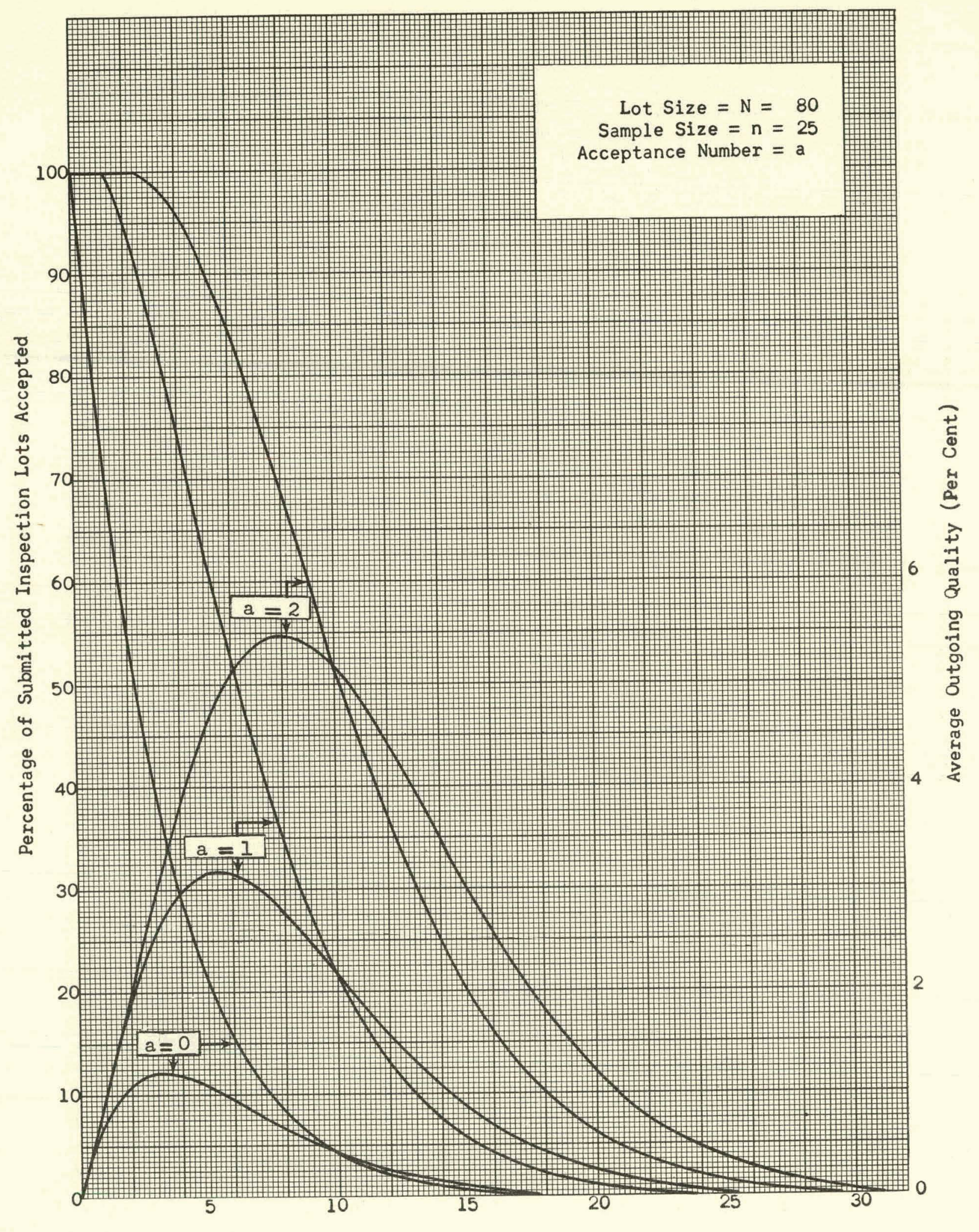

Percentage of Defective Items in Submitted Inspection Lots 


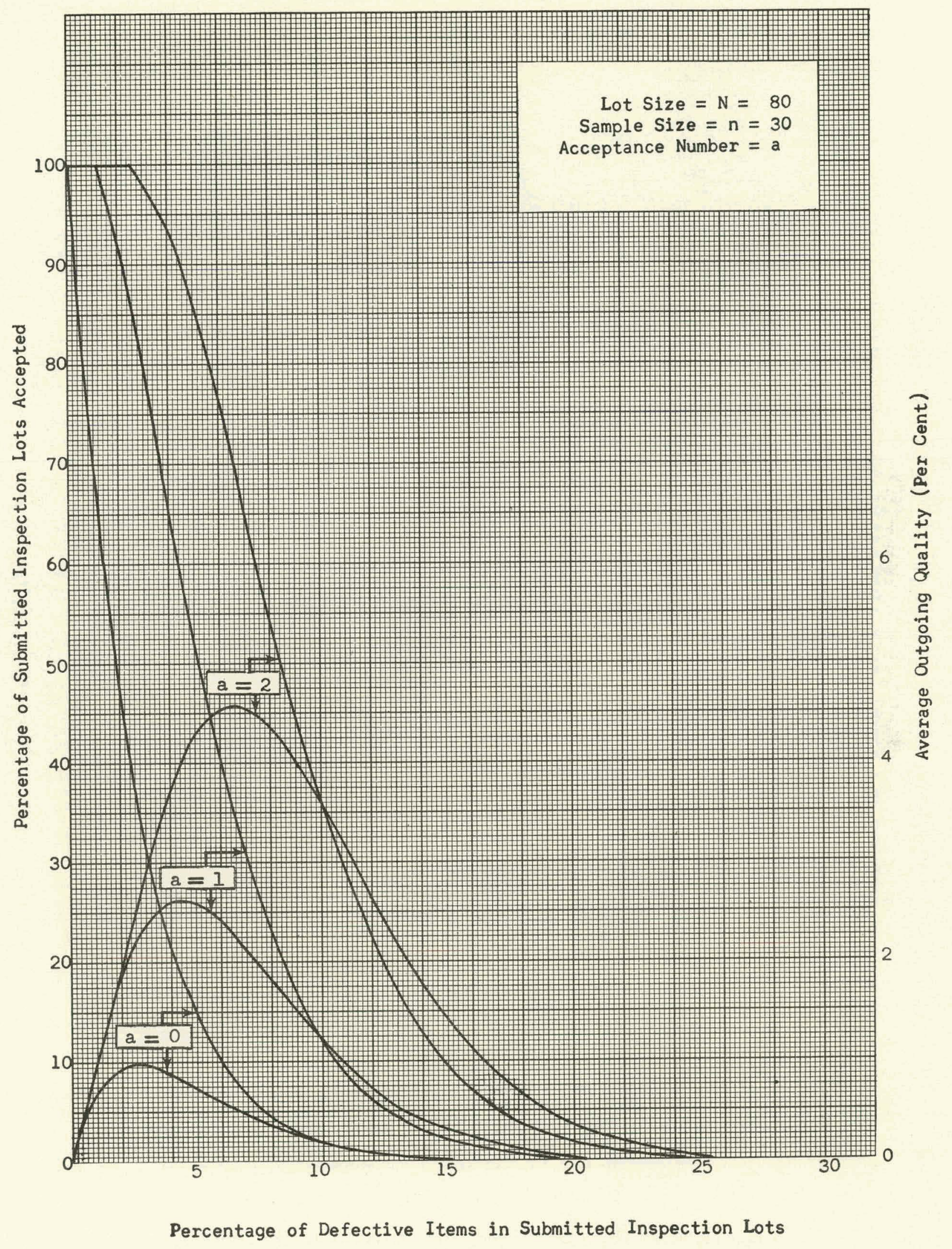




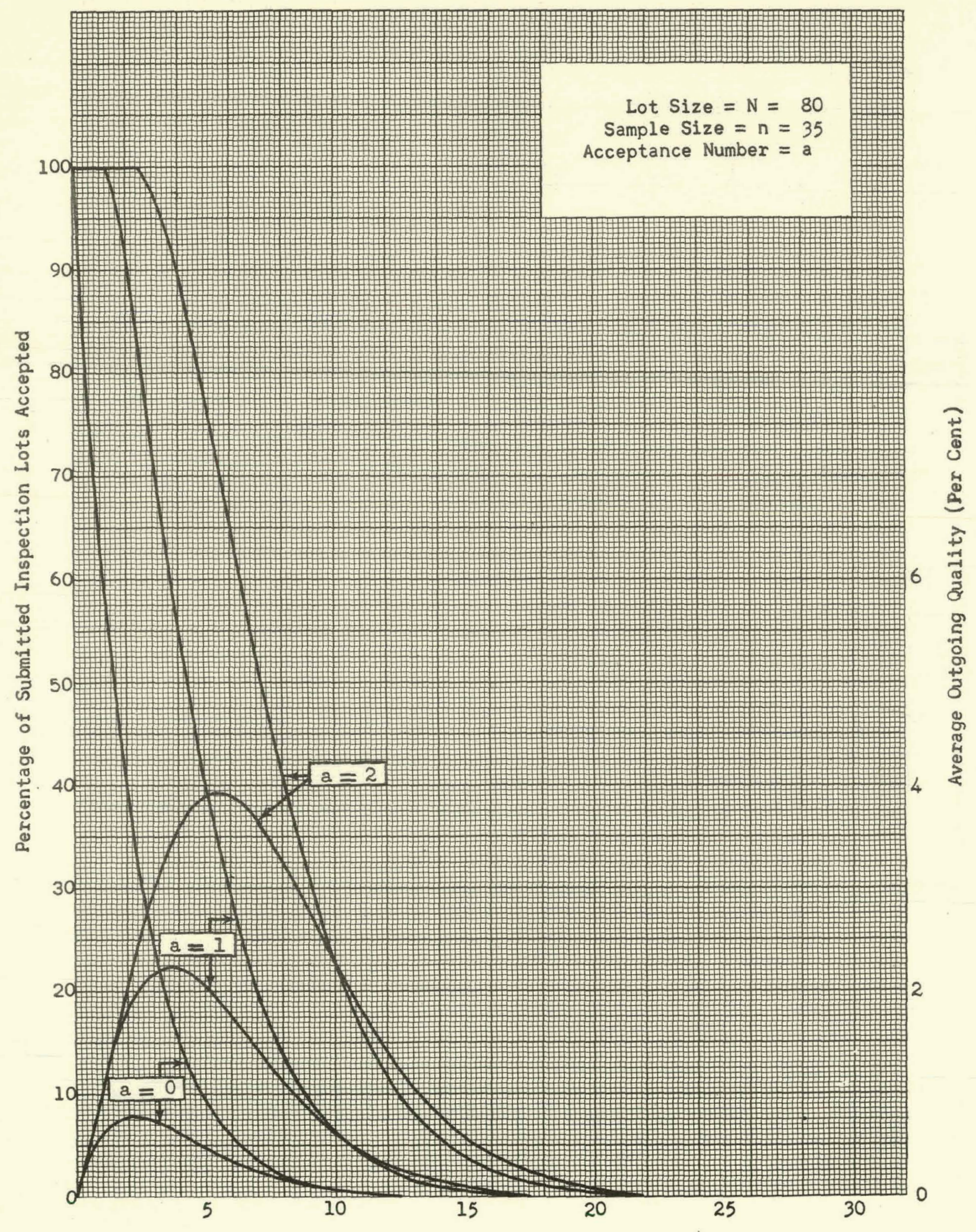

Percentage of Defective Items in Submitted Inspection Lots 


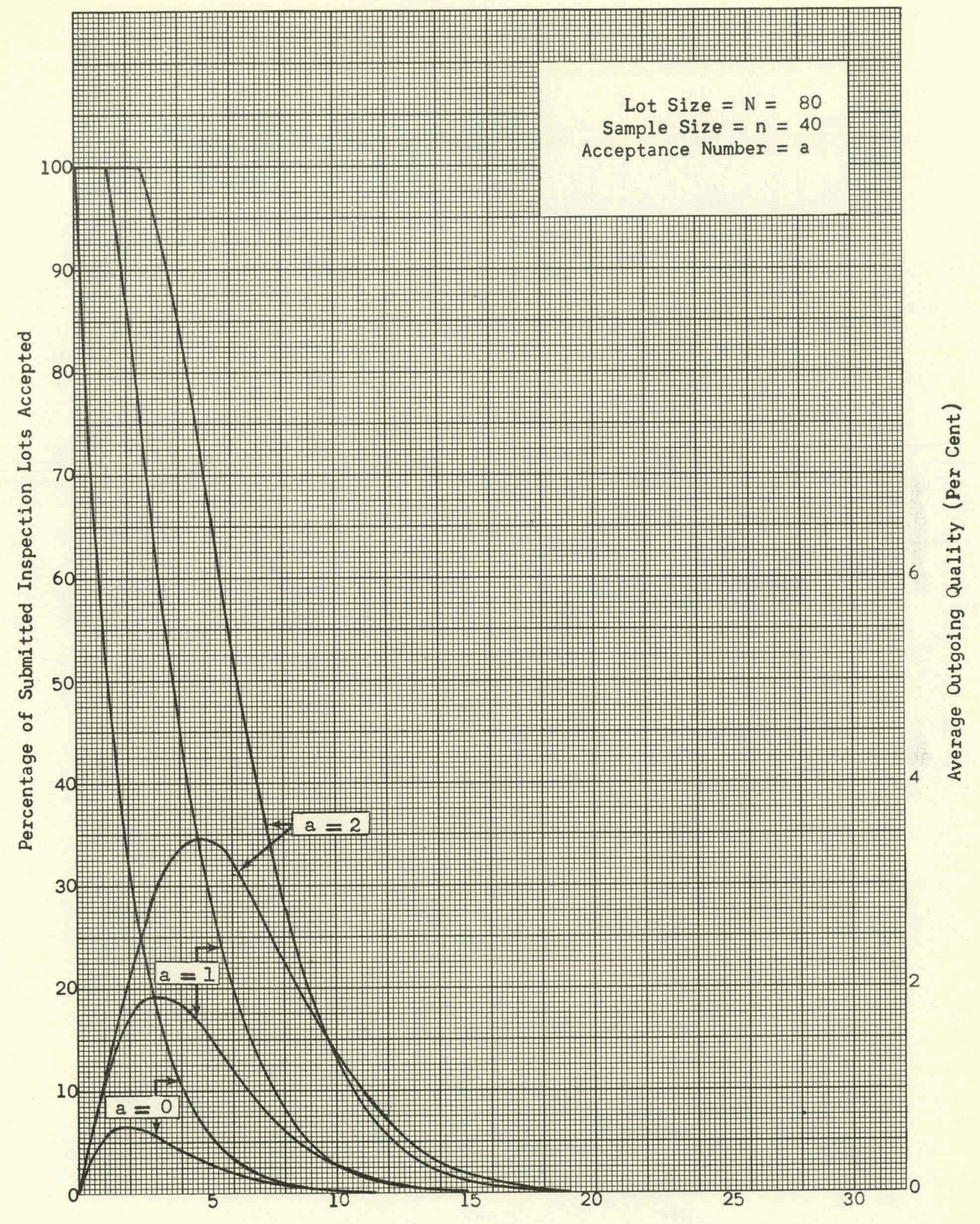

Percentage of Defective Items in Submitted Inspection Lots 


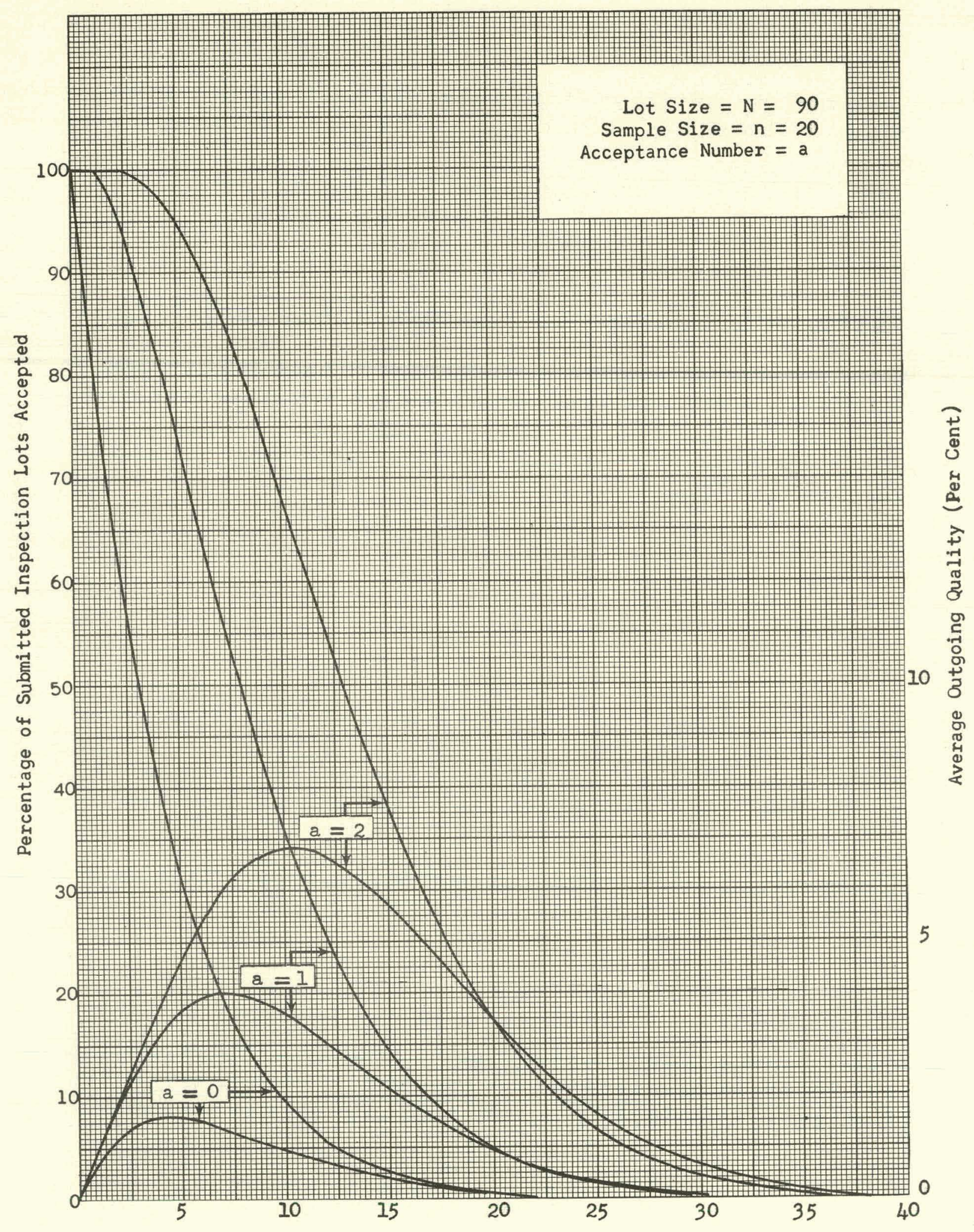

Percentage of Defective Items in Submitted Inspection Lots 


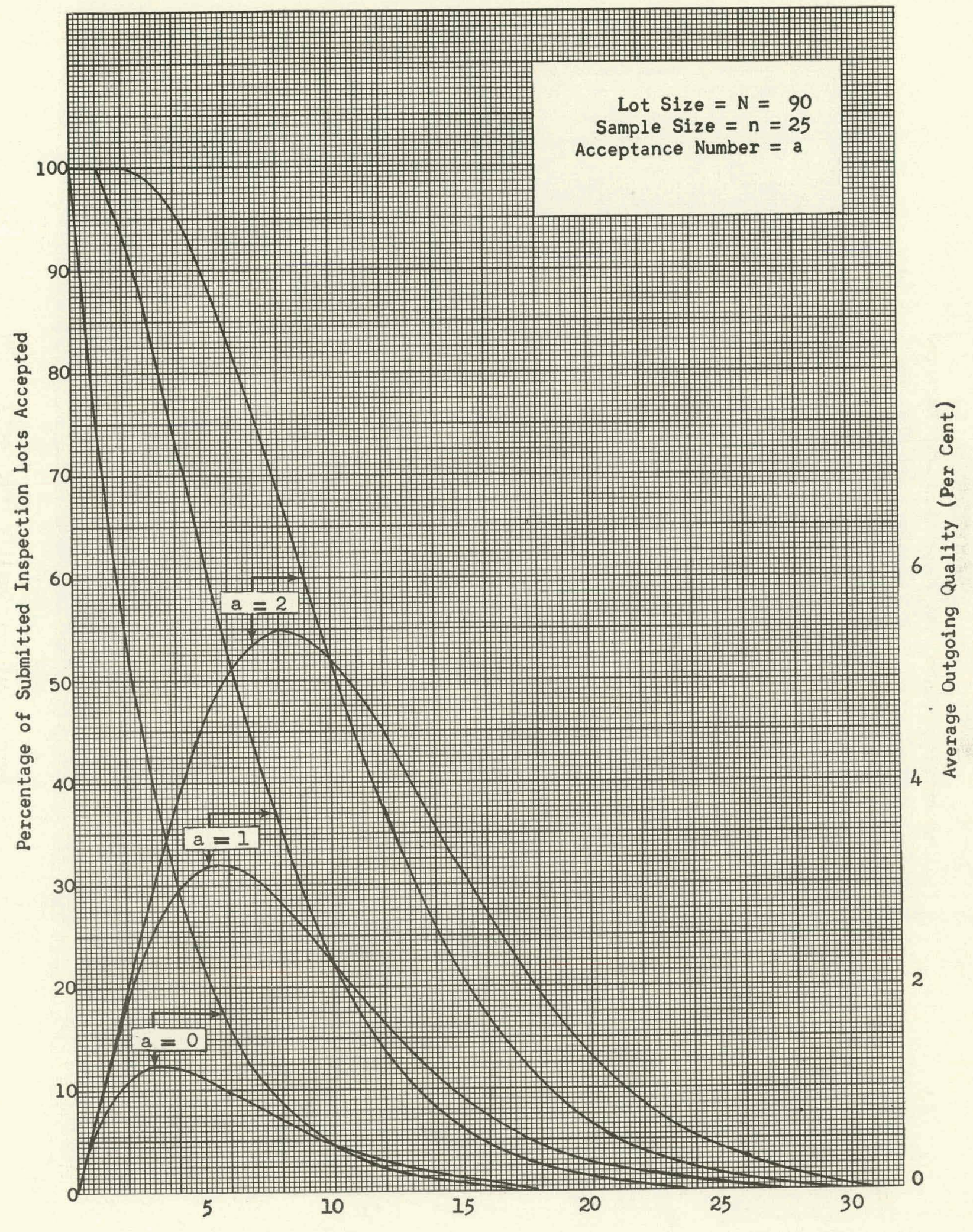

Percentage of Defective Items in Submitted Inspection Lots 


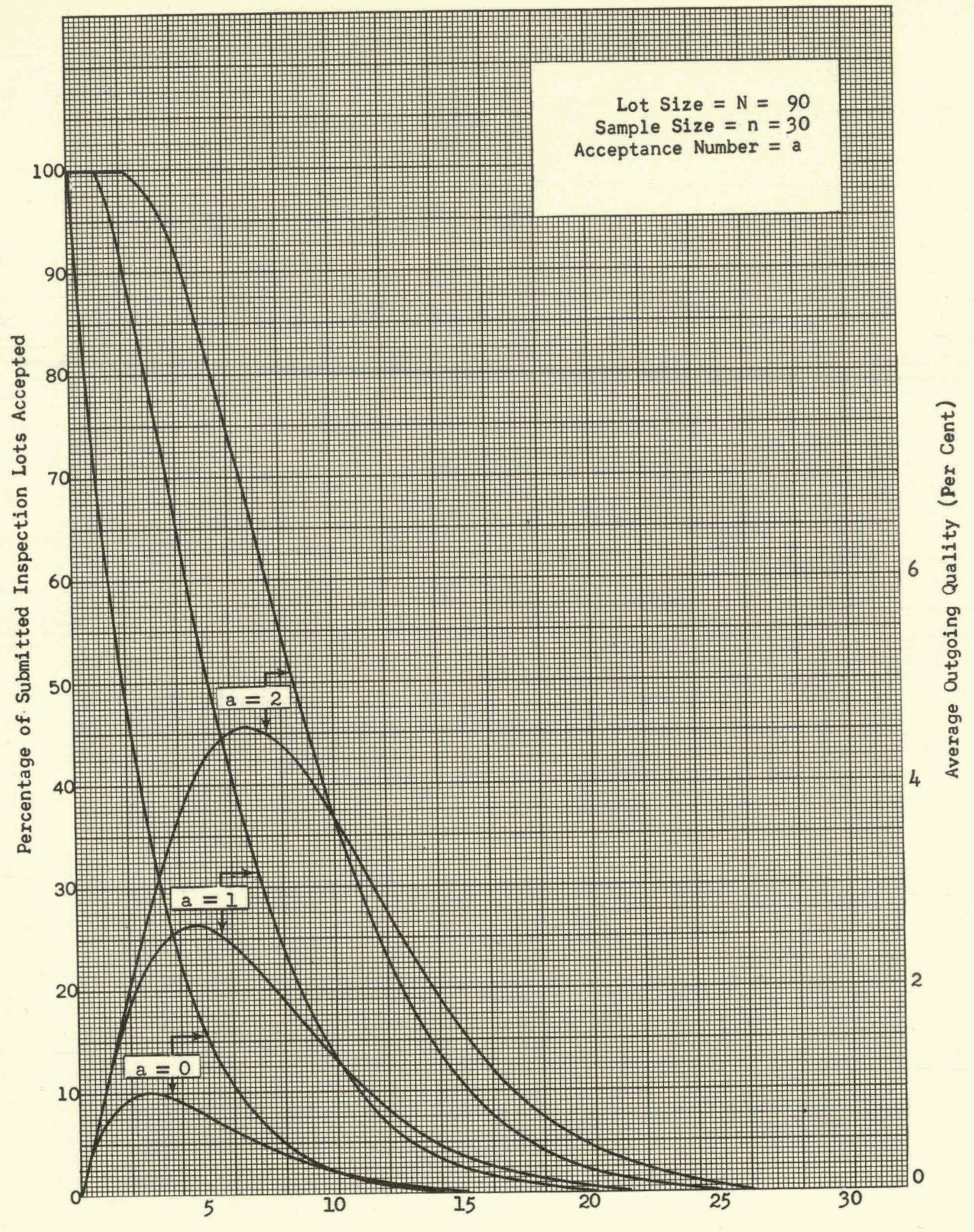

Percentage of Defective Items in Submitted Inspection Lots 


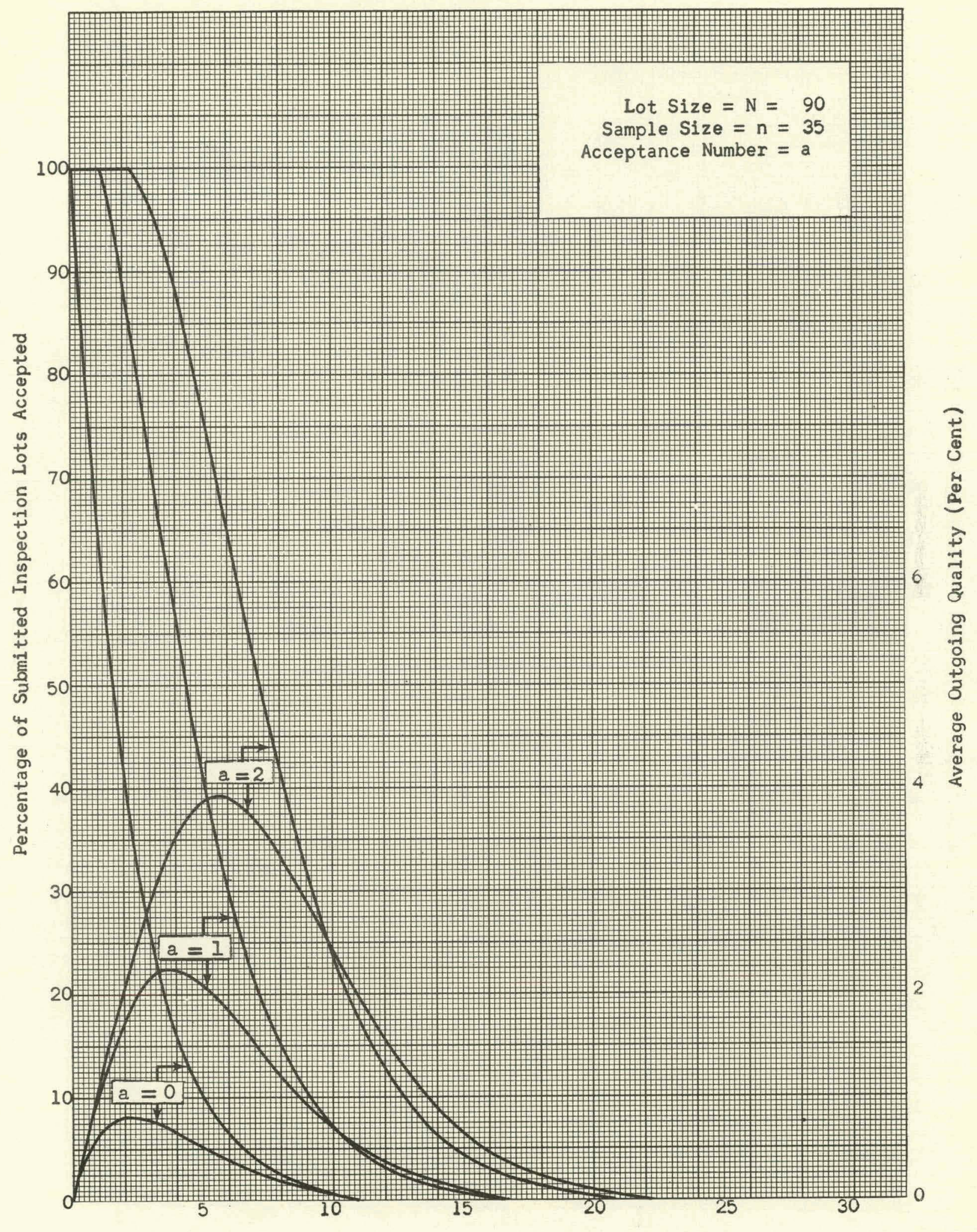

Percentage of Defective Items in Submitted Inspection Lots 


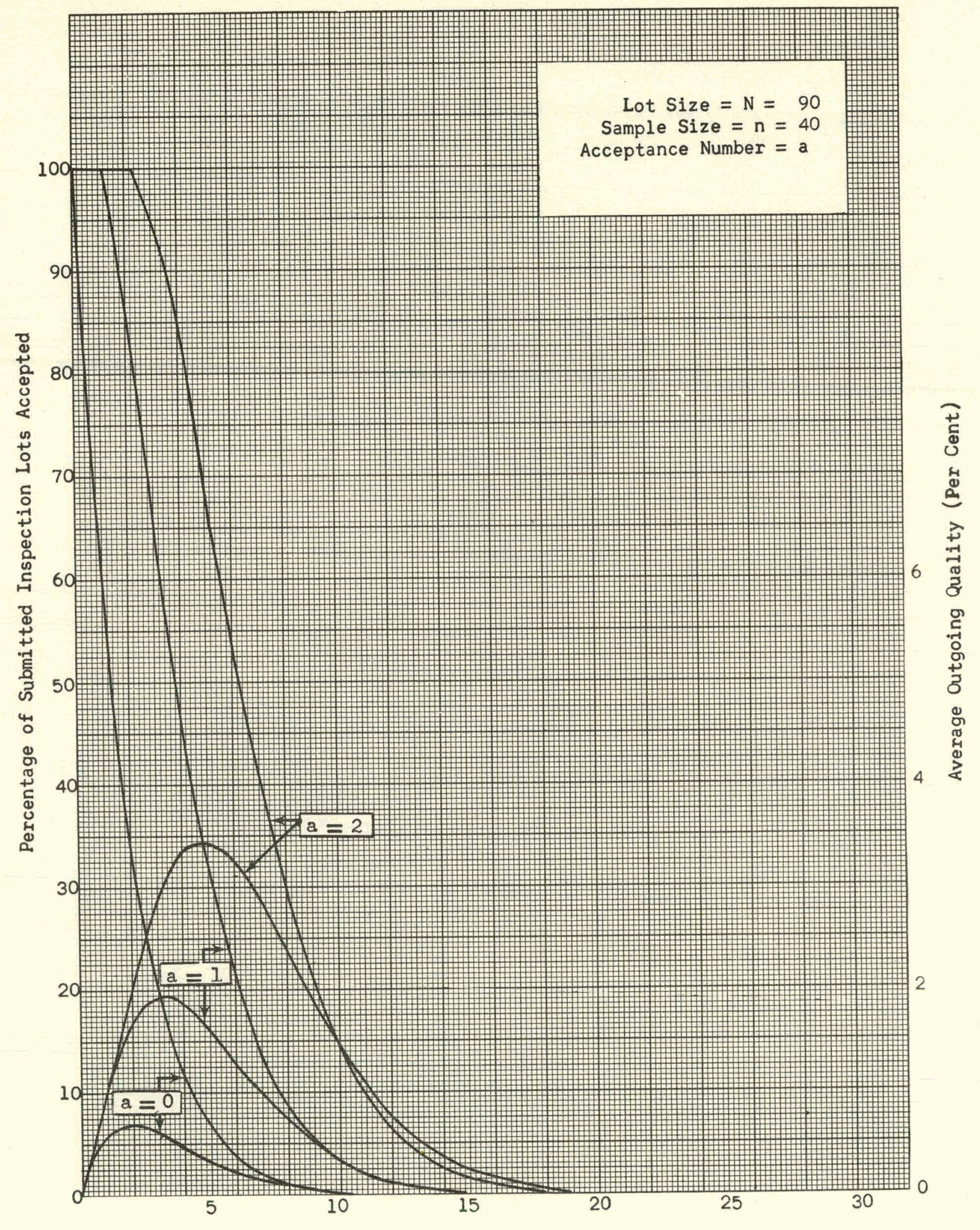

Percentage of Defective Items in Submitted Inspection Lots 


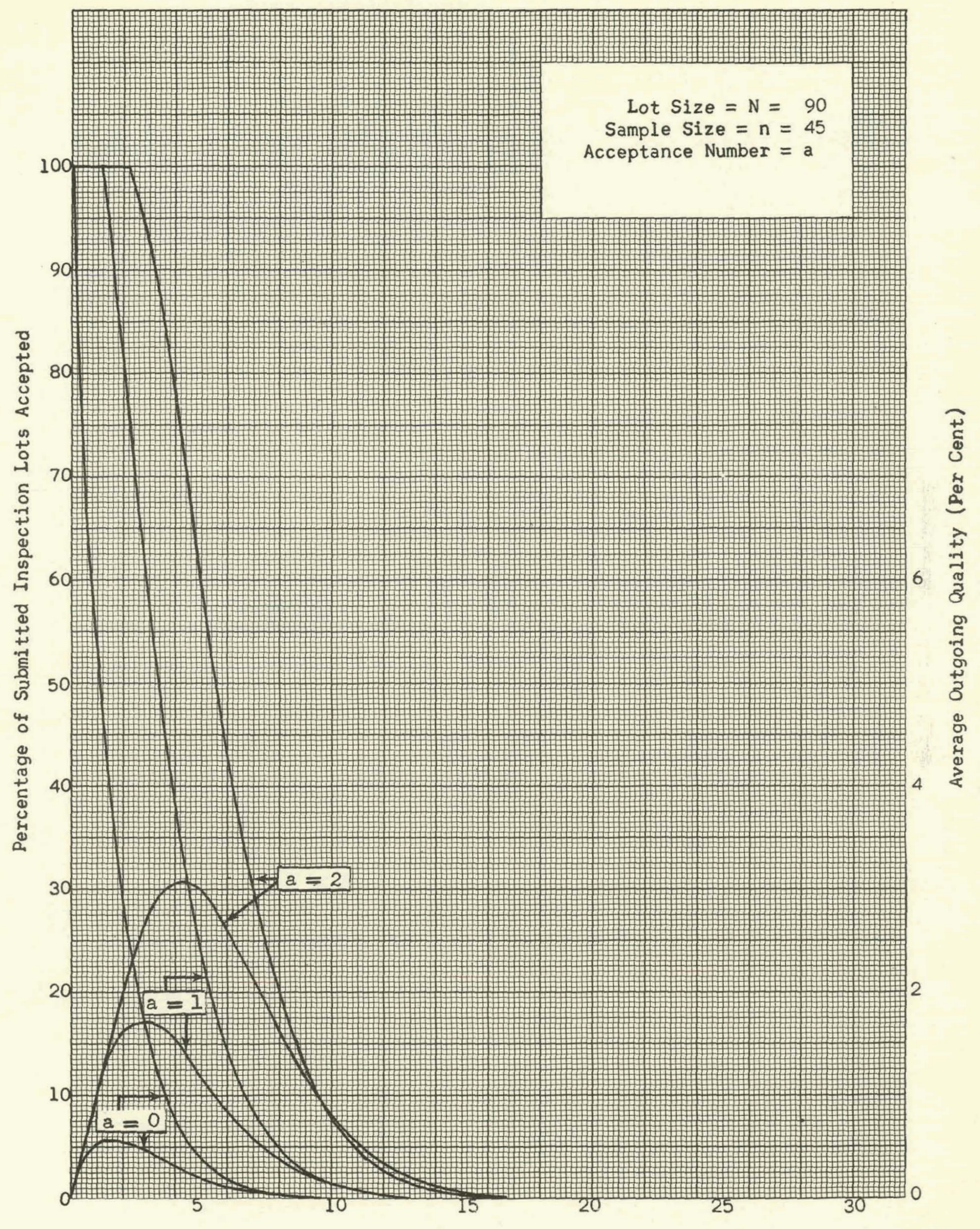

Percentage of Defective Items in Submitted Inspection Lots 


\section{SECTION II}

O. C. and A. O.Q. Curves for

$\begin{array}{rl}\mathrm{N} & \mathrm{n} \\ 40 & 3(1) 12 \\ 50 & 4(1) 13 \\ 60 & 5(1) 14 \\ 70 & 6(1) 15 \\ 80 & 7(1) 16 \\ 90 & 8(1) 17 \\ 100 & 9(1) 18 \\ 125 & 10(1) 19 \\ 150 & 10(1) 19 \\ 175 & 11(1) 20 \\ 200 & 14(1) 23 \\ 225 & 15(1) 24\end{array}$




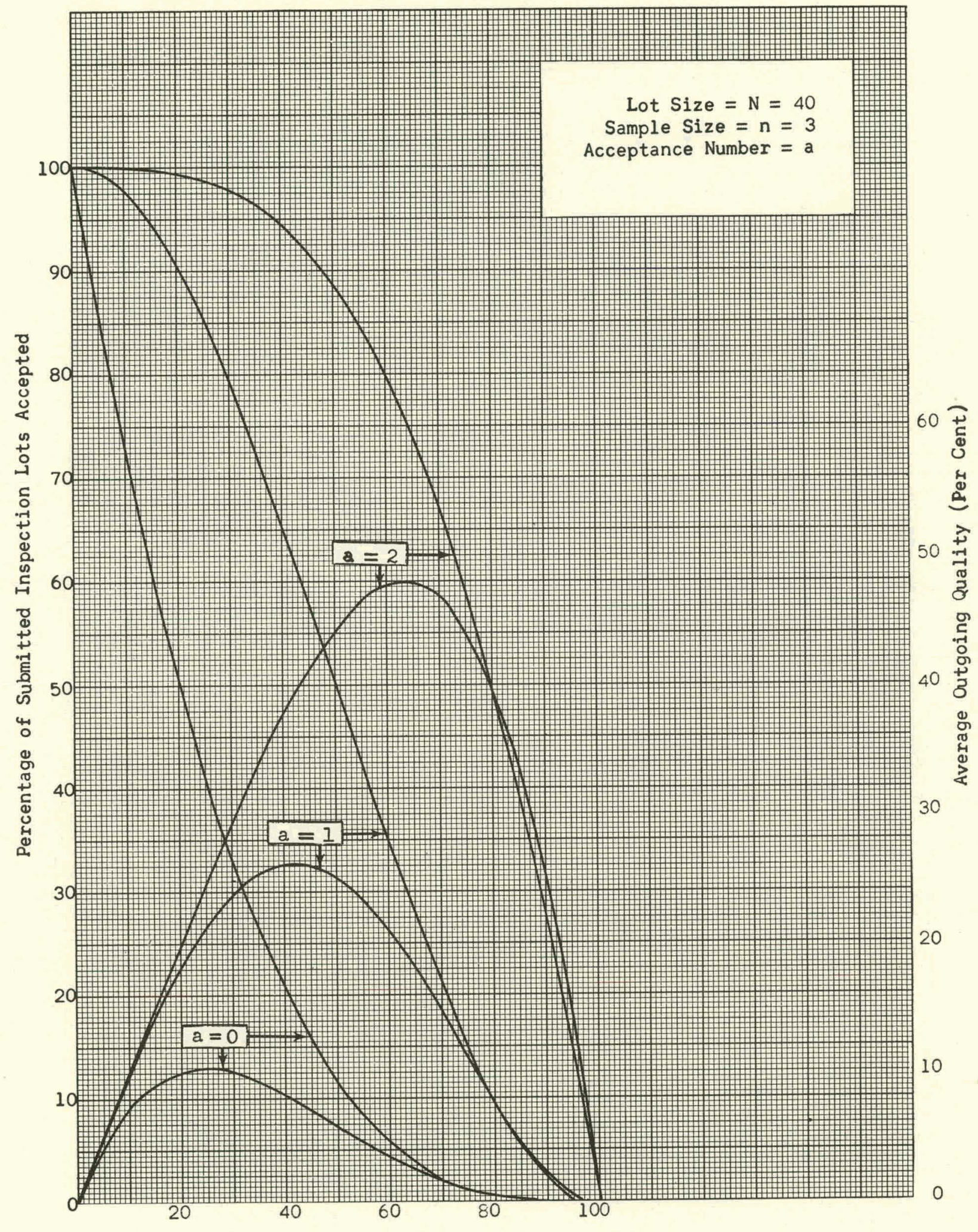

Percentage of Defective Items in Submitted Inspection Lots 


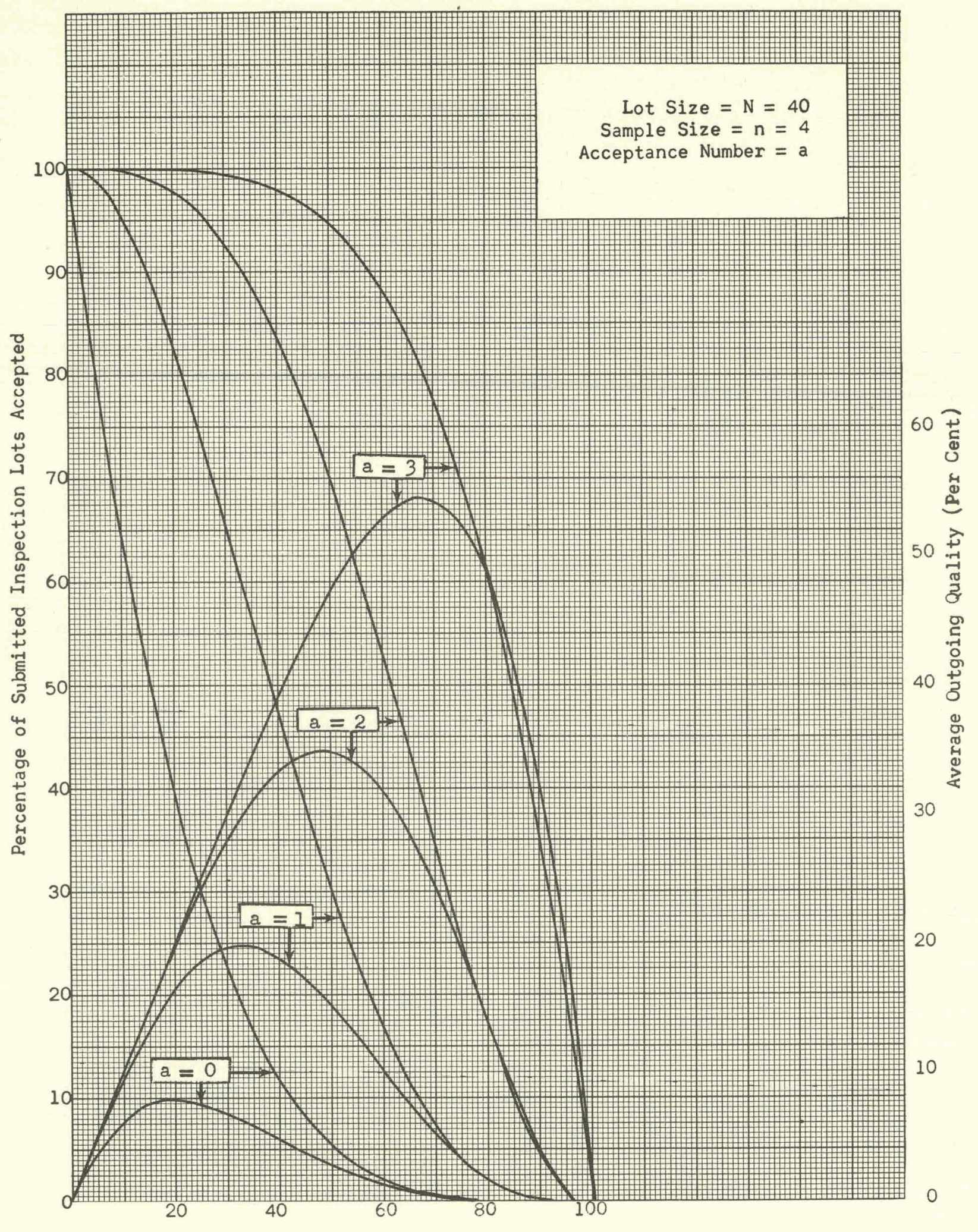

Percentage of Defective Items in Submitted Inspection Lots 


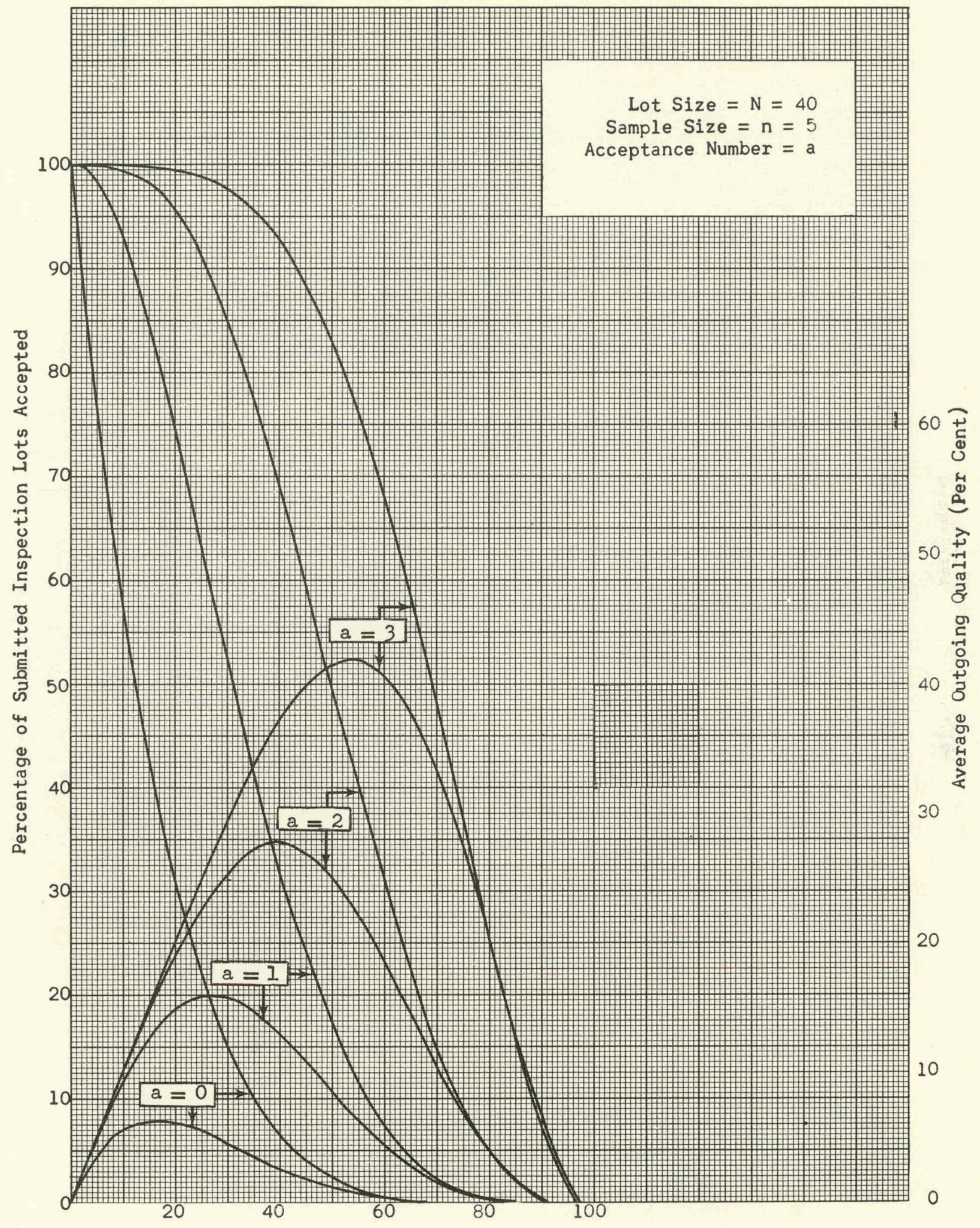

Percentage of Defective Items in Submitted Inspection Lots 


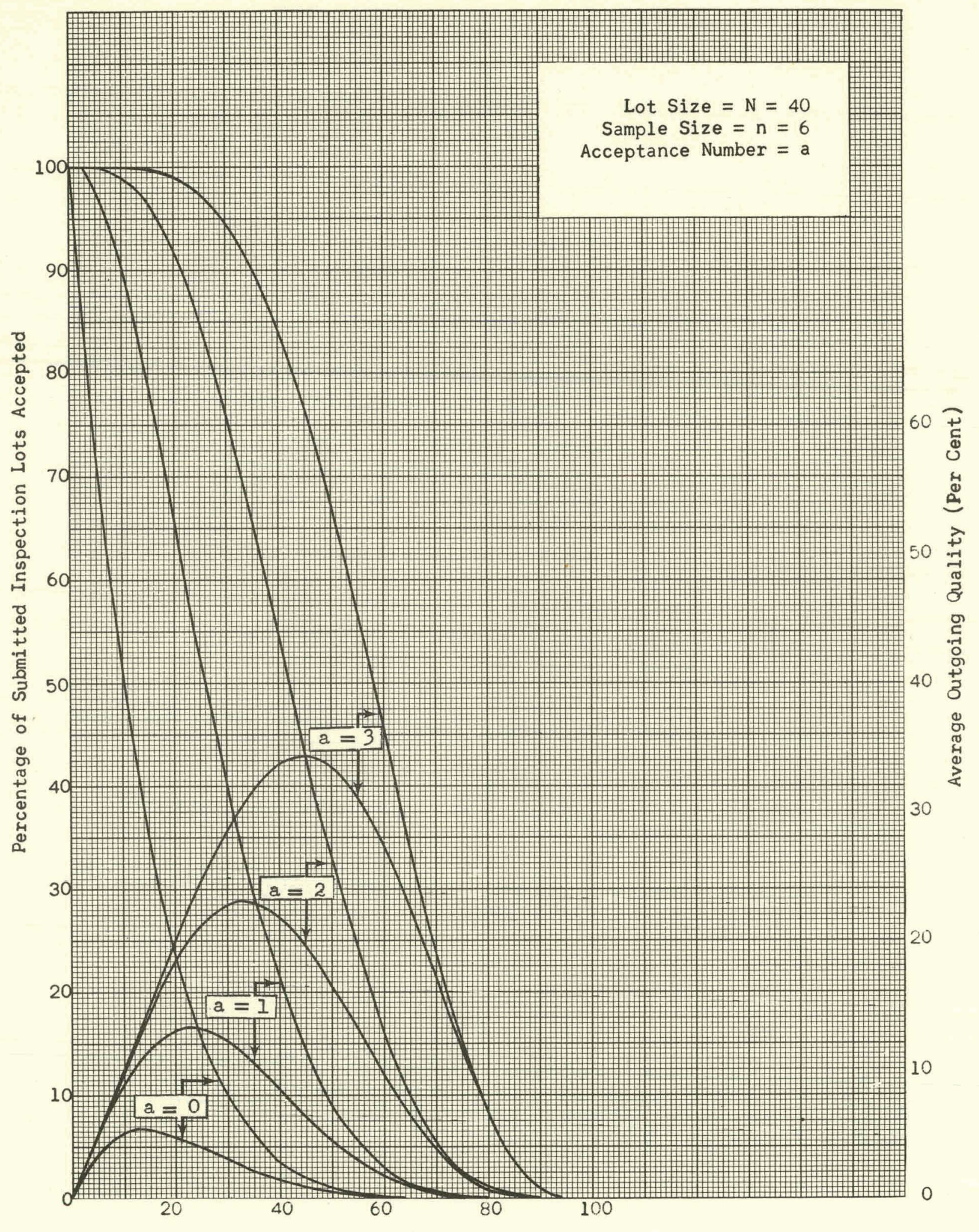

Percentage of Defective Items in Submitted Inspection Lots 


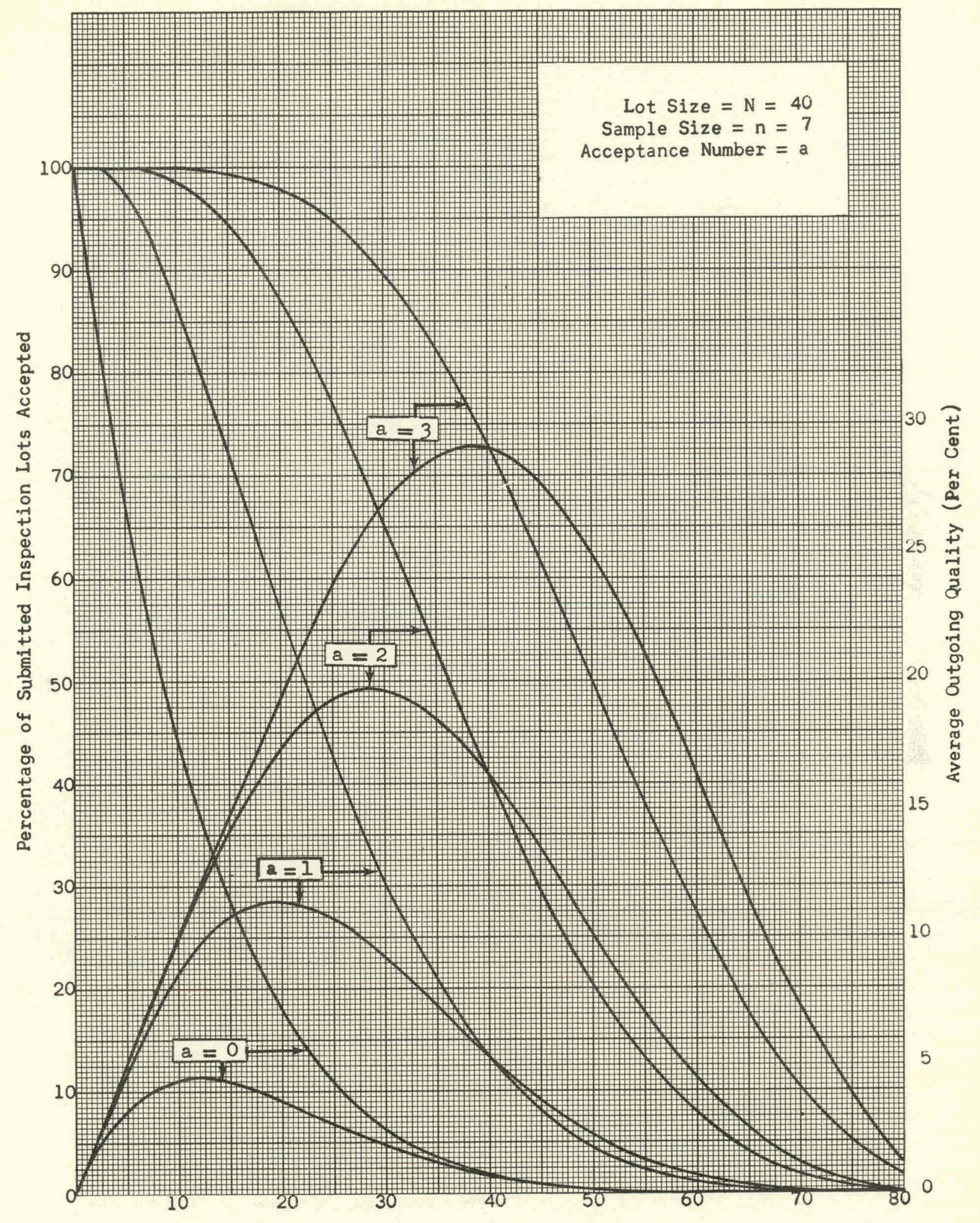

Percentage of Defective Items in Submitted Inspection Lots 


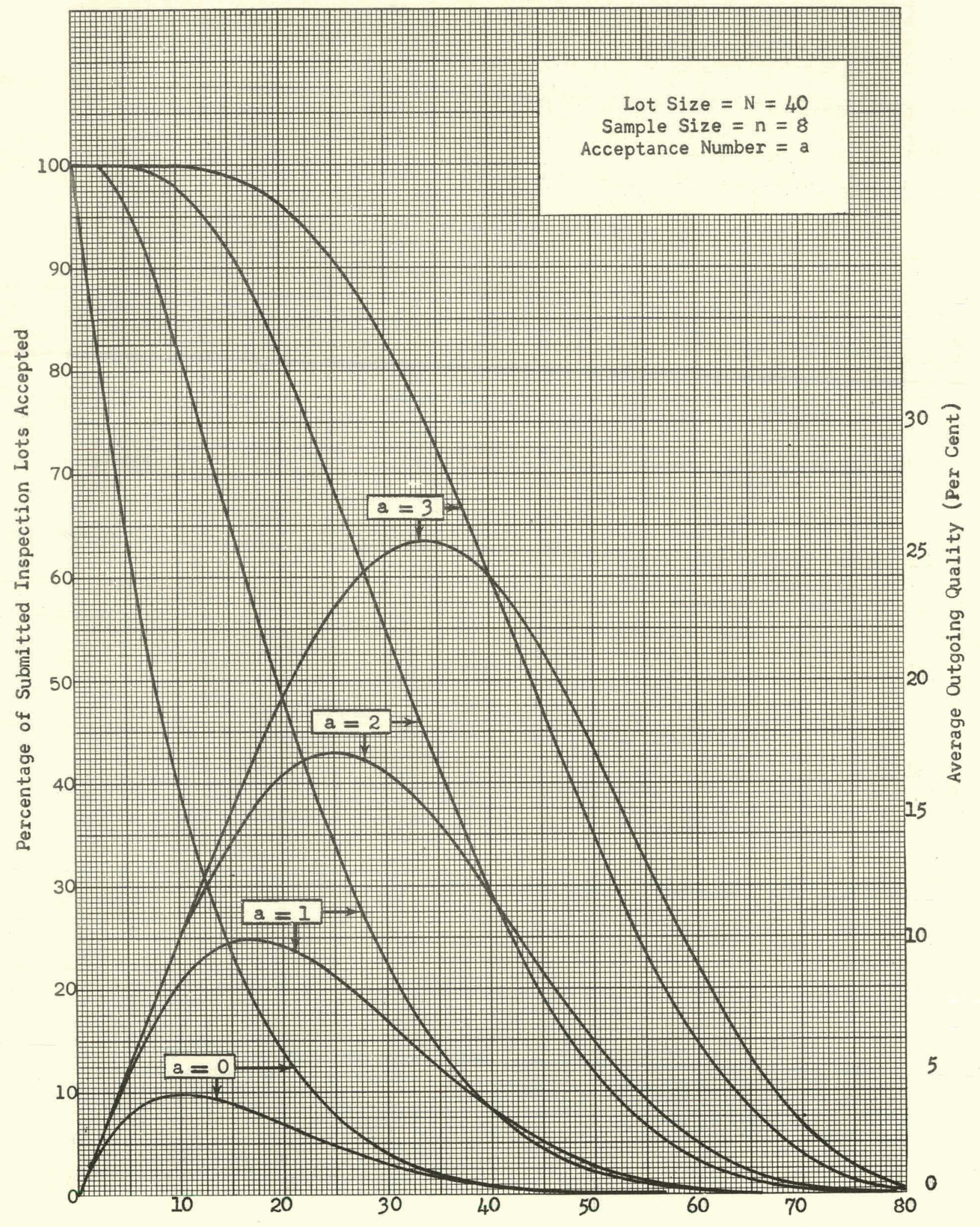

Percentage of Defective Items in Submitted Inspection Lots 


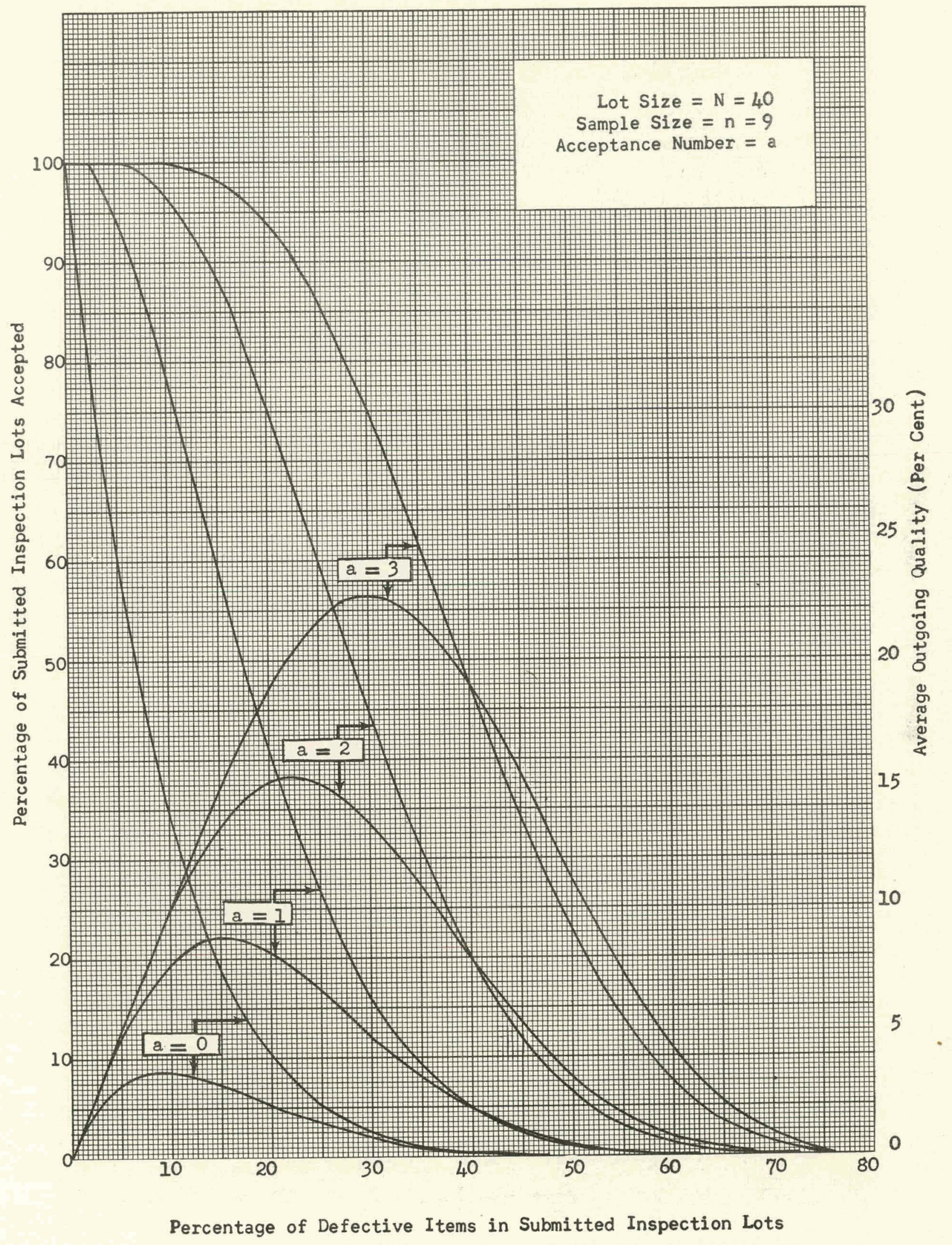




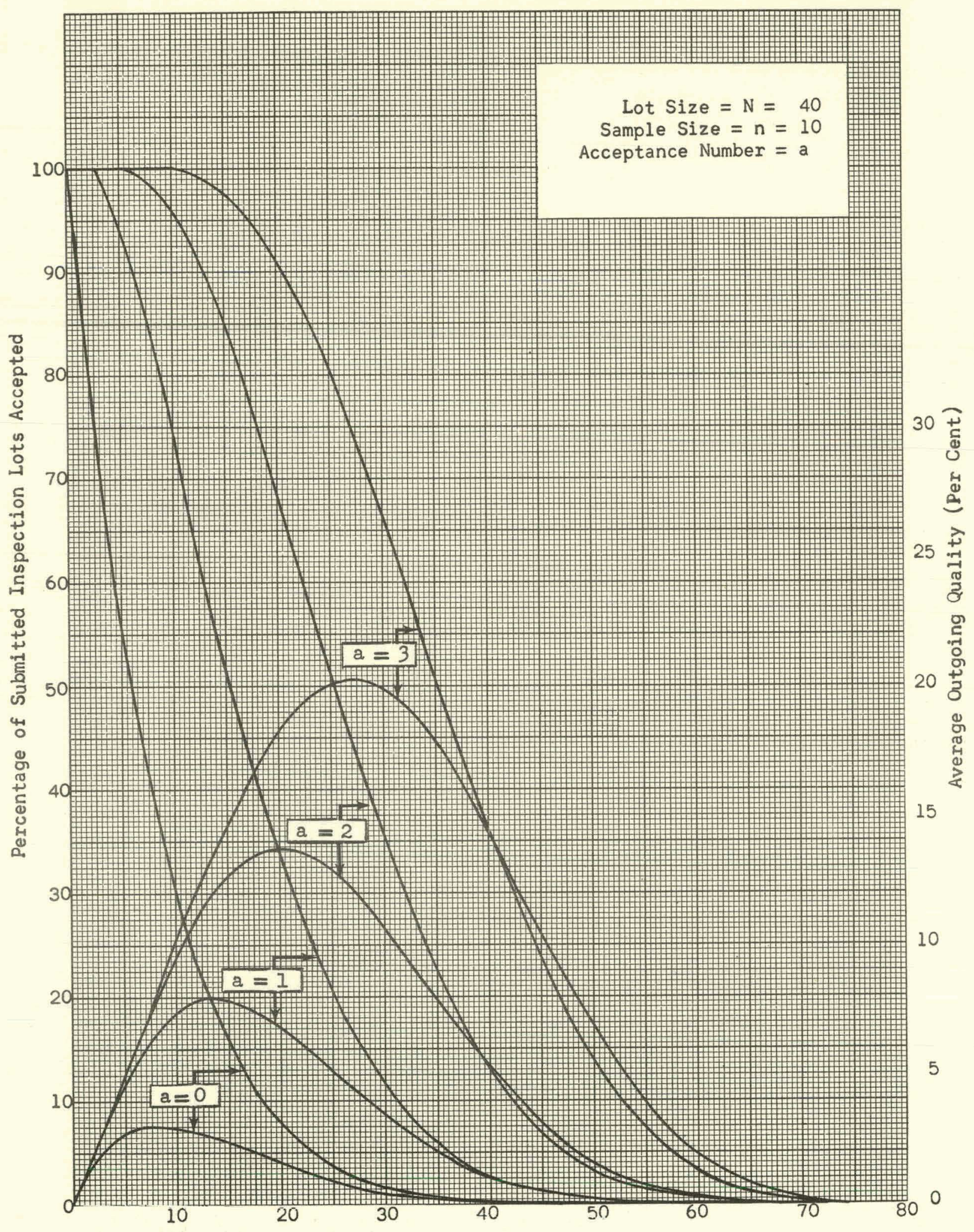

Percentage of Defective Items in Submitted Inspection Lots 


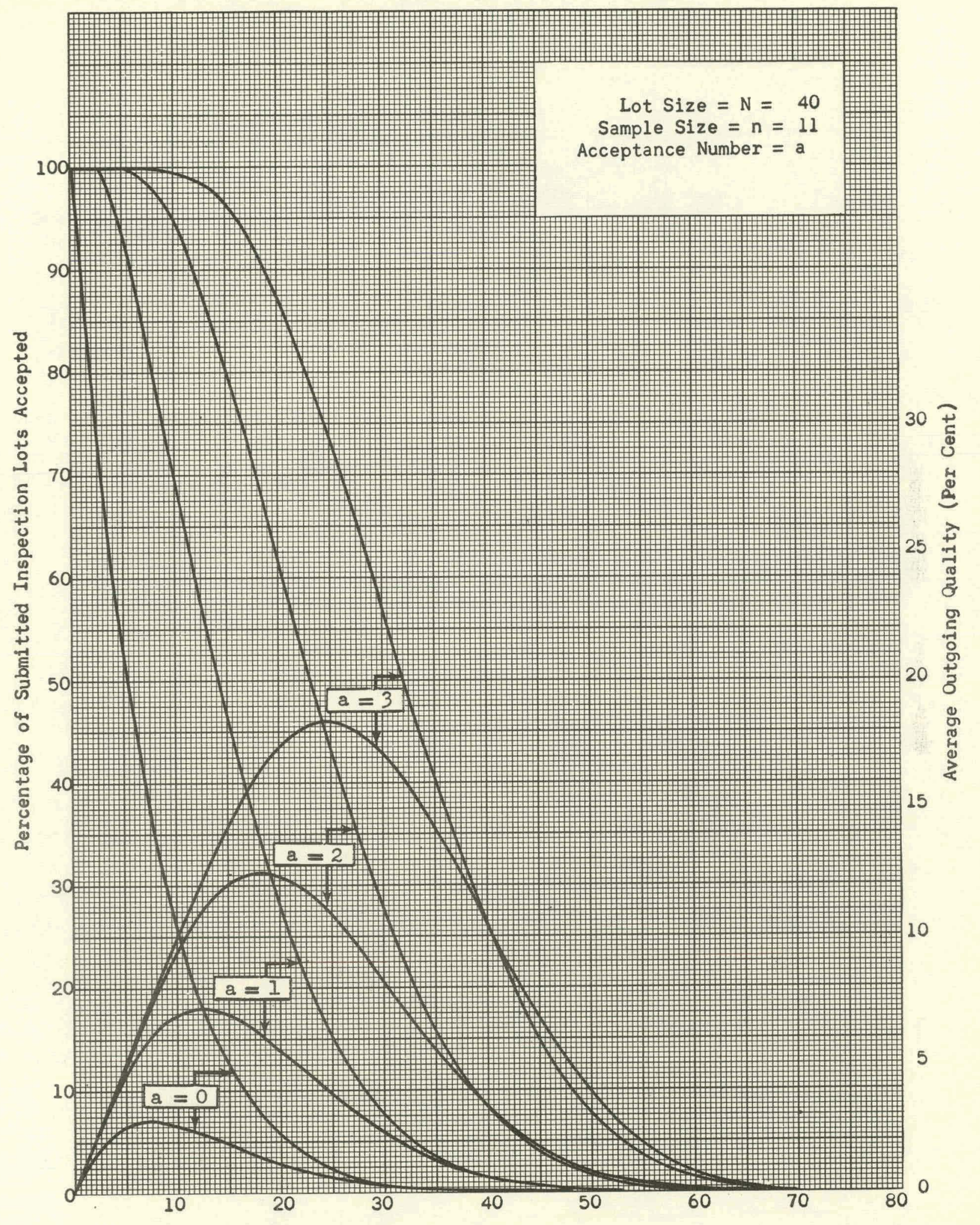

Percentage of Defective Items in Submitted Inspection Lots 


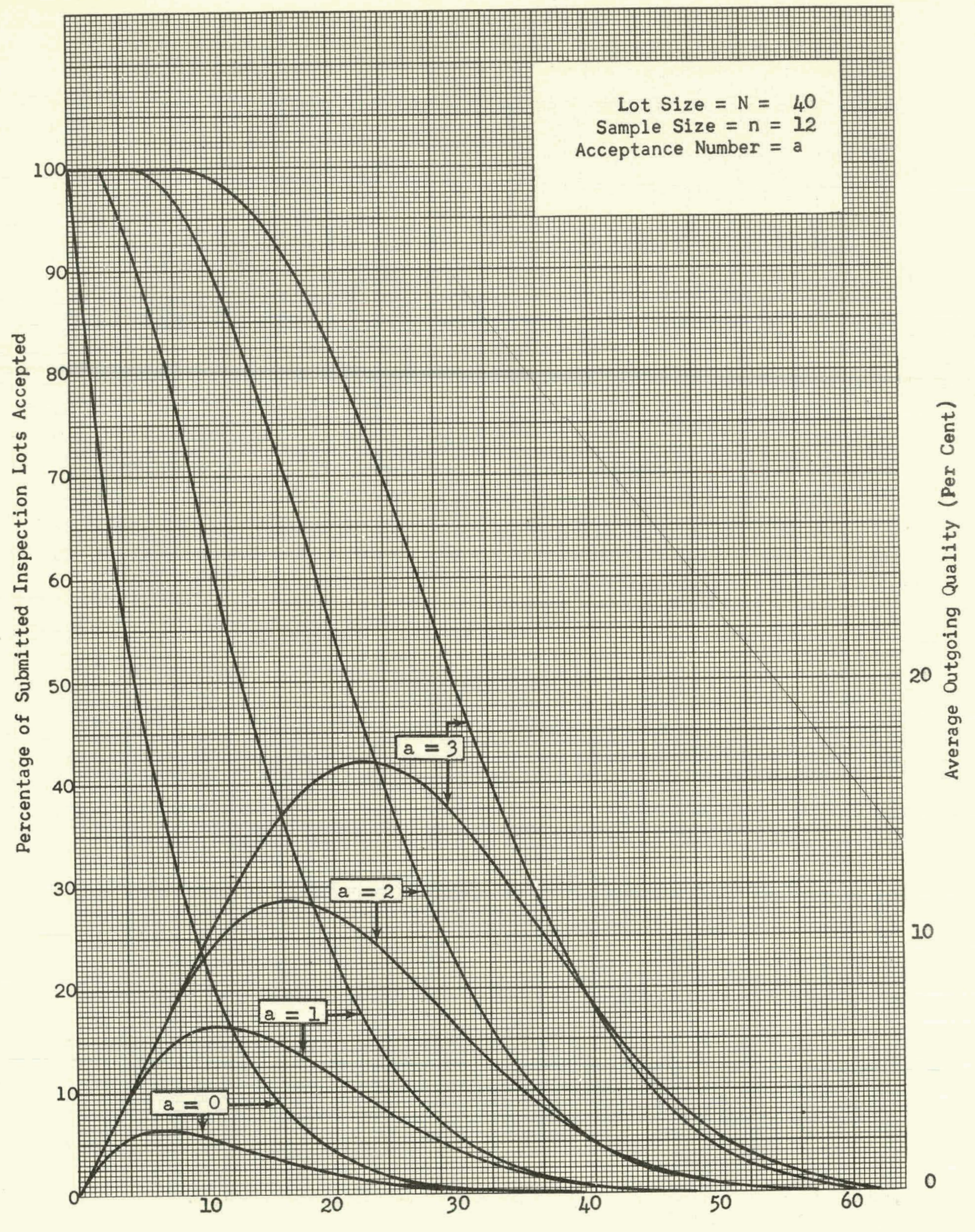

Percentage of Defective Items in Submitted Inspection Lots 


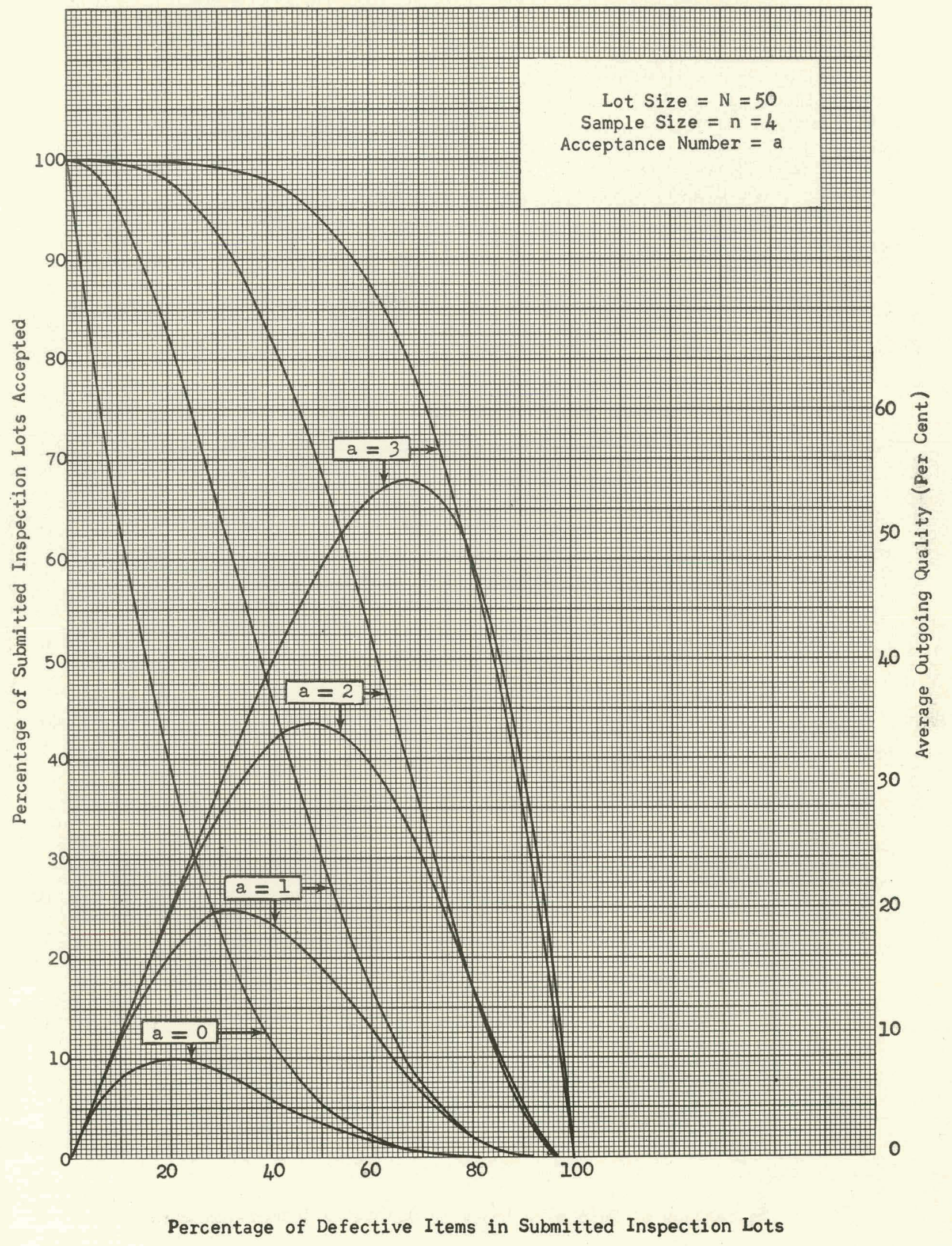




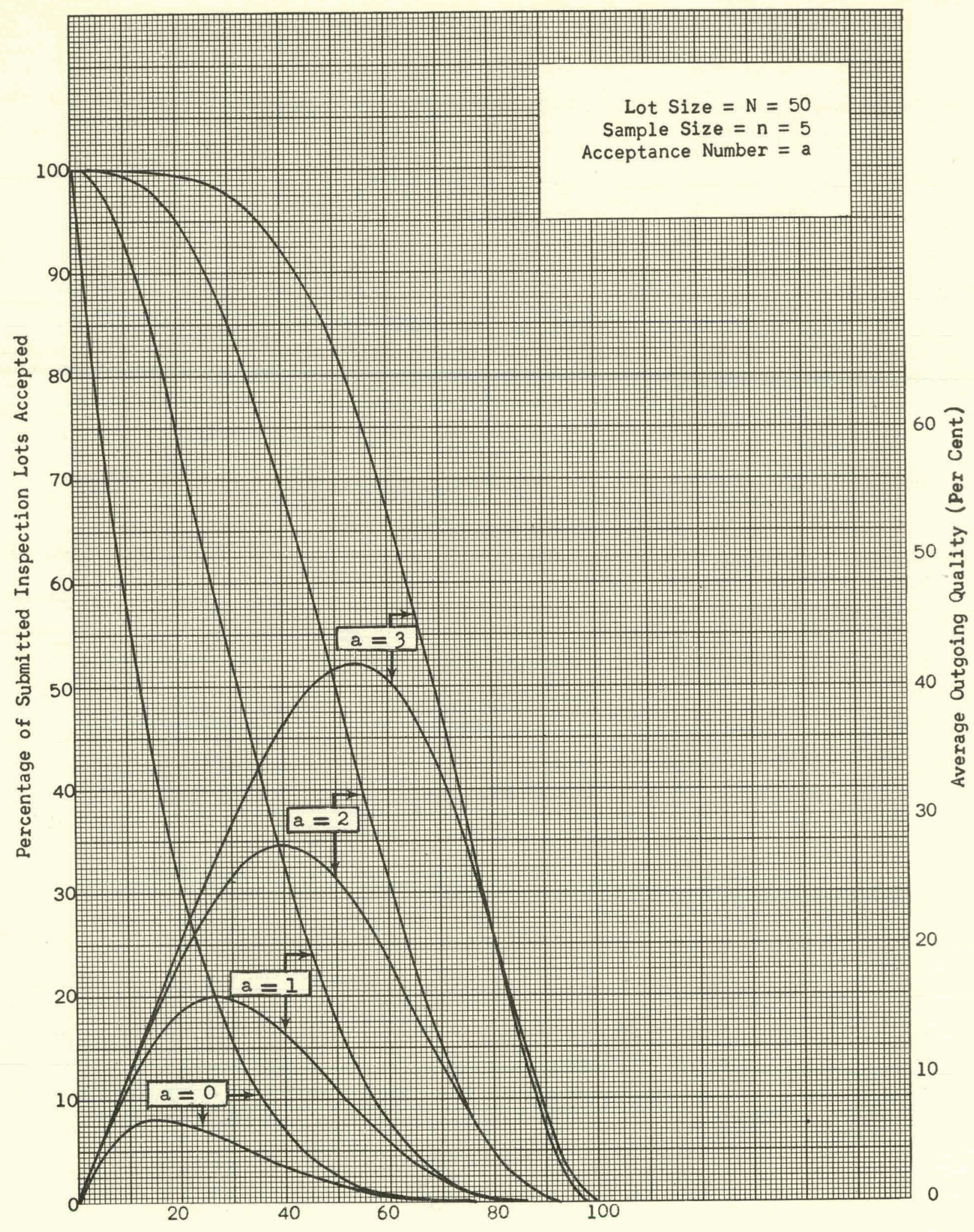

Percentage of Defective Items in Submitted Inspection Lots 


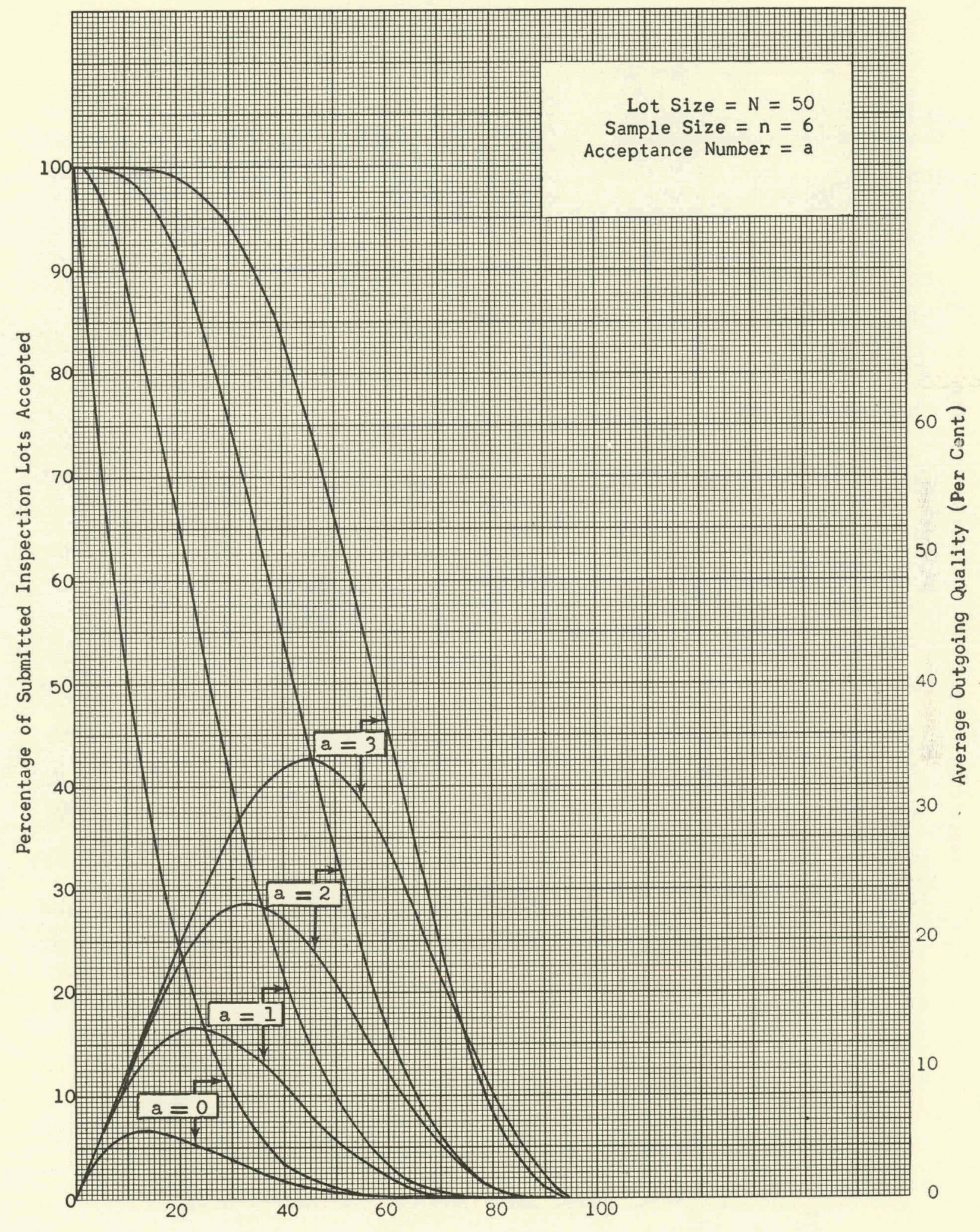

Percentage of Defective Items in Submitted Inspection Lots 


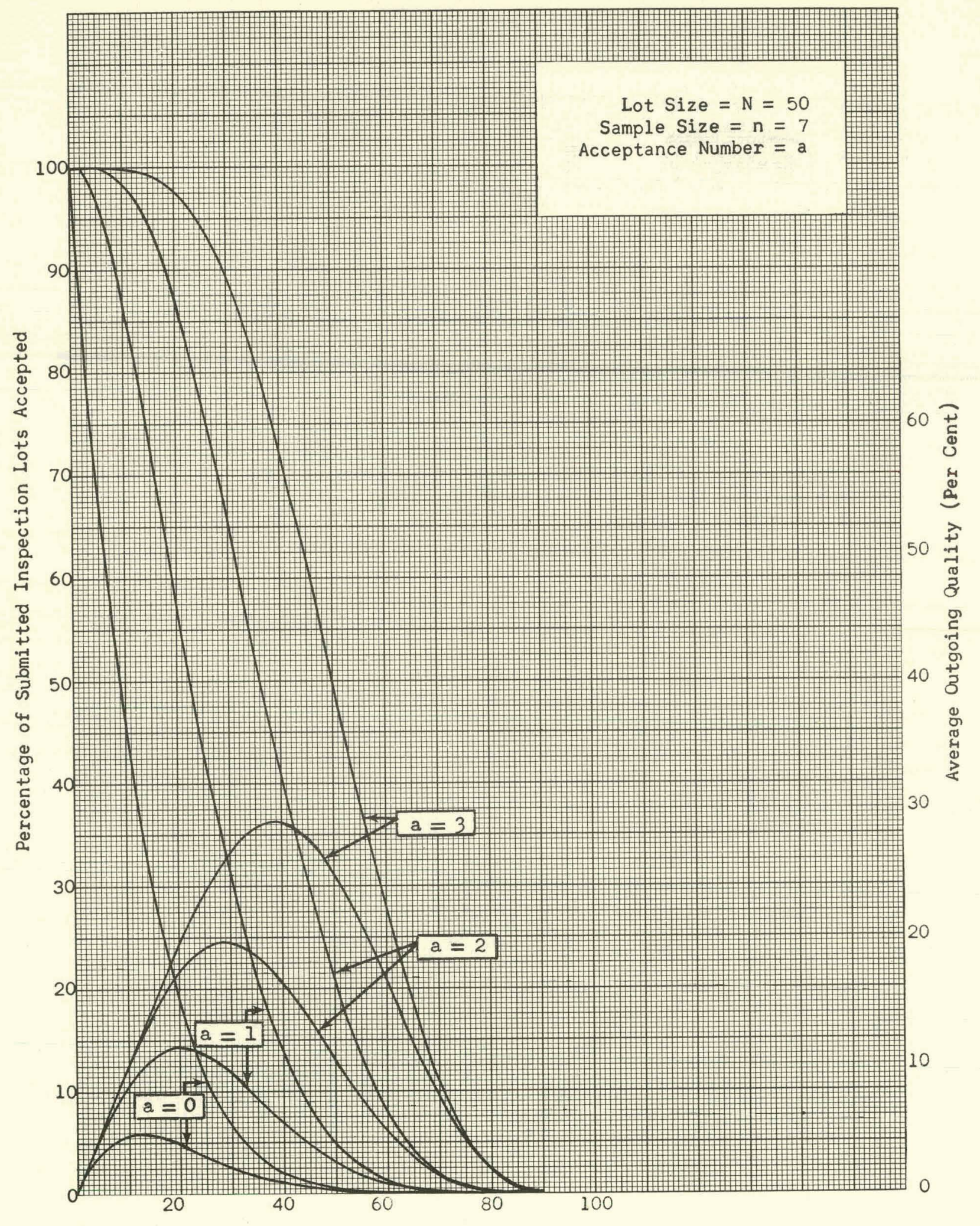

Percentage of Defective Items in Submitted Inspection Lots 


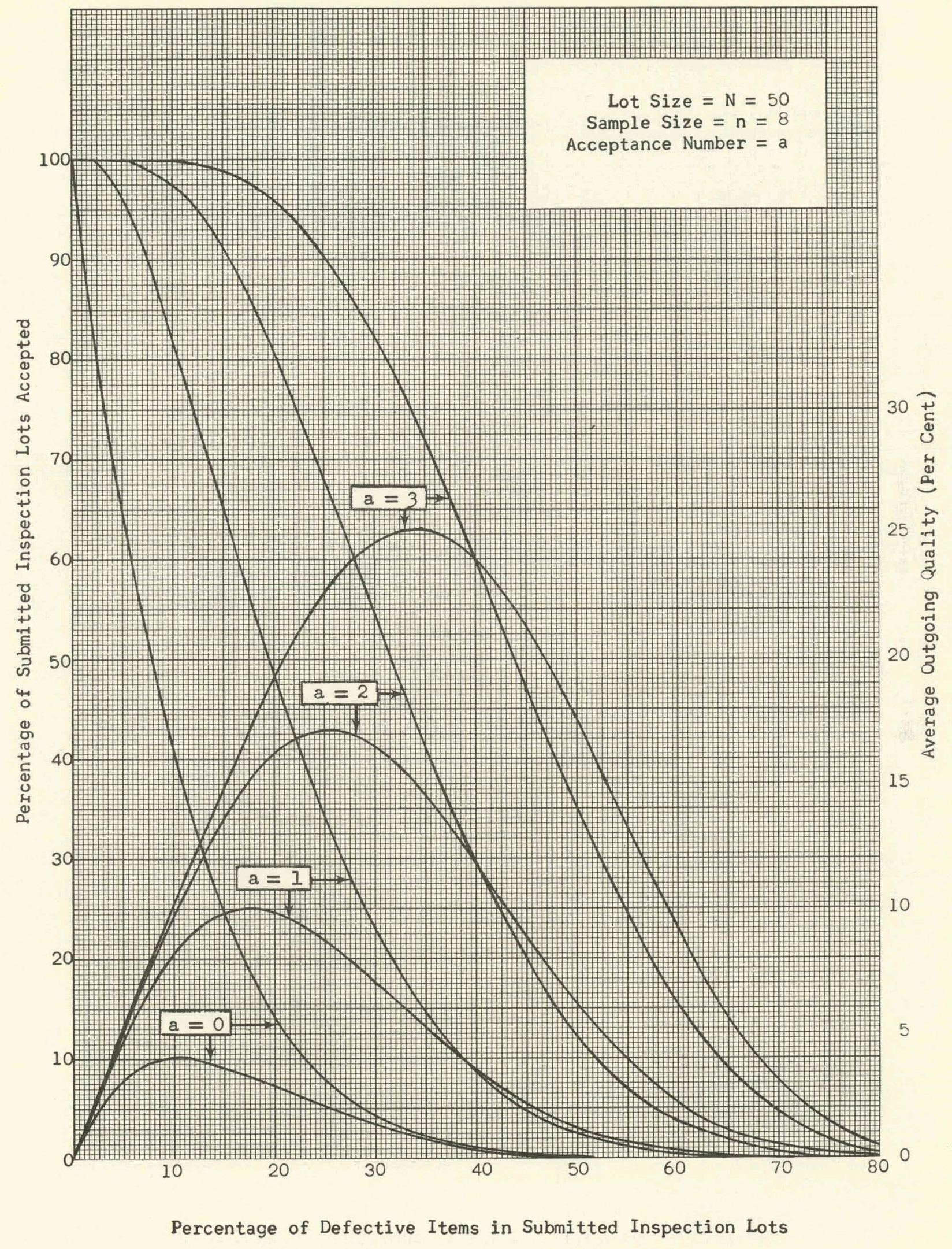




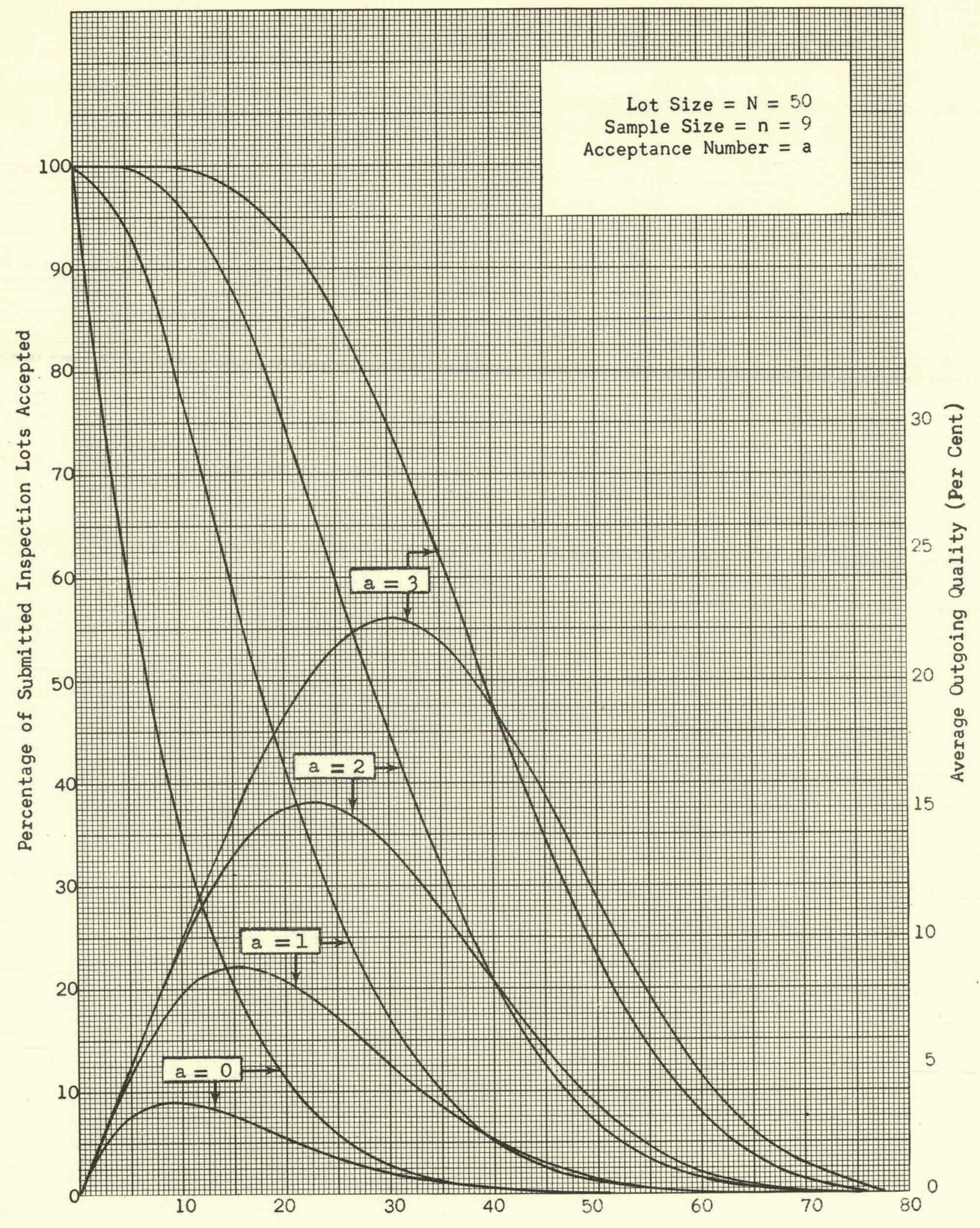

Percentage of Defective Items in Submitted Inspection Lots 


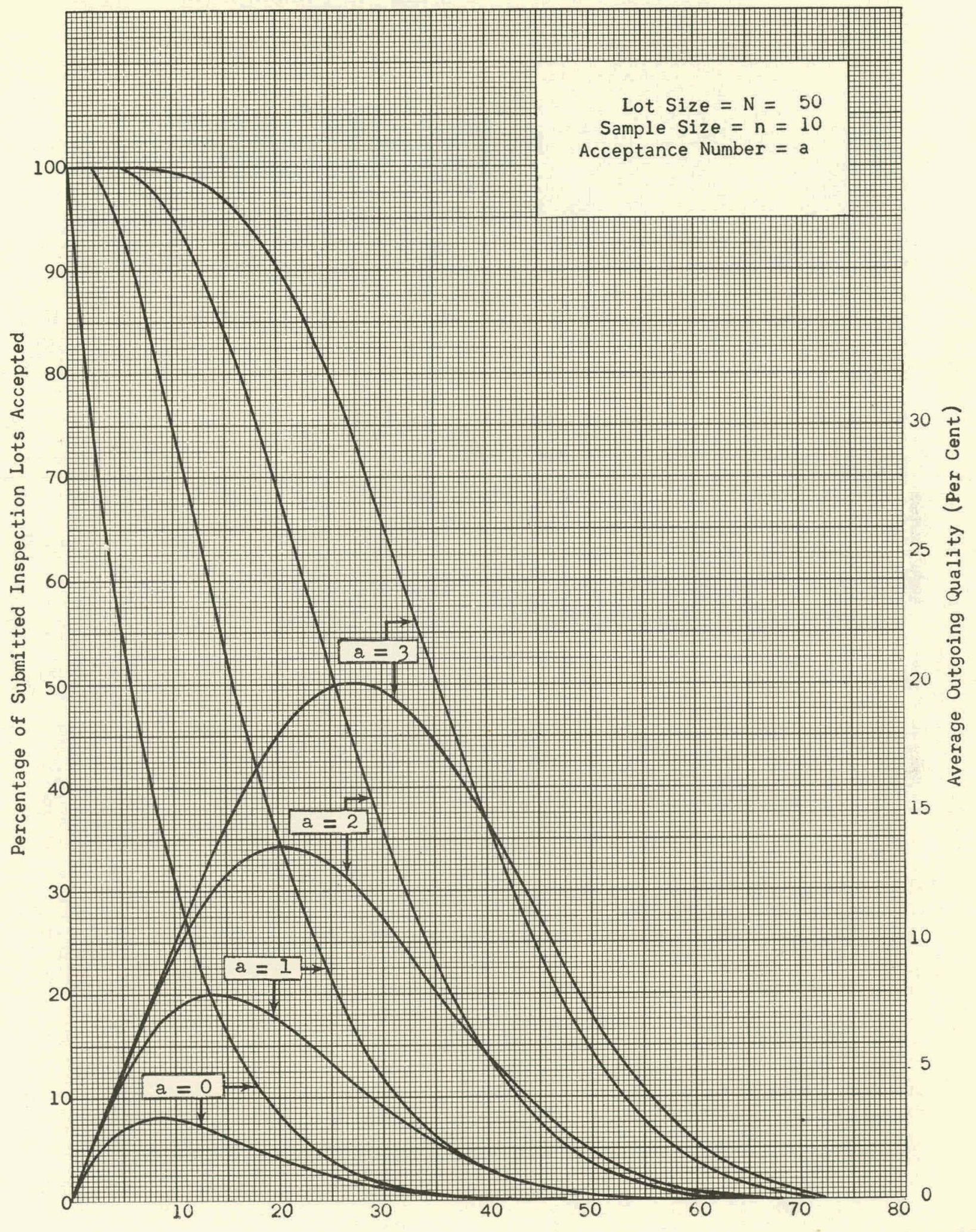

Percentage of Defective Items in Submitted Inspection Lots 


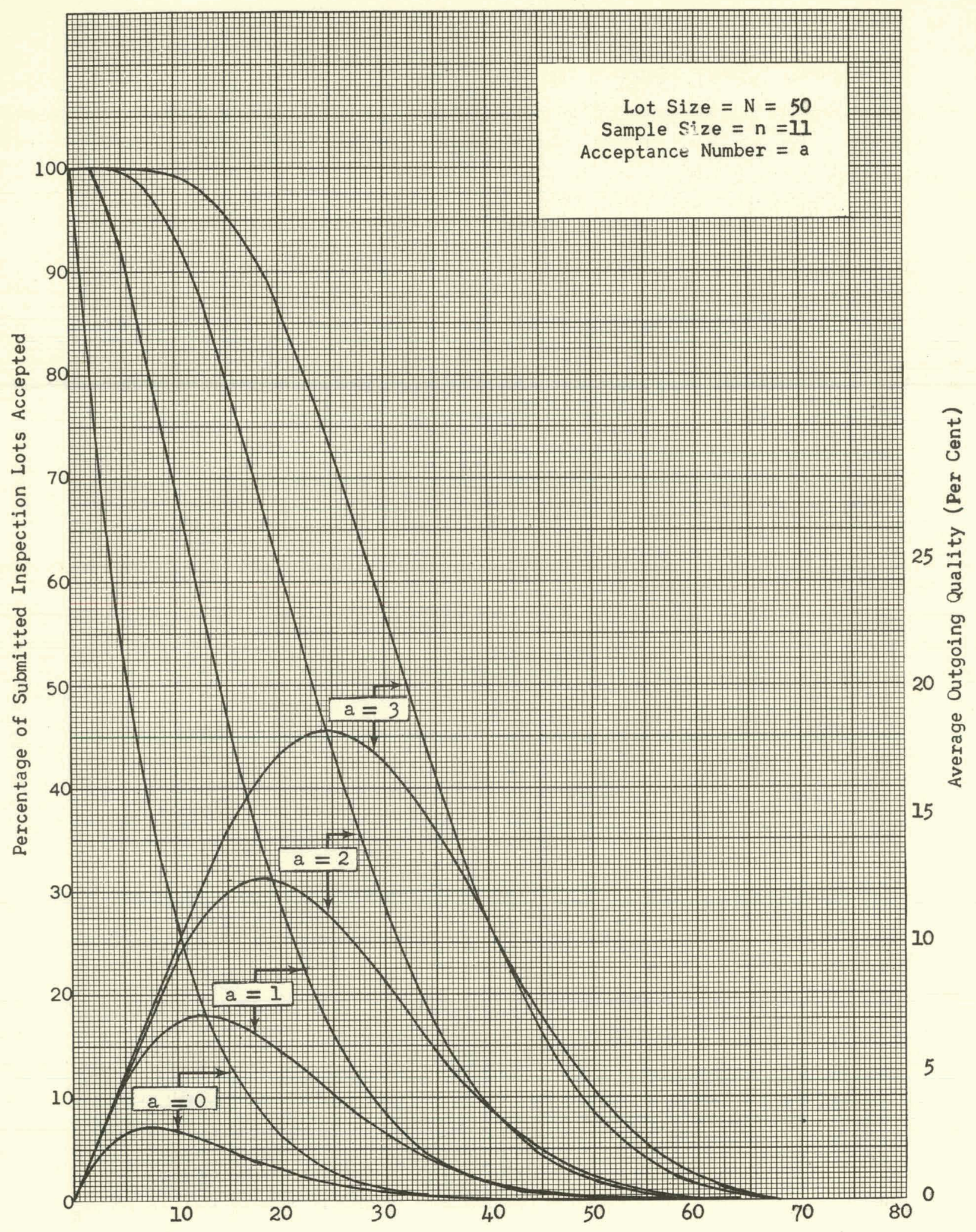

Percentage of Defective Items in Submitted Inspection Lots 


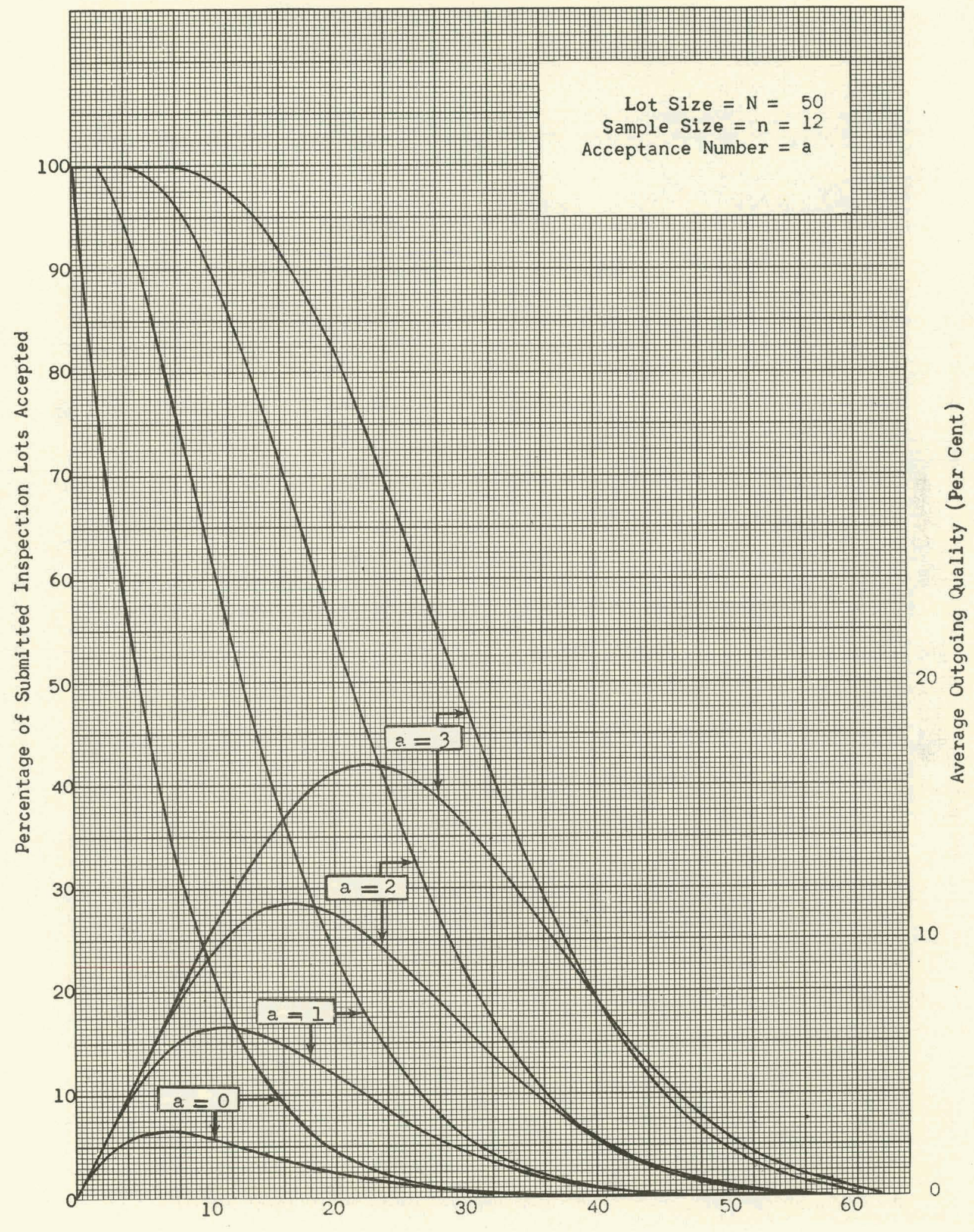

Percentage of Defective Items in Submitted Inspection Lots 


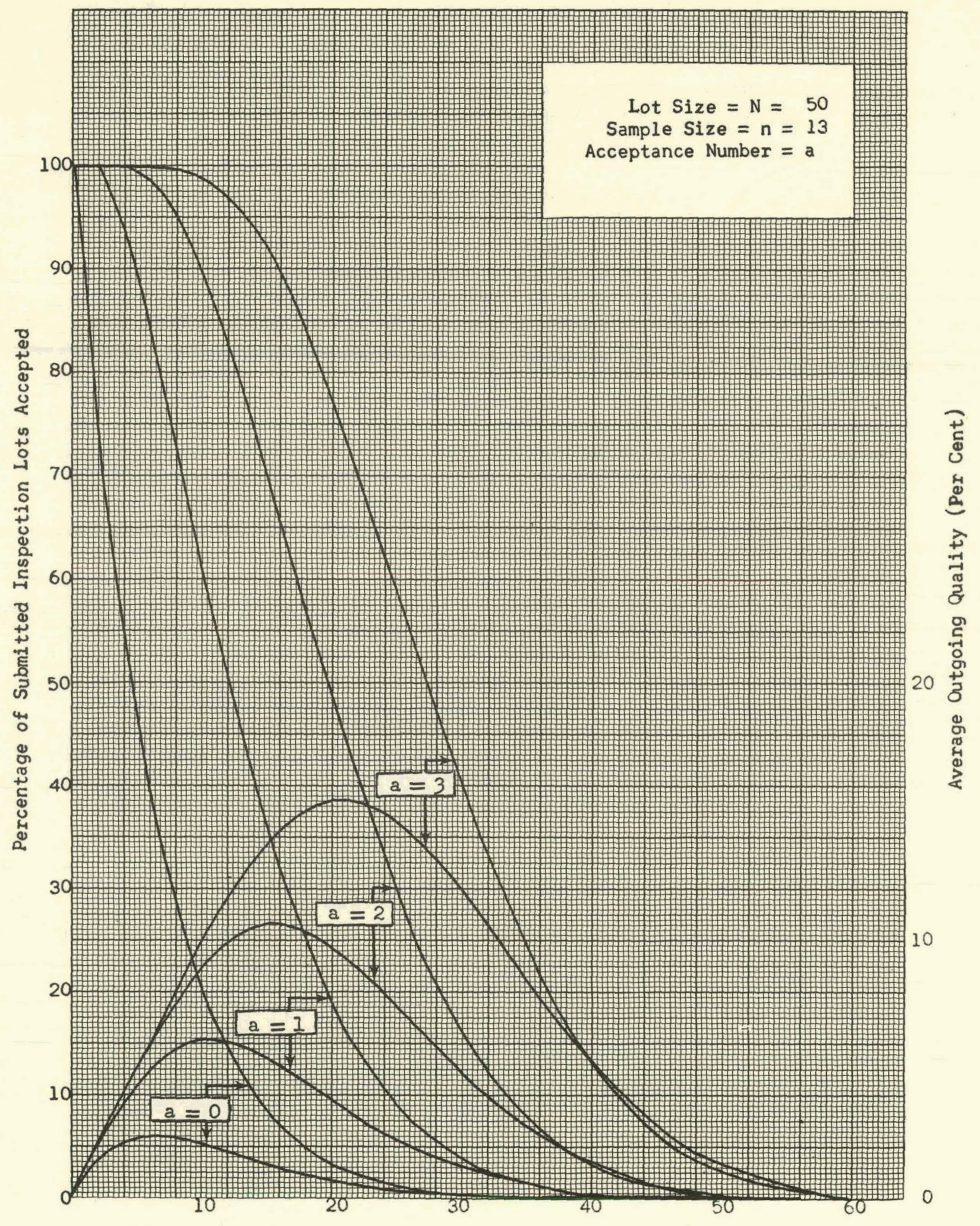

Percentage of Defective Items in Submitted Inspection Lots 


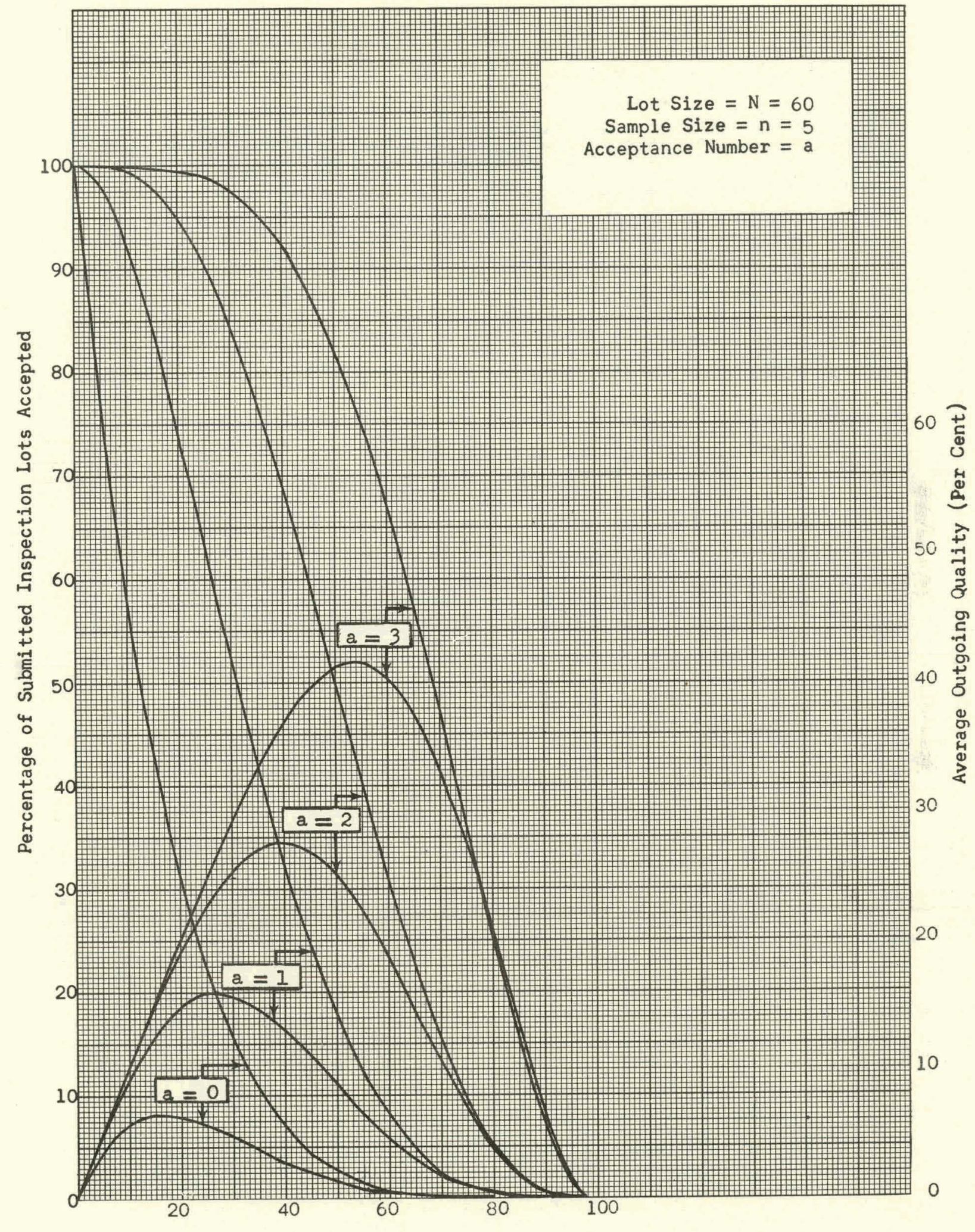

Percentage of Defective Items in Submitted Inspection Lots 


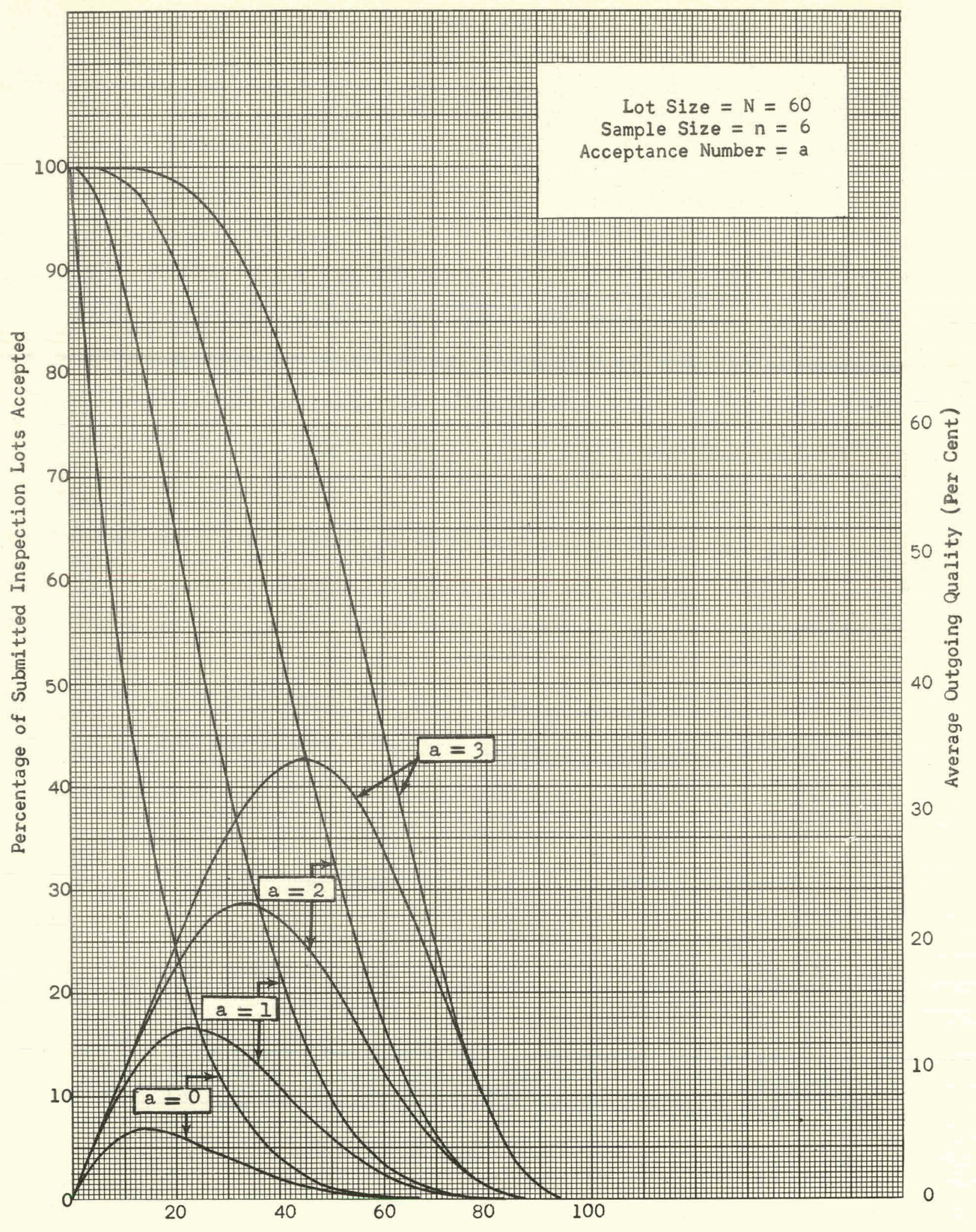

Percentage of Defective Items in Submitted Inspection Lots 


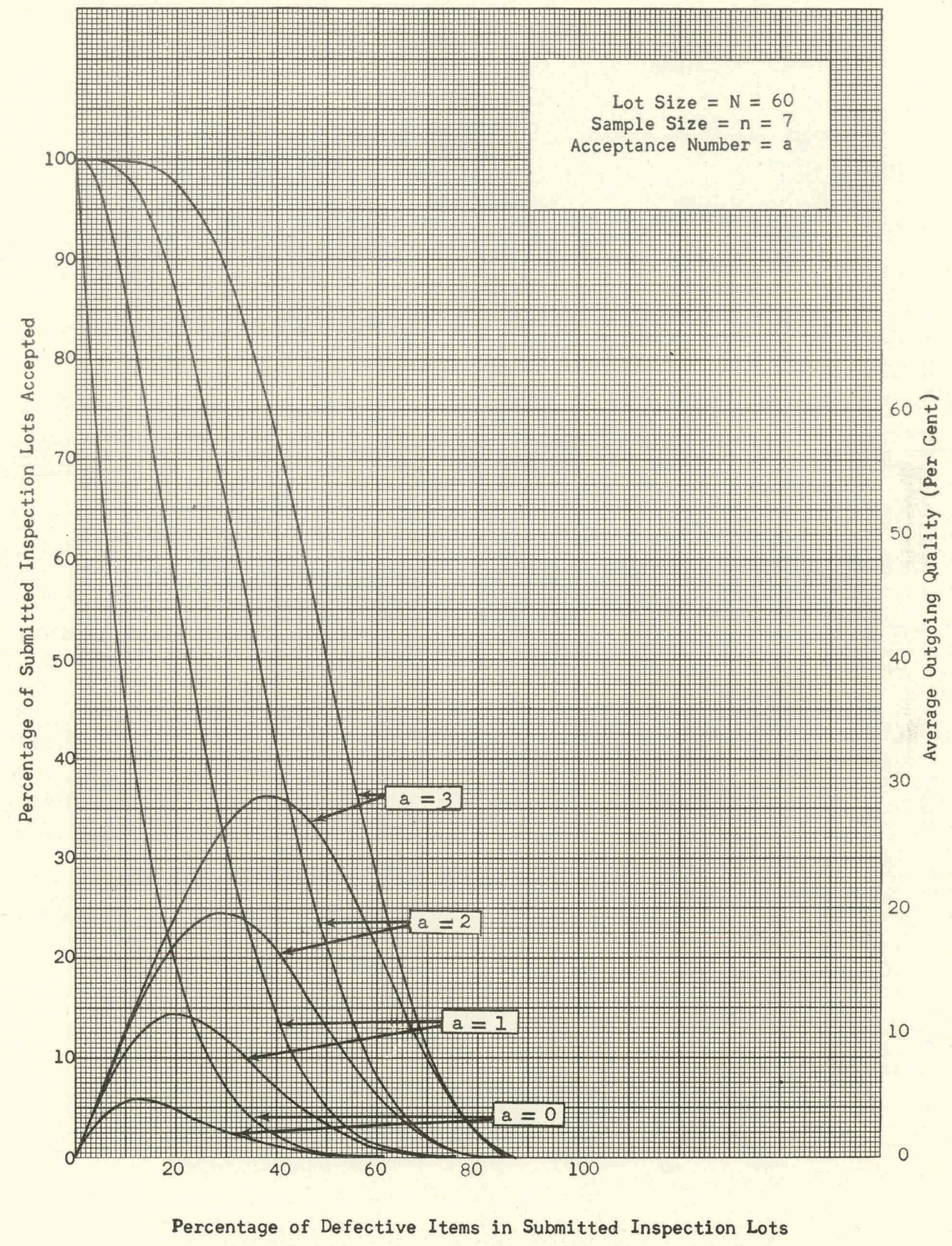




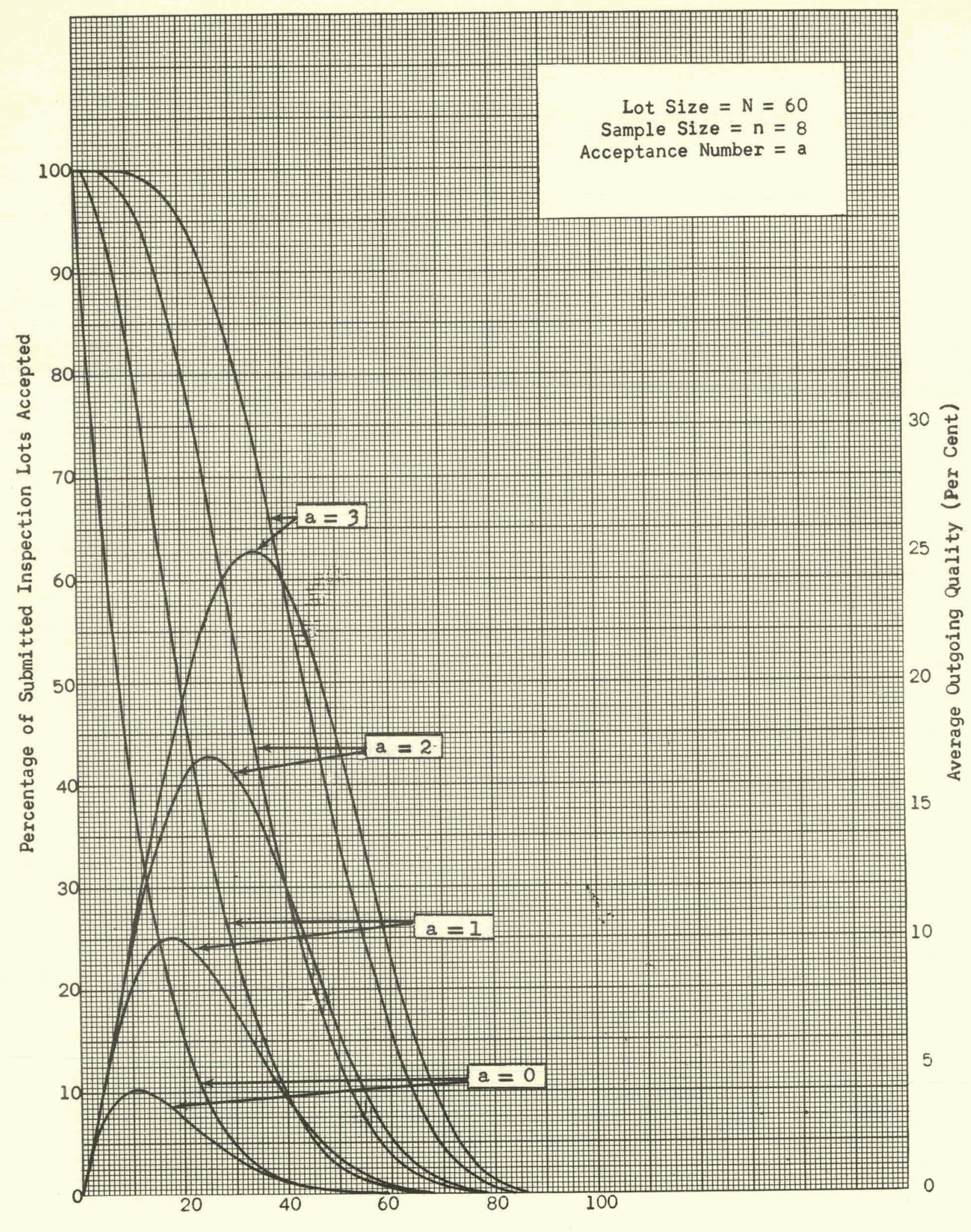

Percentage of Defective Items in Submitted Inspection Lots 


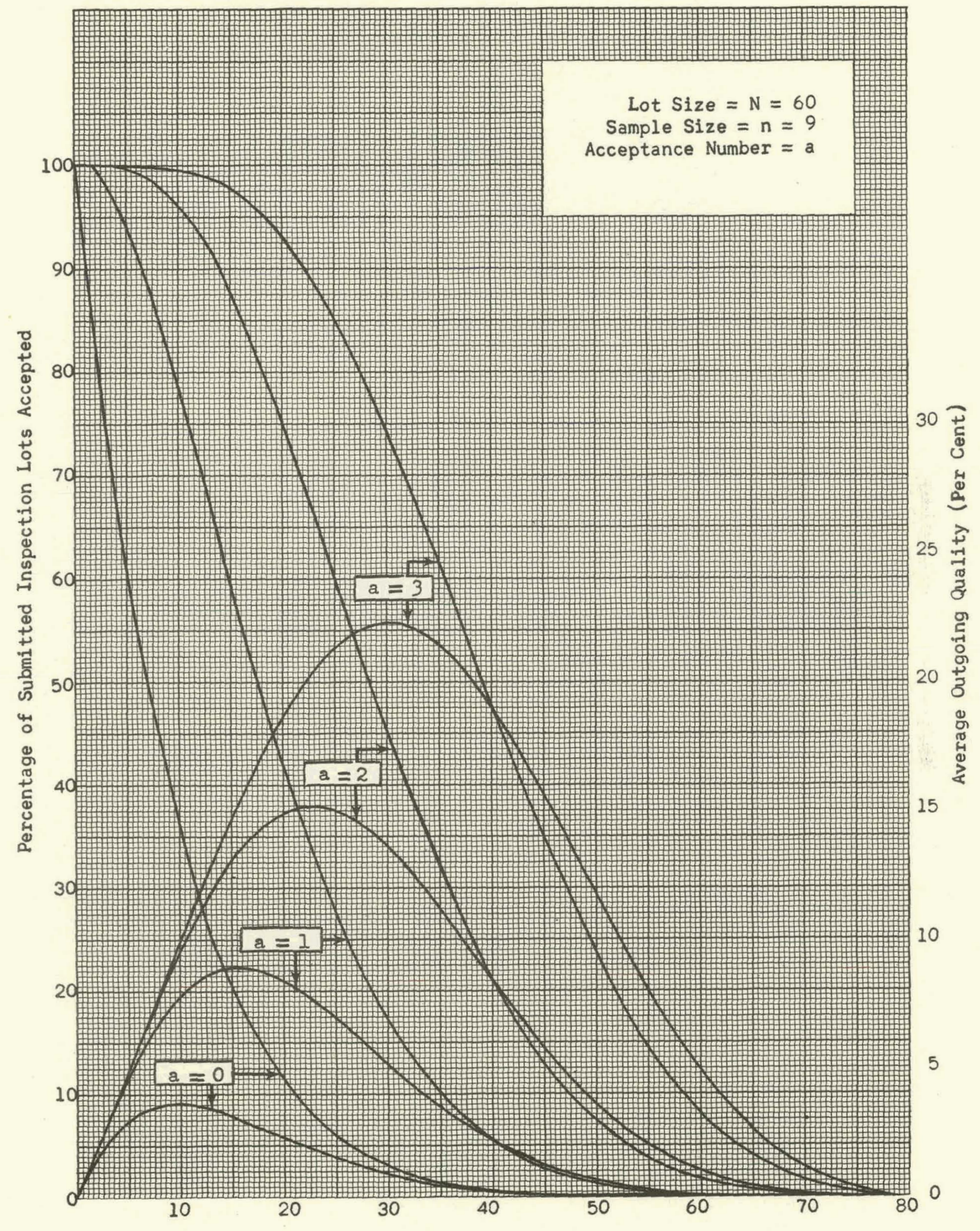

Percentage of Defective Items in Submitted Inspection Lots 


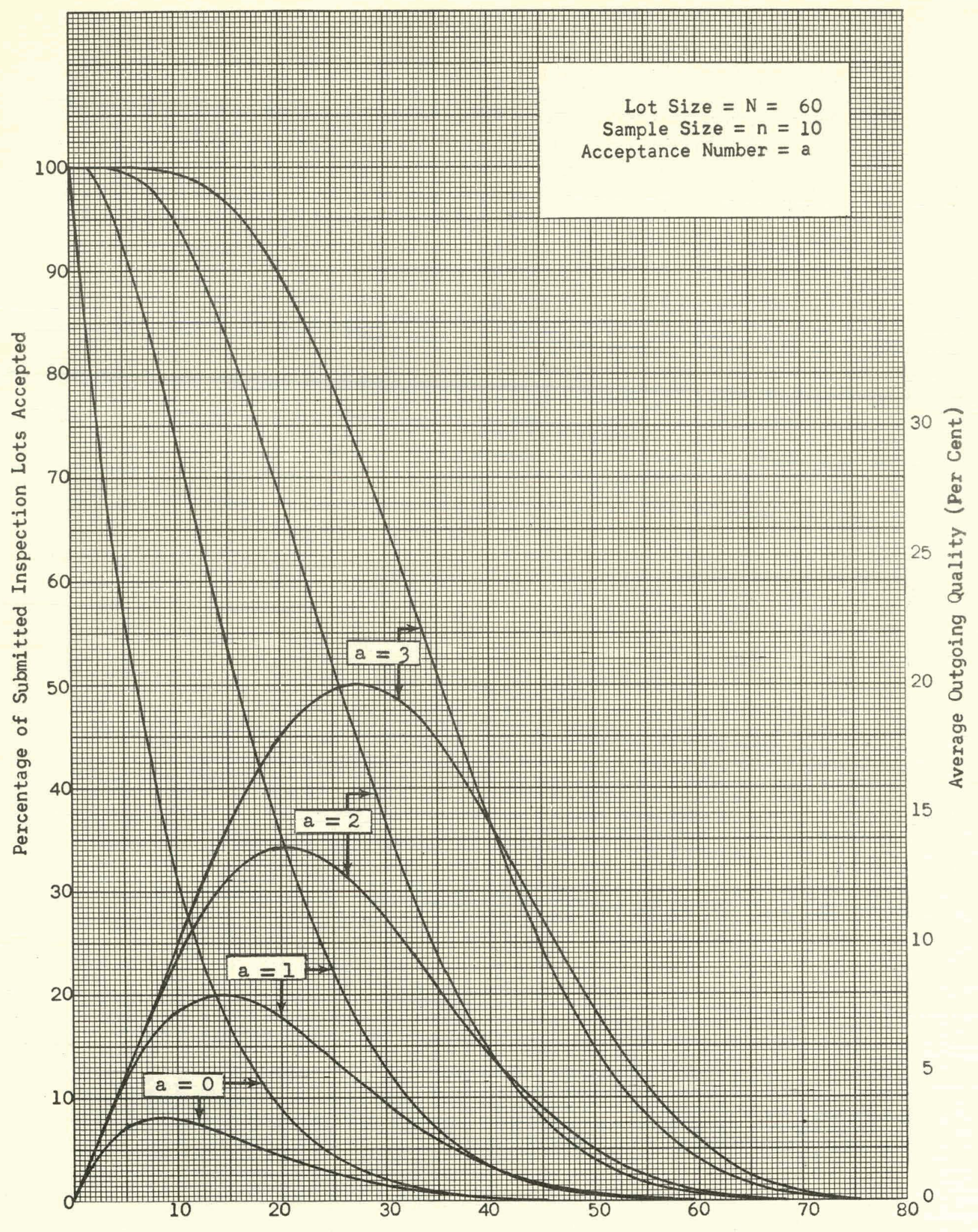

Percentage of Defective Items in Submitted Inspection Lots 


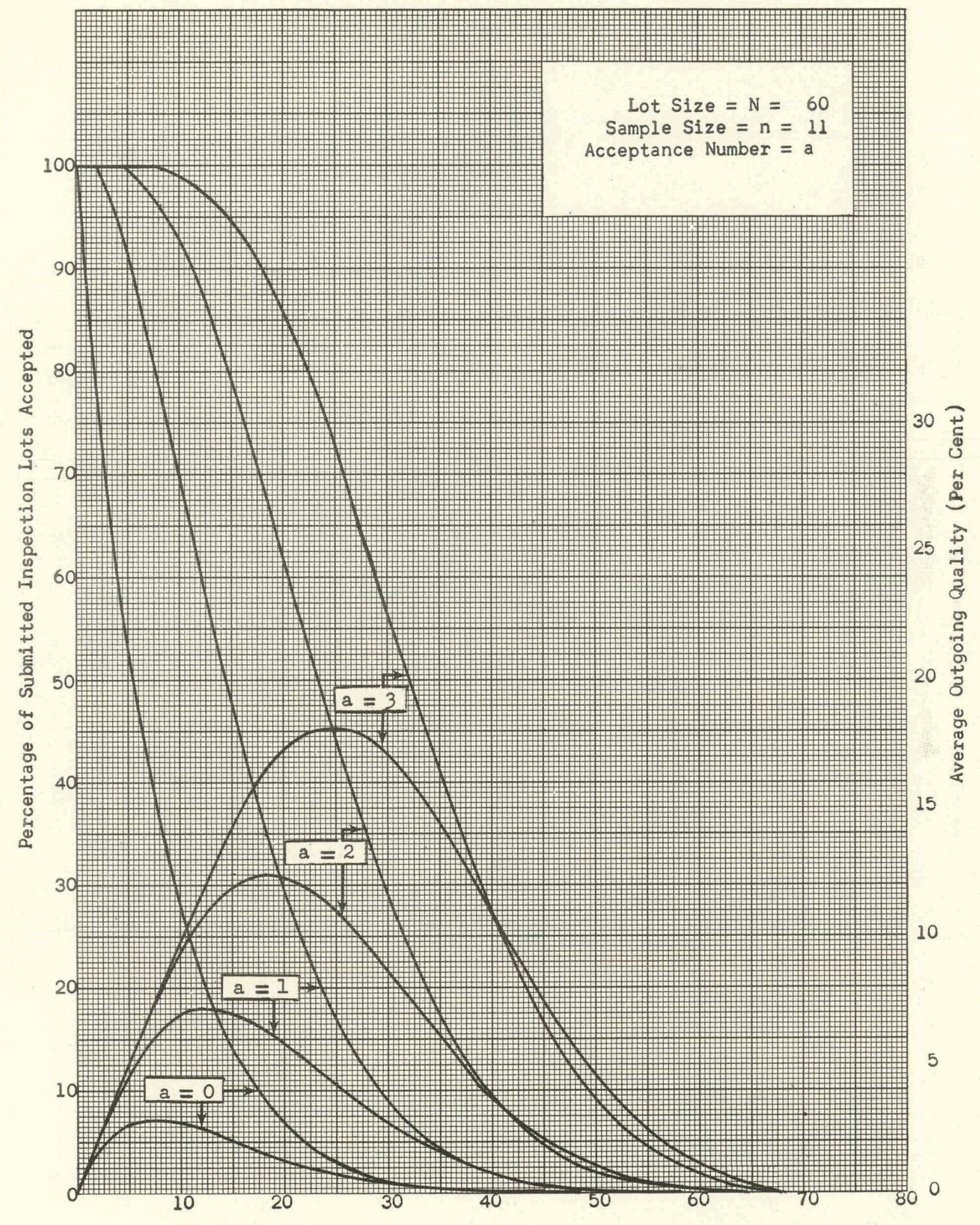

Percentage of Defective Items in Submitted Inspection Lots 


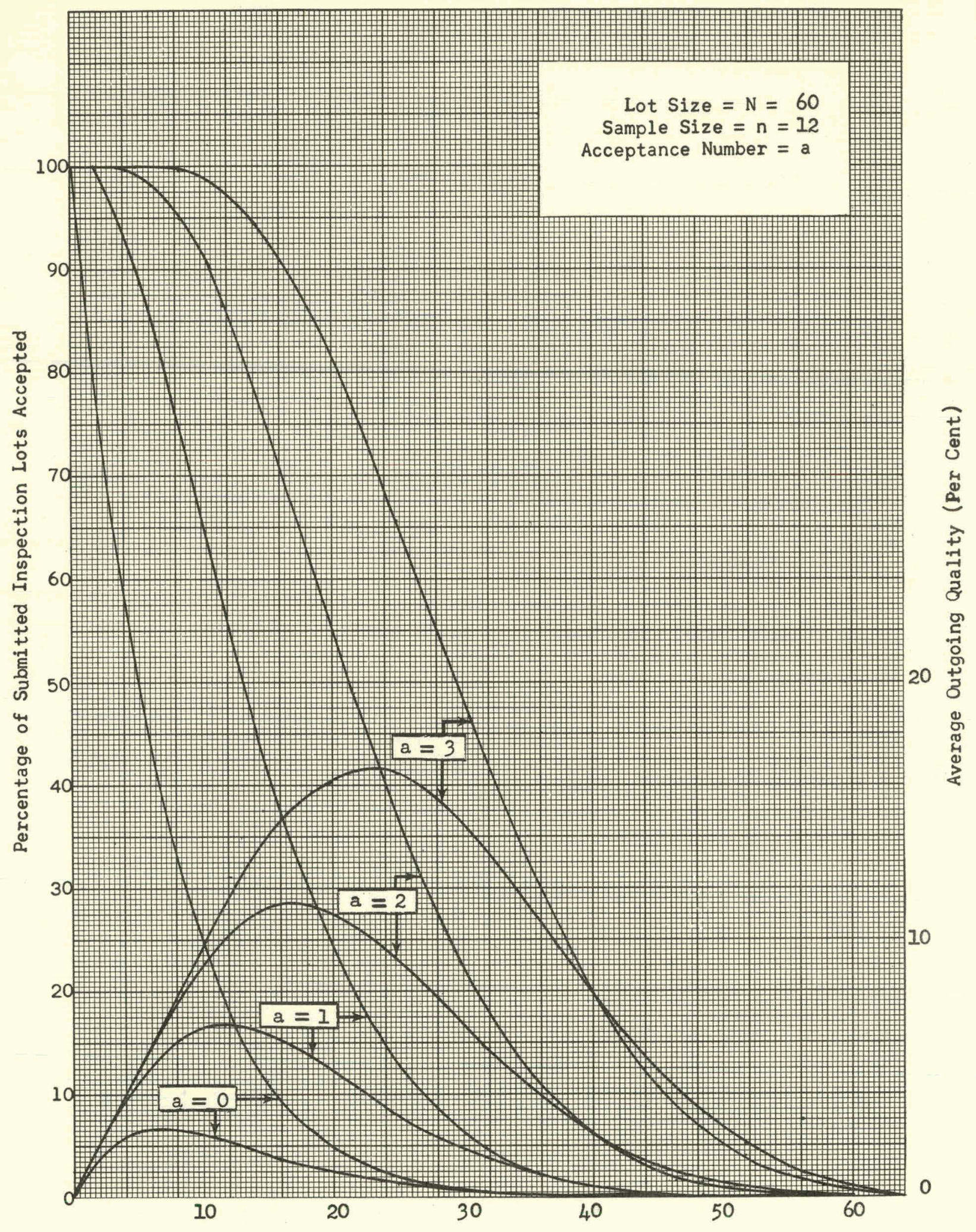

Percentage of Defective Items in Submitted Inspection Lots 


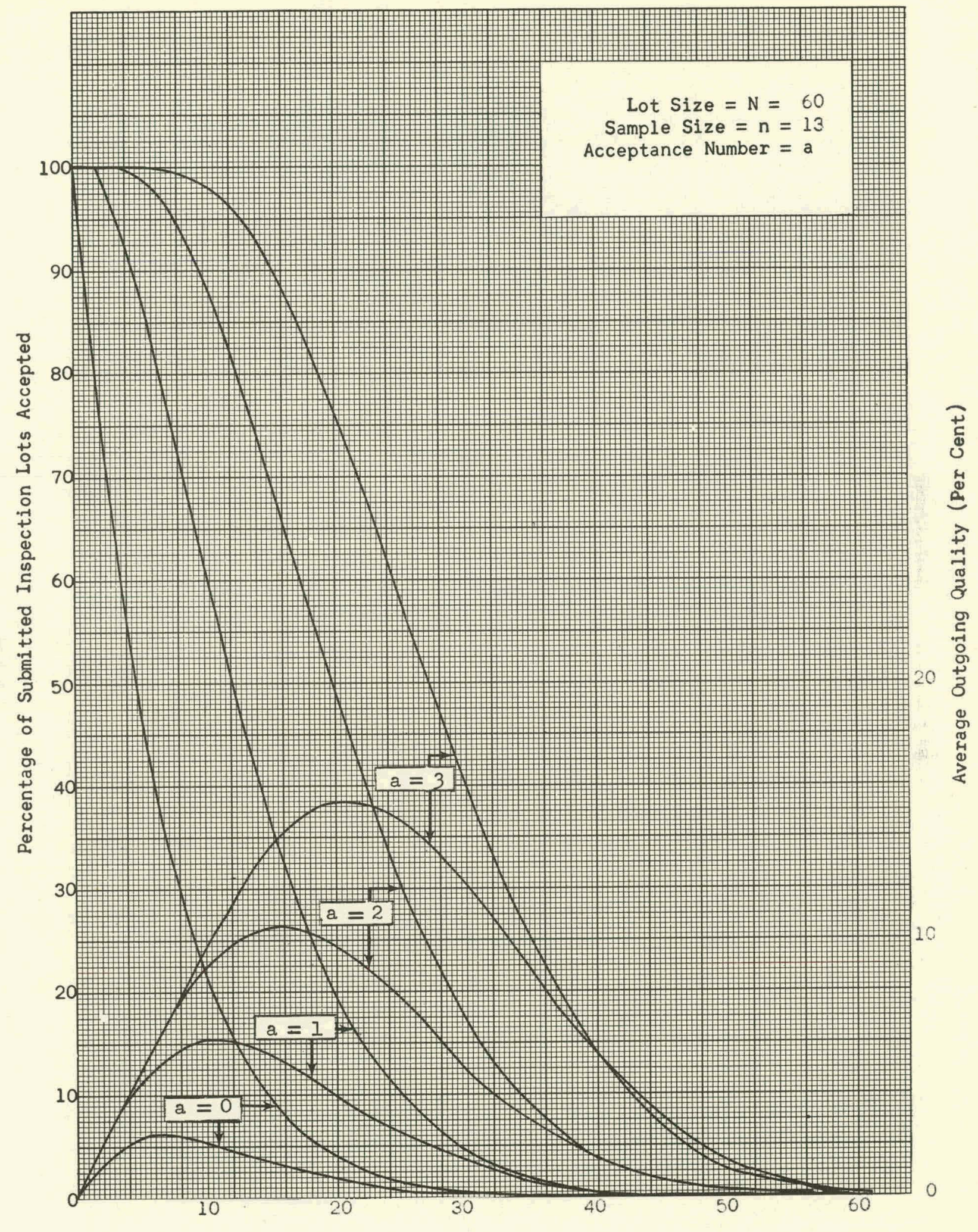

Percentage of Defective Items in Submitted Inspection Lots 


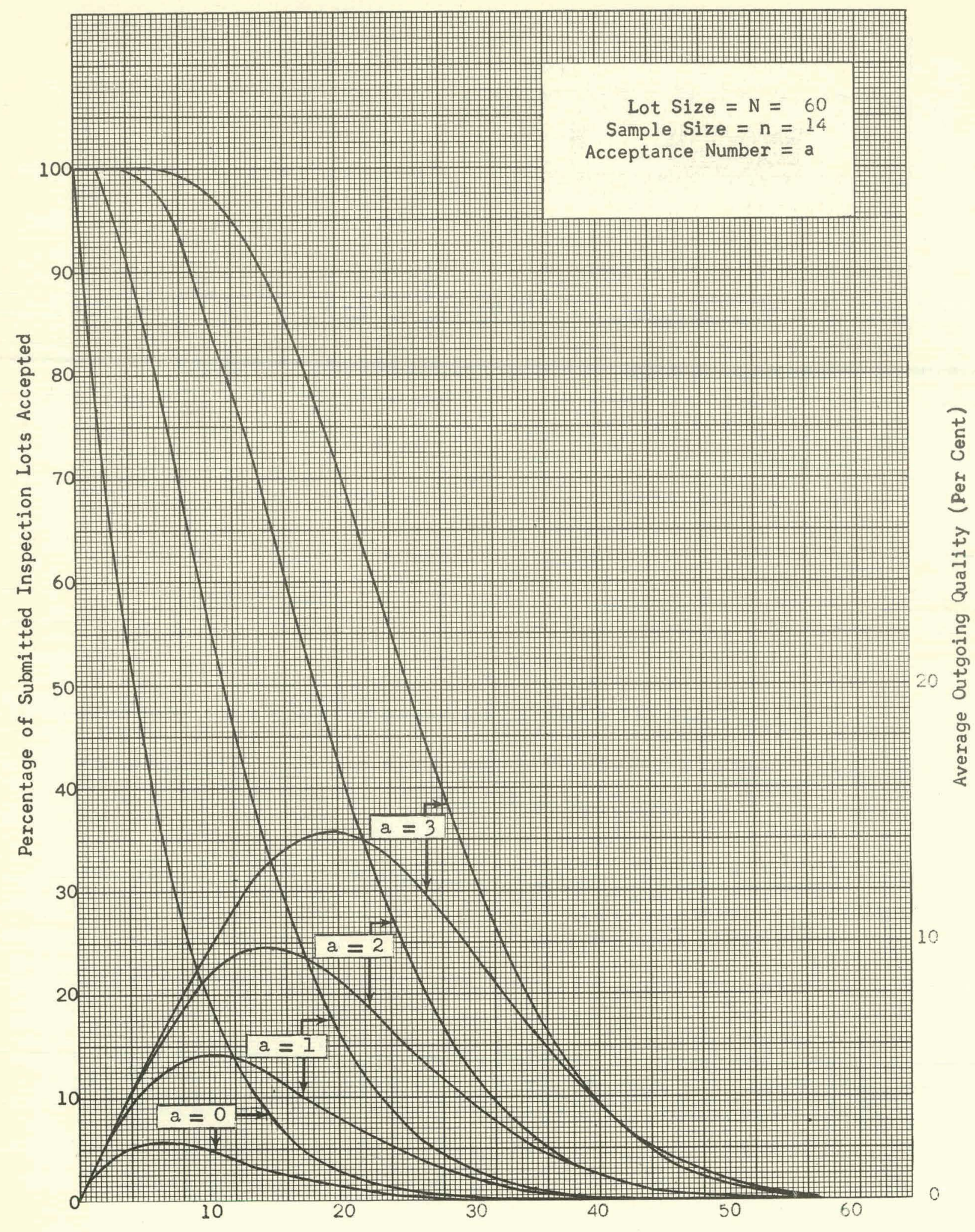

Percentage of Defective Items in Submitted Inspection Lots 


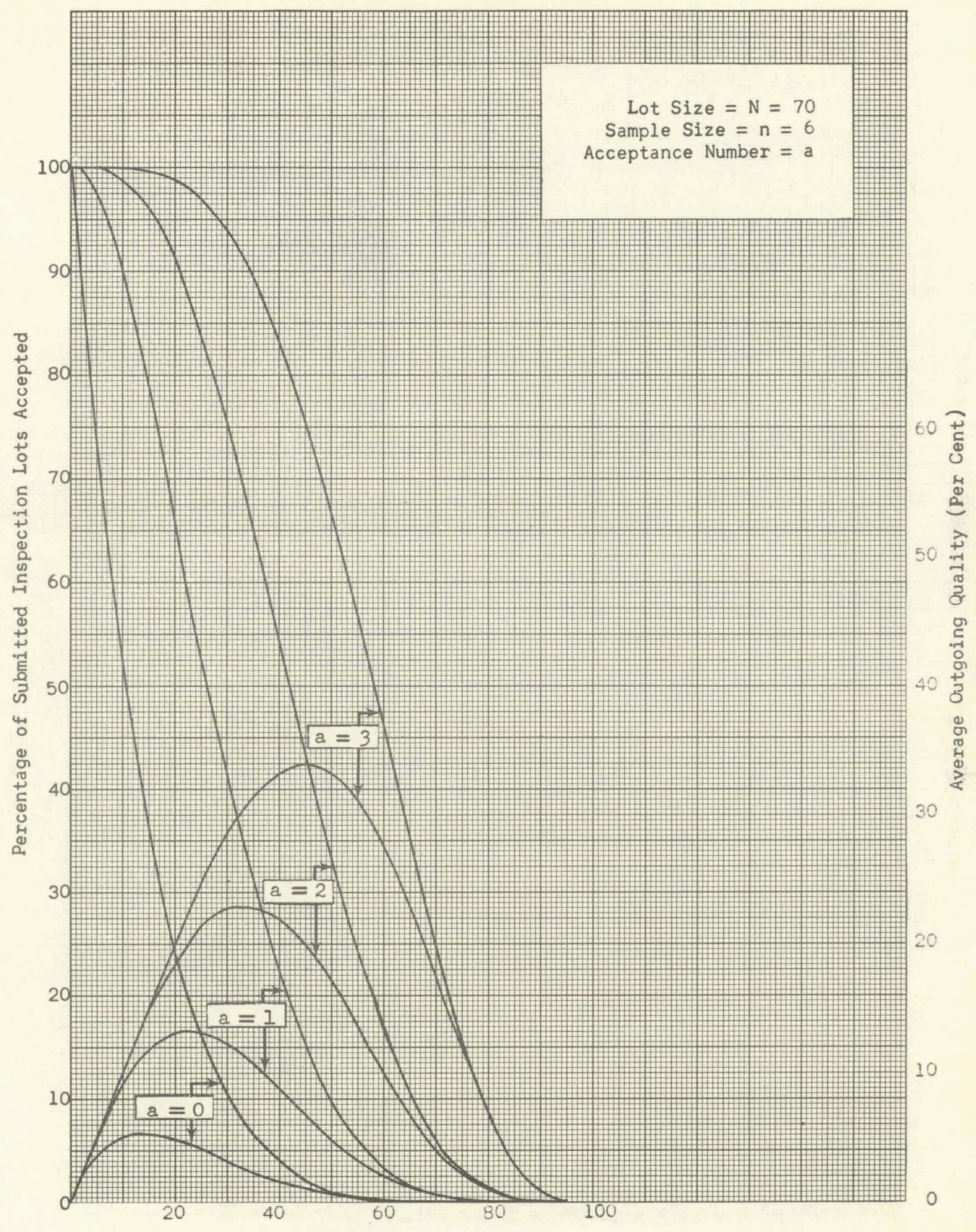

Percentage of Defective Items in Submitted Inspection Lots 


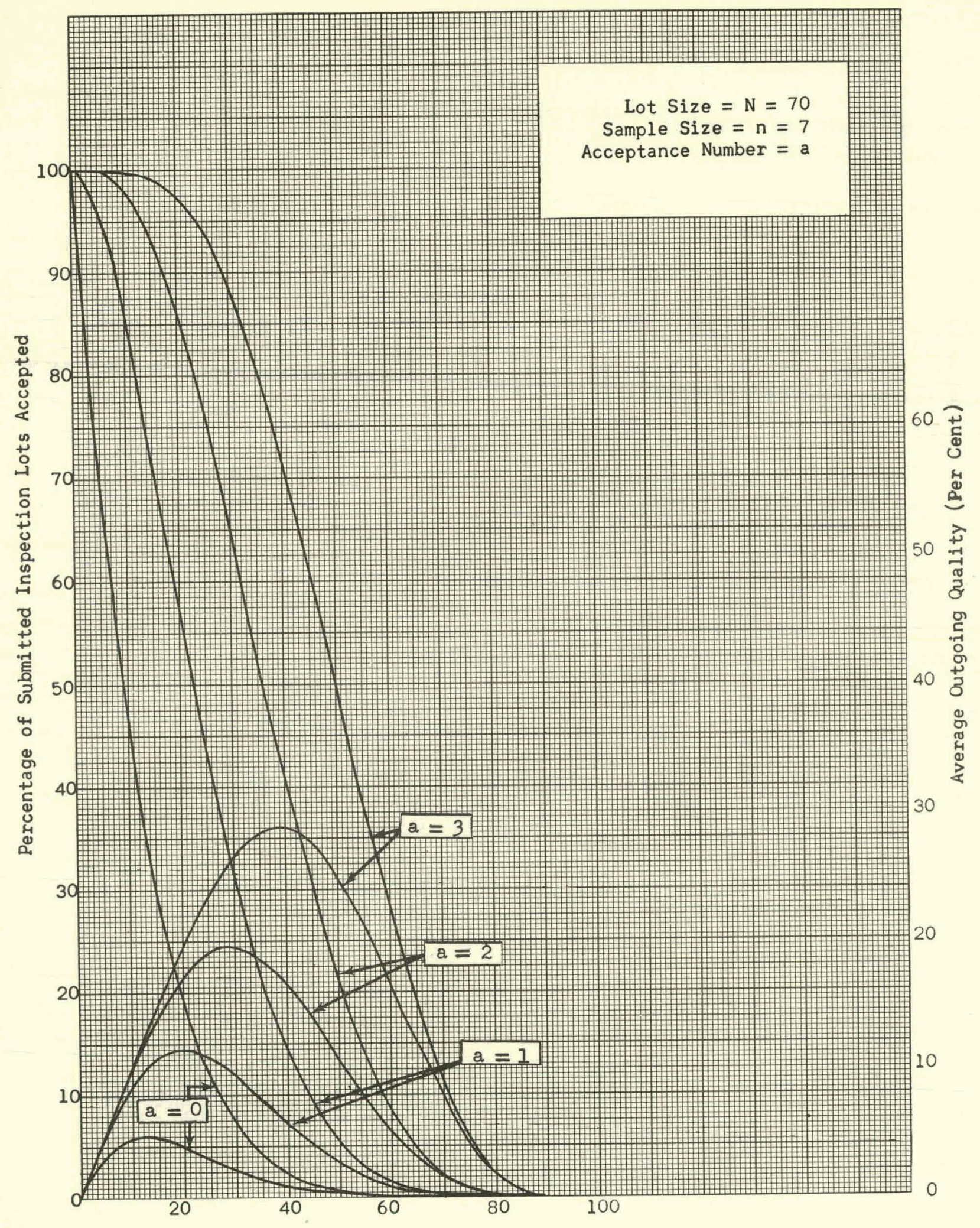

Percentage of Defective Items in Submitted Inspection Lots 


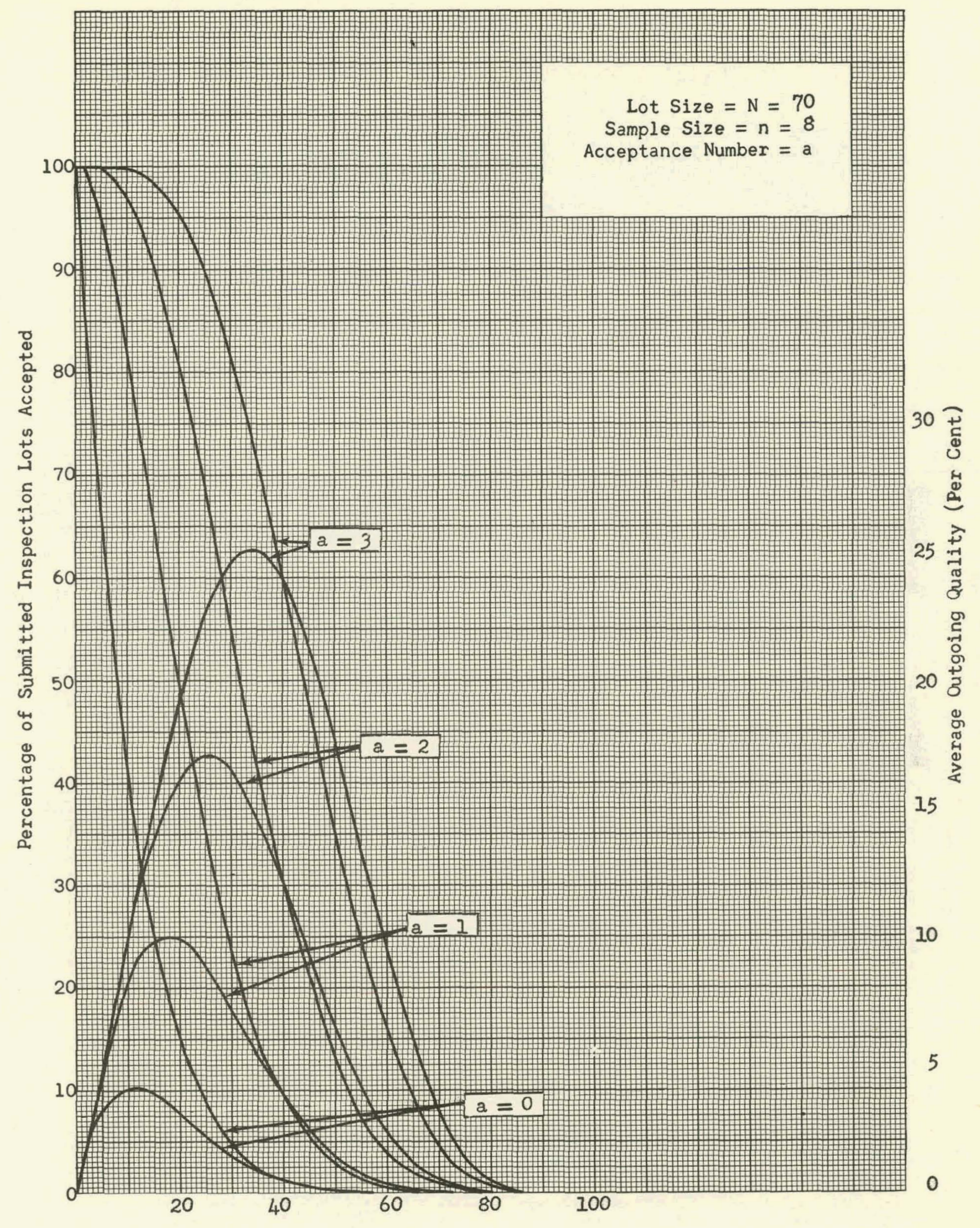

Percentage of Defective Items in Submitted Inspection Lots 


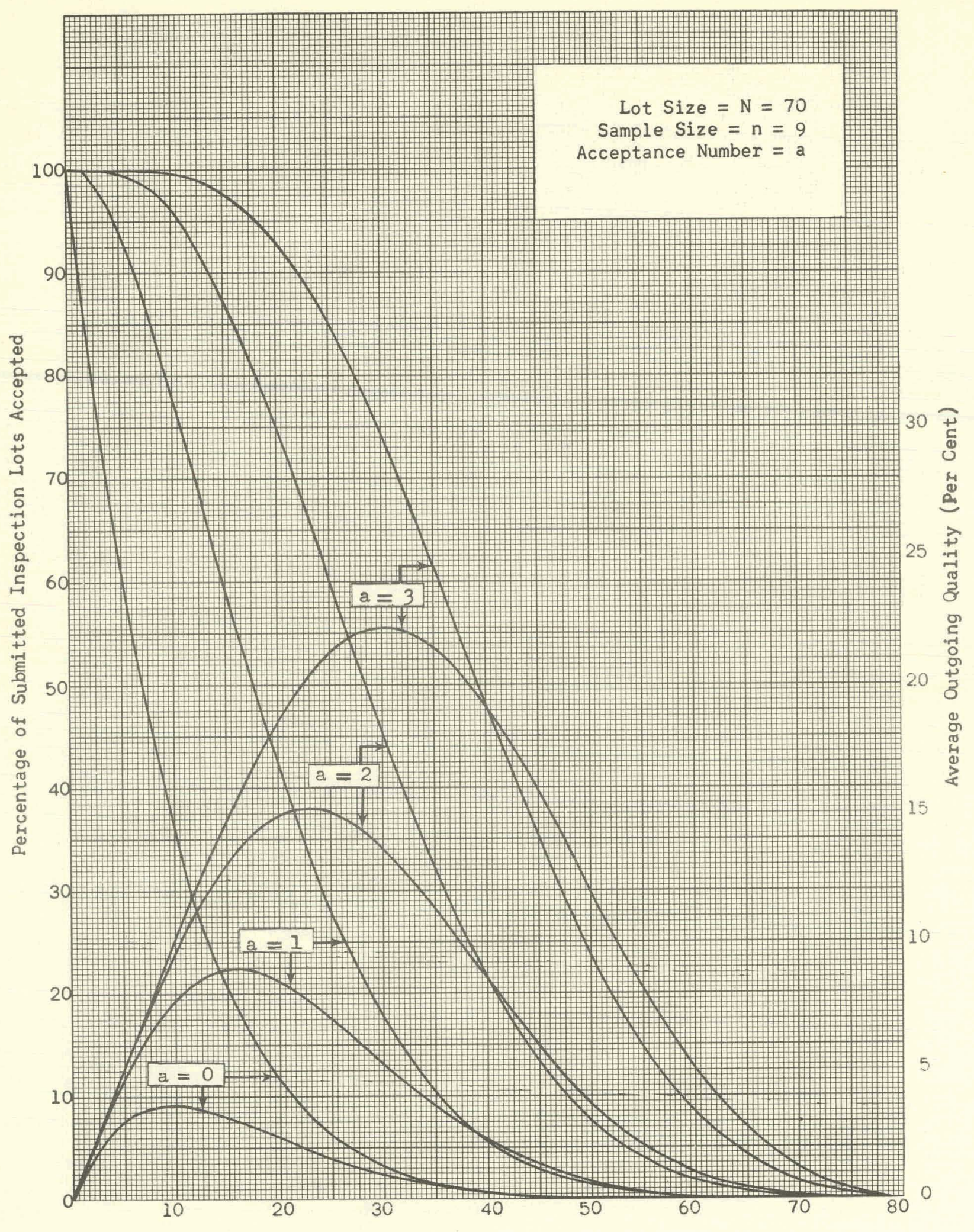

Percentage of Defective Items in Submitted Inspection Lots 


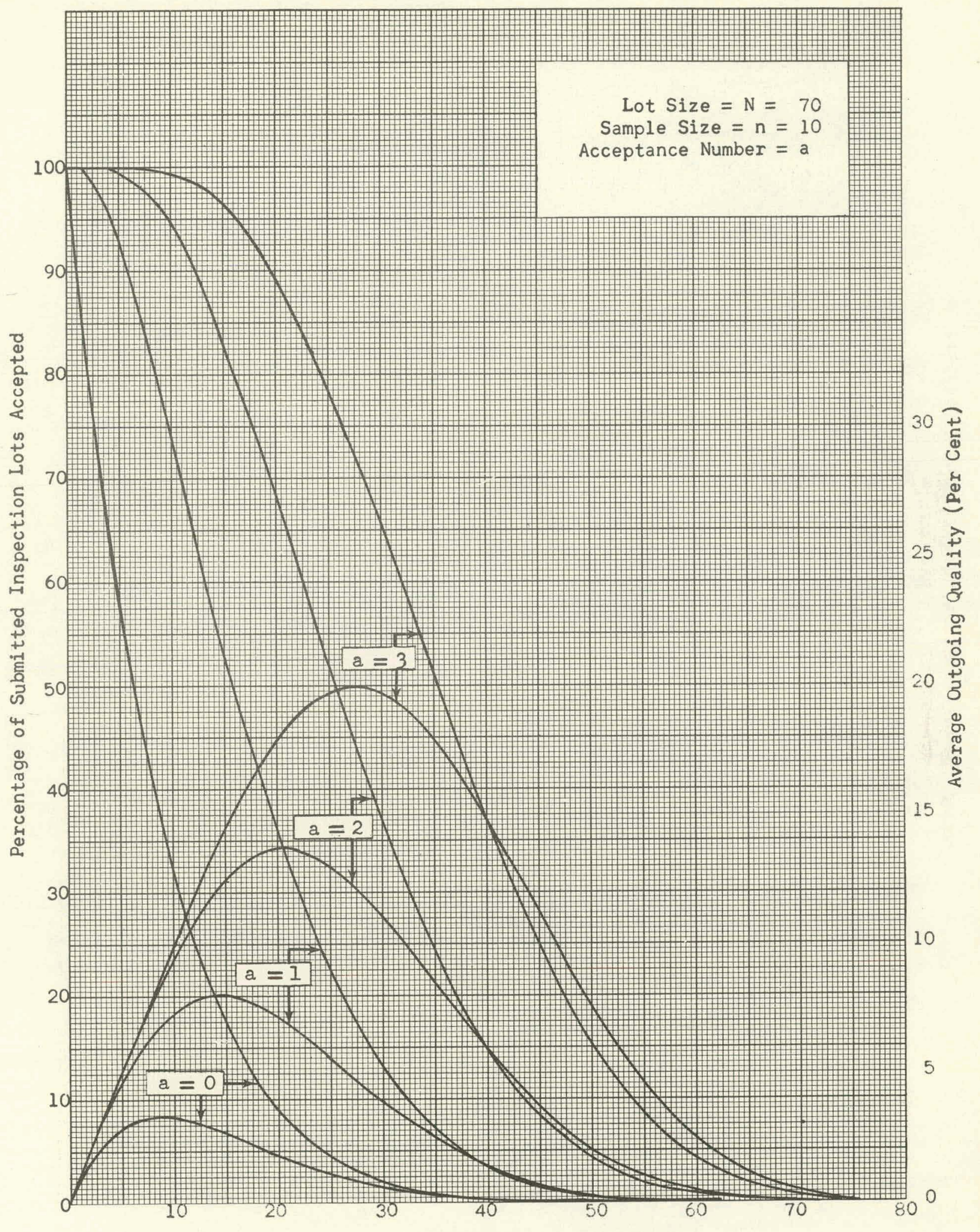

Percentage of Defective Items in Submitted Inspection Lots 


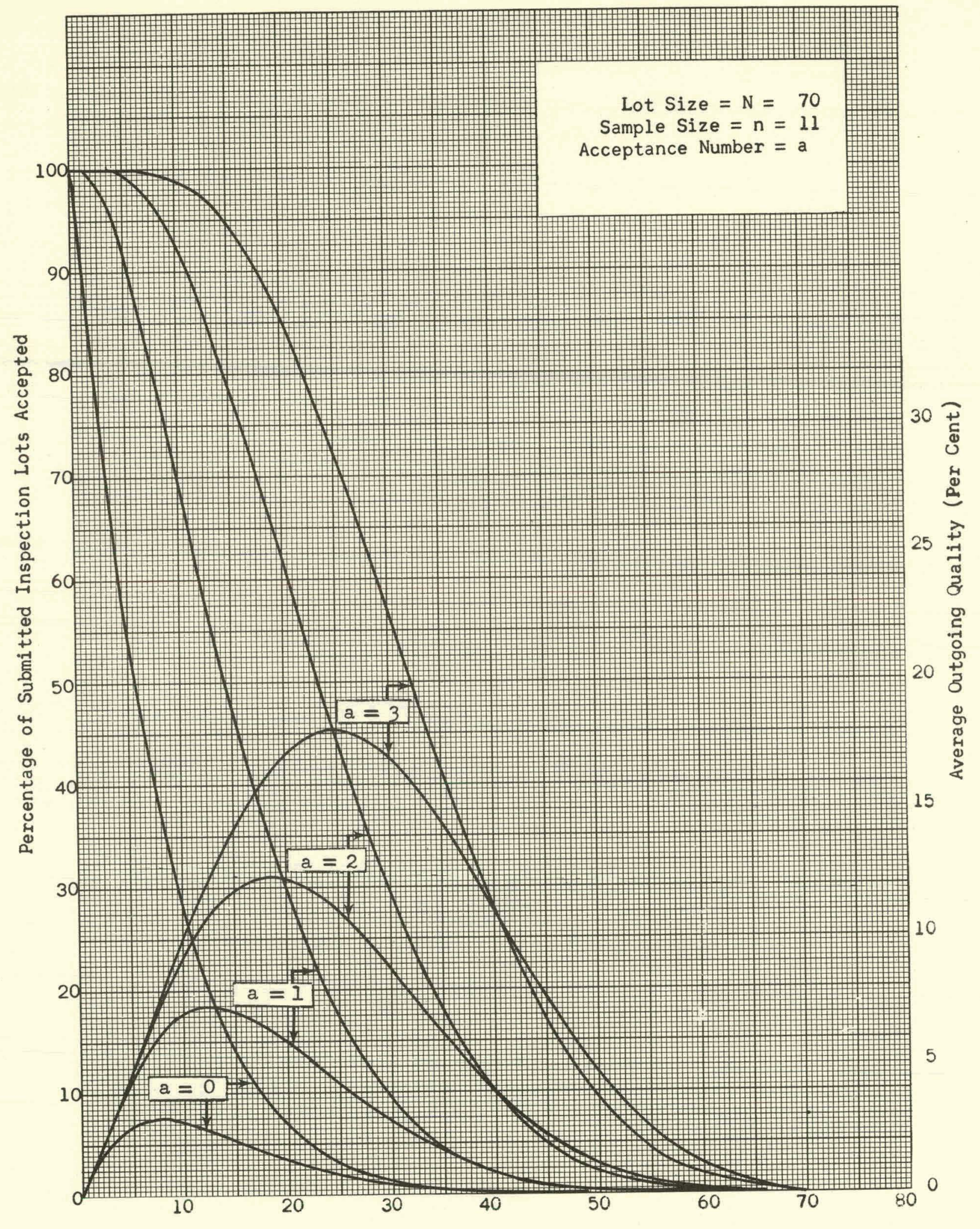

Percentage of Defective Items in Submitted Inspection Lots 


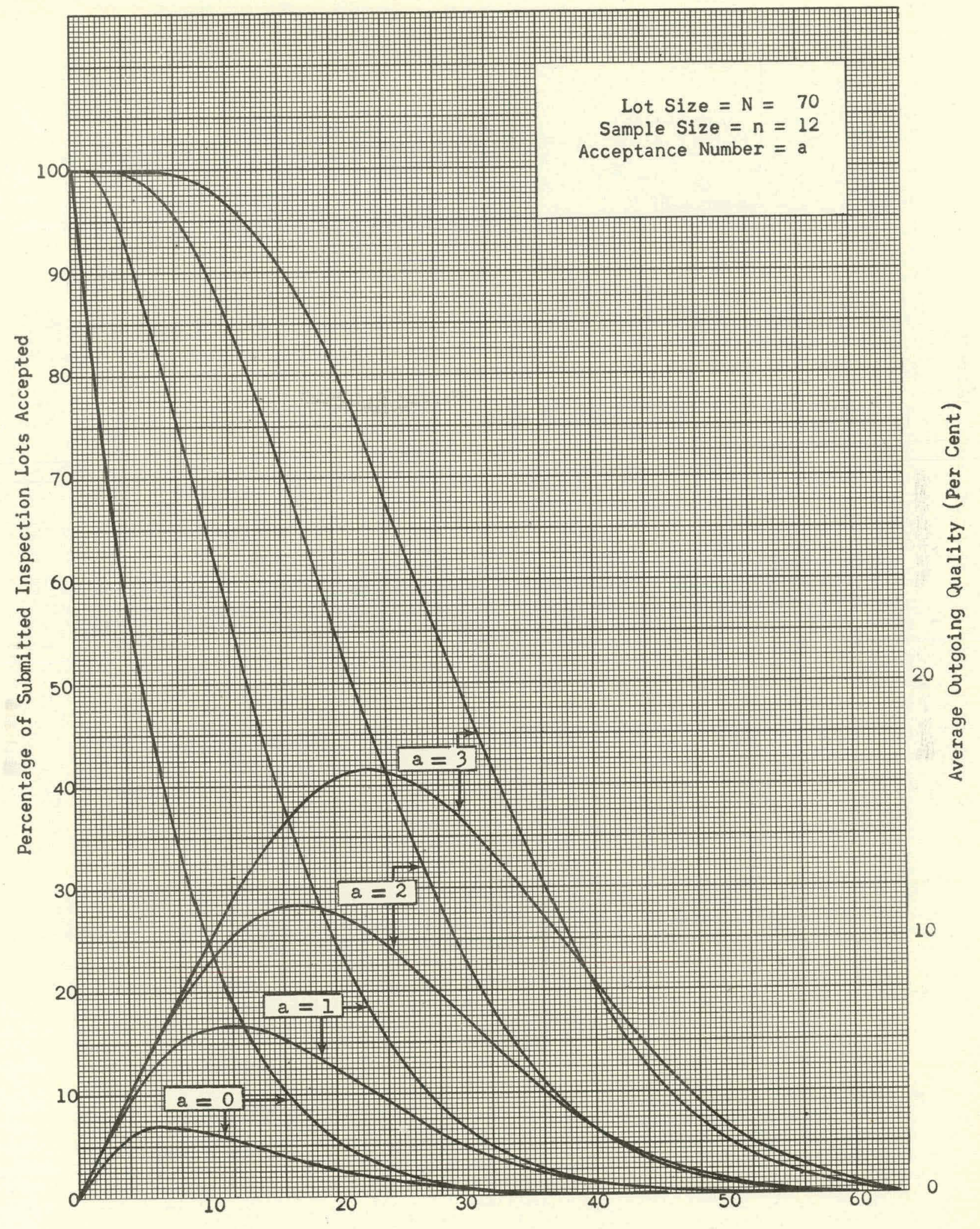

Percentage of Defective Items in Submitted Inspection Lots 


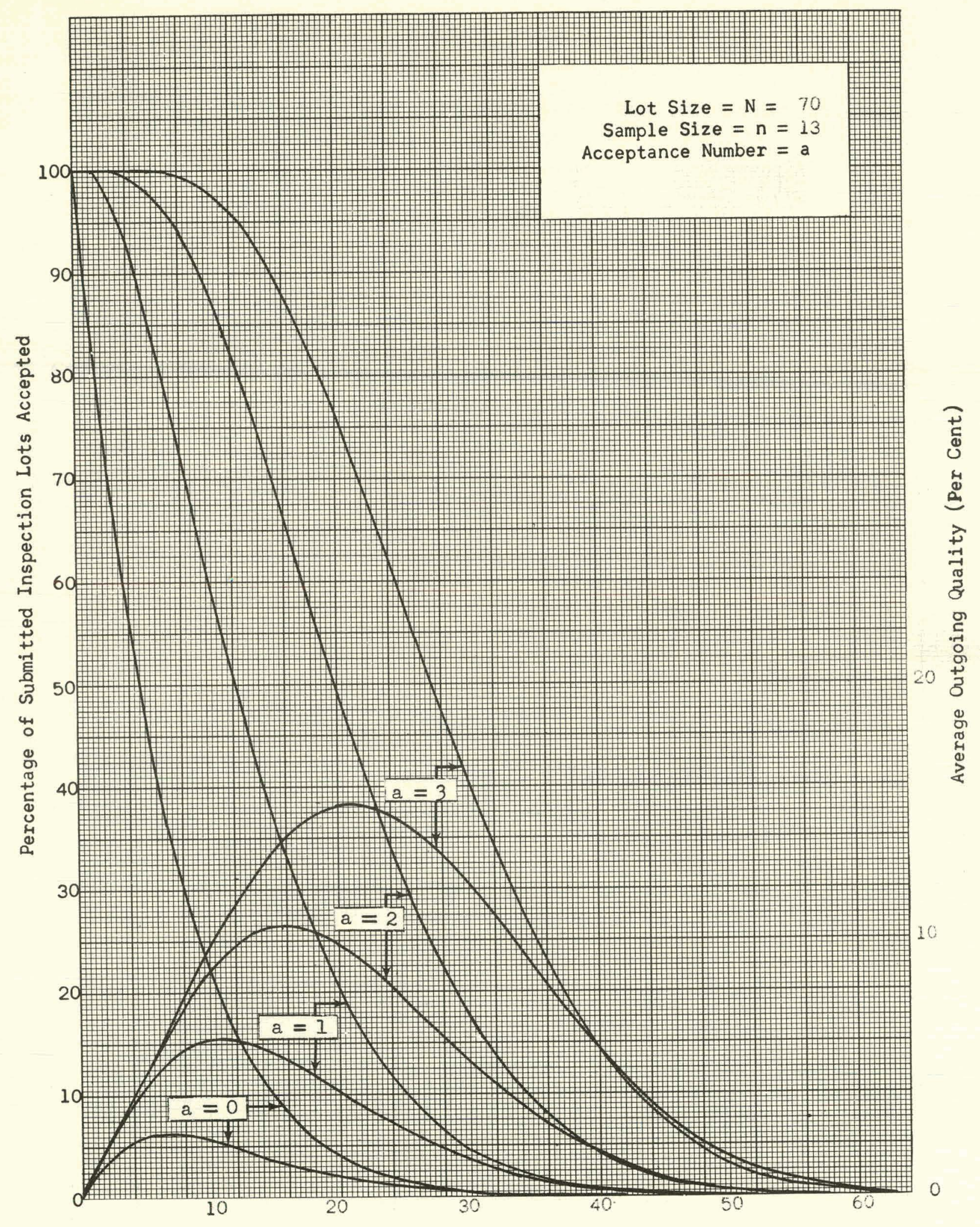

Percentage of Defective Items in Submitted Inspection Lots 


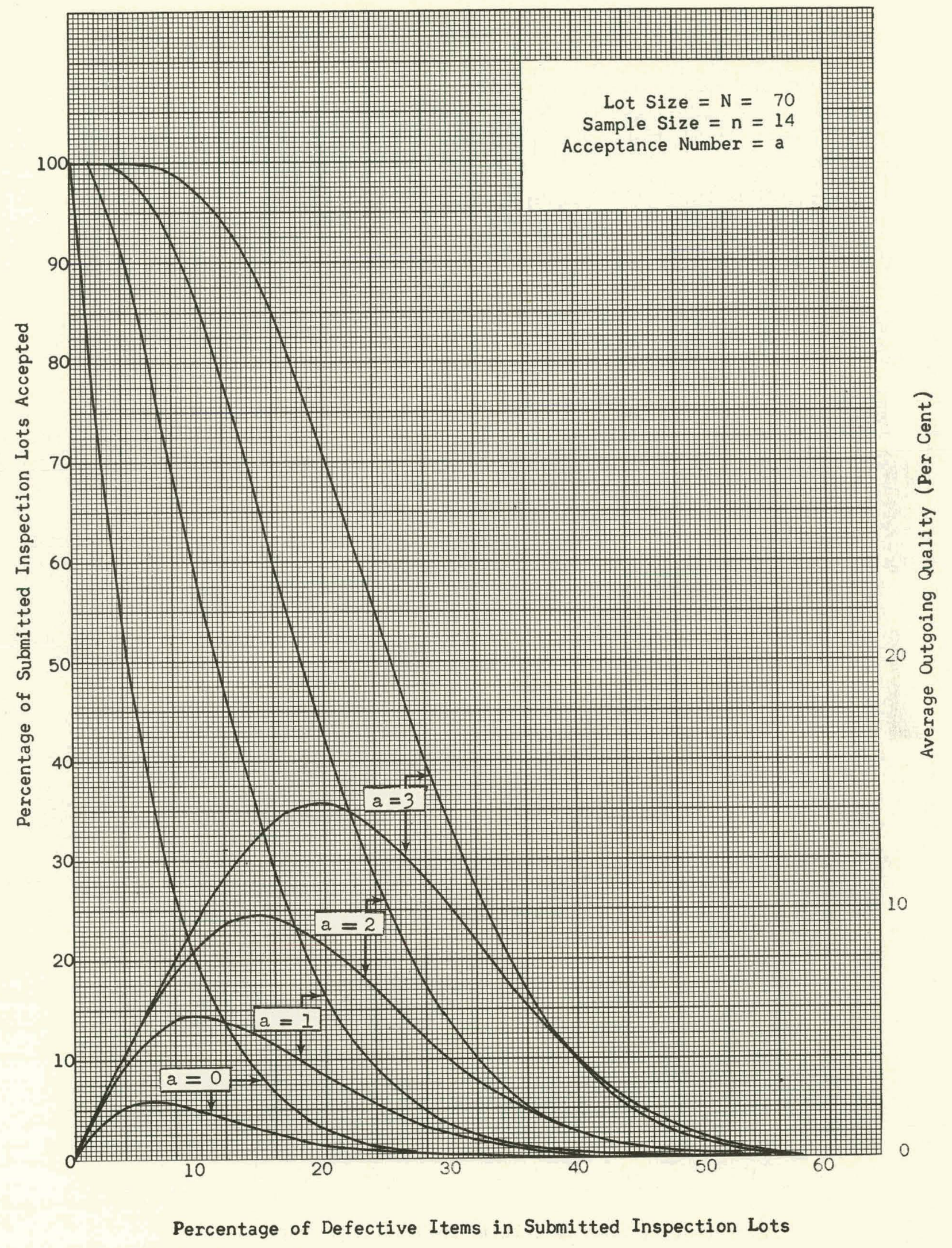




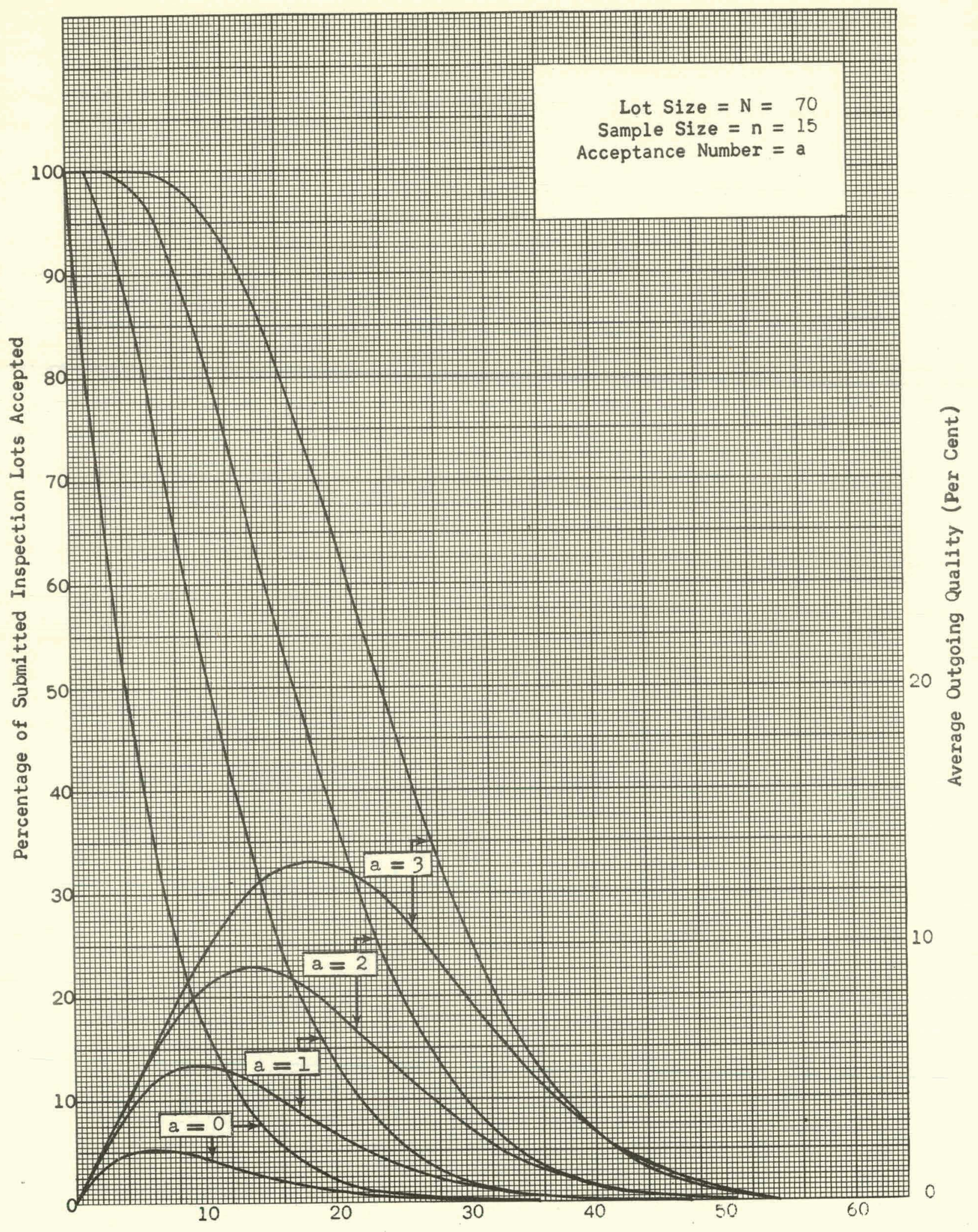

Percentage of Defective Items in Submitted Inspection Lots 


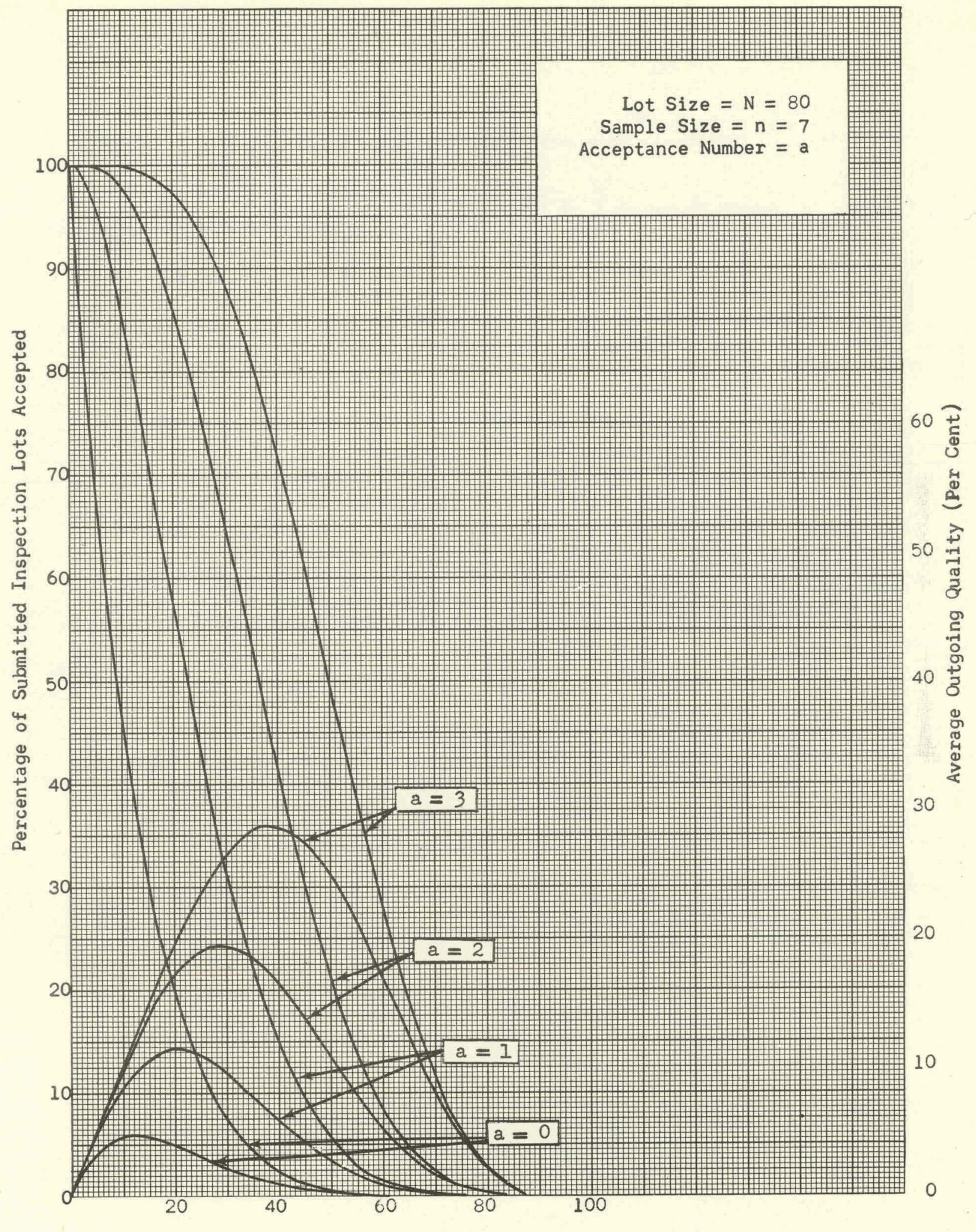

Percentage of Defective Items in Submitted Inspection Lots 


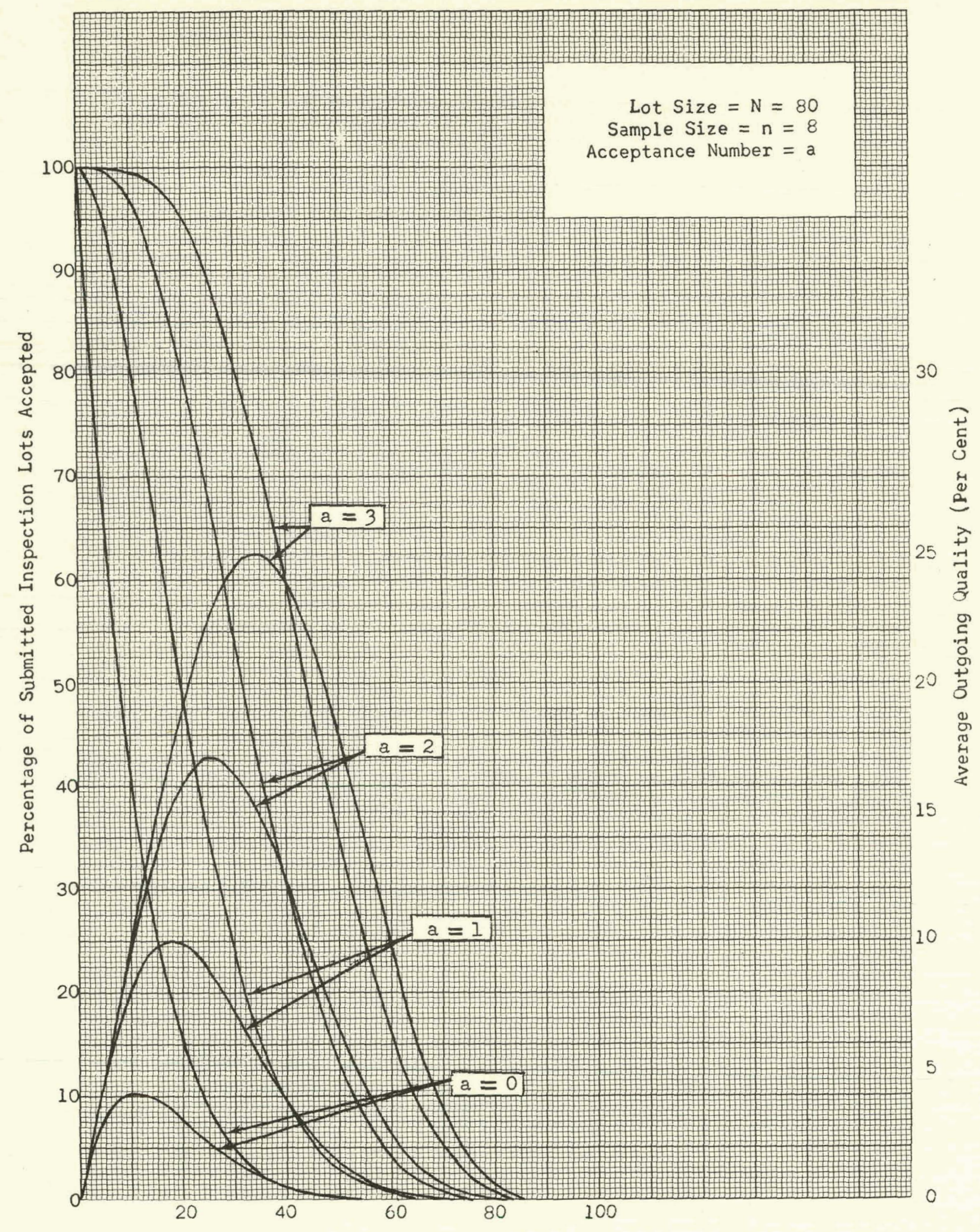

Percentage of Defective Items in Submitted Inspection Lots 


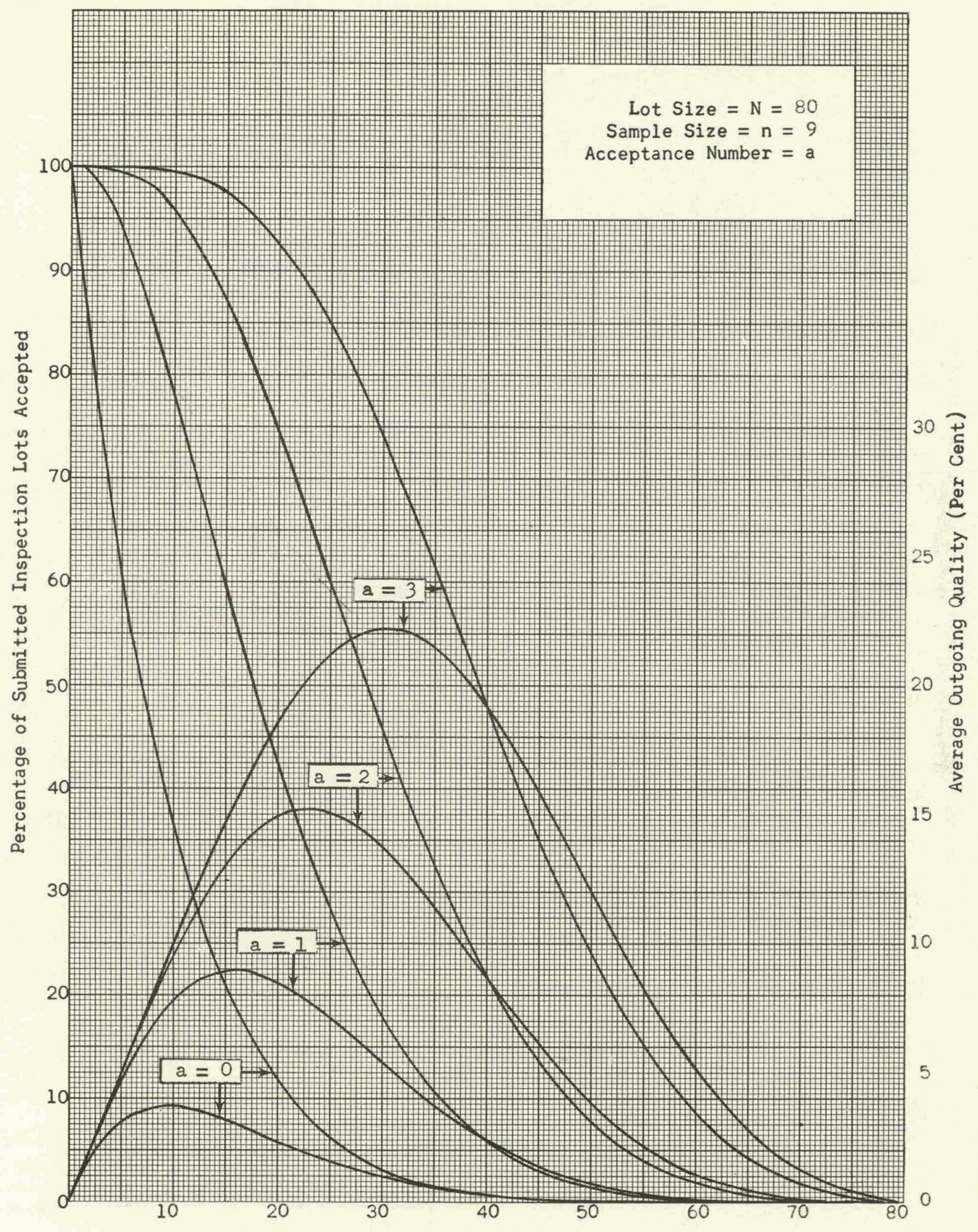

Percentage of Defective Items in Submitted Inspection Lots 


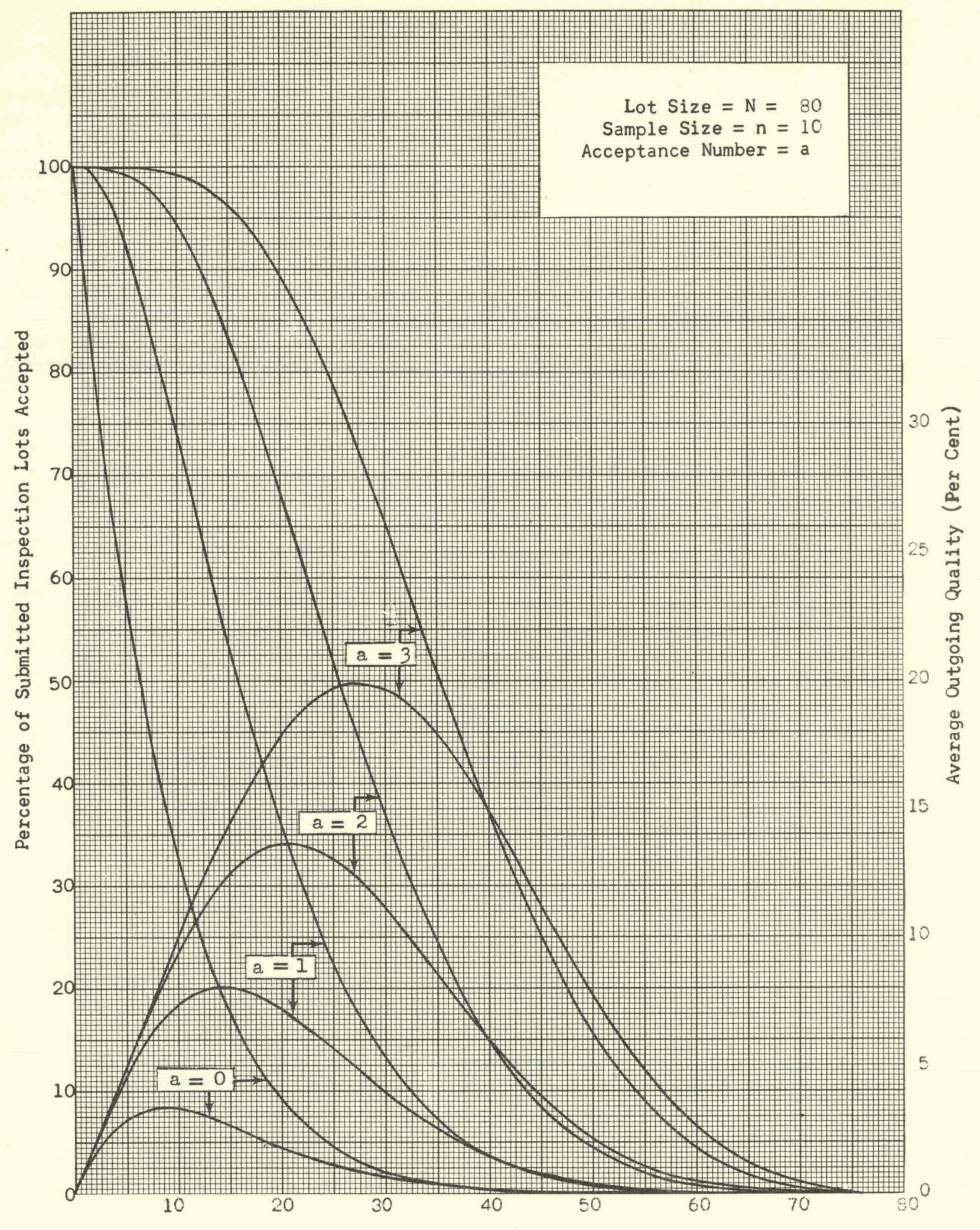

Percentage of Defective Items in Submitted Inspection Lots 


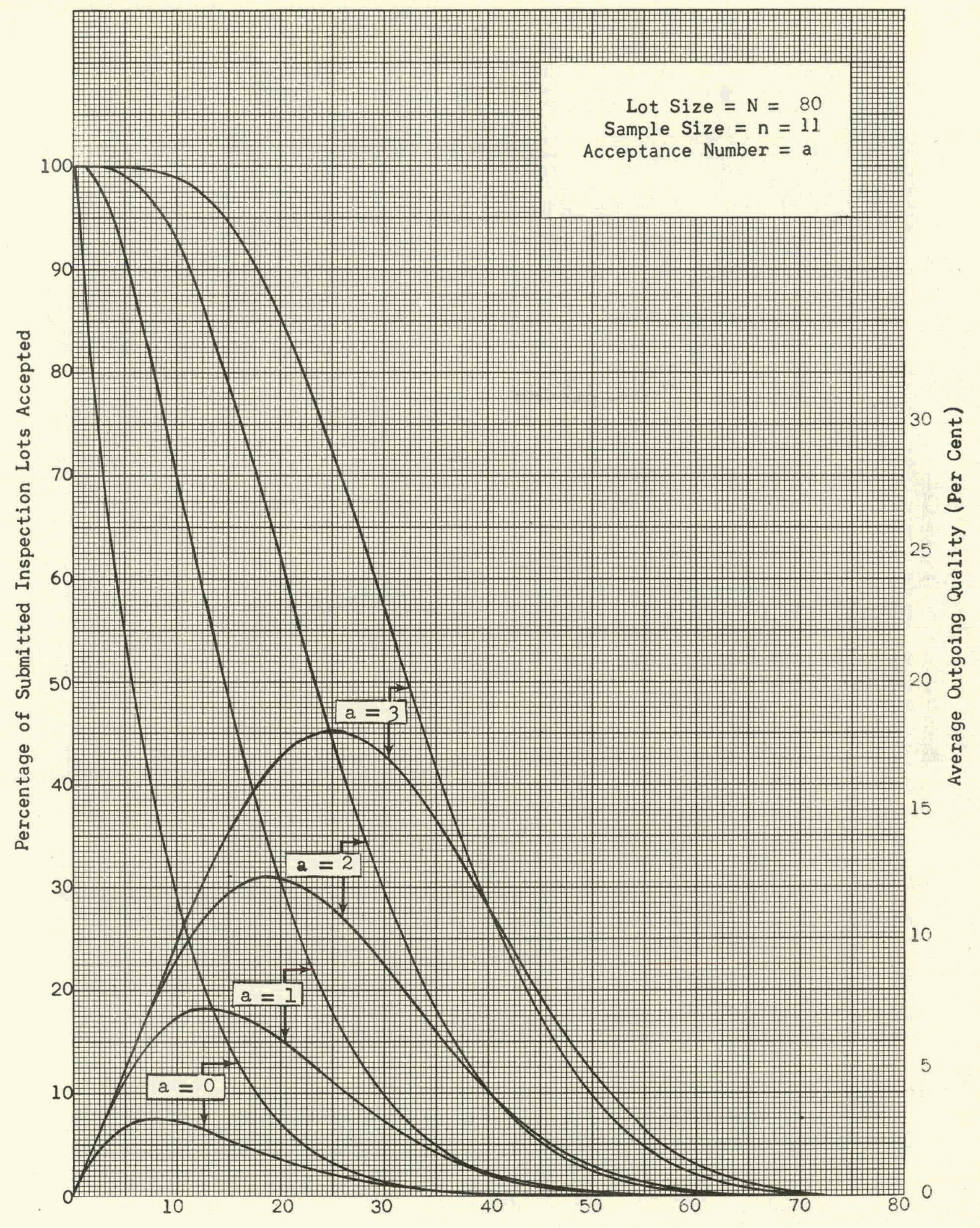

Percentage of Defective Items in Submitted Inspection Lots 


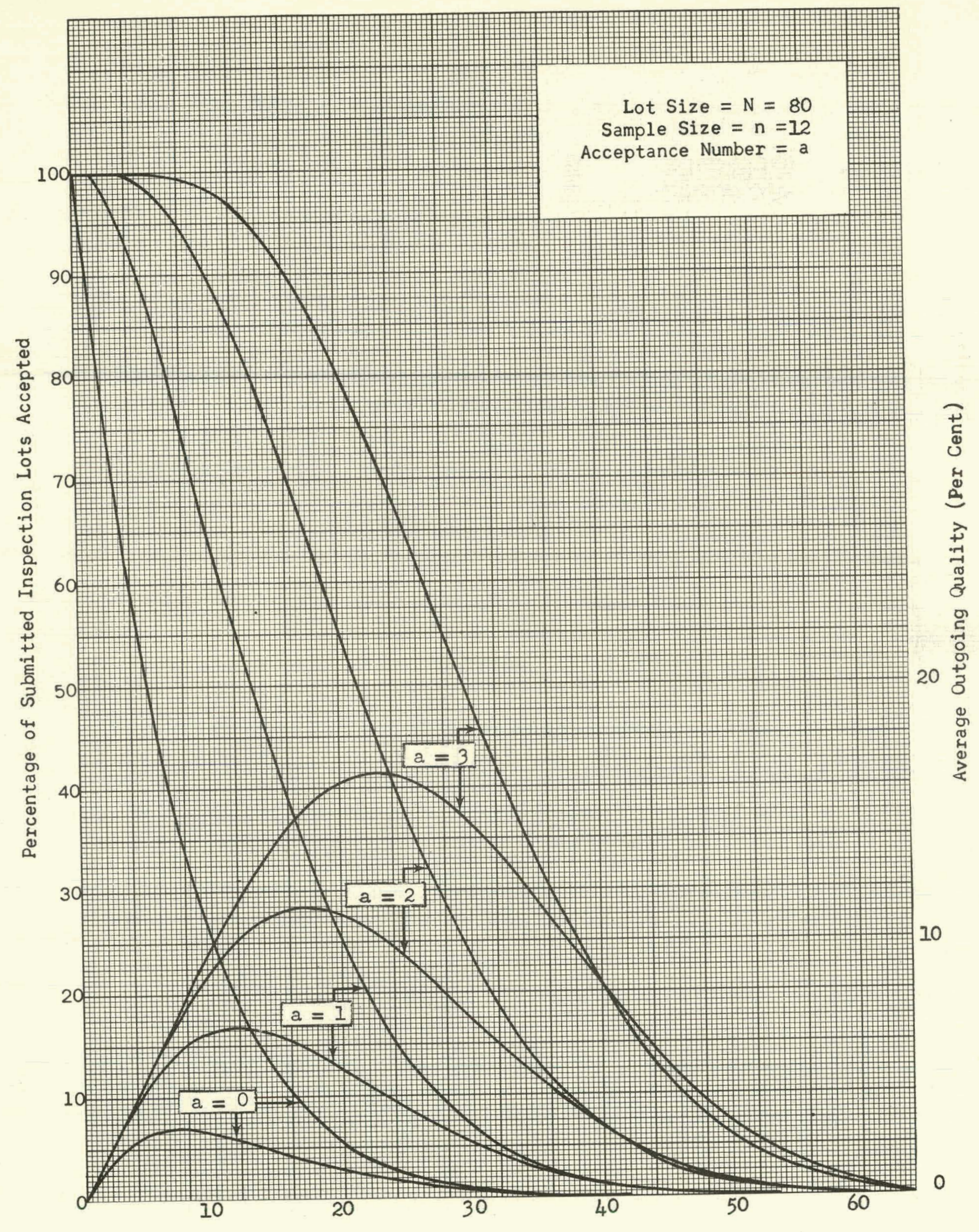

Percentage of Defective Items in Submitted Inspection Lots 


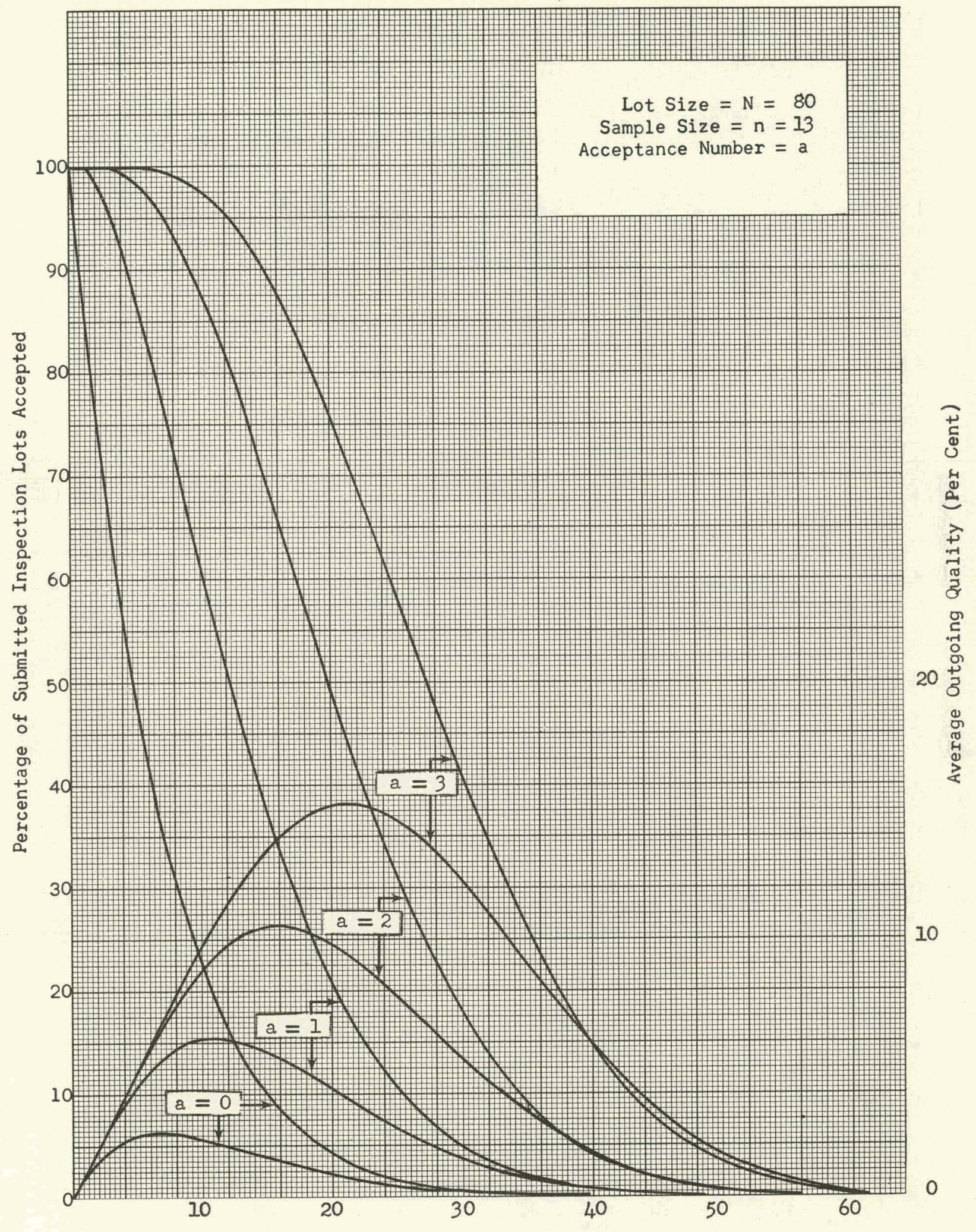

Percentage of Defective Items in Submitted Inspection Lots 


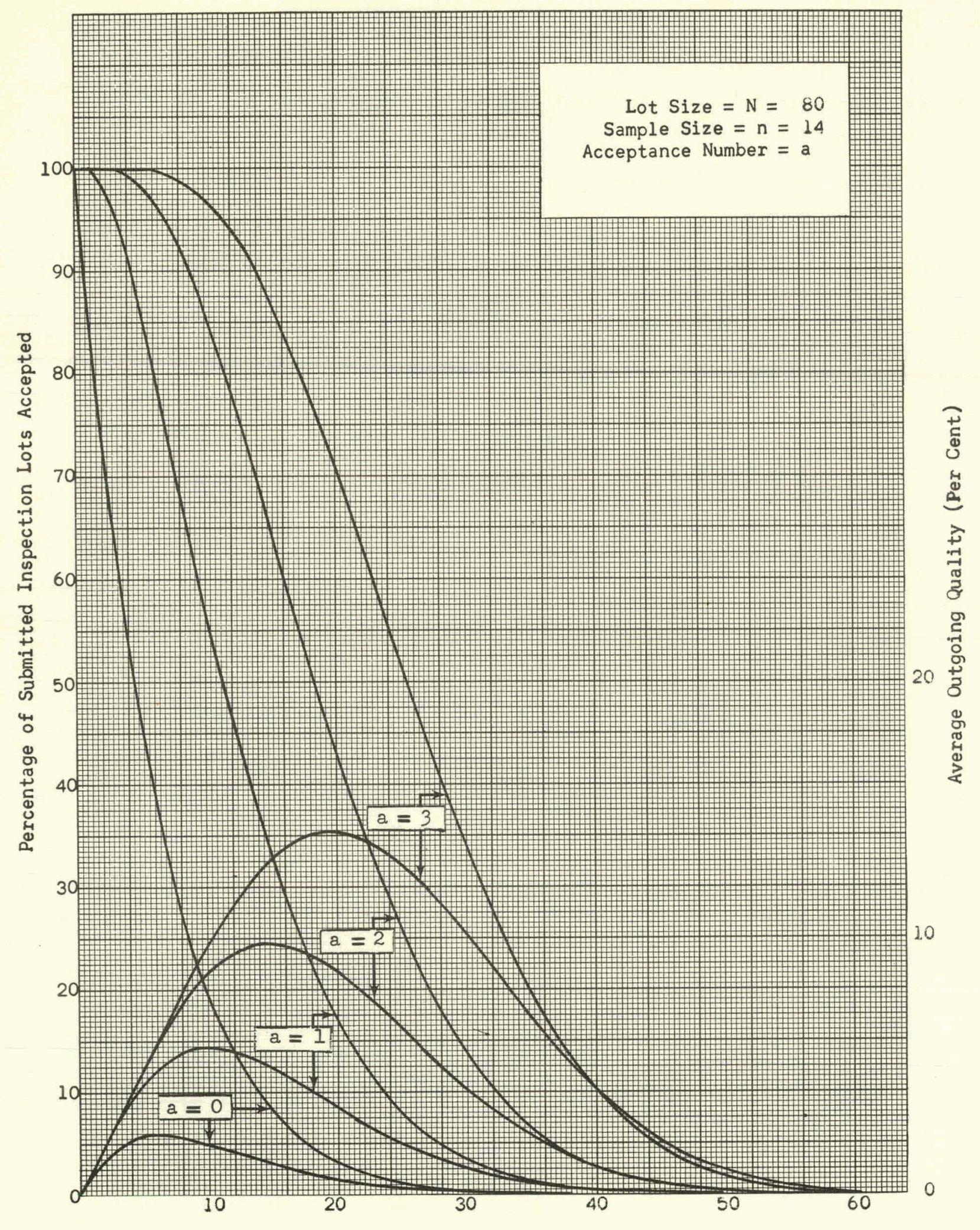

Percentage of Defective Items in Submitted Inspection Lots 


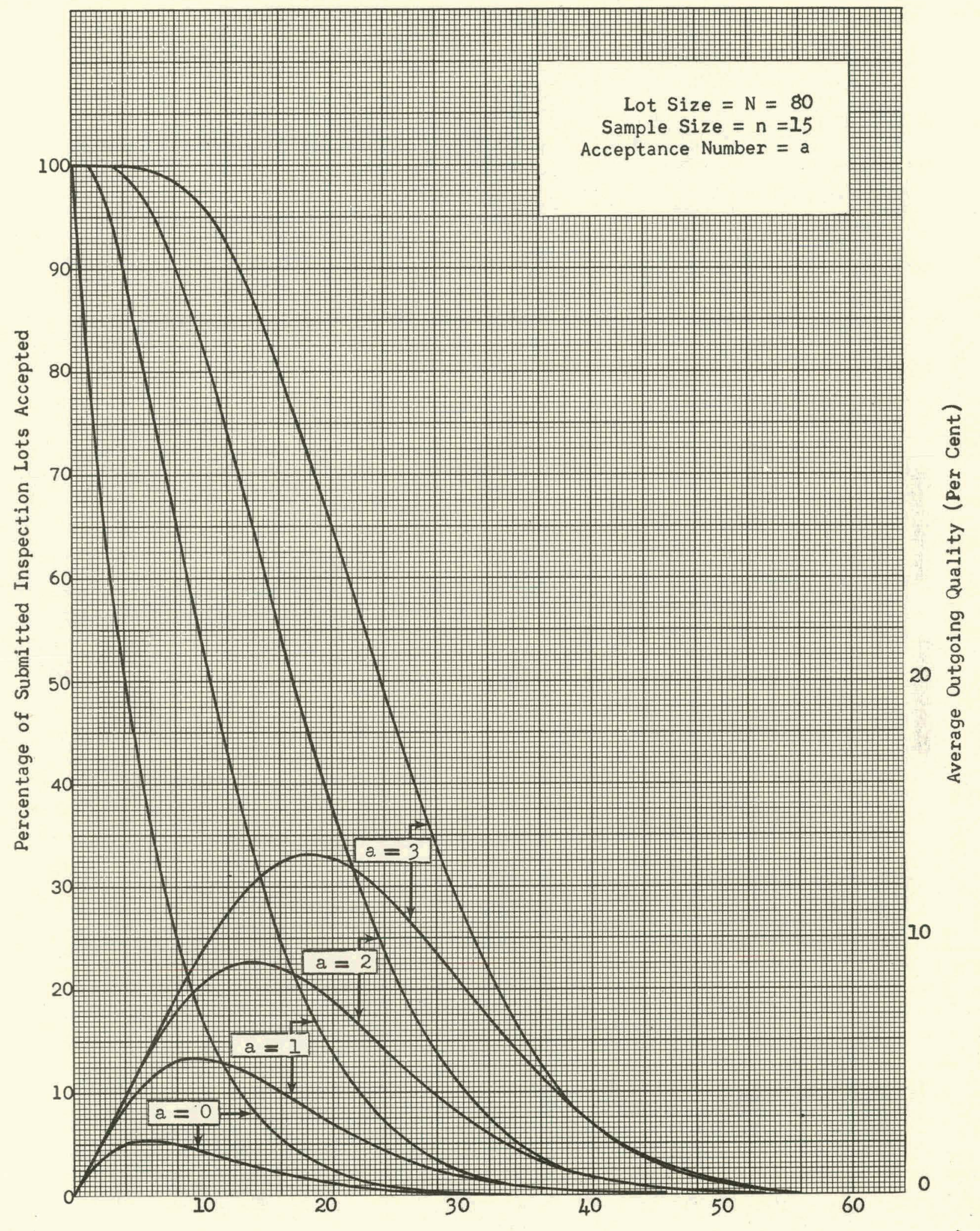

Percentage of Defective Items in Submitted Inspection Lots 


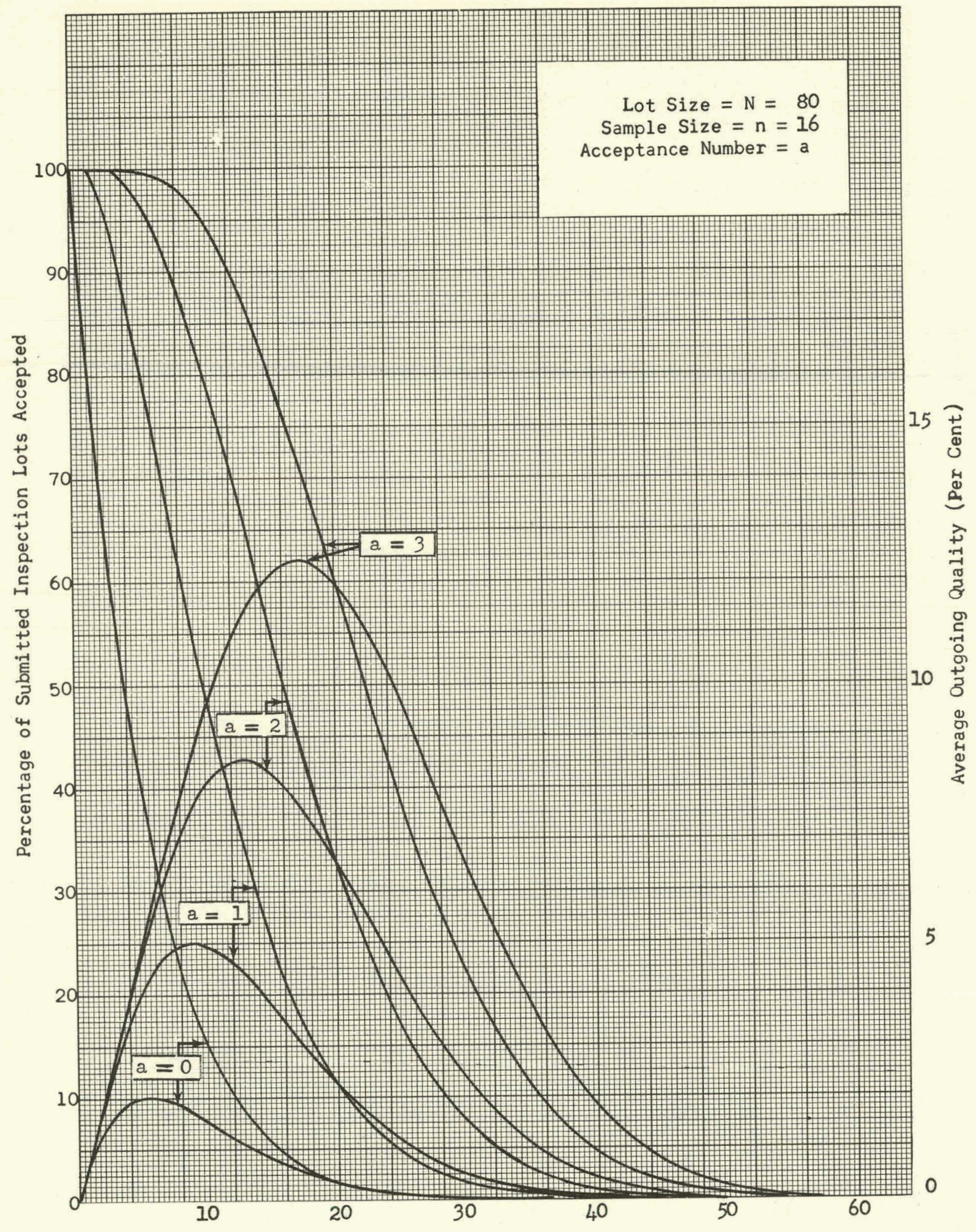

Percentage of Defective Items in Submitted Inspection Lots 


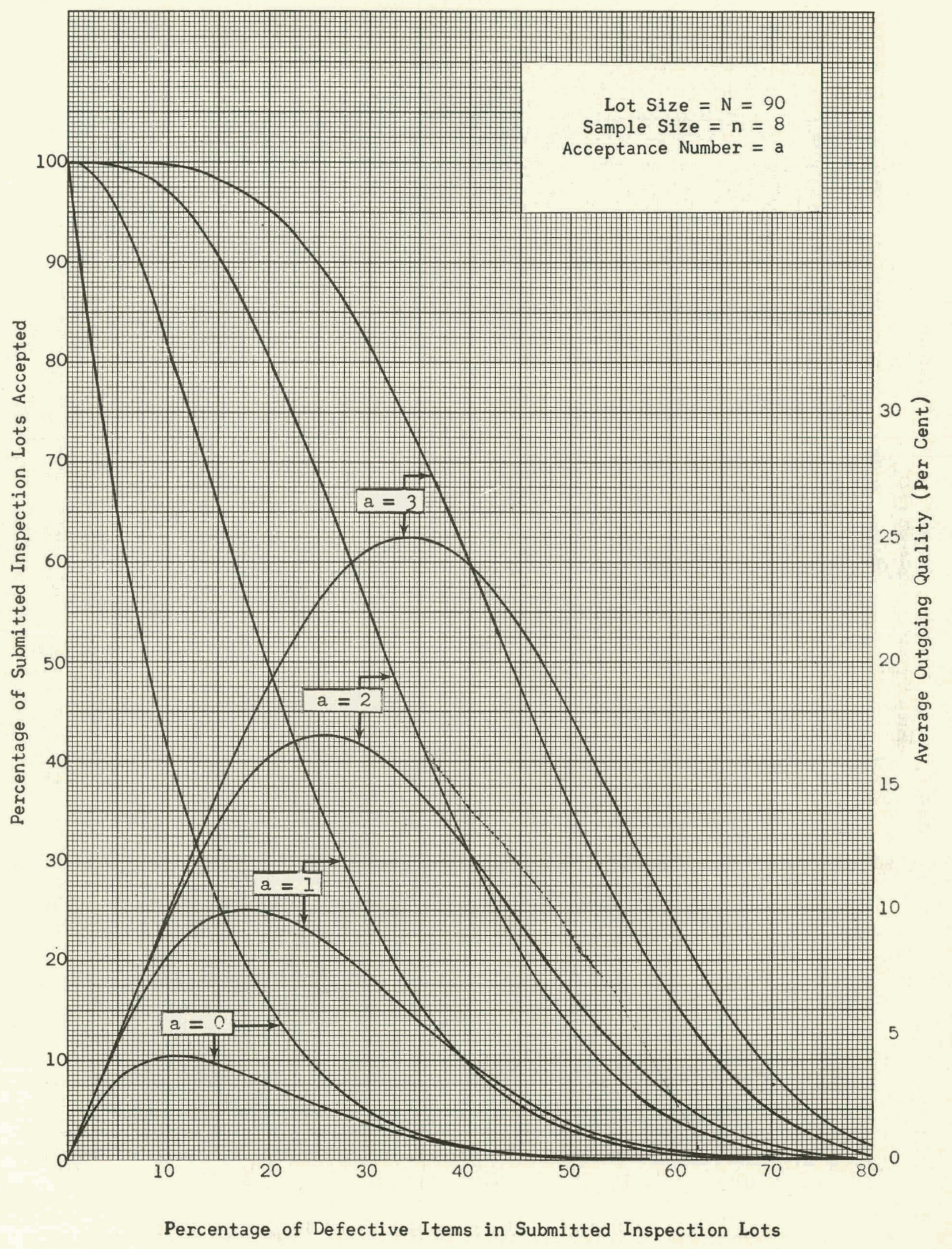




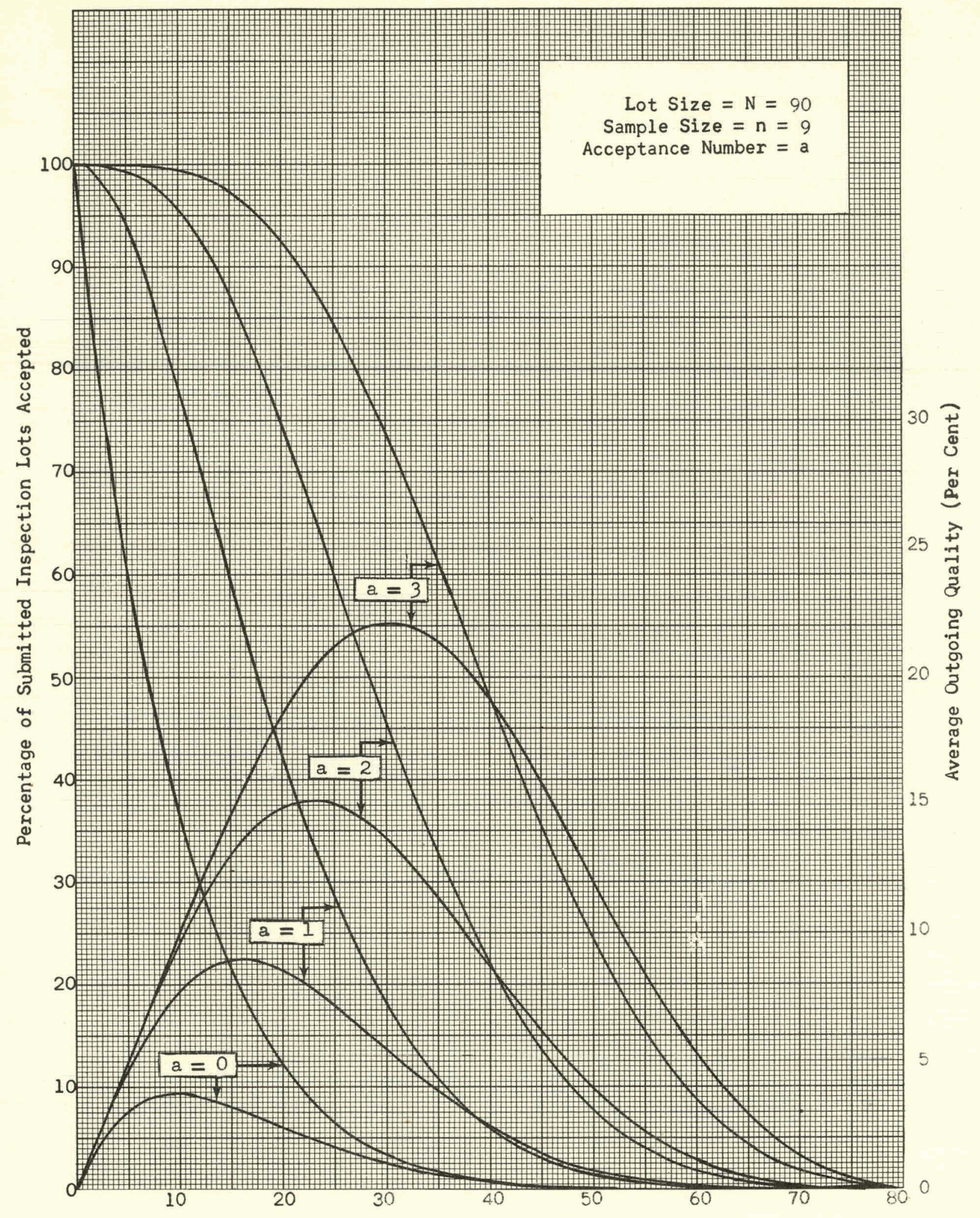

Percentage of Defective Items in Submitted Inspection Lots 


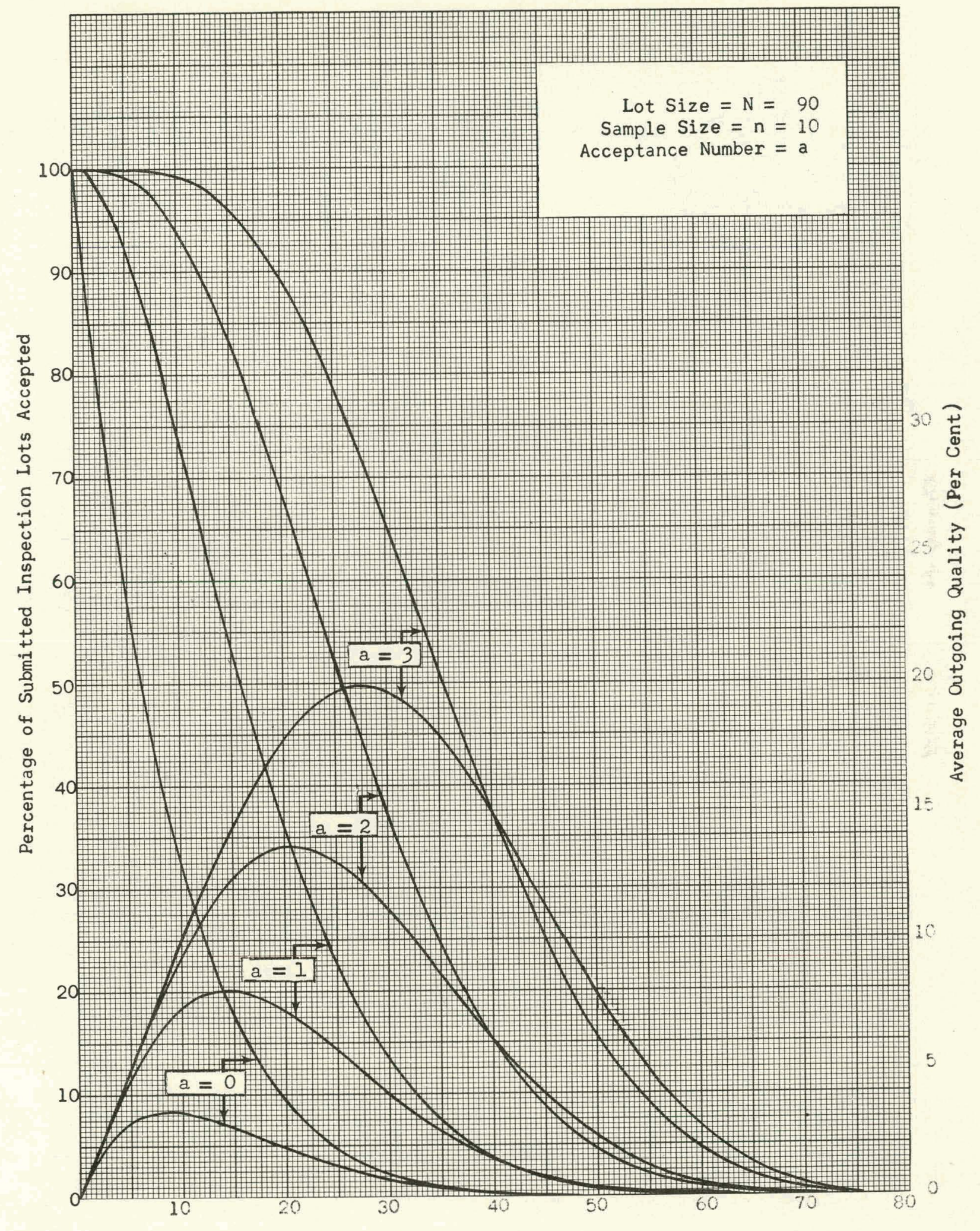

Percentage of Defective Items in Submitted Inspection Lots 


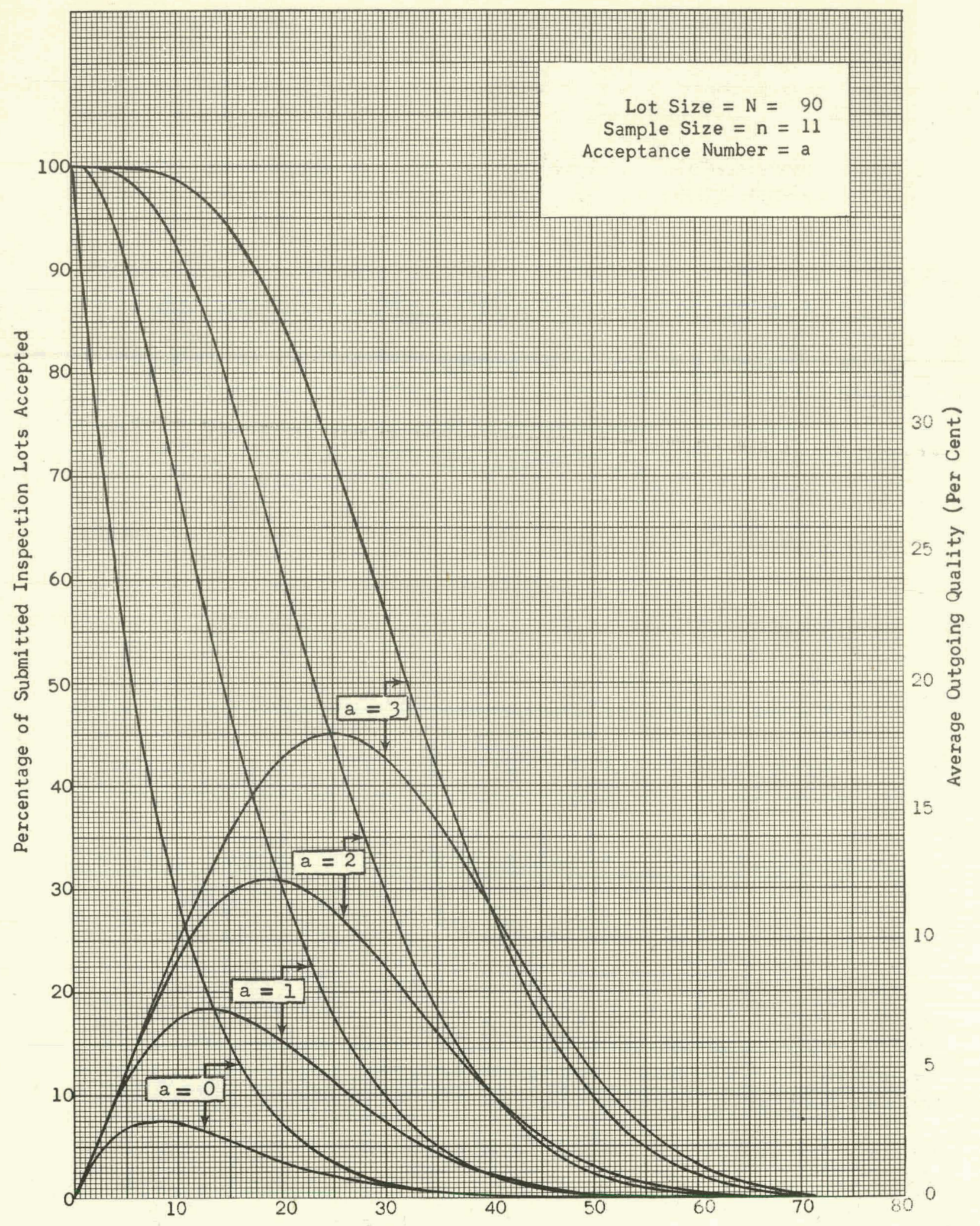

Percentage of Defective Items in Submitted Inspection Lots 


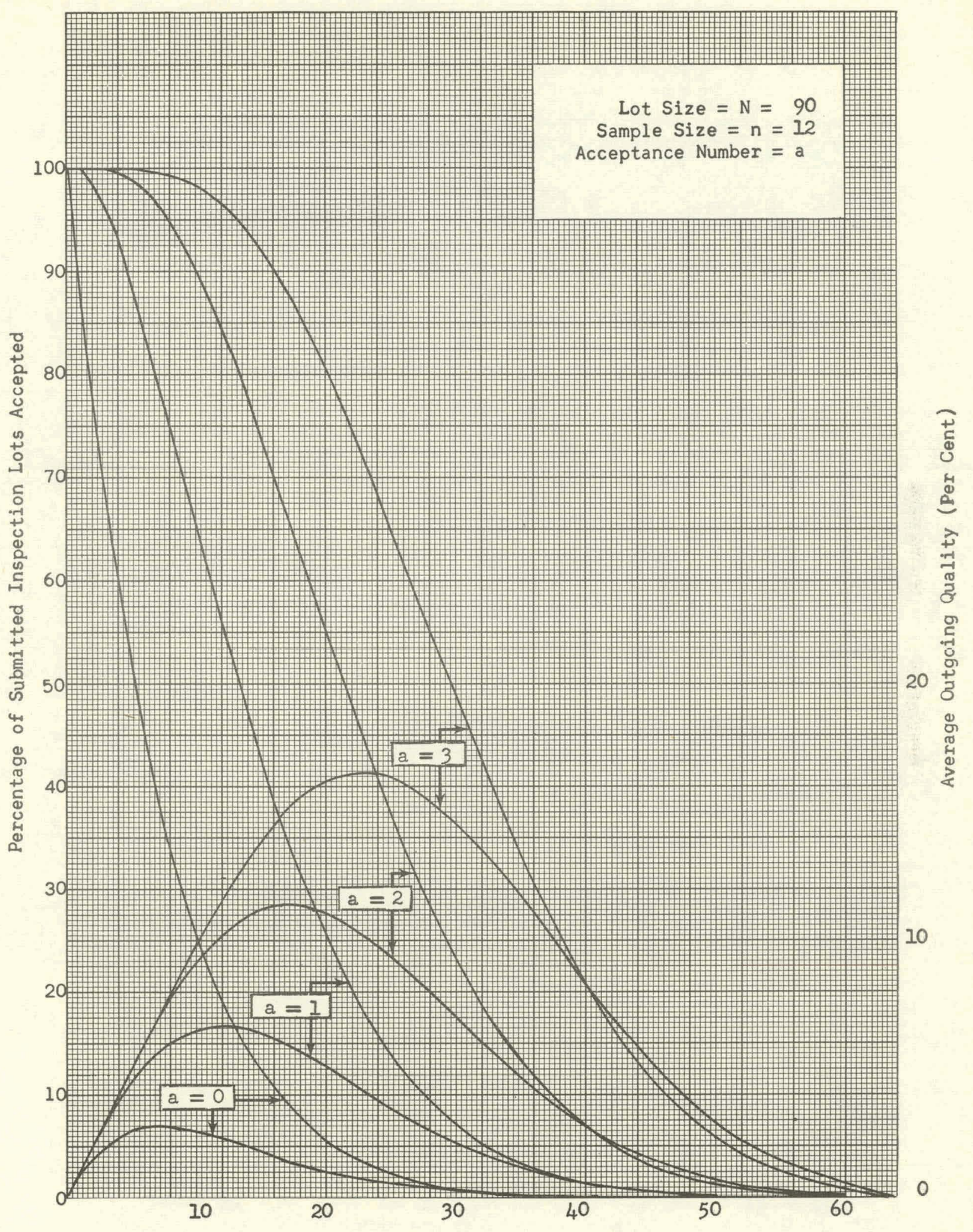

Percentage of Defective Items in Submitted Inspection Lots 


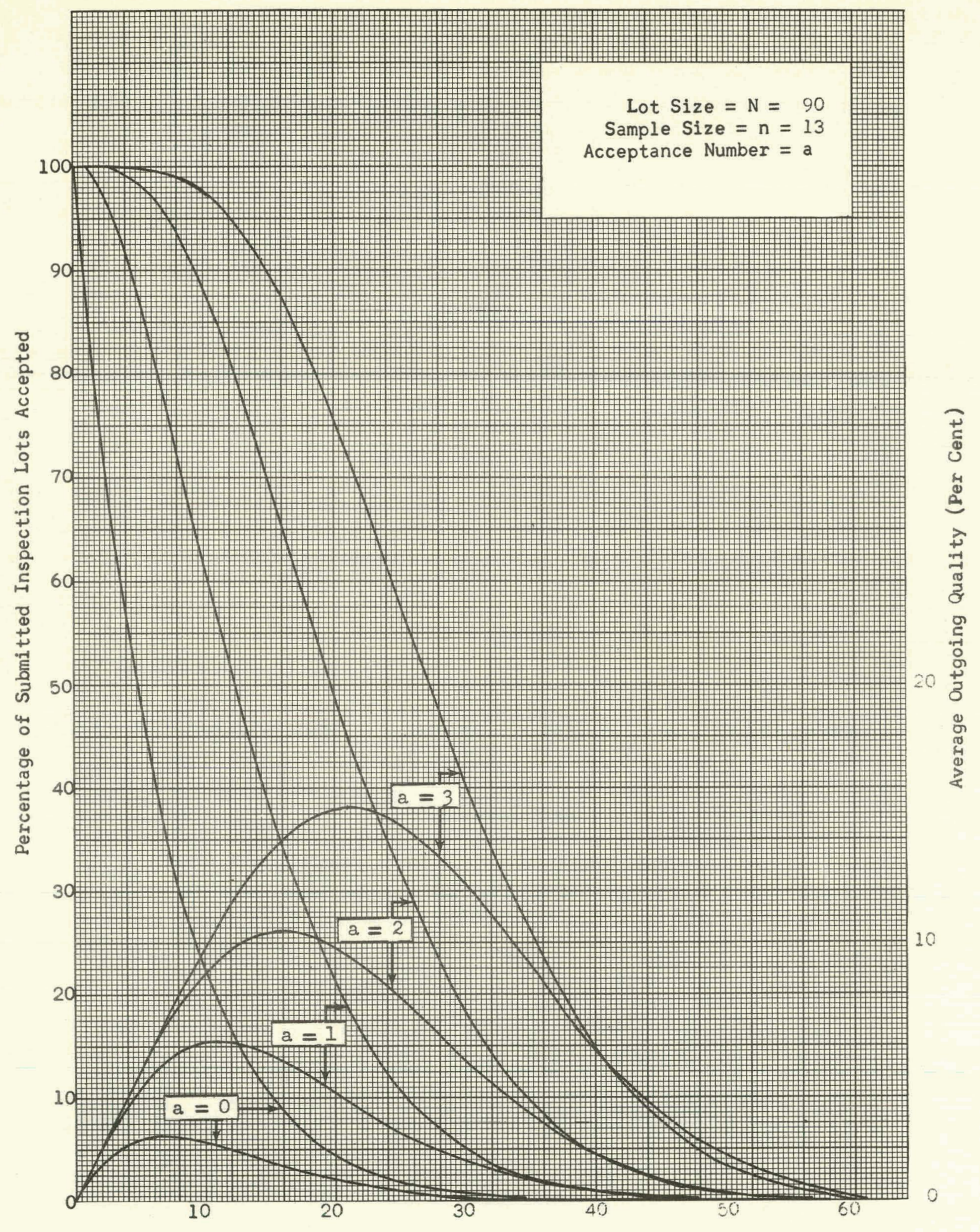

Percentage of Defective Items in Submitted Inspection Lots 


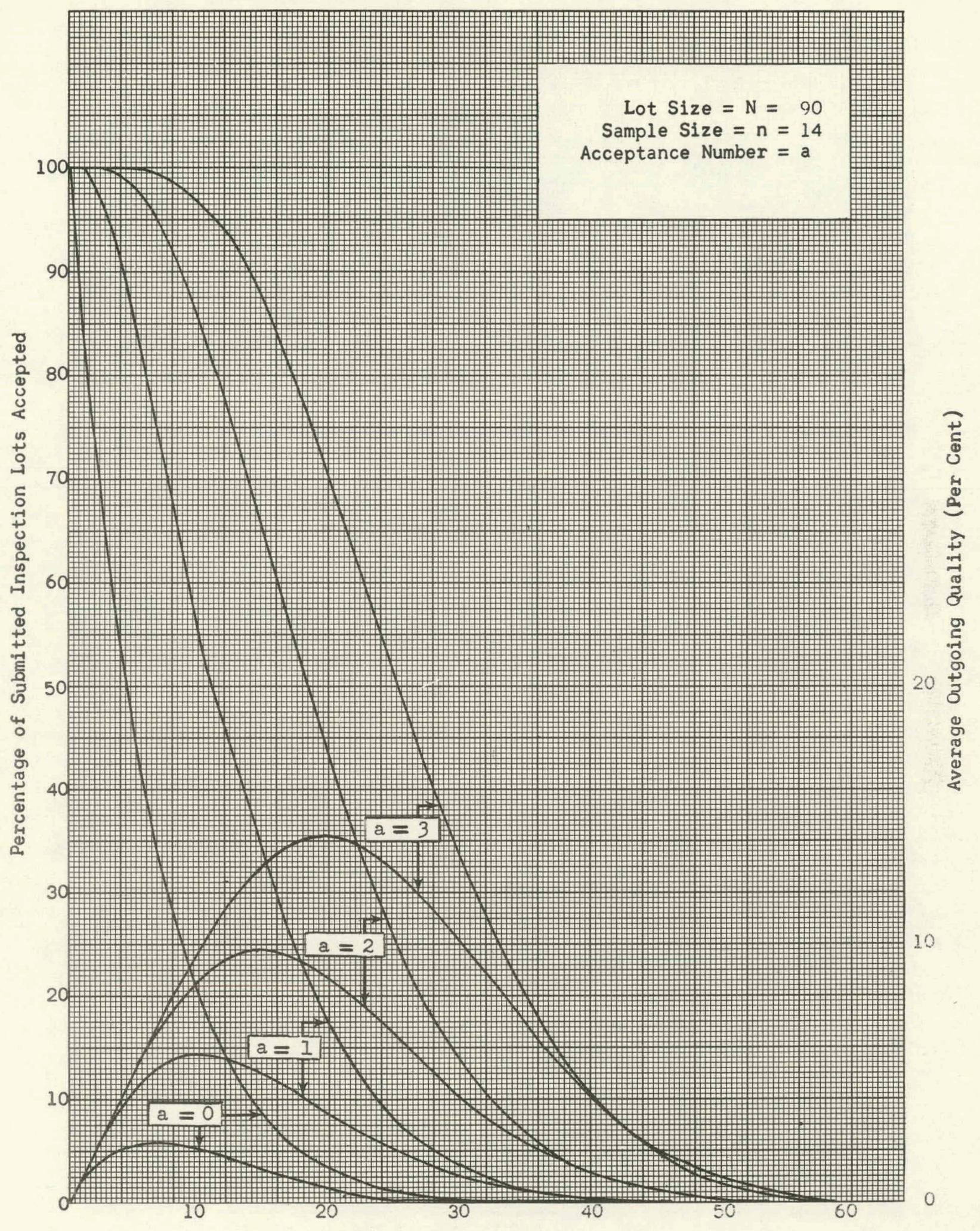

Percentage of Defective Items in Submitted Inspection Lots 


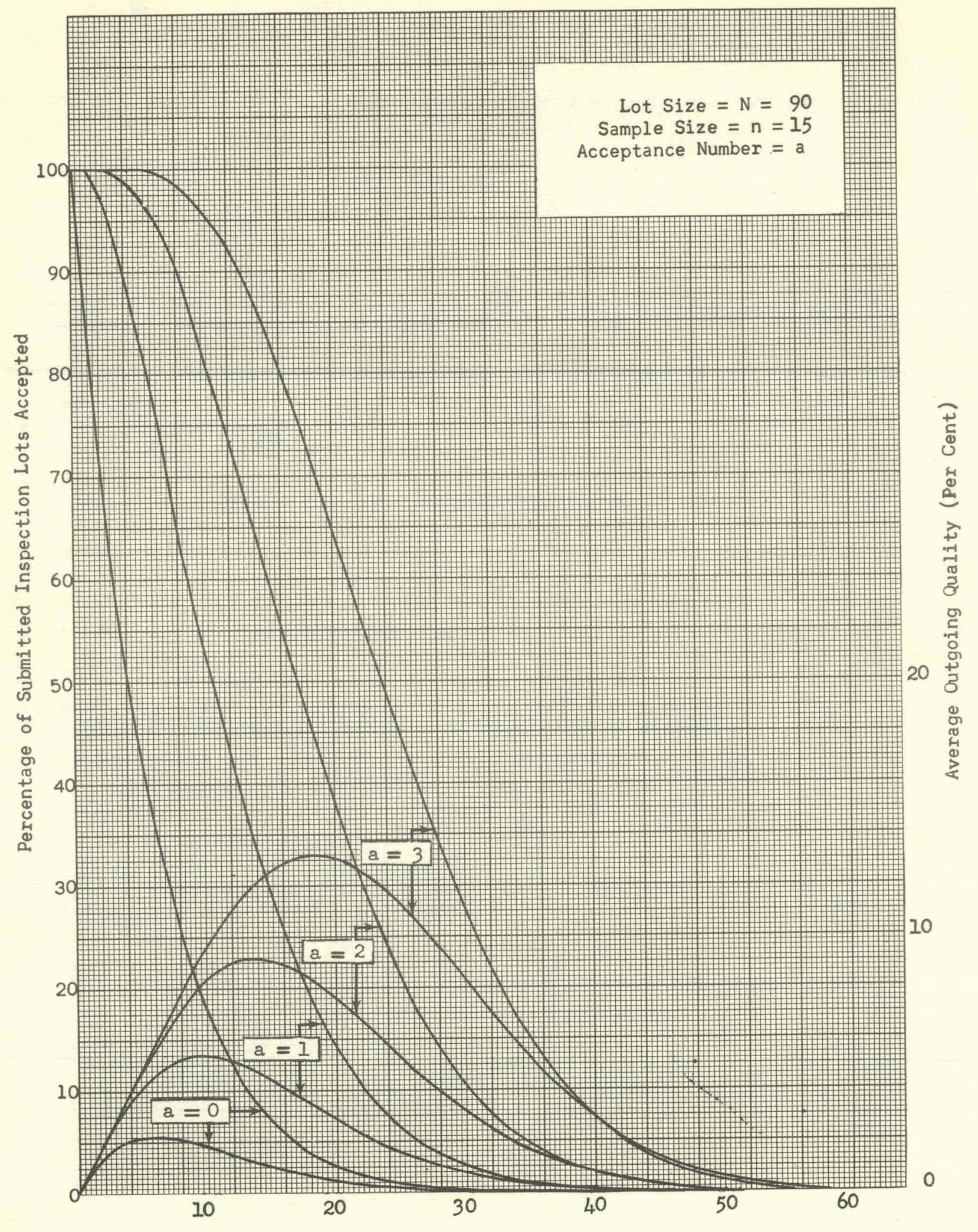

Percentage of Defective Items in Submitted Inspection Lots 


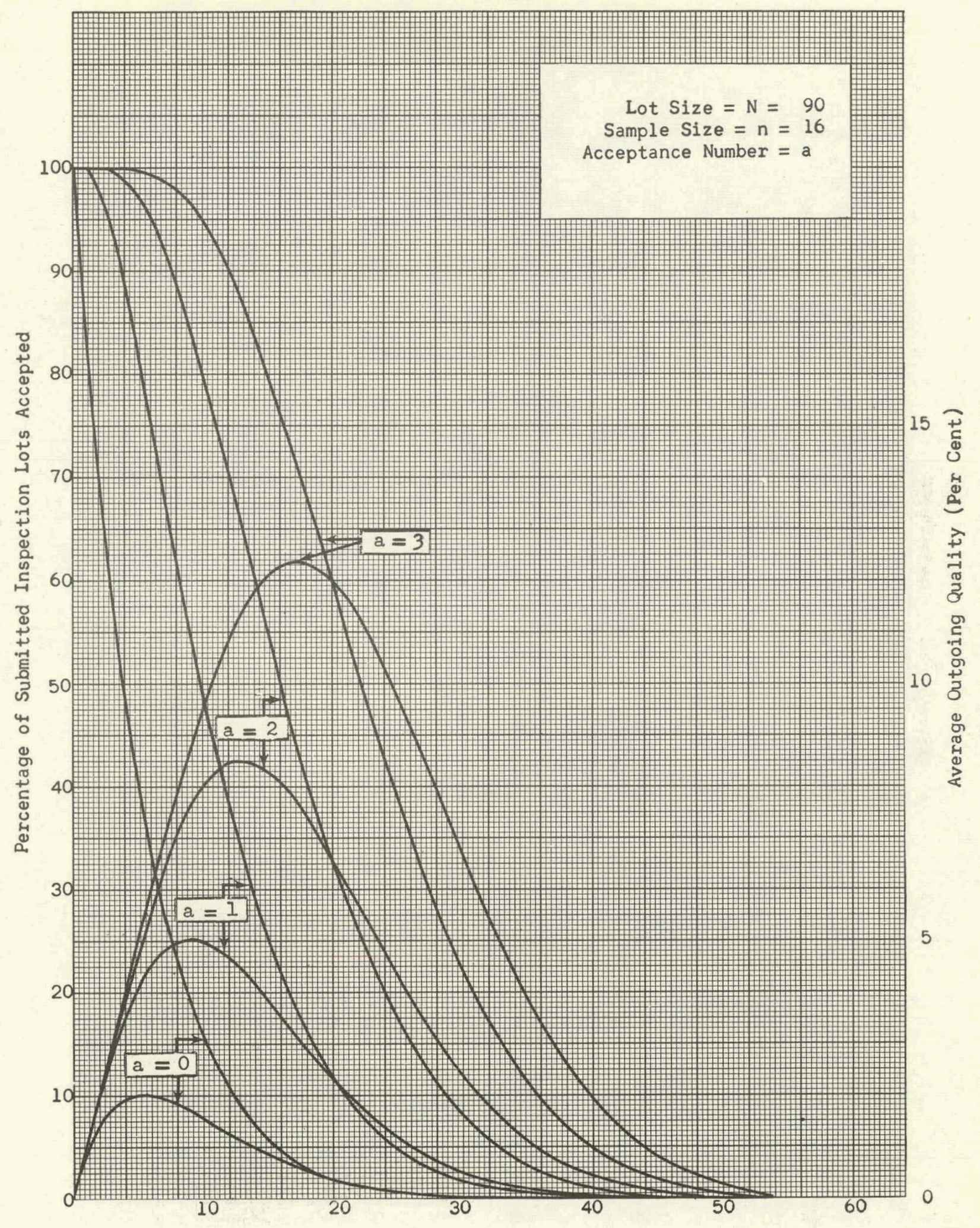

Percentage of Defective Items in Submitted Inspection Lots 


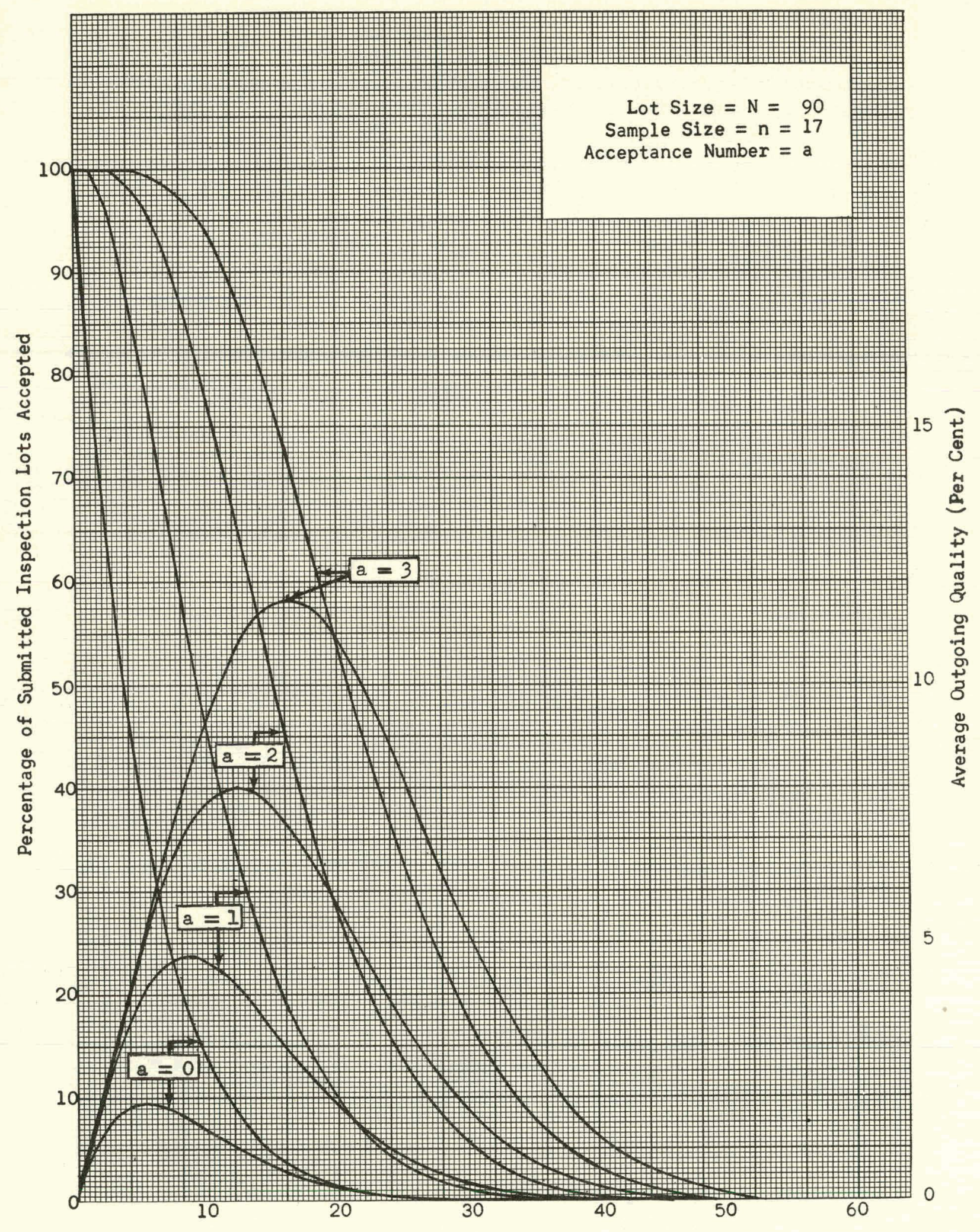

Percentage of Defective Items in Submitted Inspection Lots 


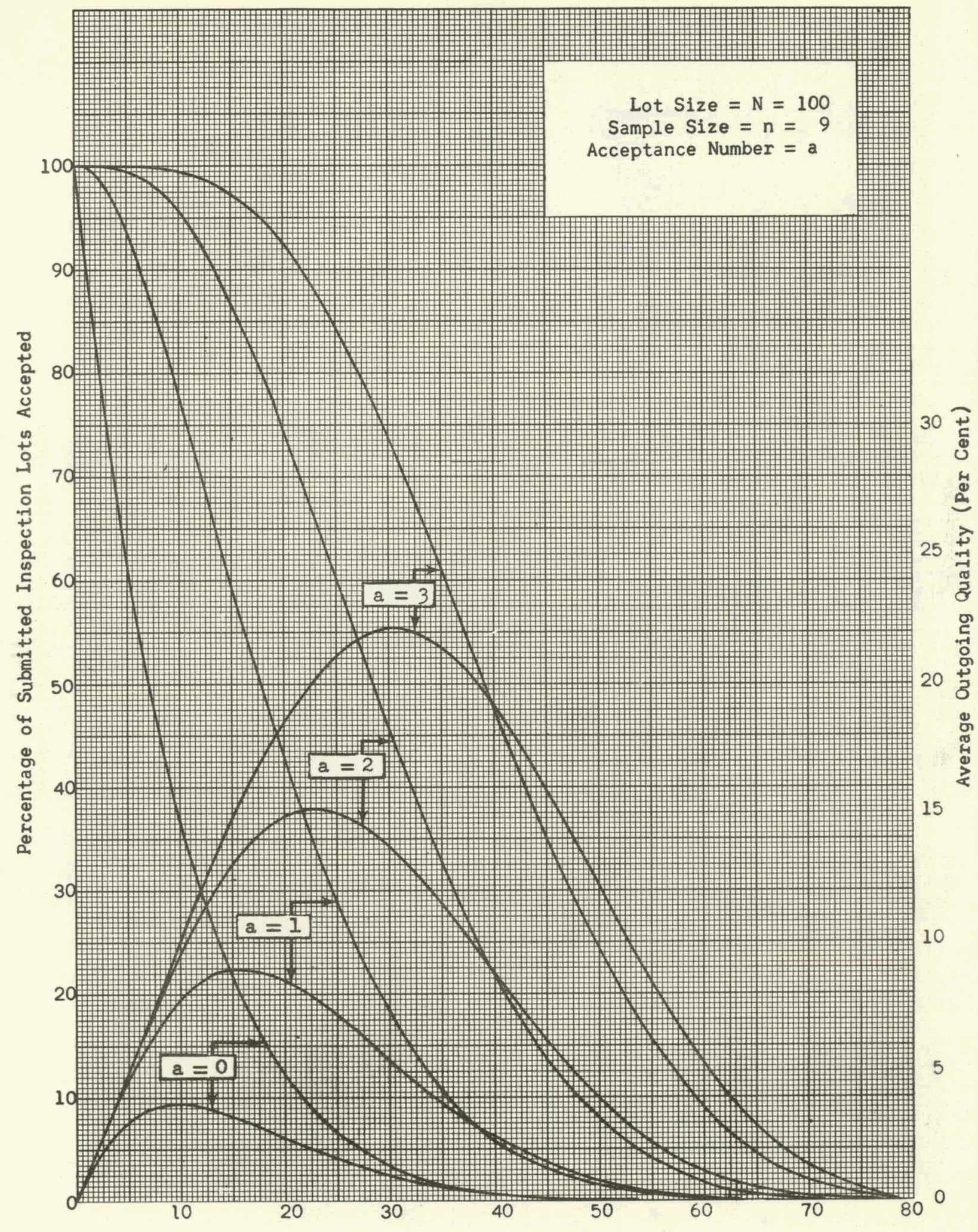

Percentage of Defective Items in Submitted Inspection Lots 


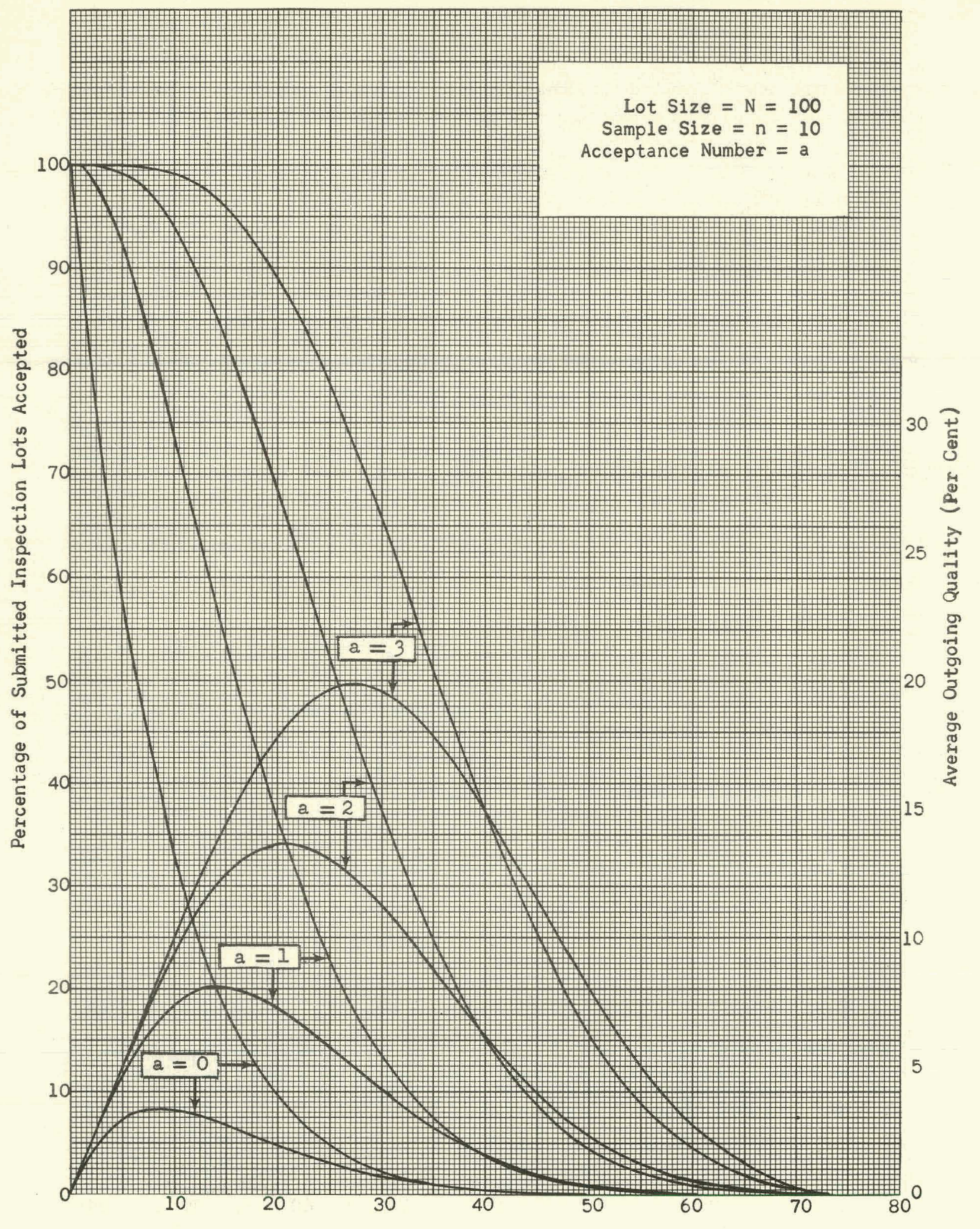

Percentage of Defective Items in Submitted Inspection Lots 


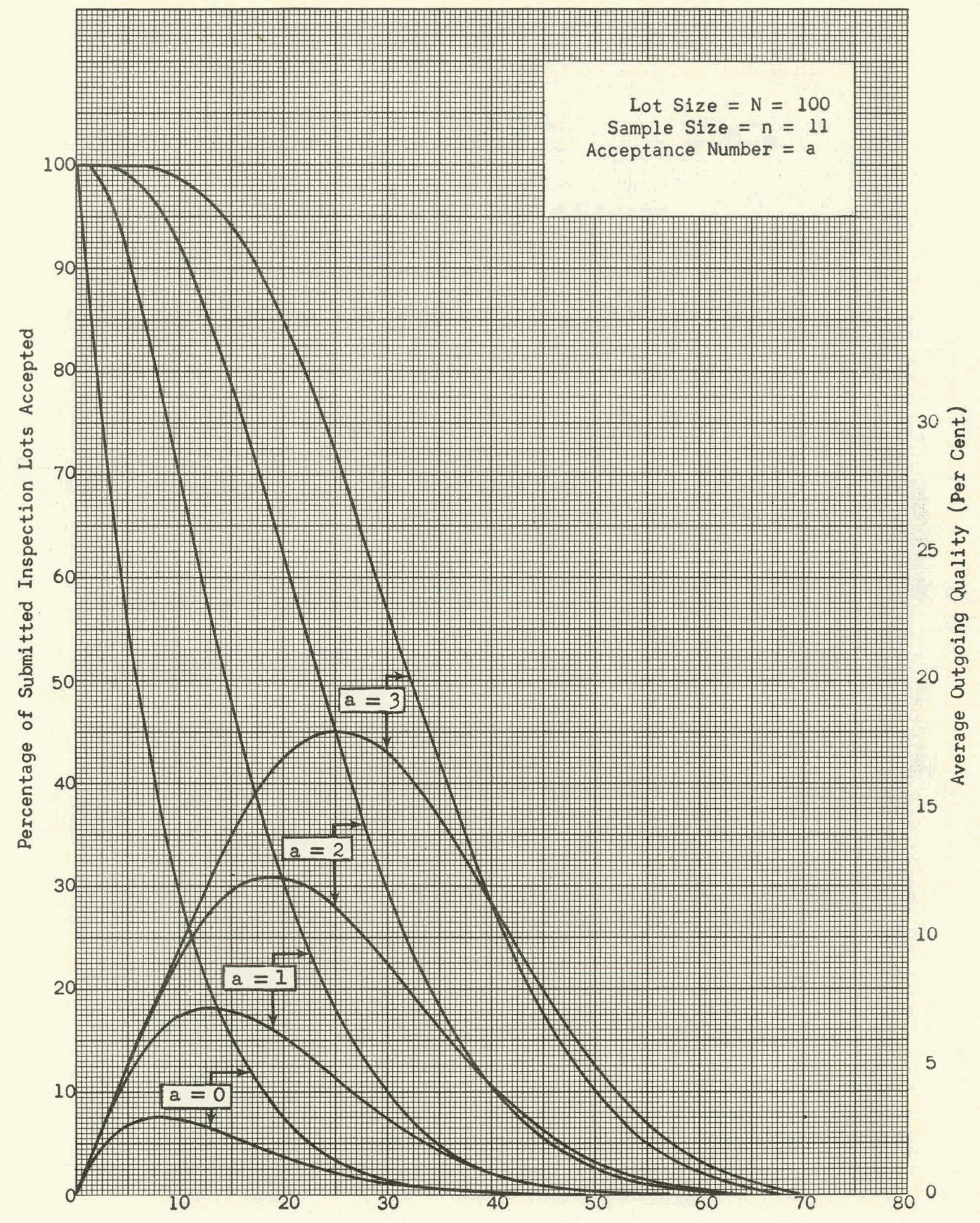

Percentage of Defective Items in Submitted Inspection Lots 


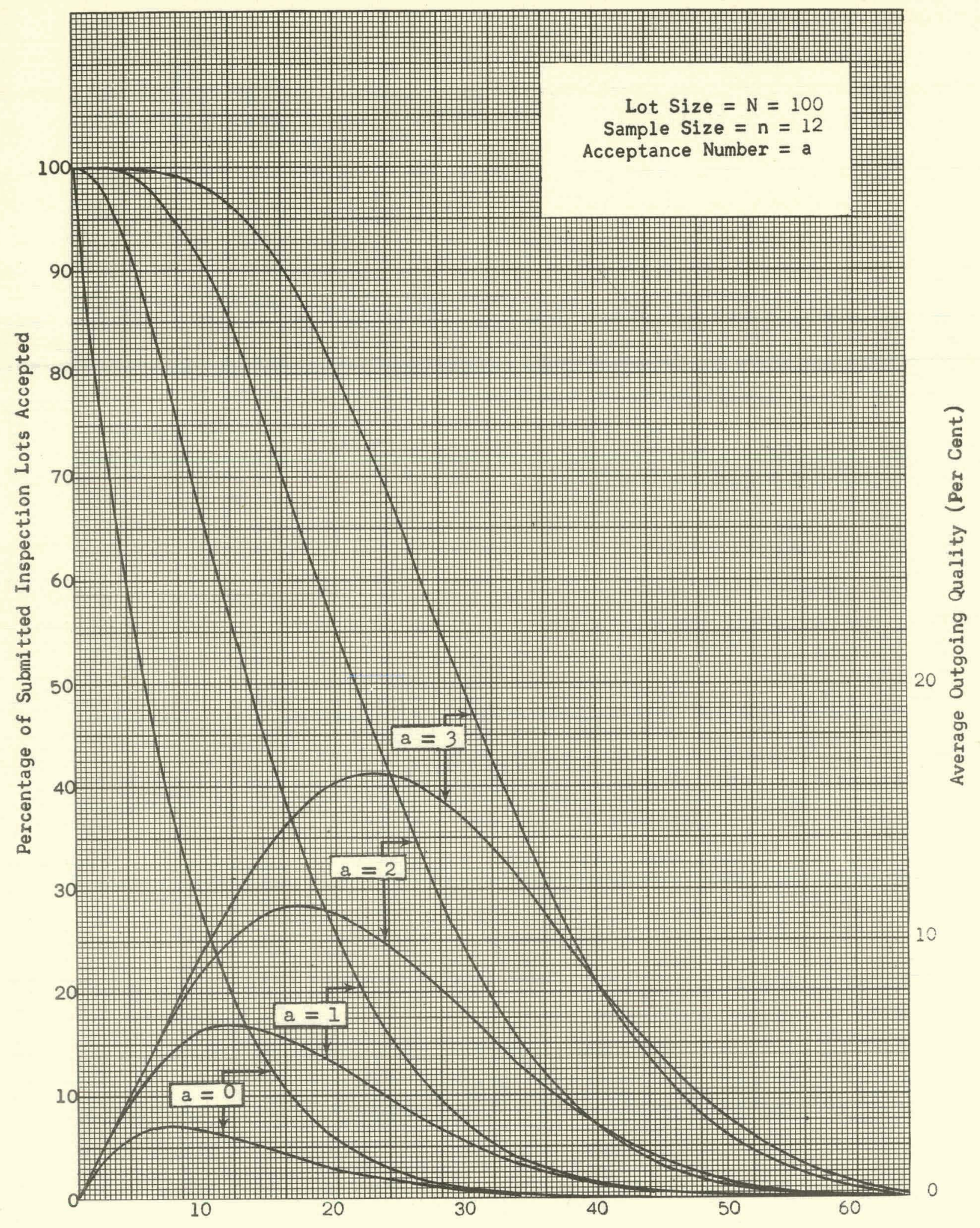

Percentage of Defective Items in Submitted Inspection Lots 


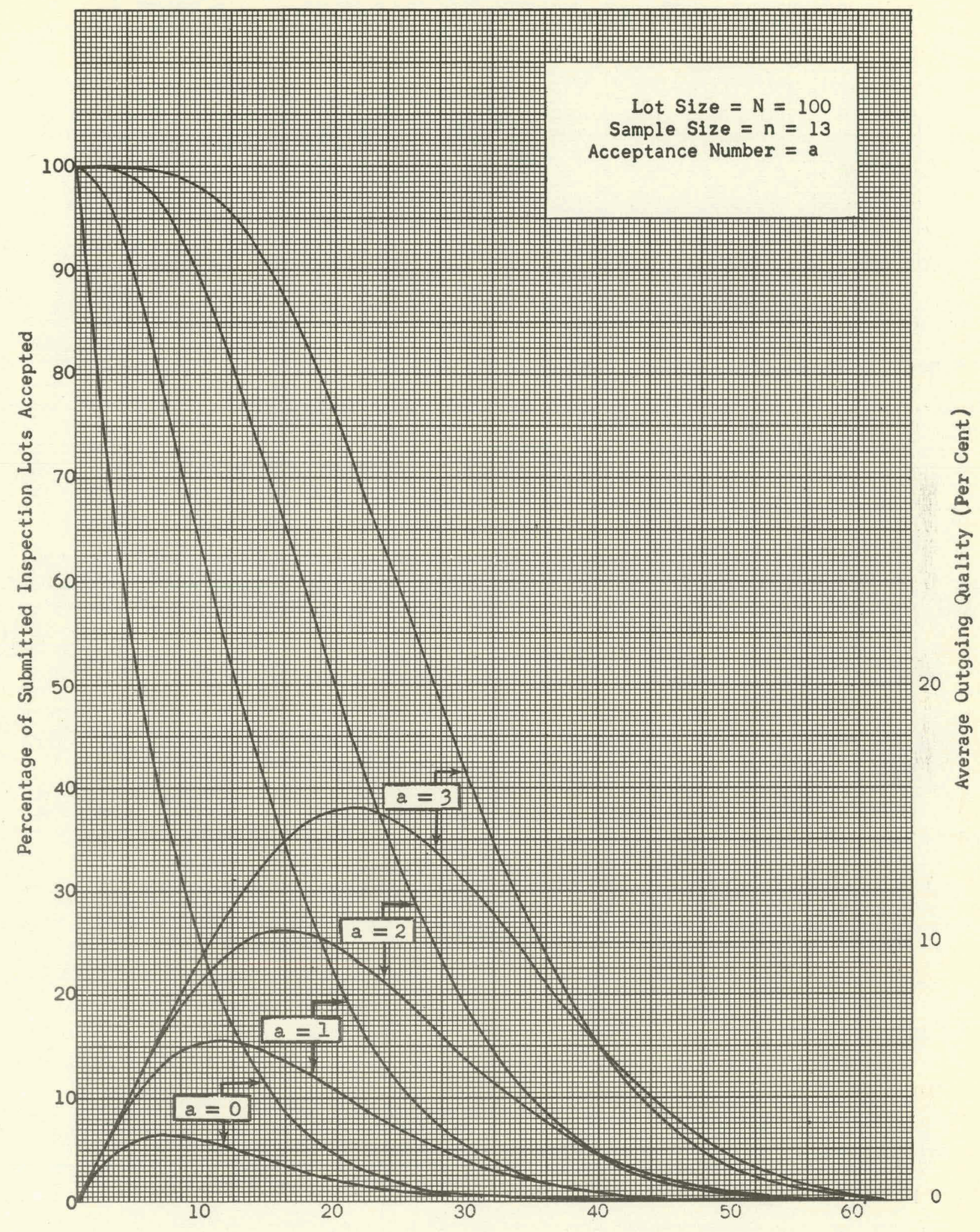

Percentage of Defective Items in Submitted Inspection Lots 


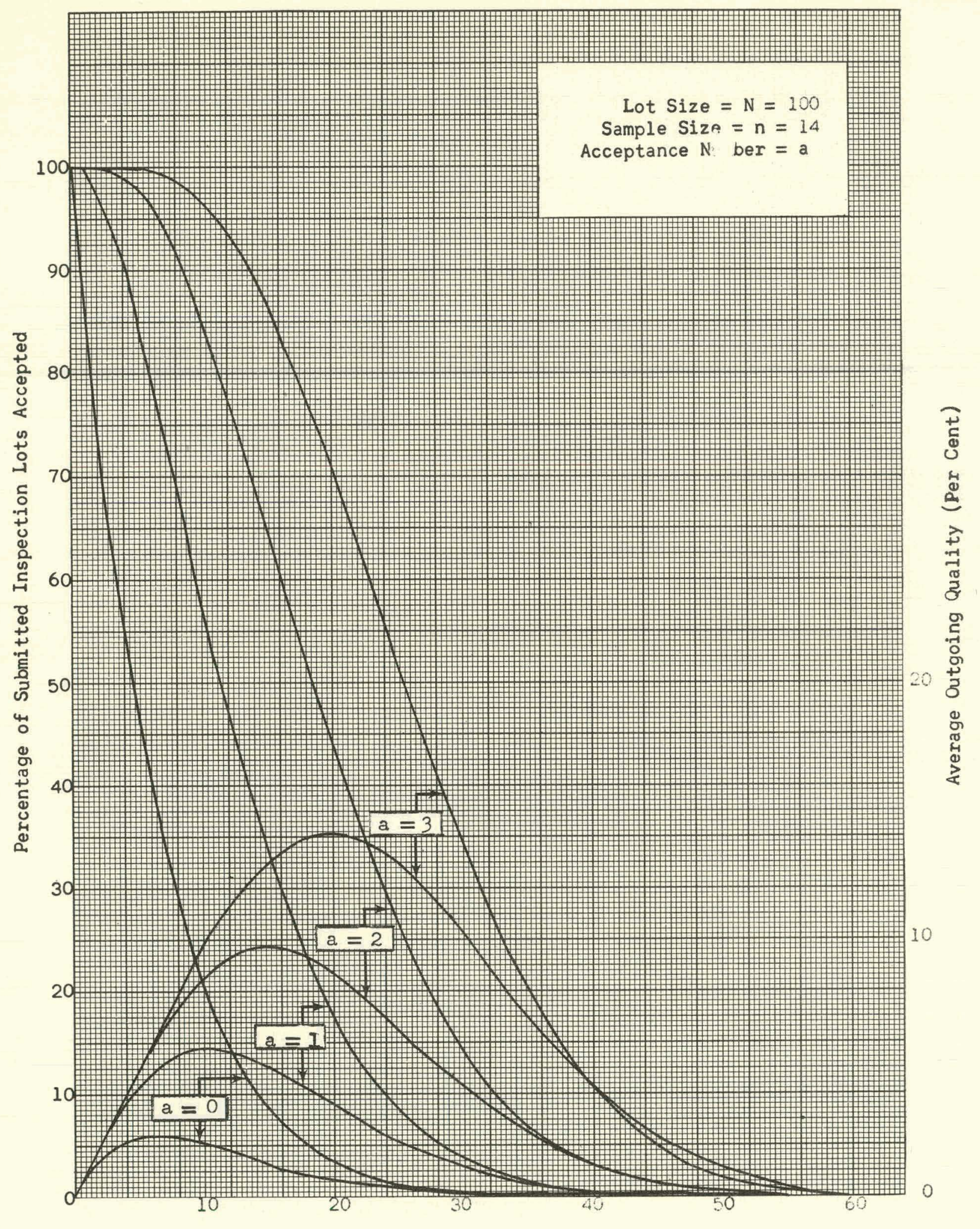

Percentage of Defective Items in Submitted Inspection Lots 


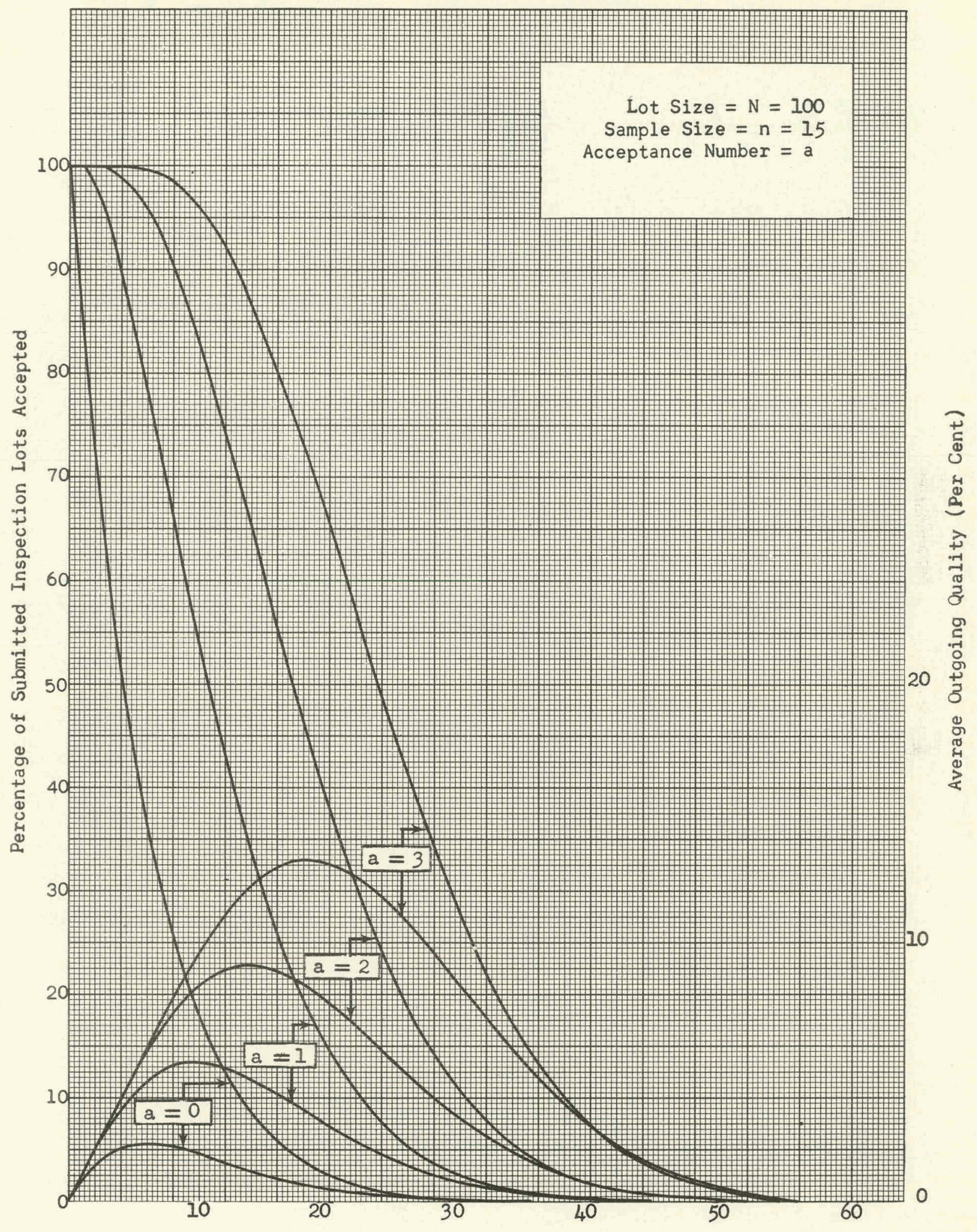

Percentage of Defective Items in Submitted Inspection Lots 


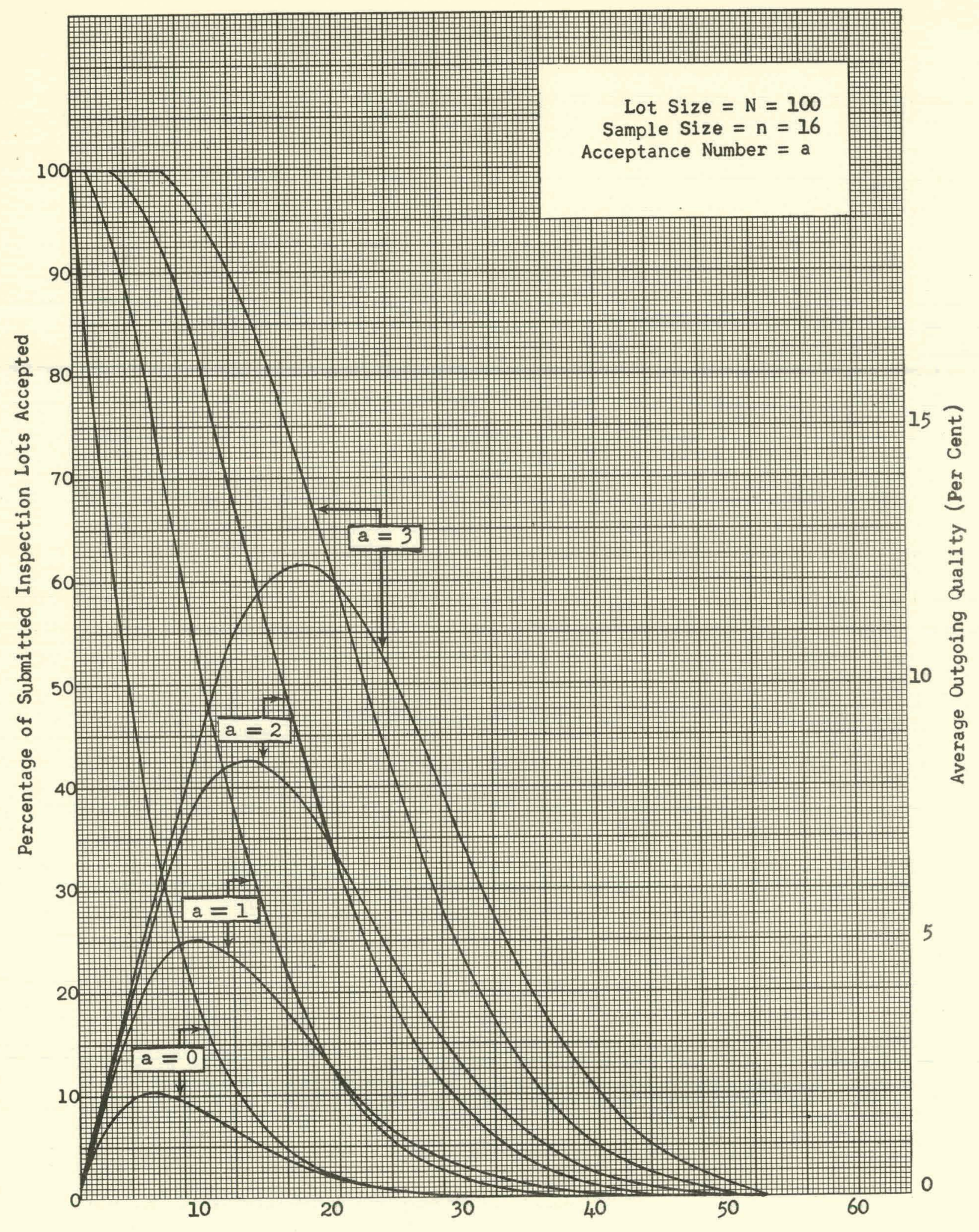

Percentage of Defective Items in Submitted Inspection Lots 


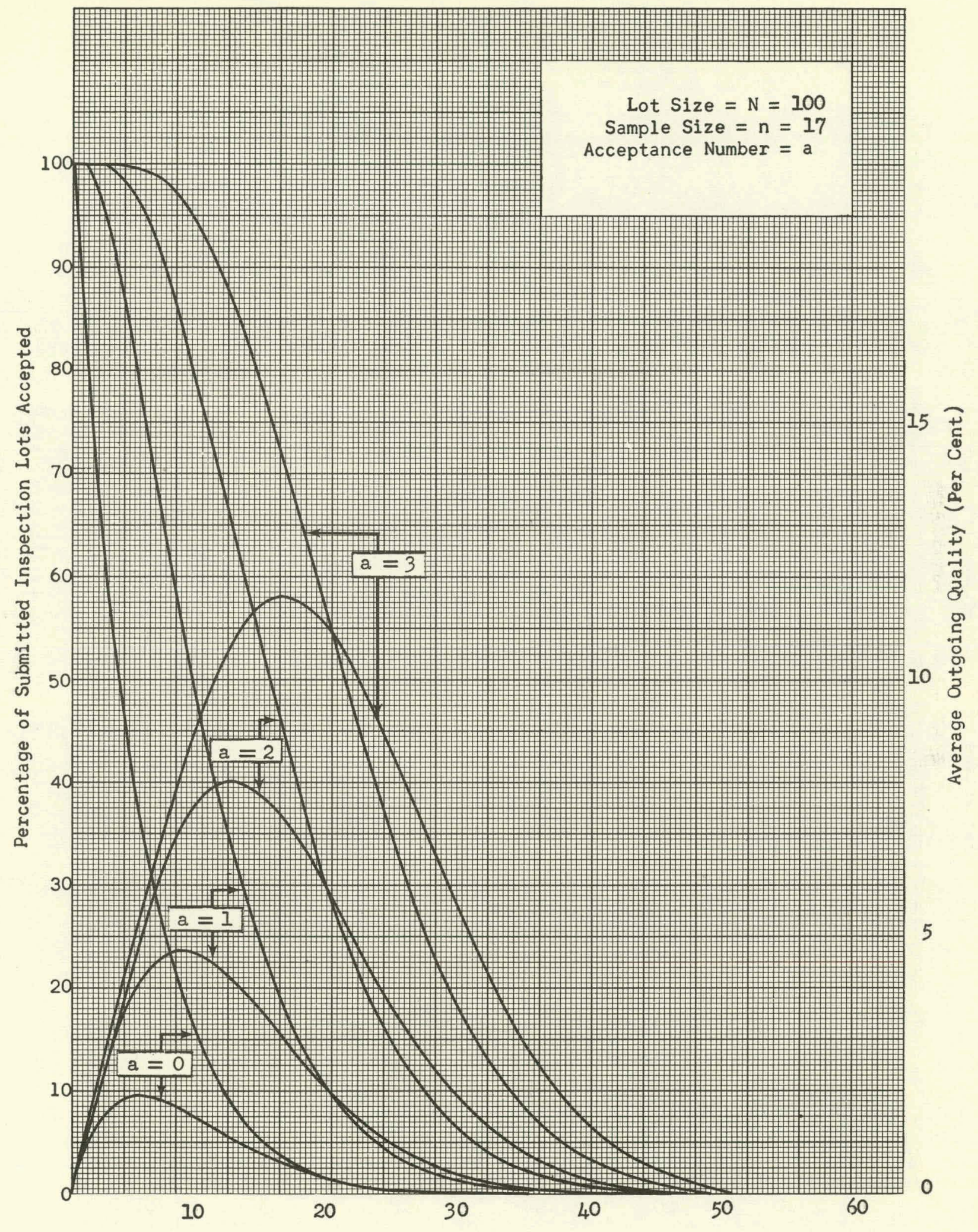

Percentage of Defective Items in Submitted Inspection Lots 


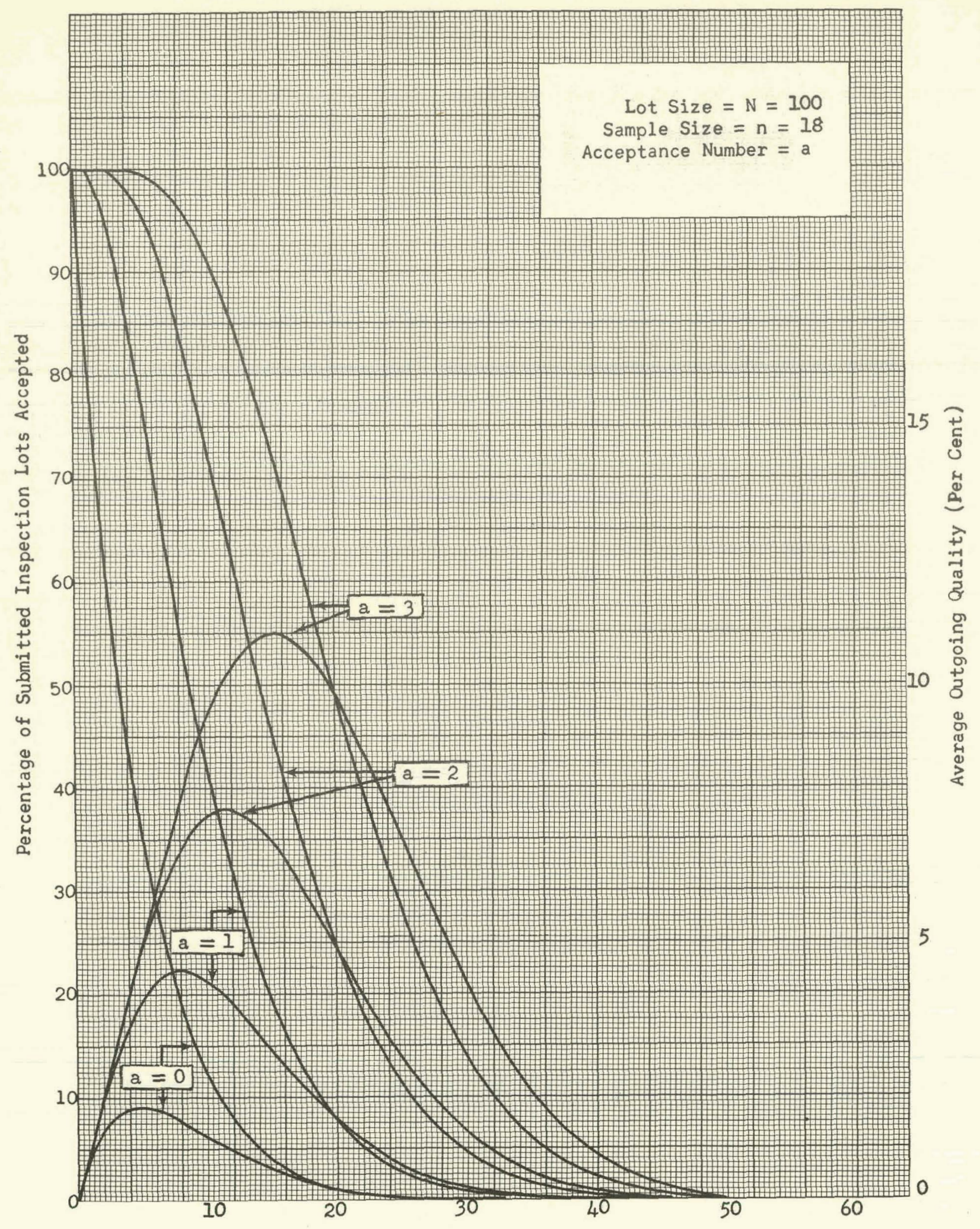

Percentage of Defective Items in Submitted Inspection Lots 


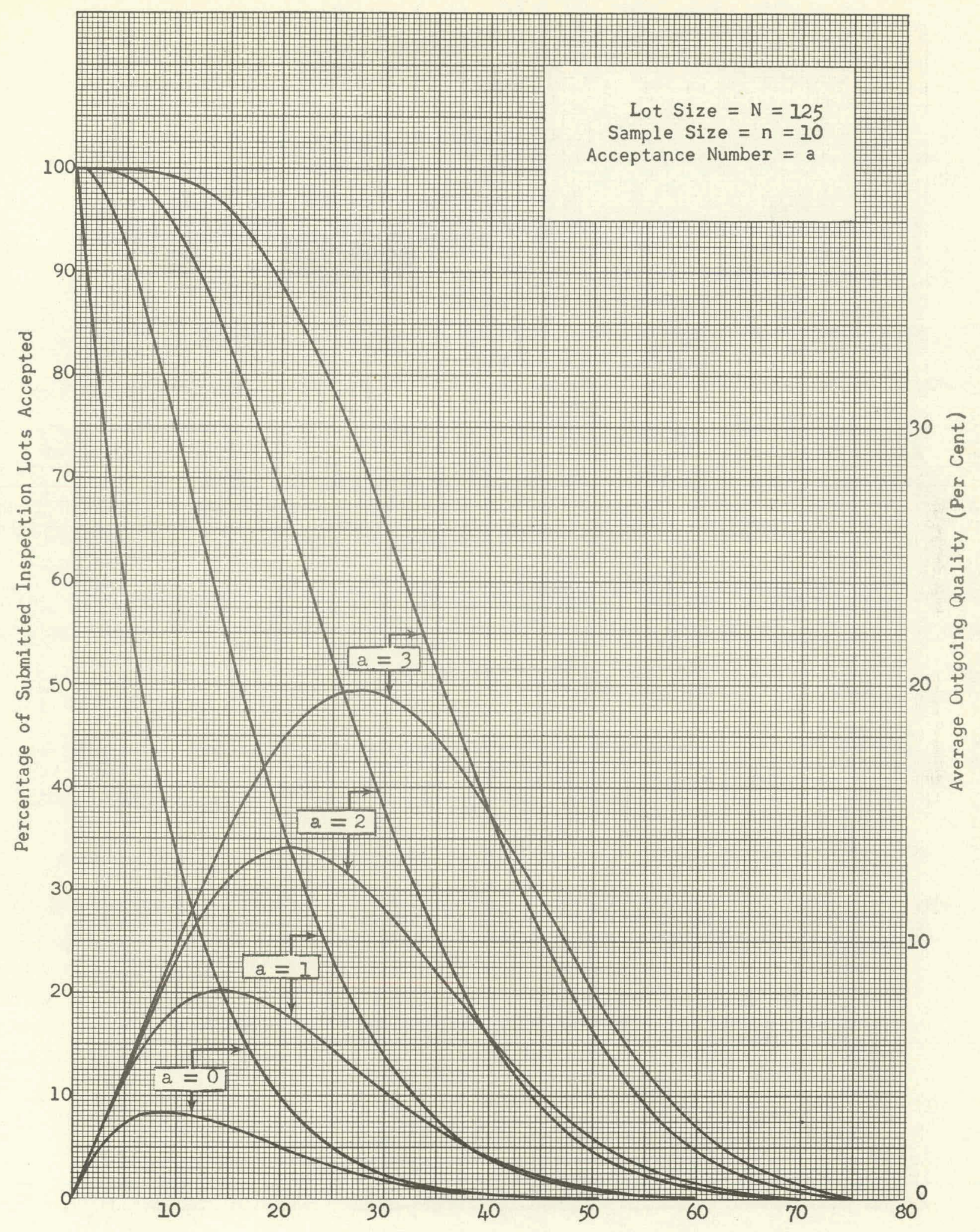

Percentage of Defective Items in Submitted Inspection Lots 


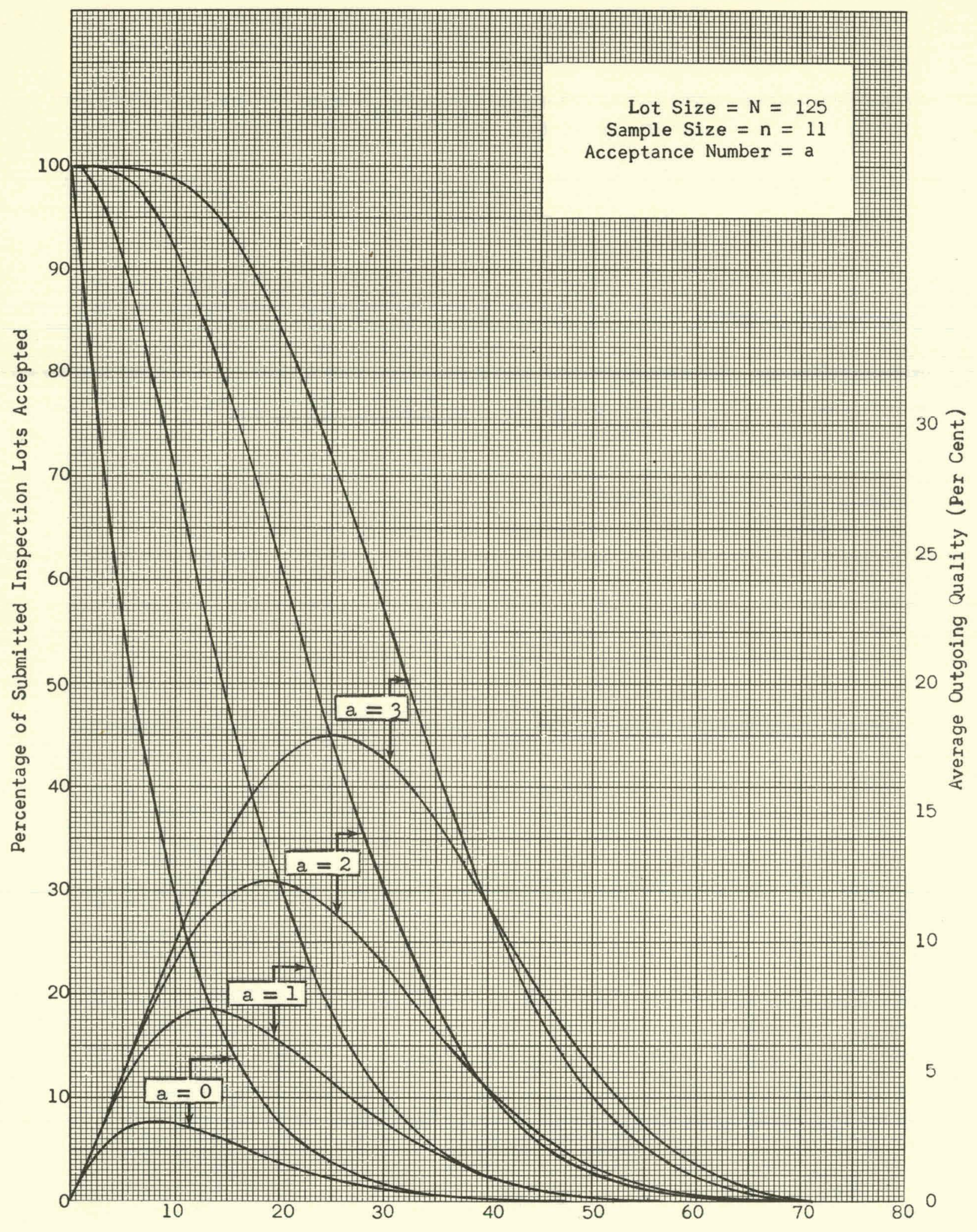

Percentage of Defective Items in Submitted Inspection Lots 


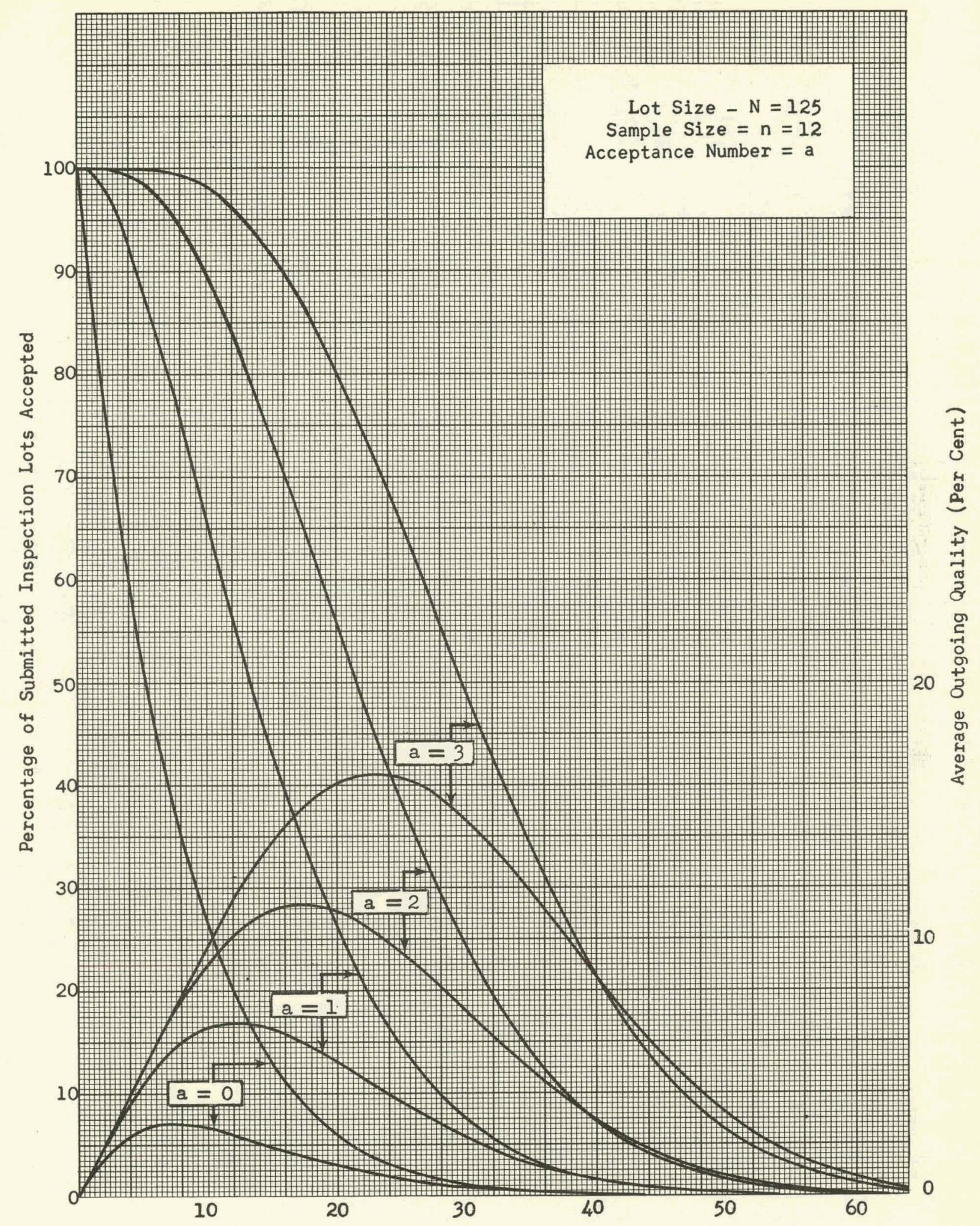

Percentage of Defective Items in Submitted Inspection Lots 


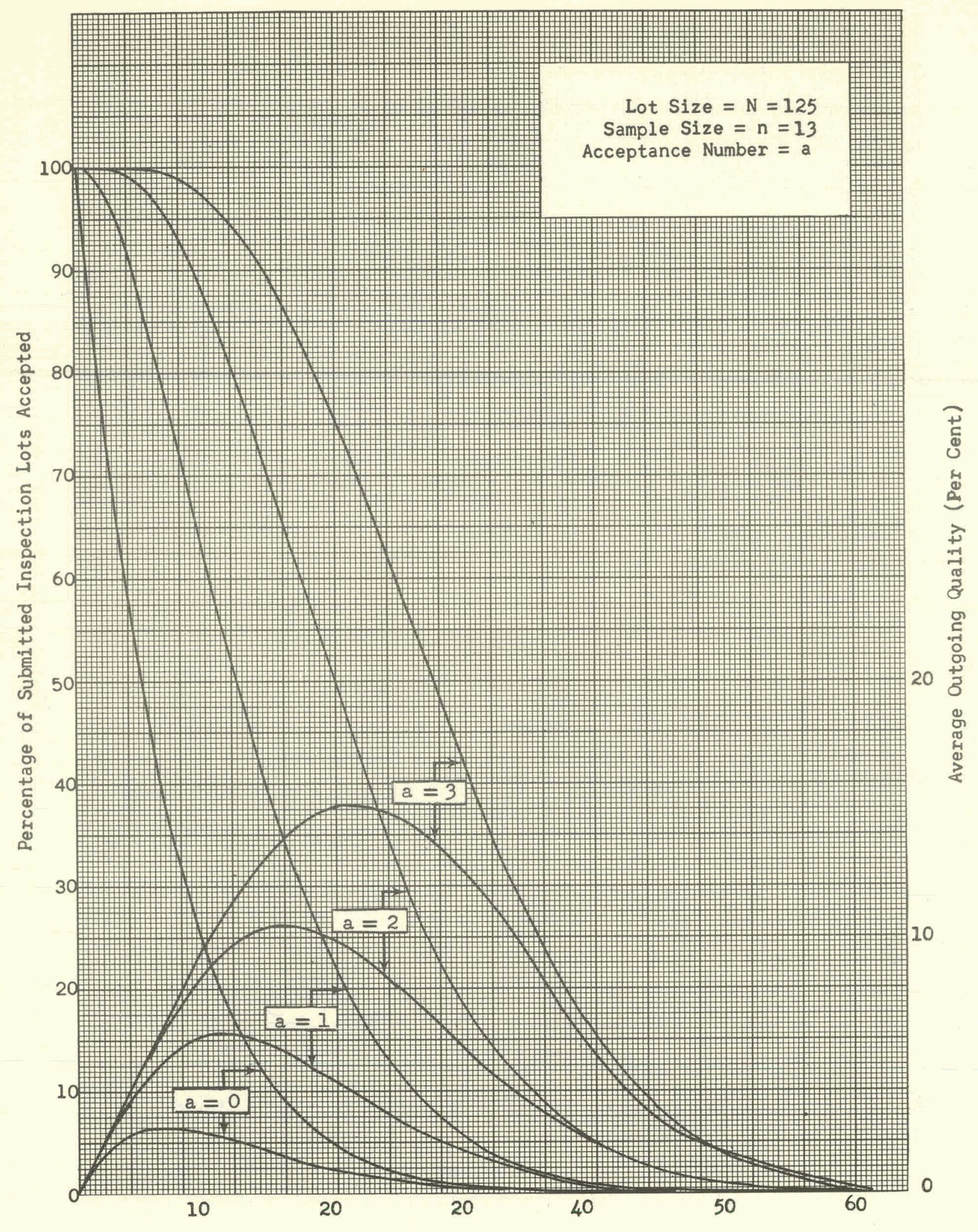

Percentage of Defective Items in Submitted Inspection Lots 


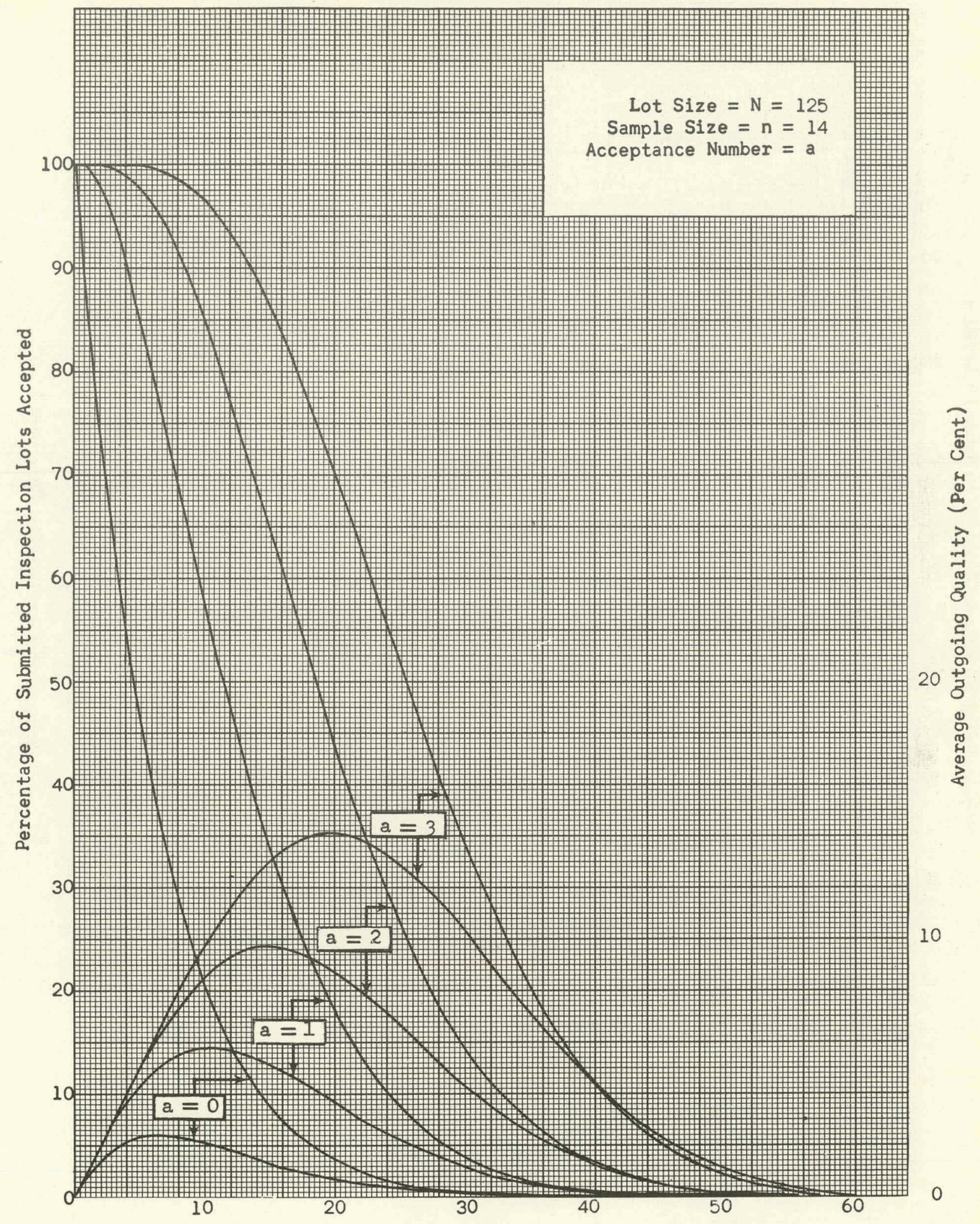

Percentage of Defective Items in Submitted Inspection Lots 


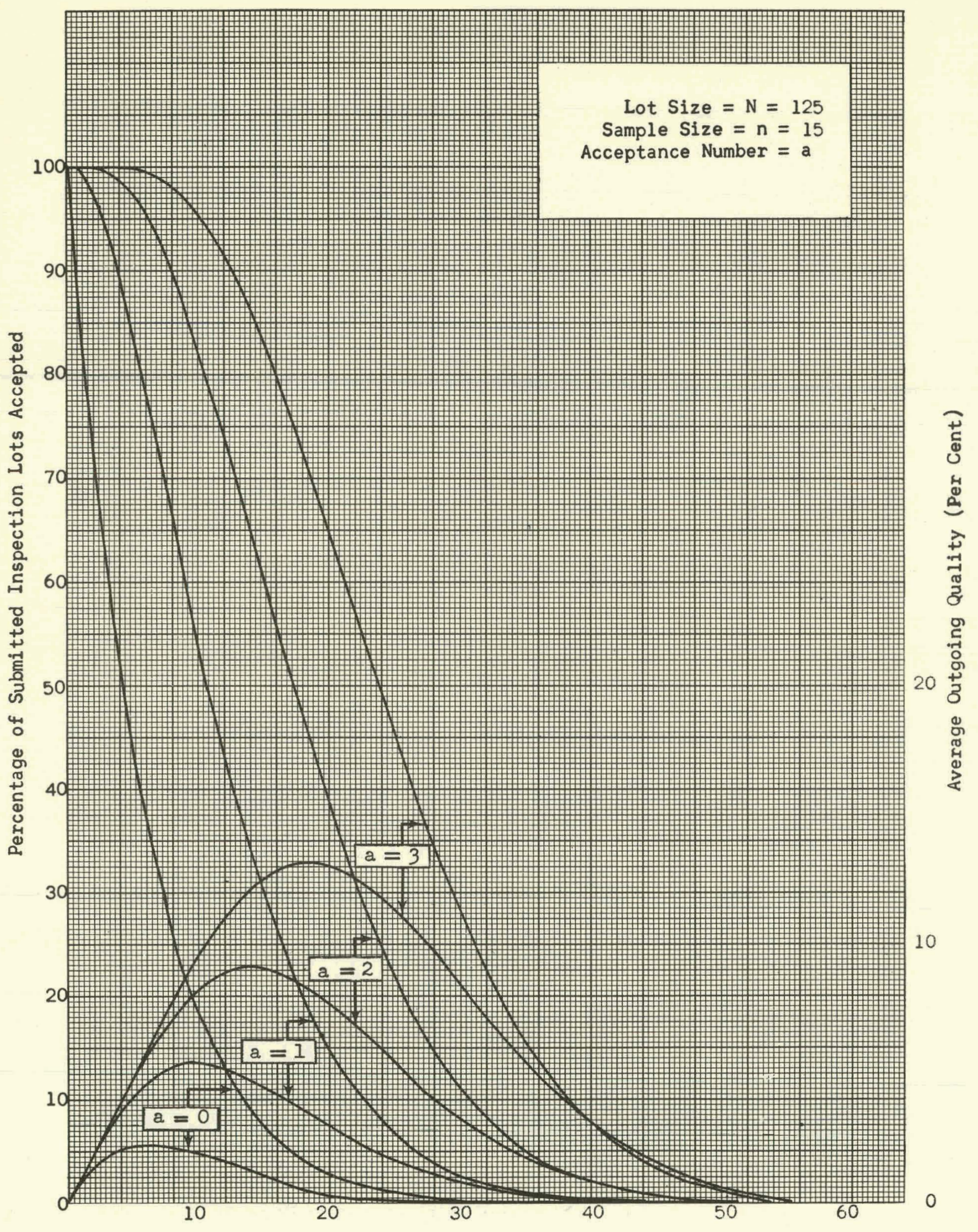

Percentage of Defective Items in Submitted Inspection Lots 


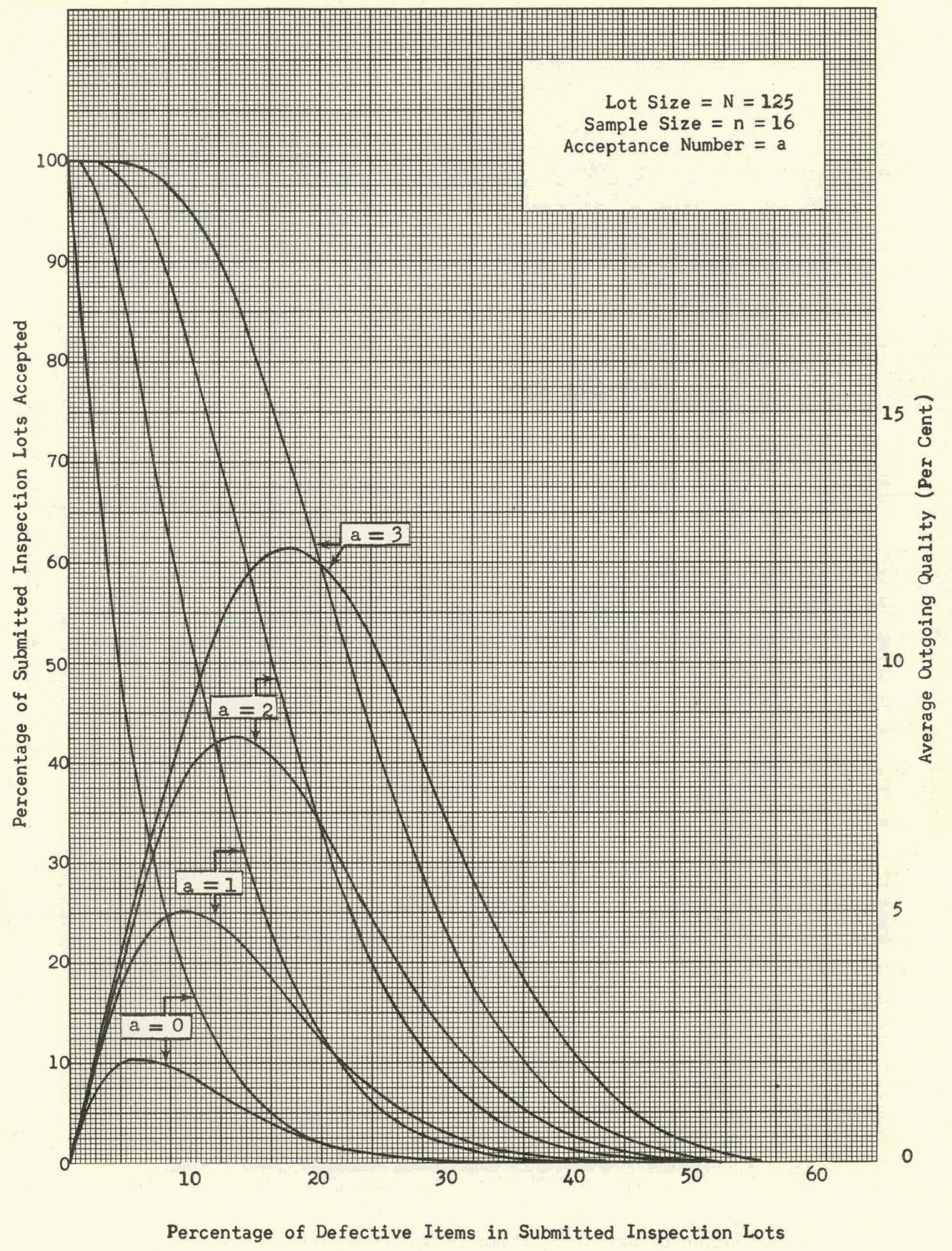




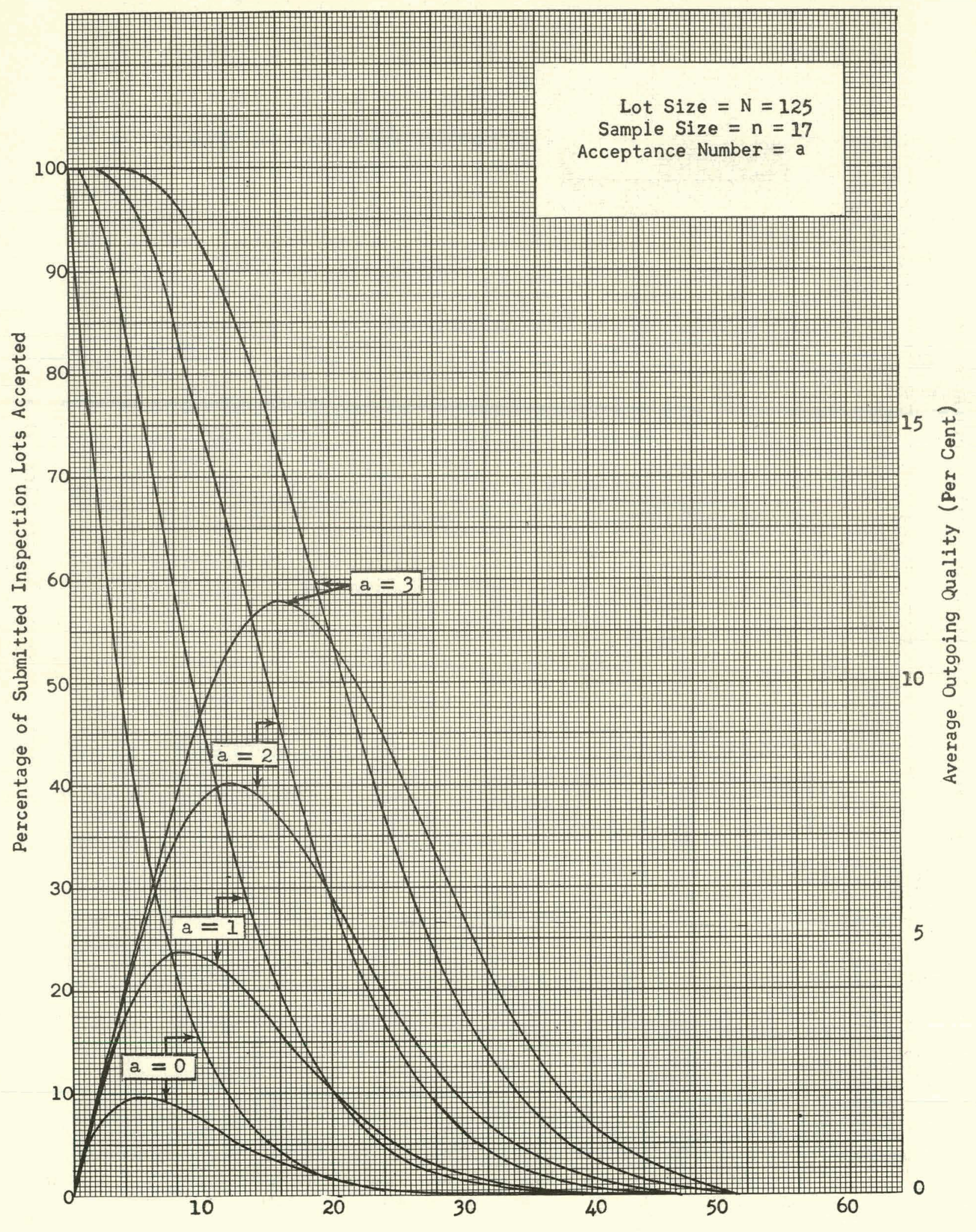

Percentage of Defective Items in Submitted Inspection Lots 


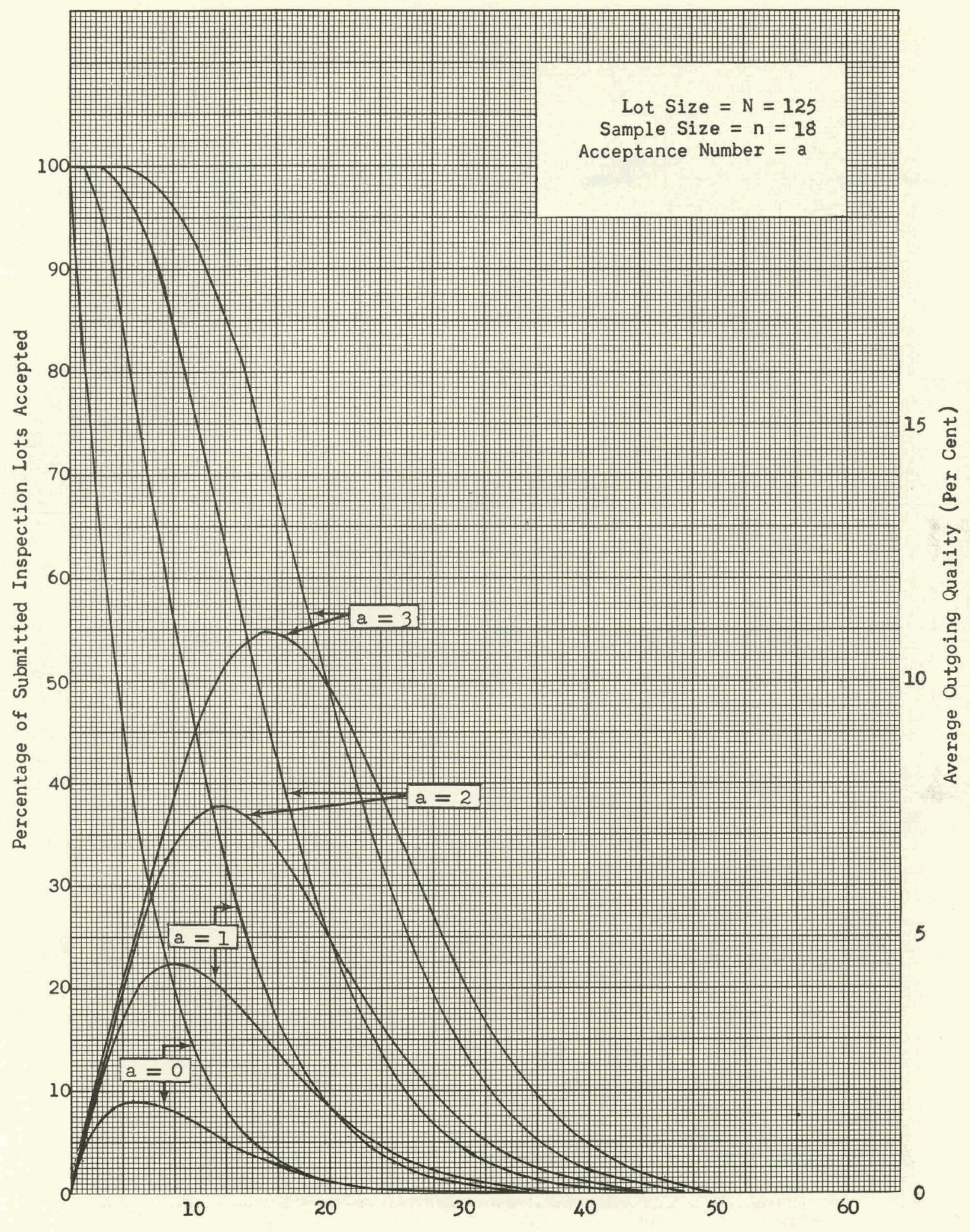

Percentage of Defective Items in Submitted Inspection Lots 


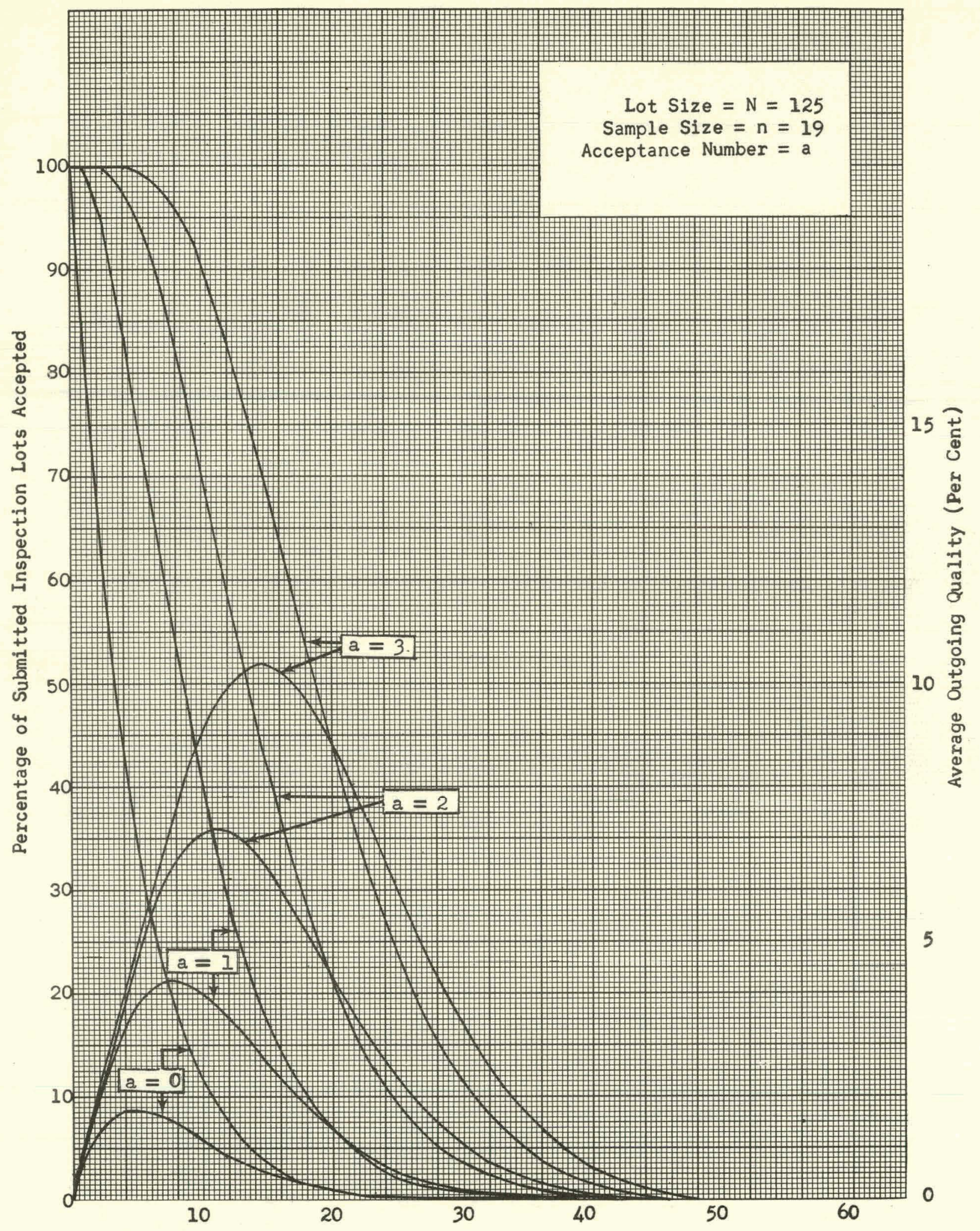

Percentage of Defective Items in Submitted Inspection Lots 


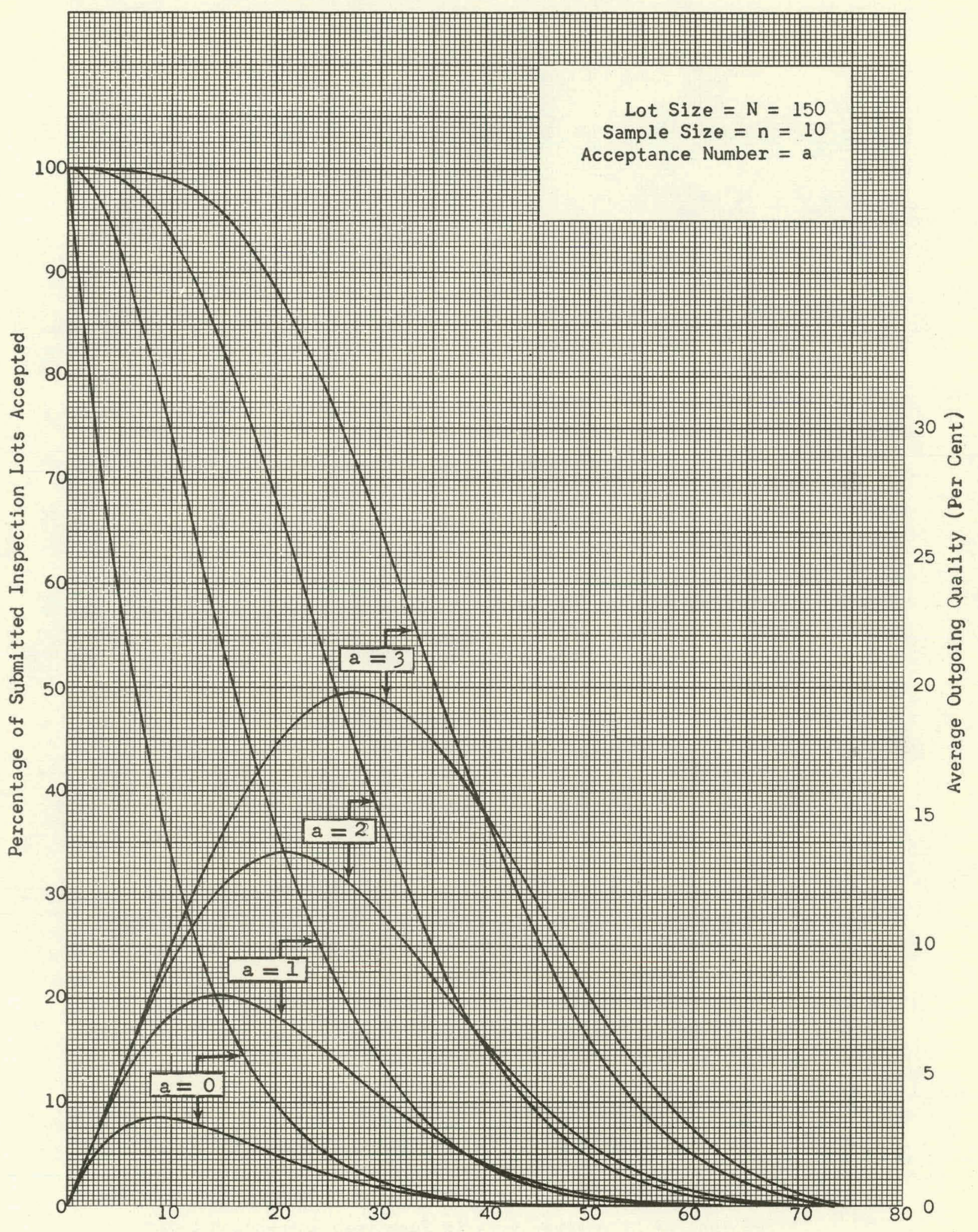

Percentage of Defective Items in Submitted Inspection Lots 


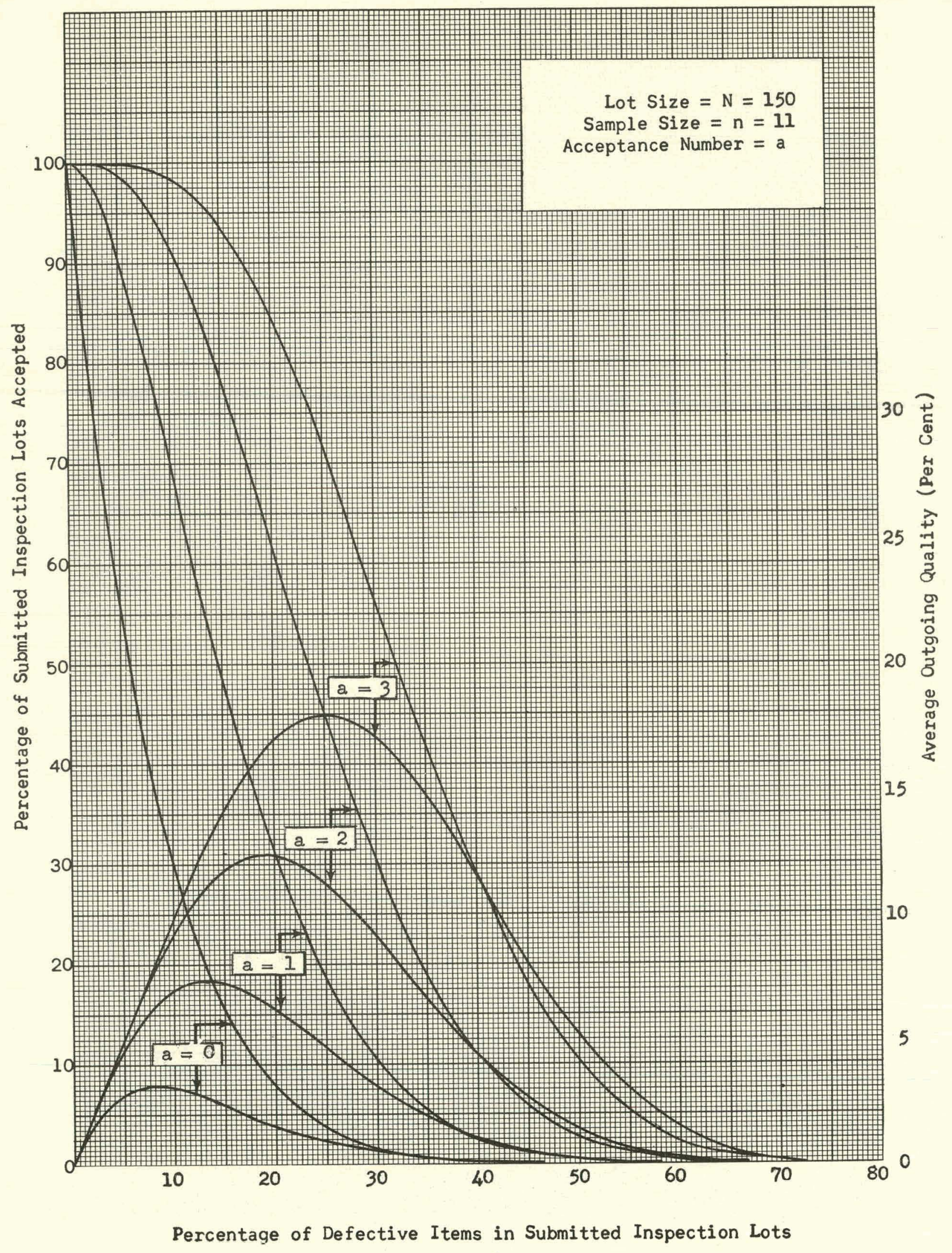




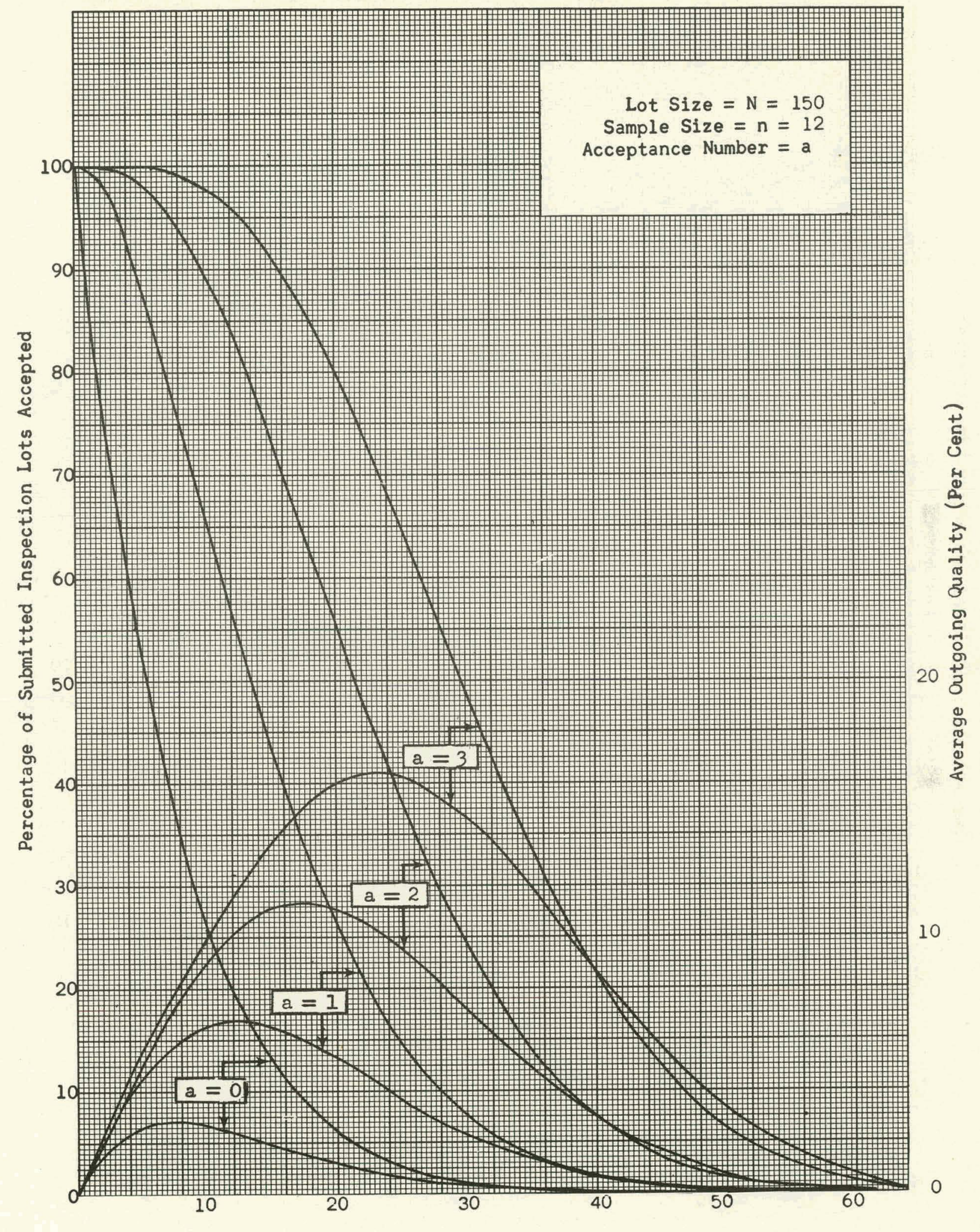

Percentage of Defective Items in Submitted Inspection Lots 


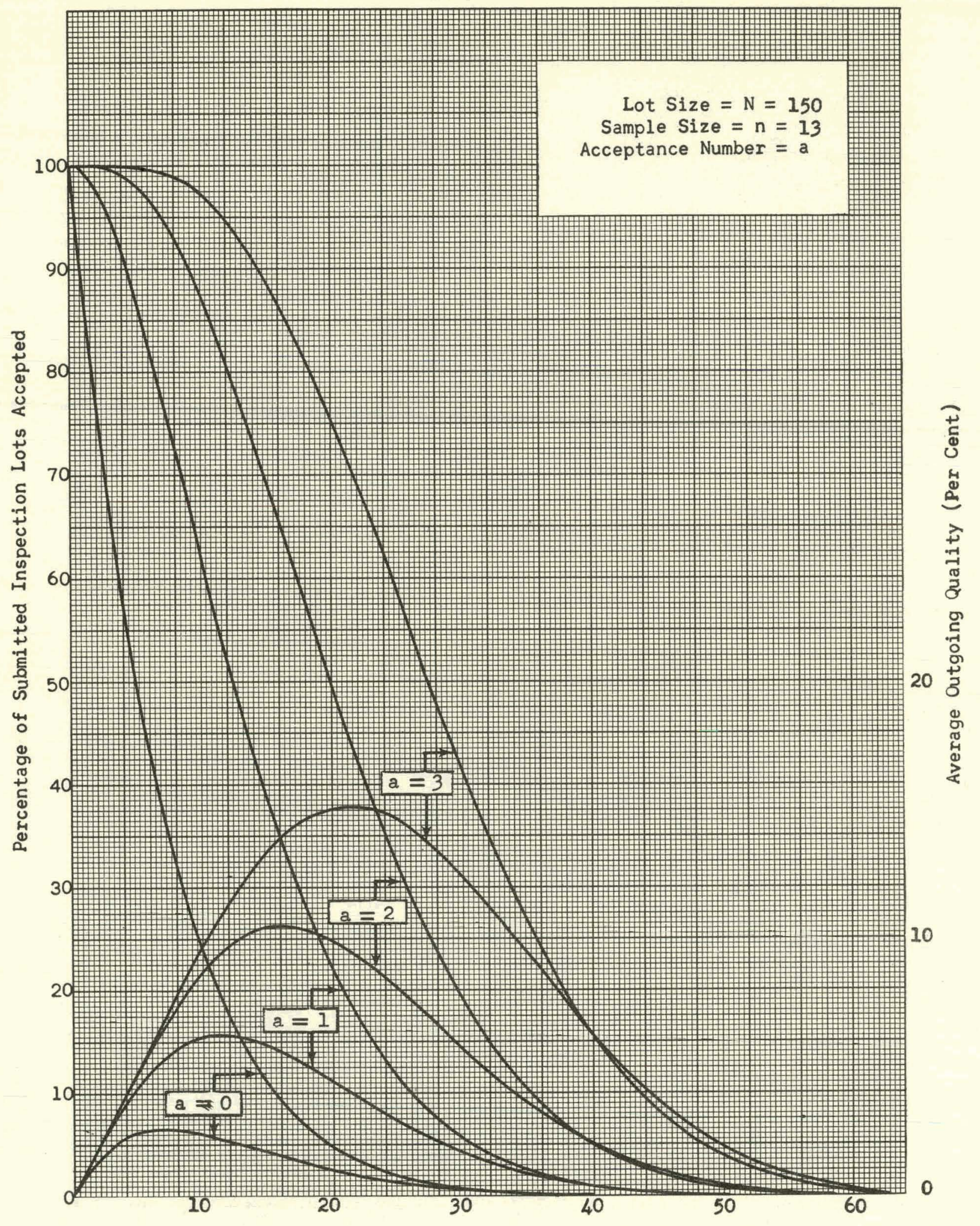

Percentage of Defective Items in Submitted Inspection Lots 


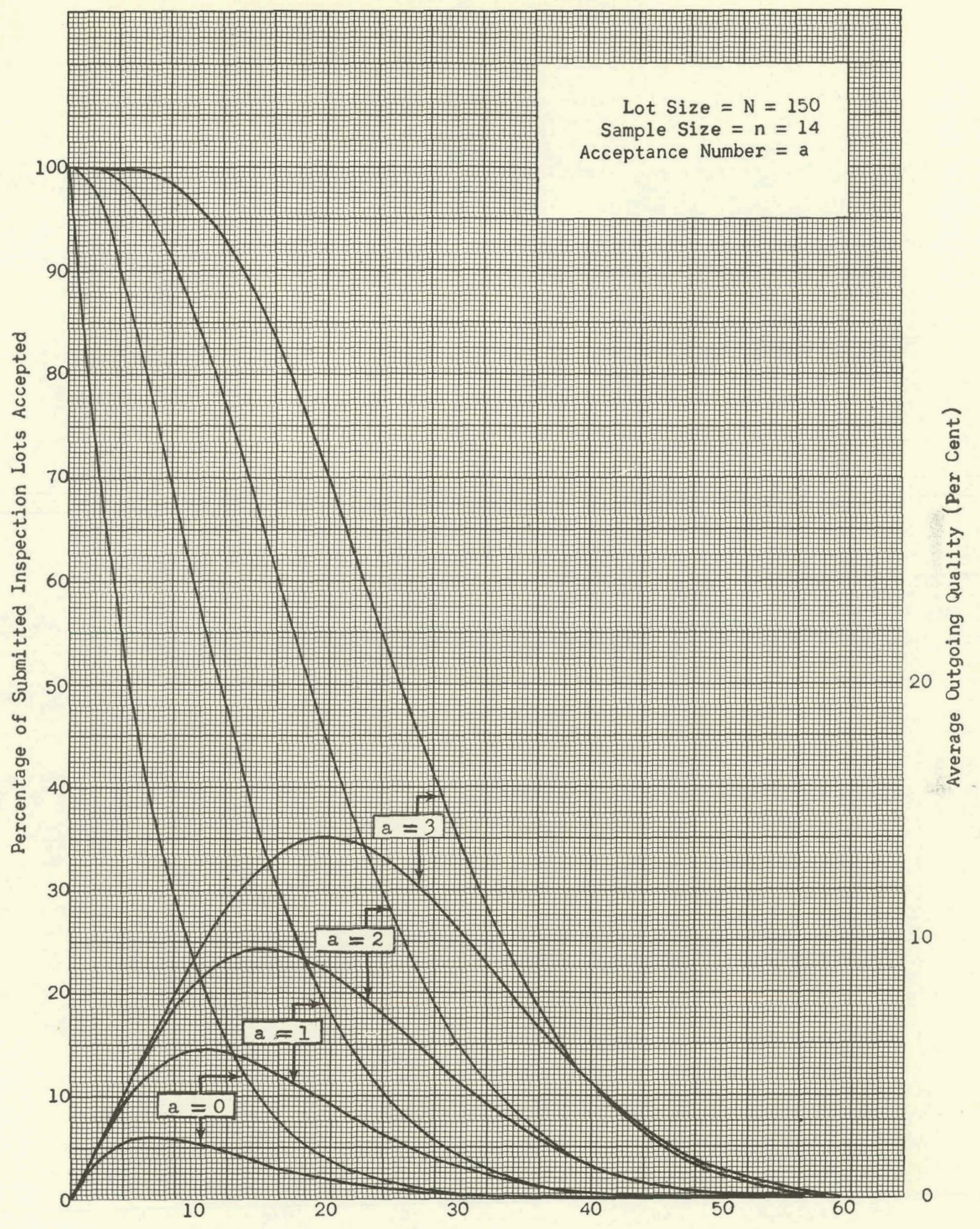

Percentage of Defective Items in Submitted Inspection Lots 


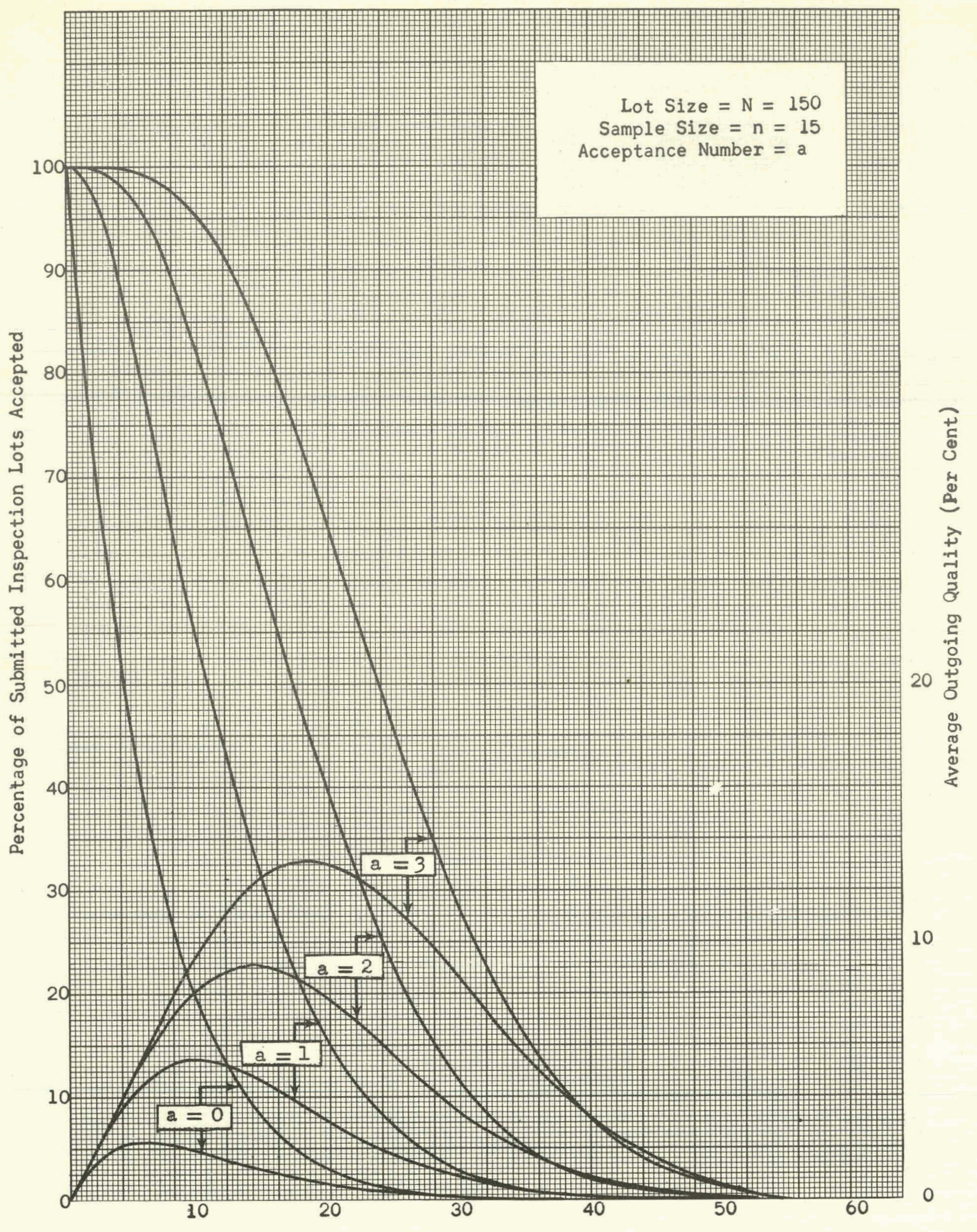

Percentage of Defective Items in Submitted Inspection Lots 


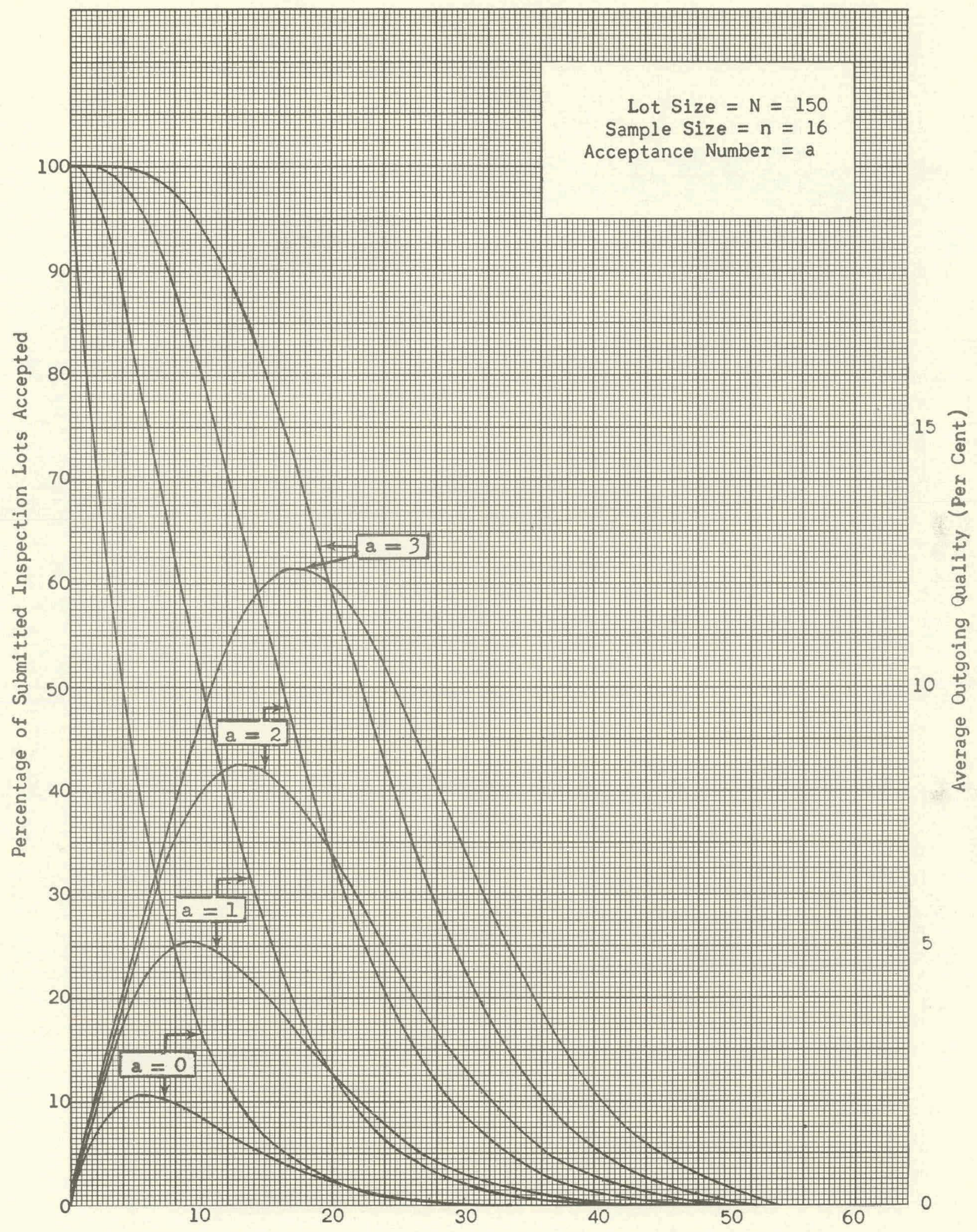

Percentage of Defective Items in Submitted Inspection Lots 


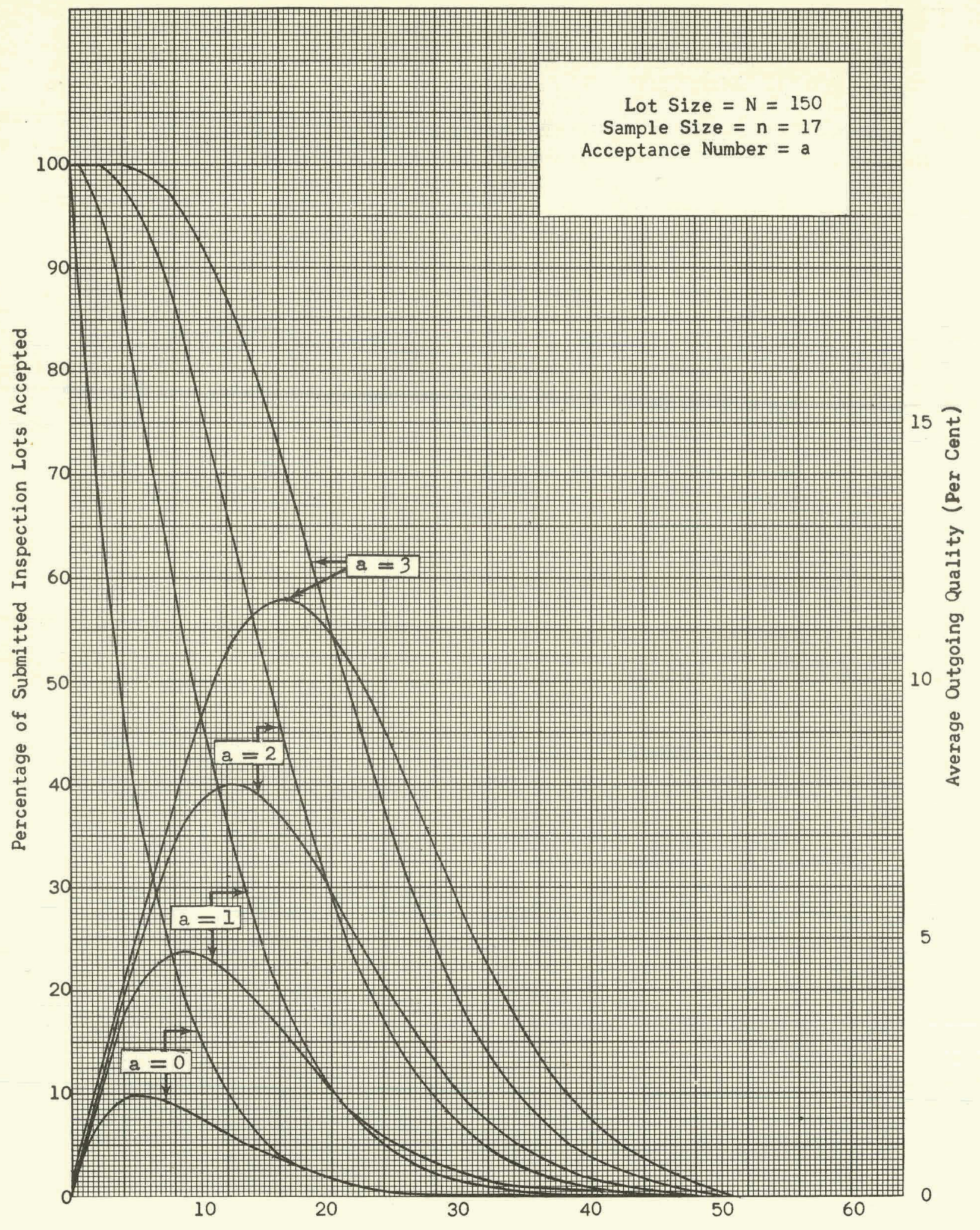

Percentage of Defective Items in Submitted Inspection Lots 


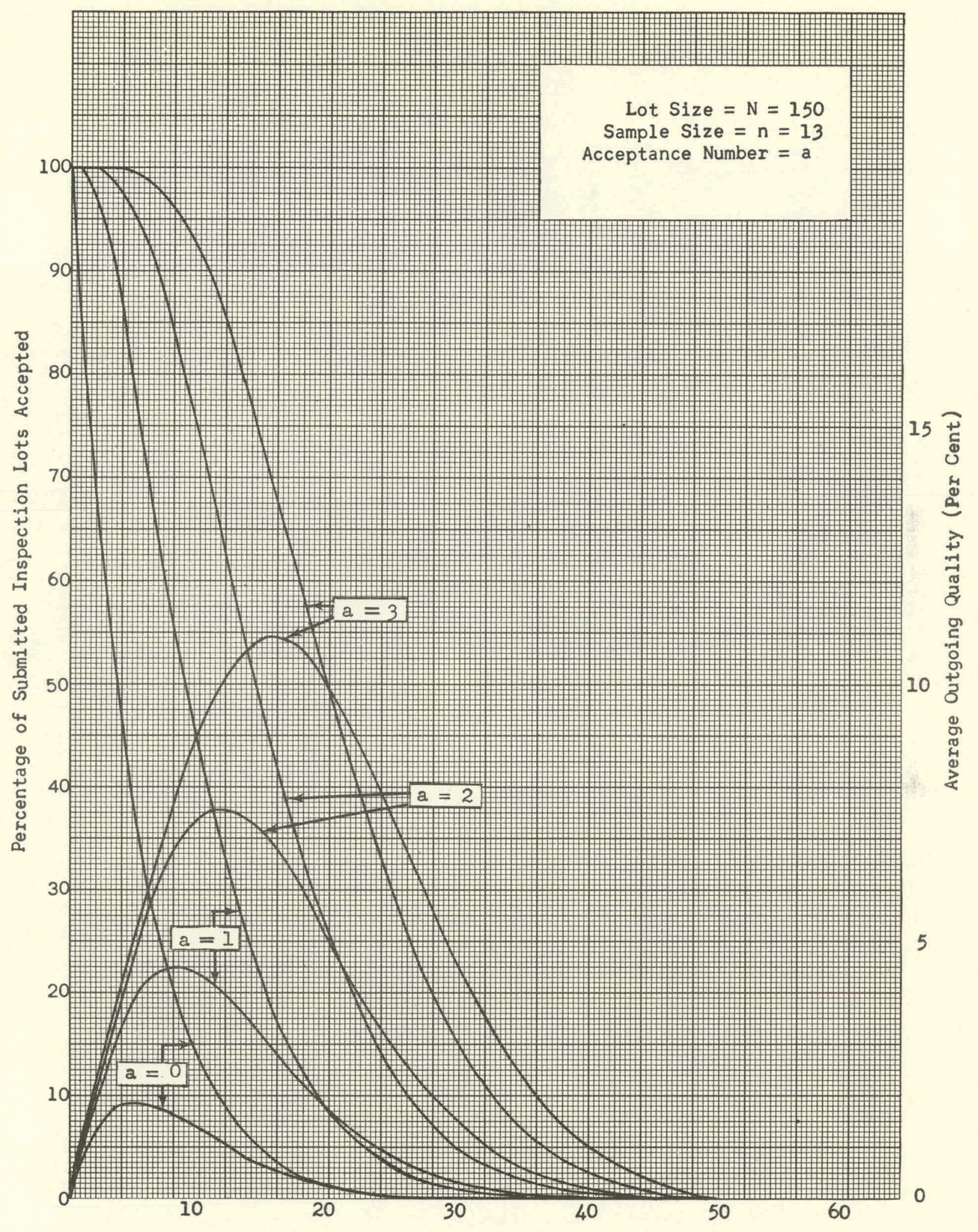

Percentage of Defective Items in Submitted Inspection Lots 


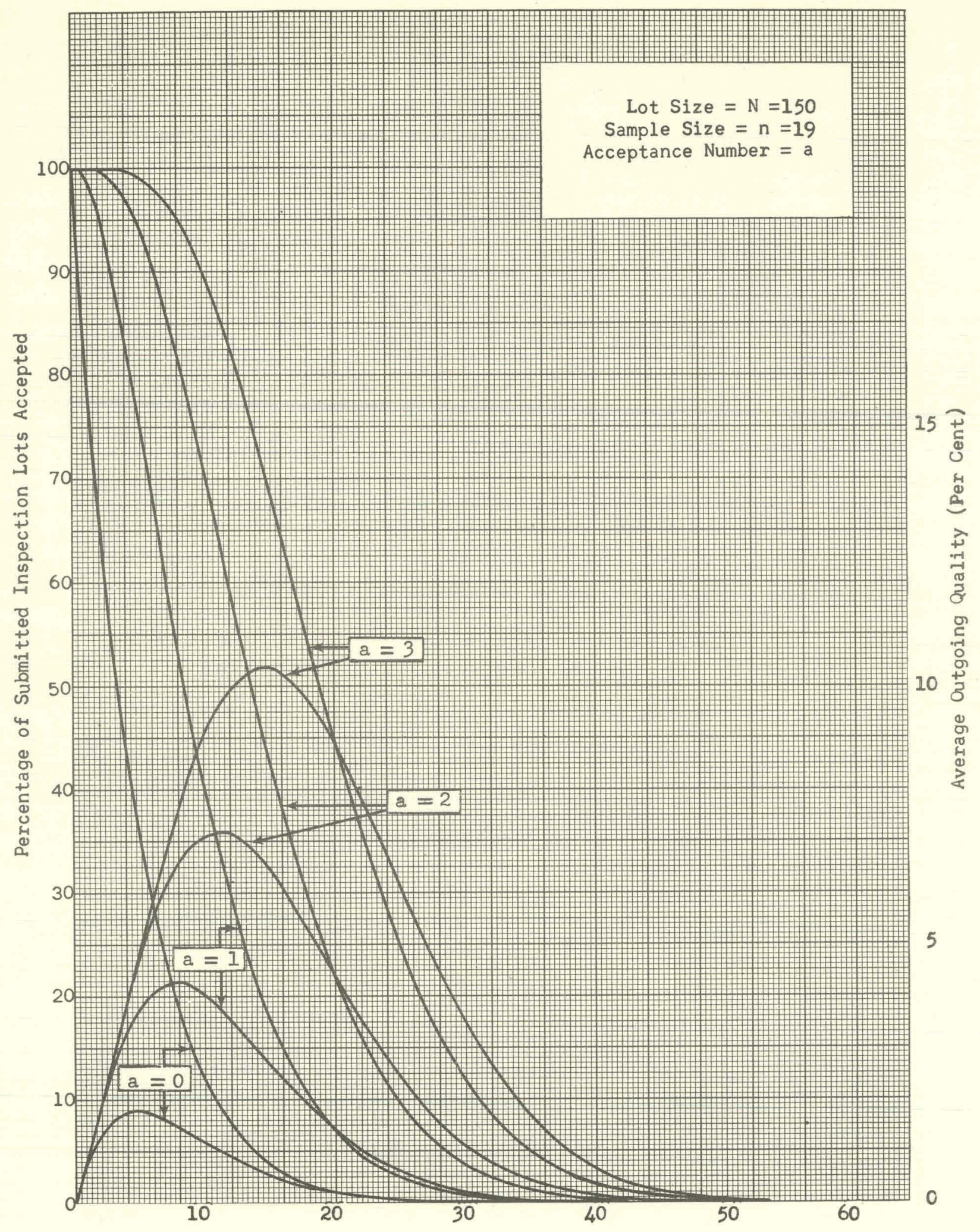

Percentage of Defective Items in Submitted Inspection Lots 


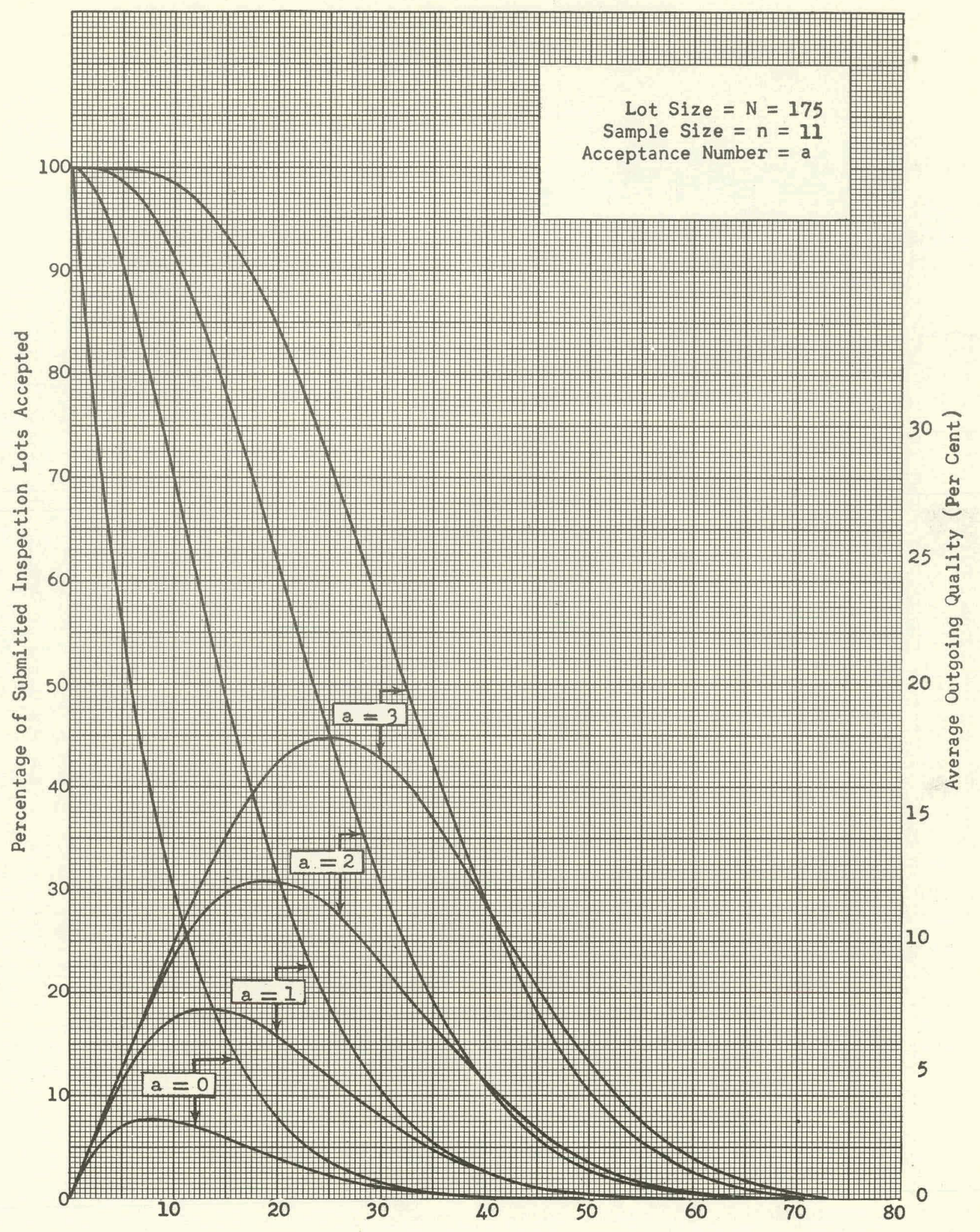

Percentage of Defective Items in Submitted Inspection Lots 


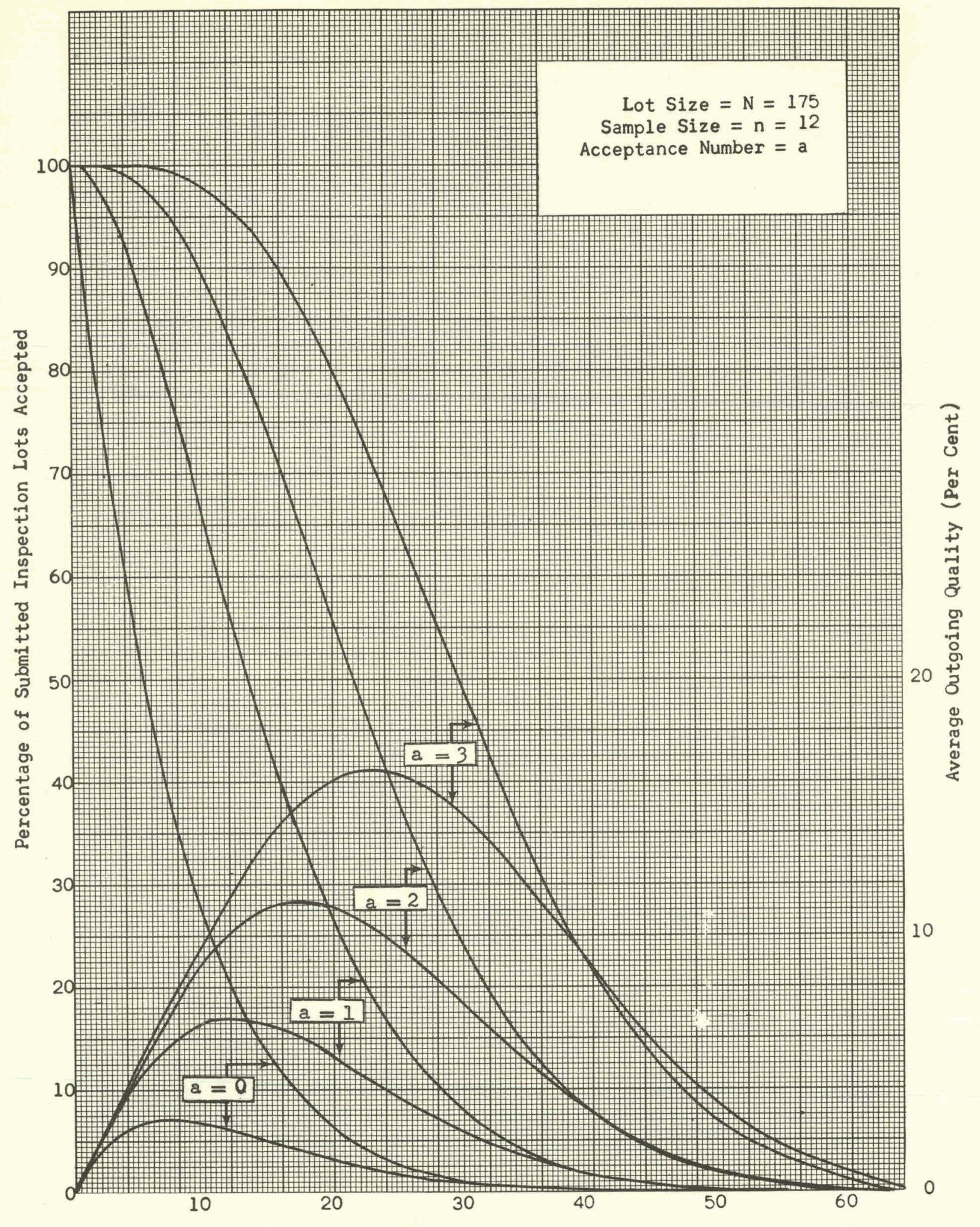

Percentage of Defective Items in Submitted Inspection Lots 


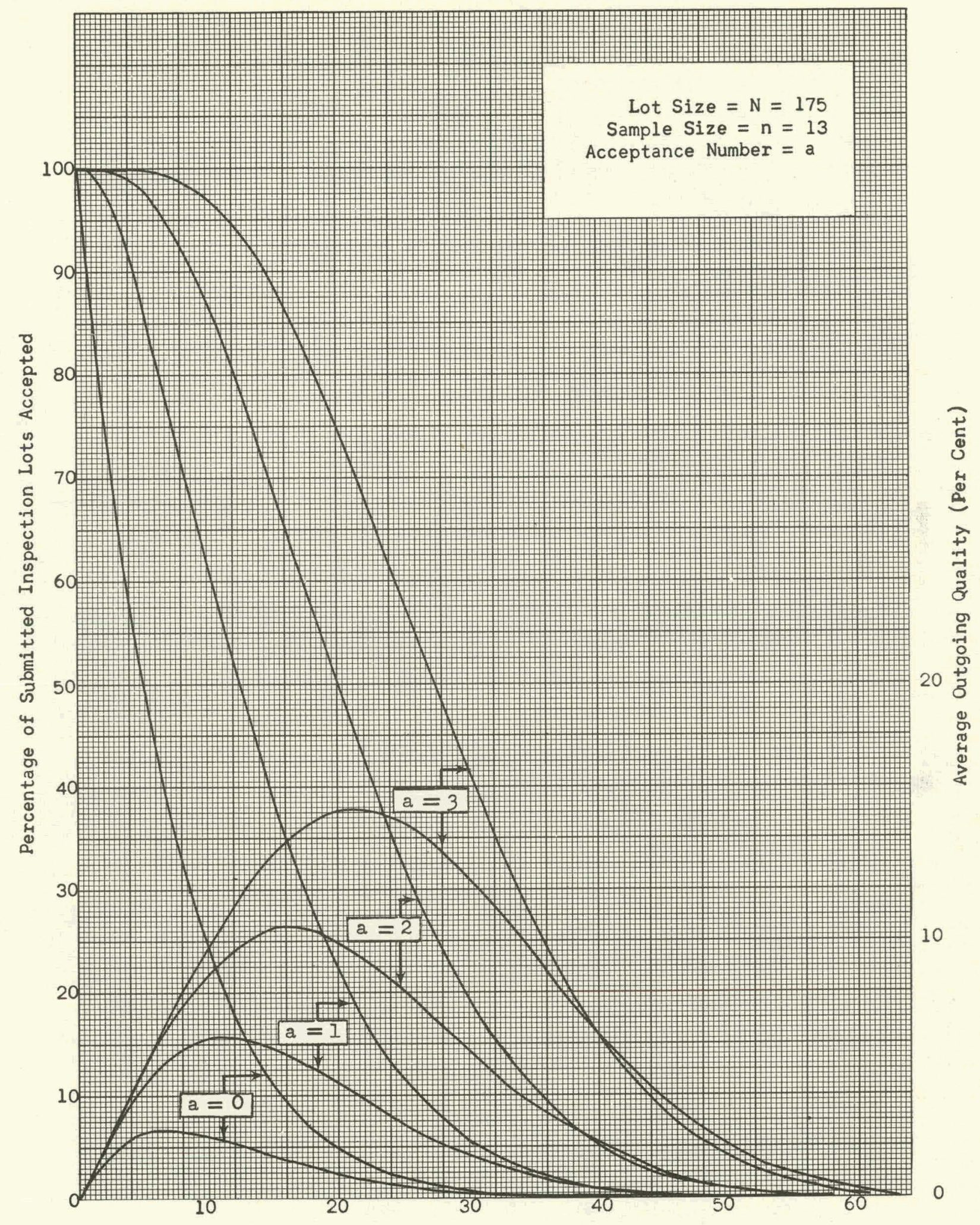

Percentage of Defective Items in Submitted Inspection Lots 


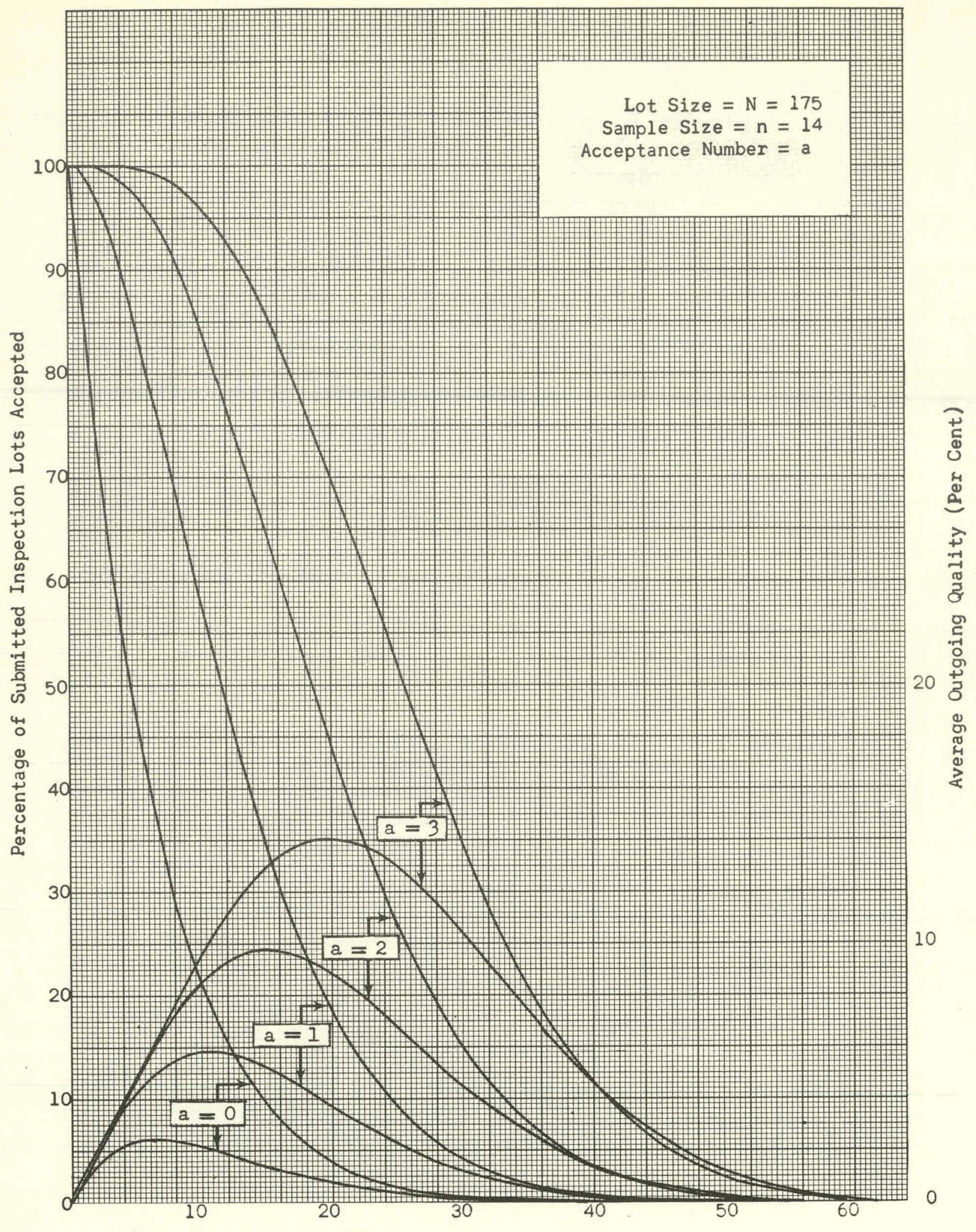

Percentage of Defective Items in Submitted Inspection Lots 


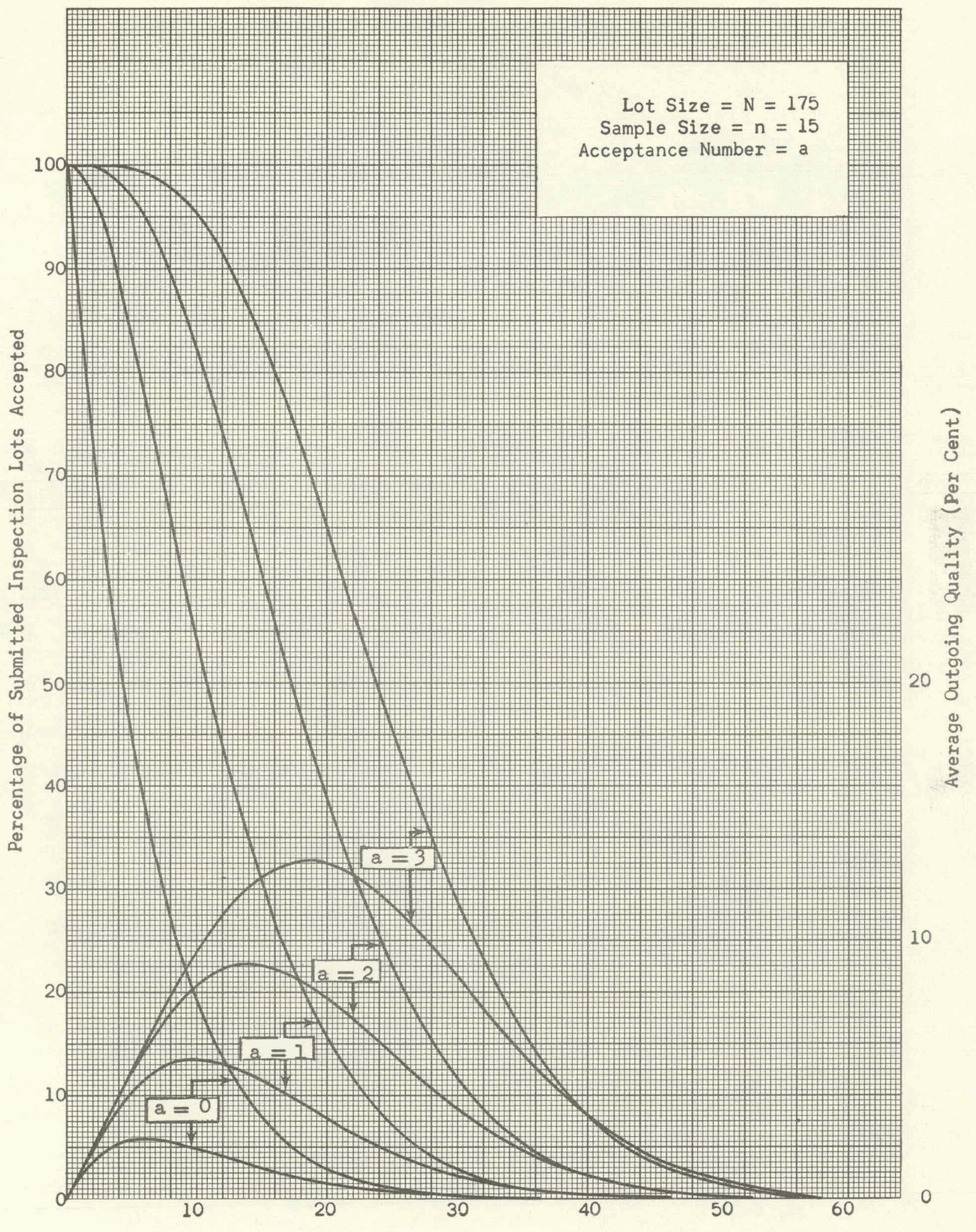

Percentage of Defective Items in Submitted Inspection Lots 


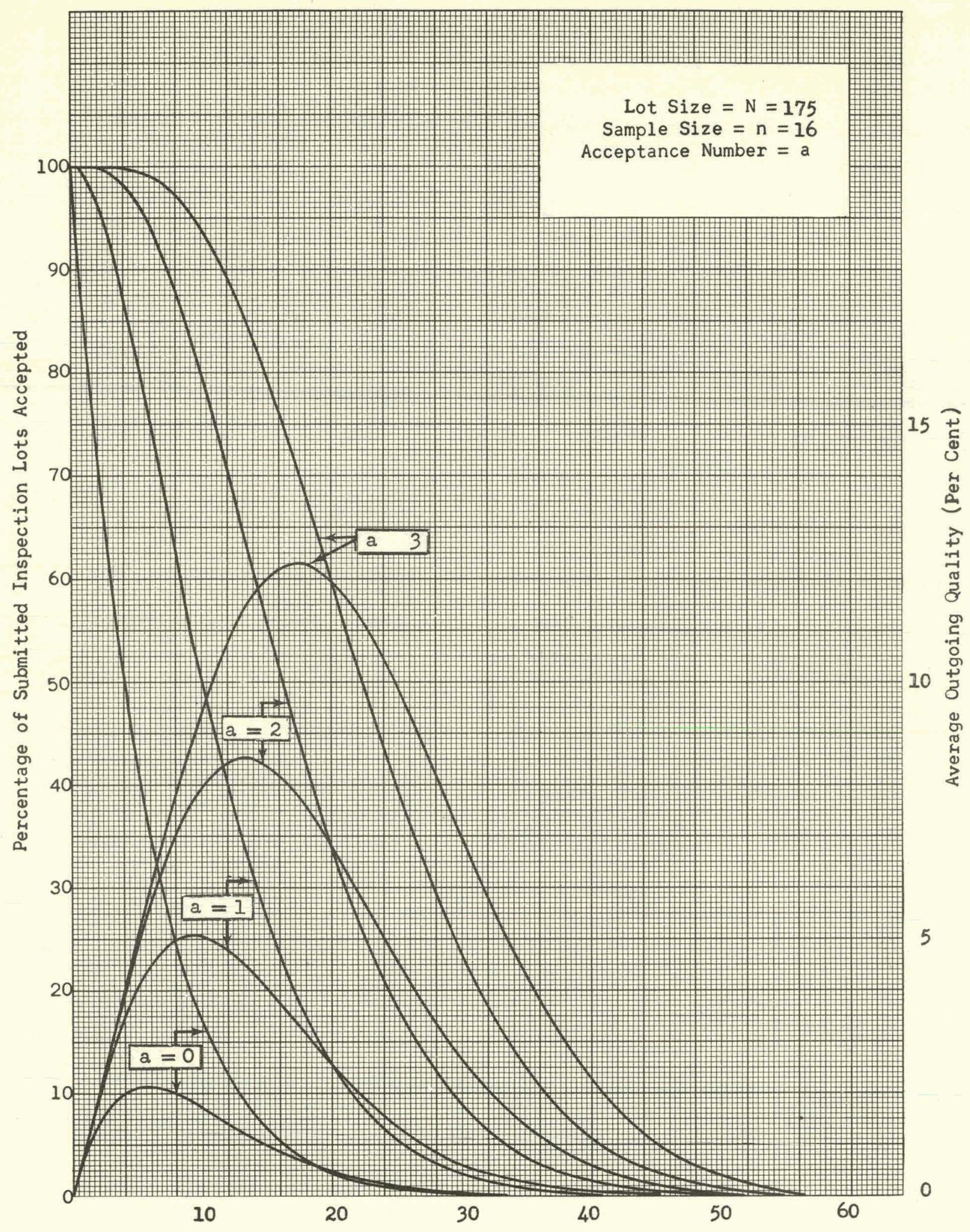

Percentage of Defective Items in Submitted Inspection Lots 


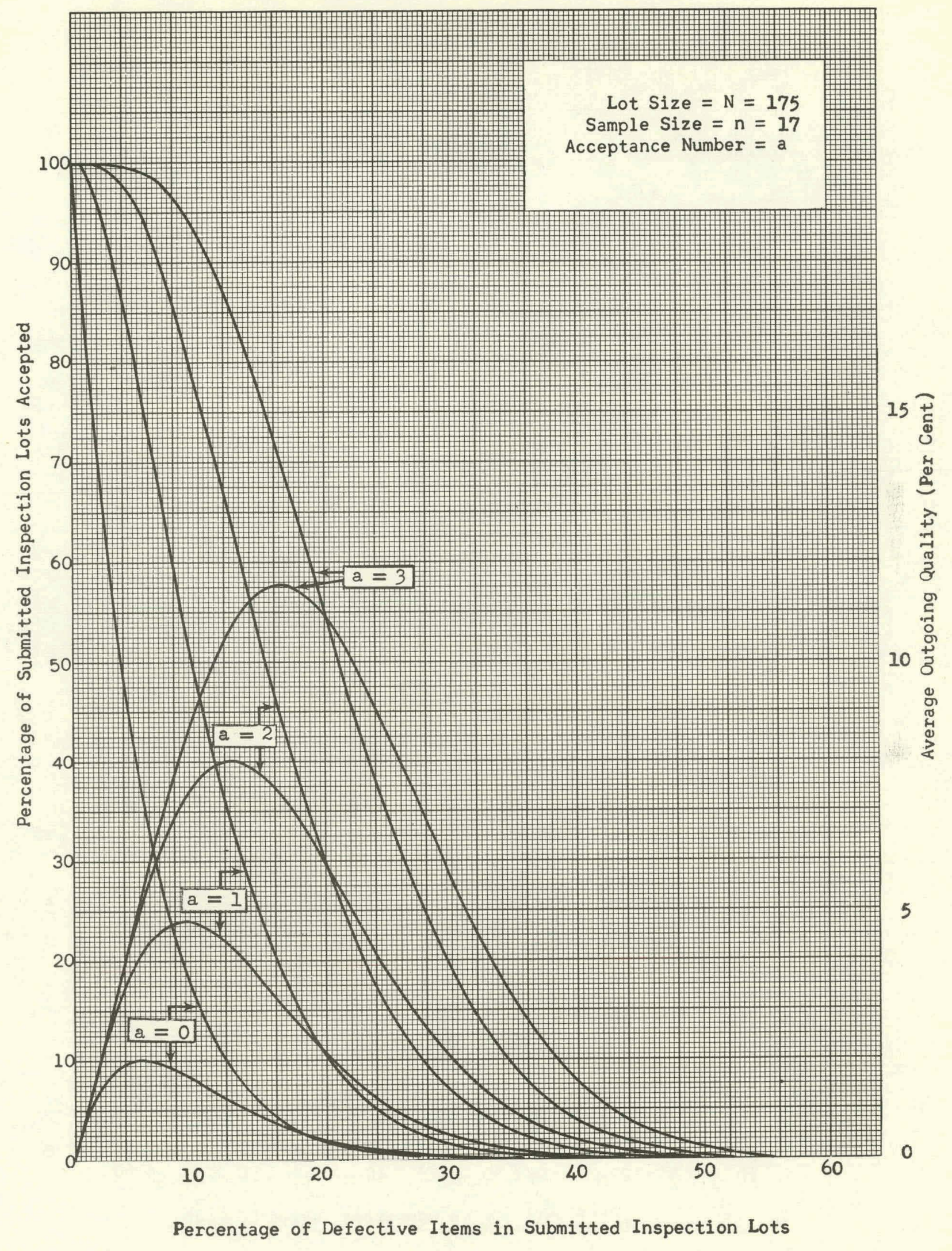




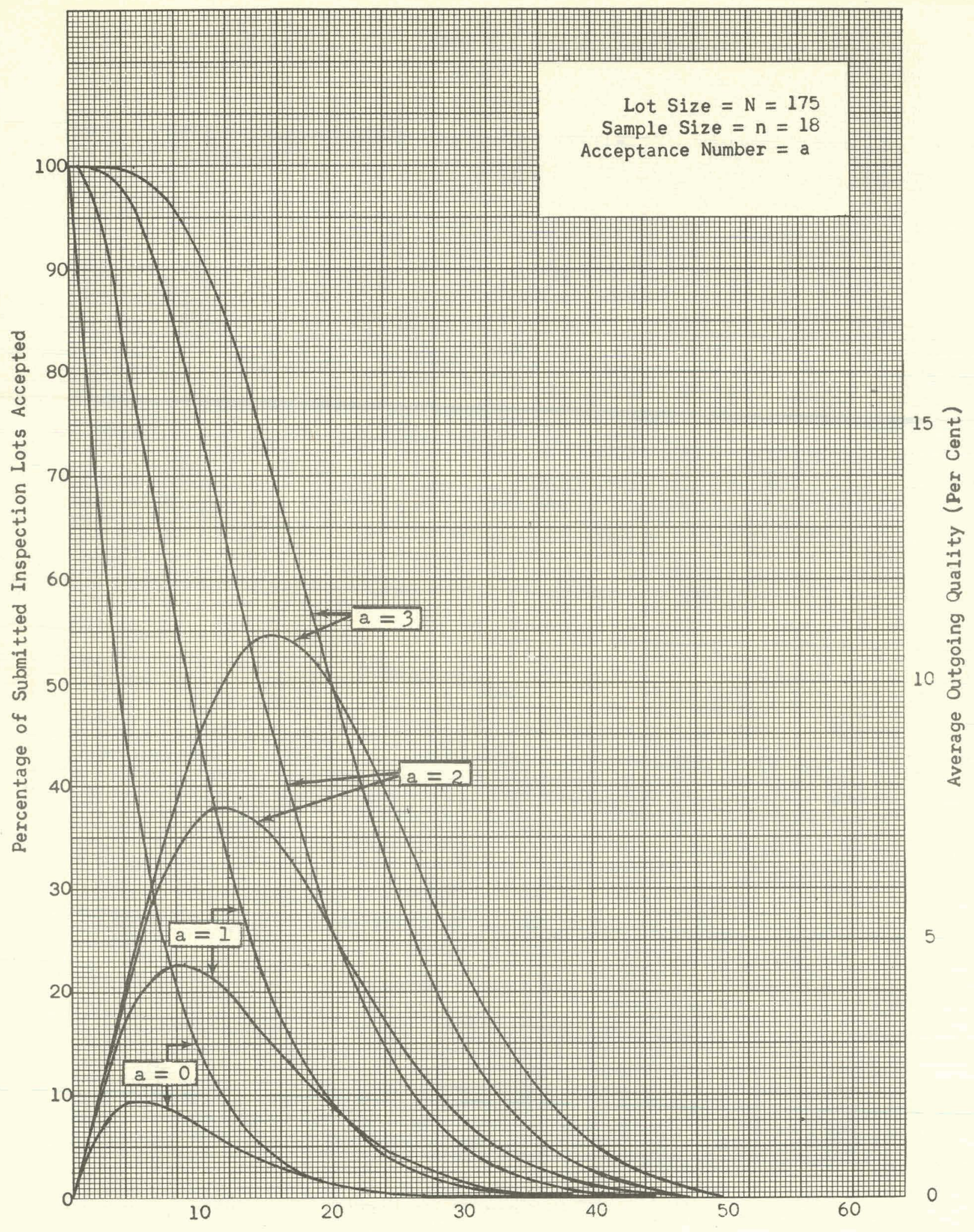

Percentage of Defective Items in Submitted Inspection Lots 


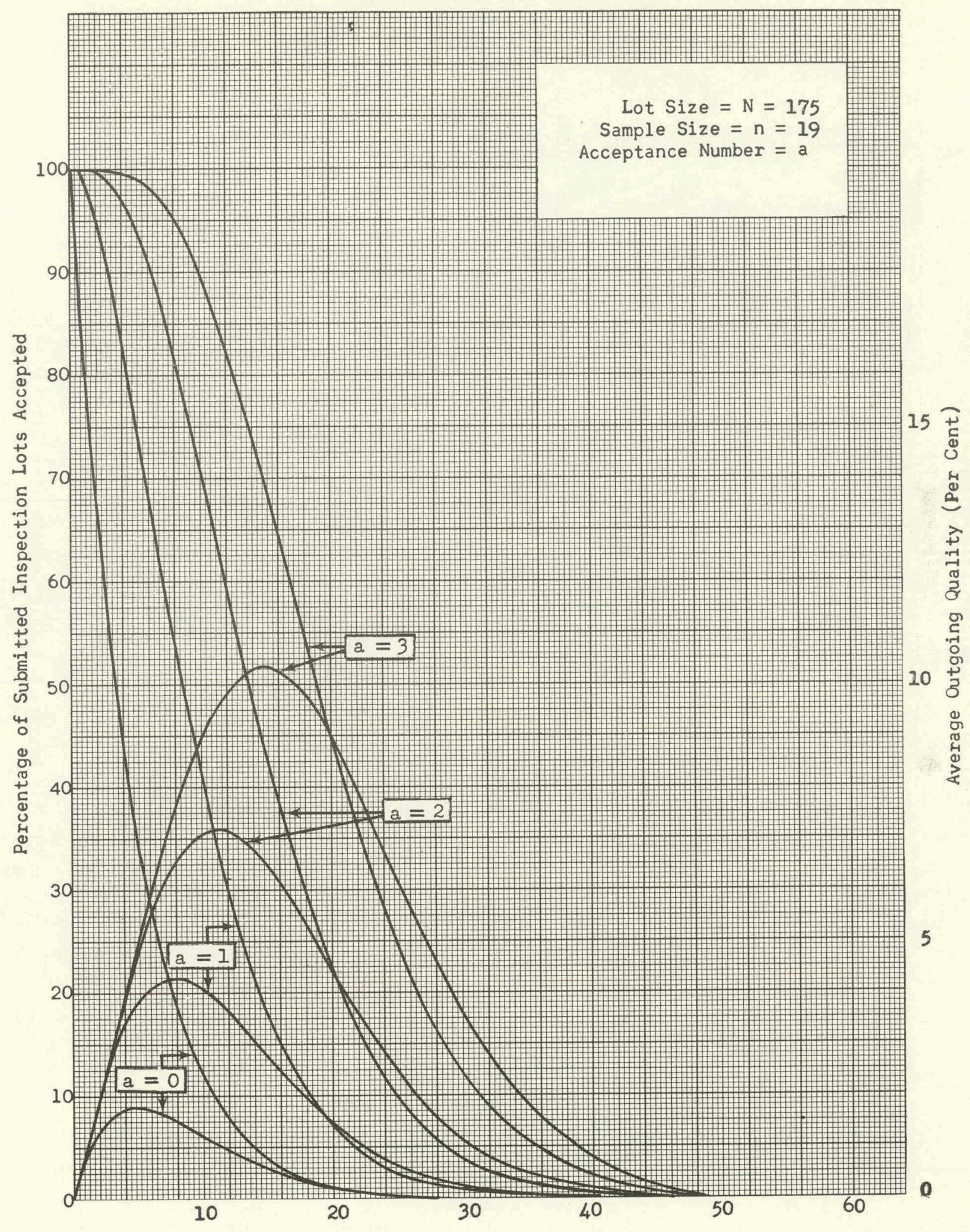

Percentage of Defective Items in Submitted Inspection Lots 


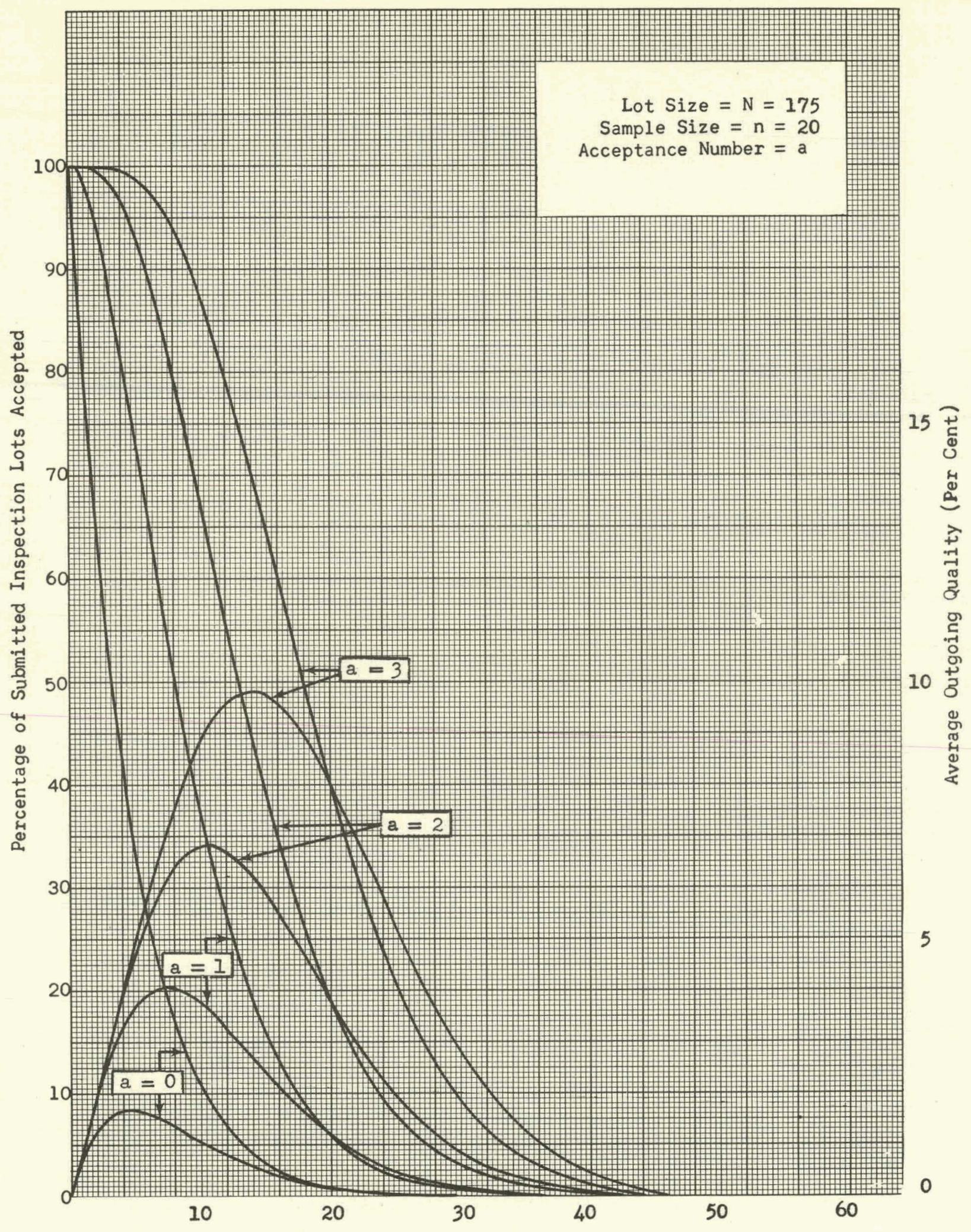

Percentage of Defective Items in Submitted Inspection Lots 


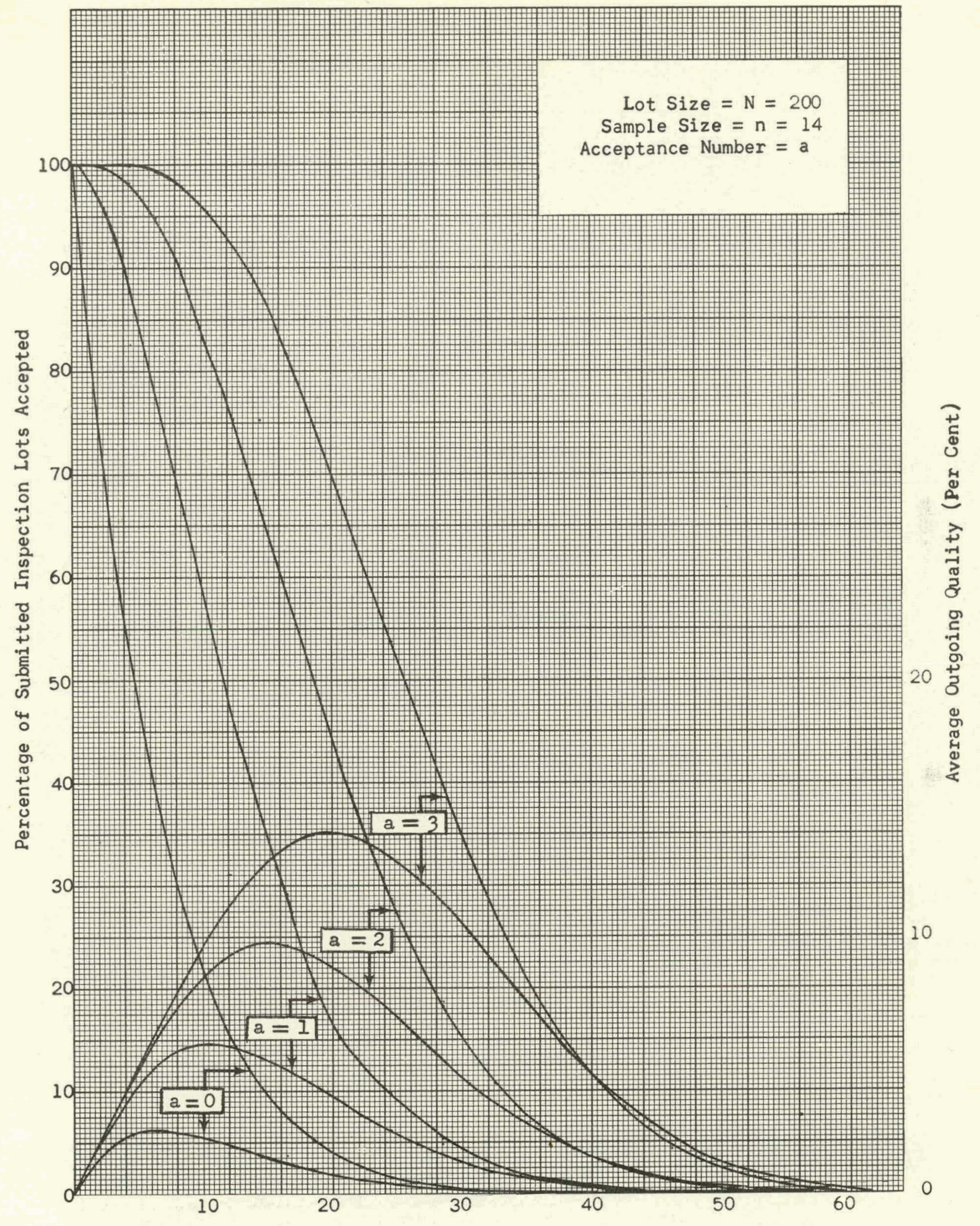

Percentage of Defective Items in Submitted Inspection Lots 


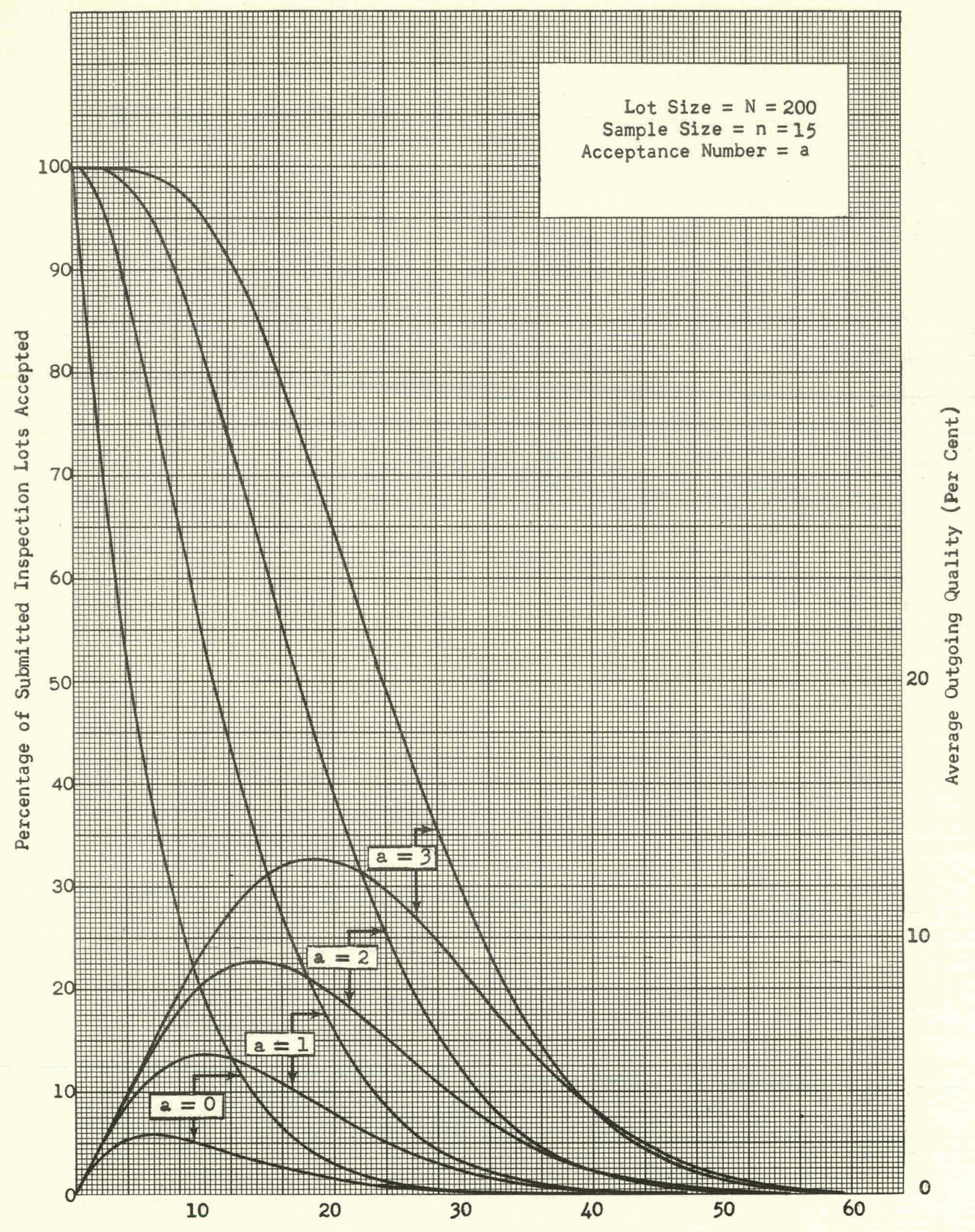

Percentage of Defective Items in Submitted Inspection Lots 


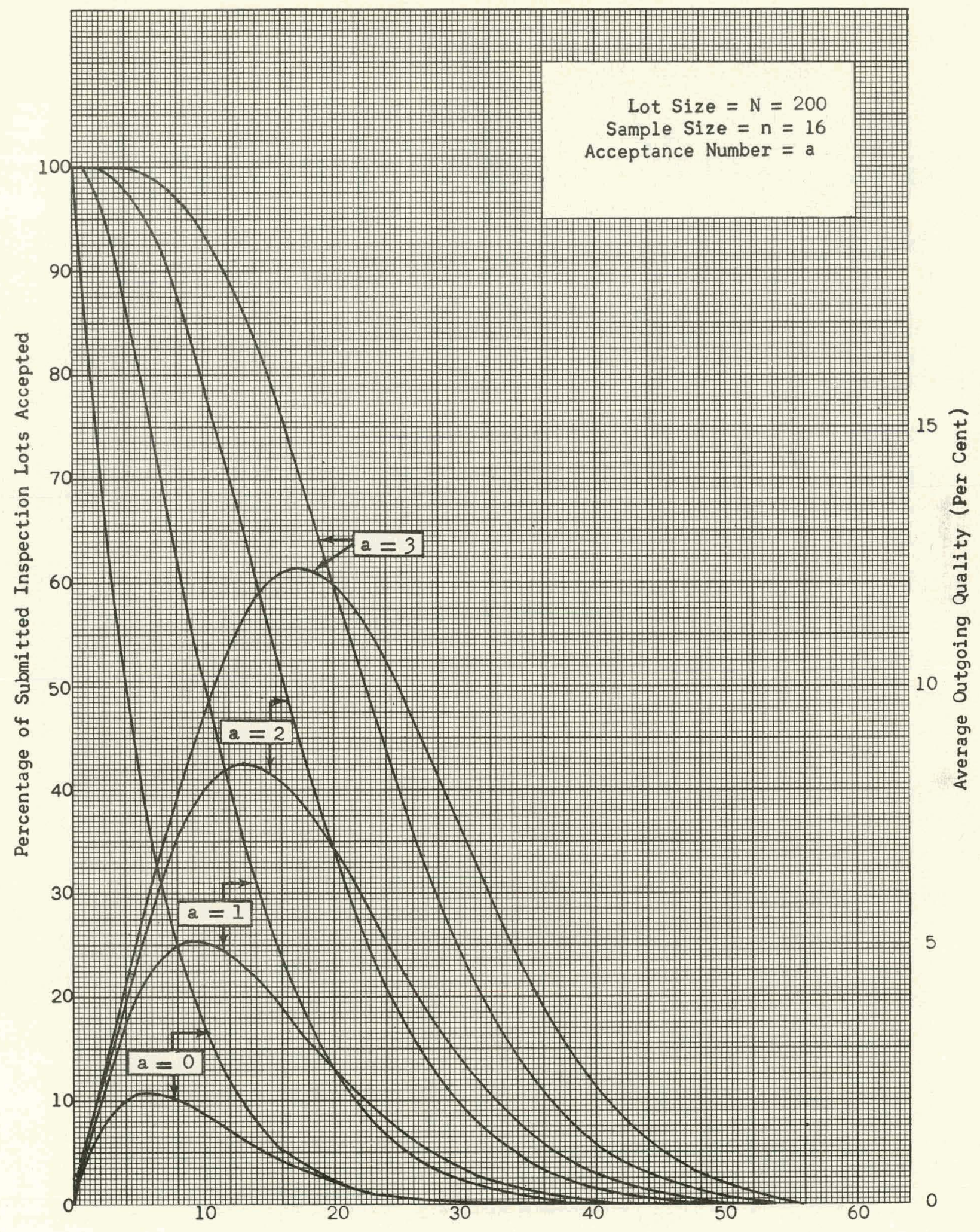

Percentage of Defective Items in Submitted Inspection Lots 


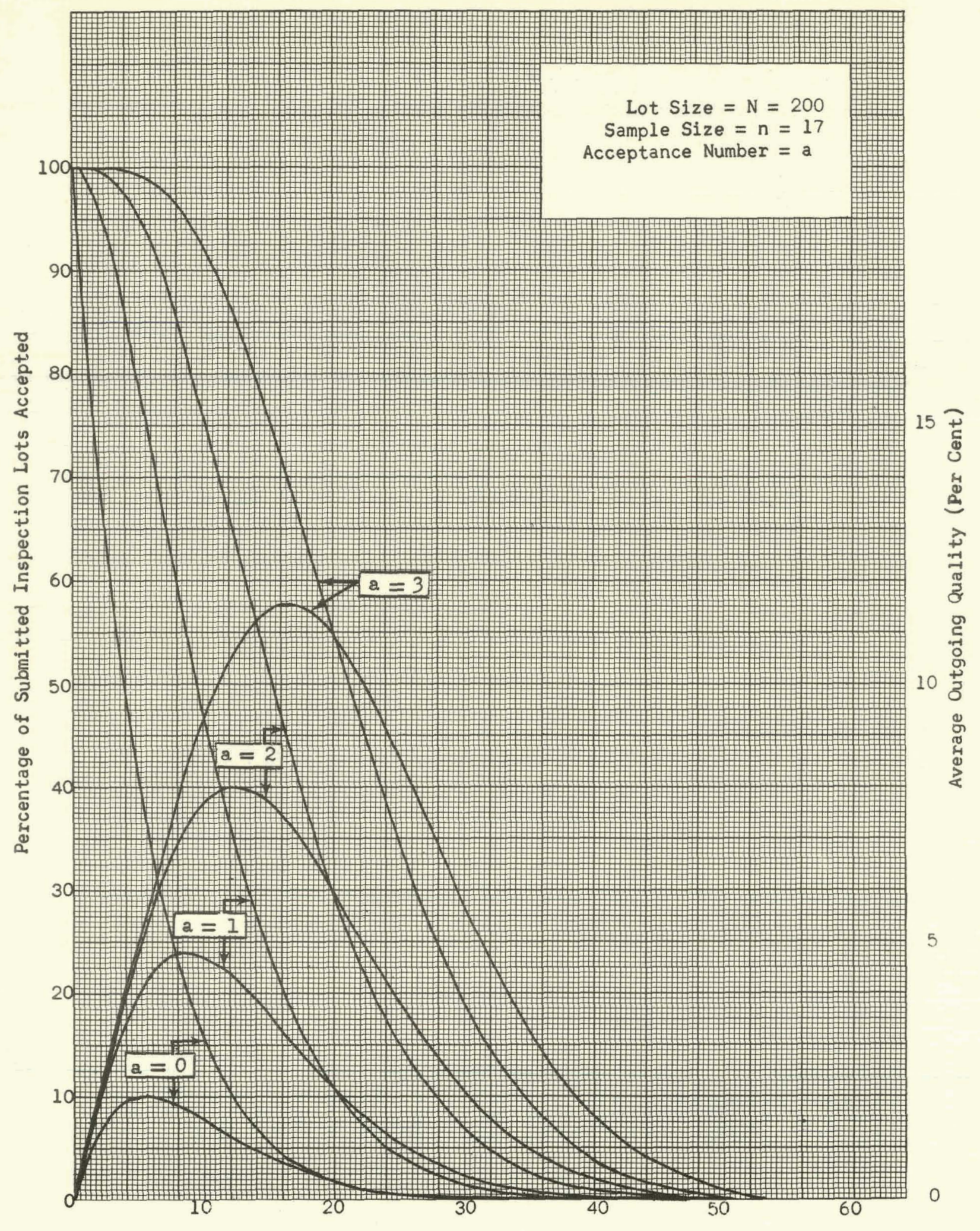

Percentage of Defective Items in Submitted Inspection Lots 


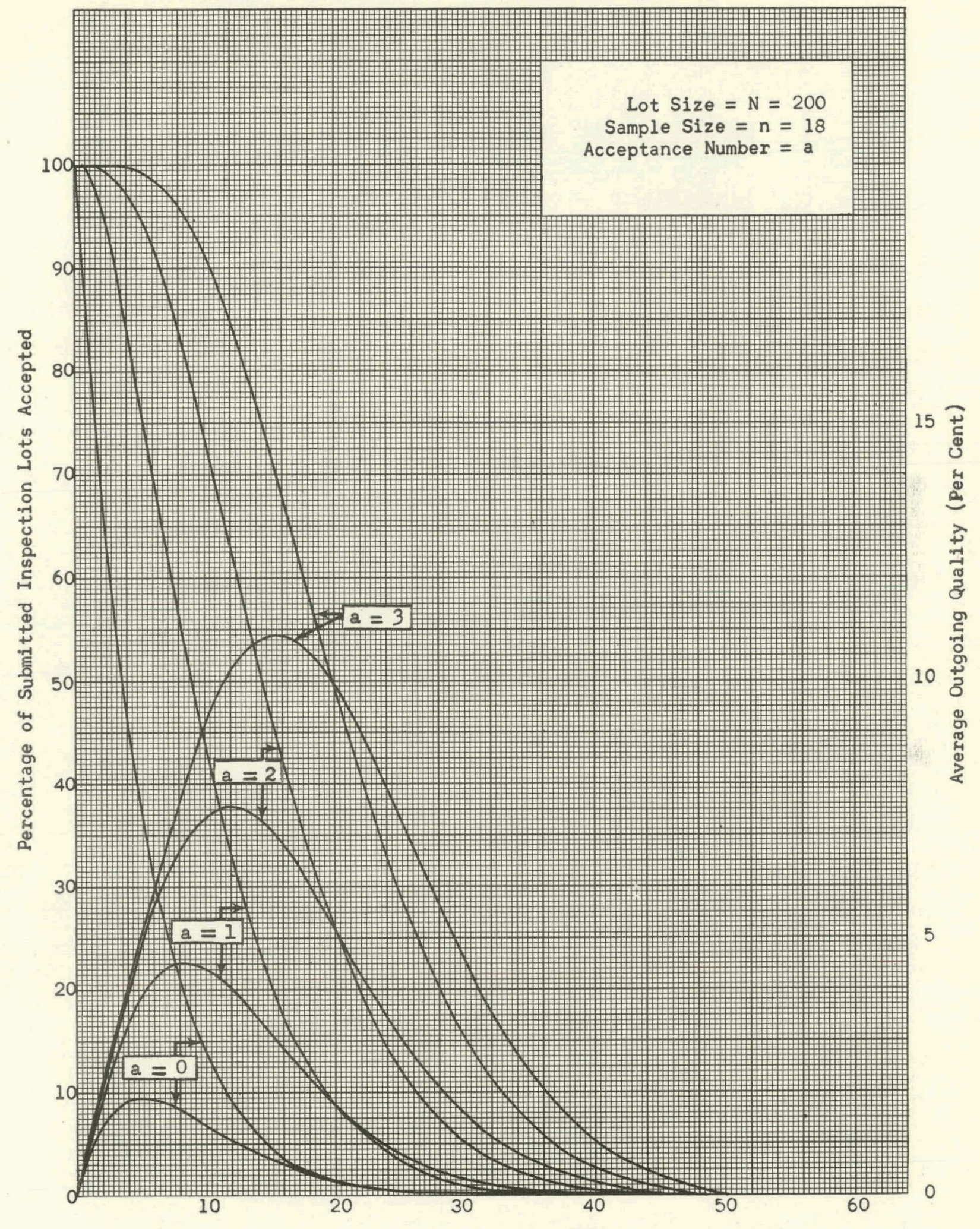

Percentage of Defective Items in Submitted Inspection Lots 


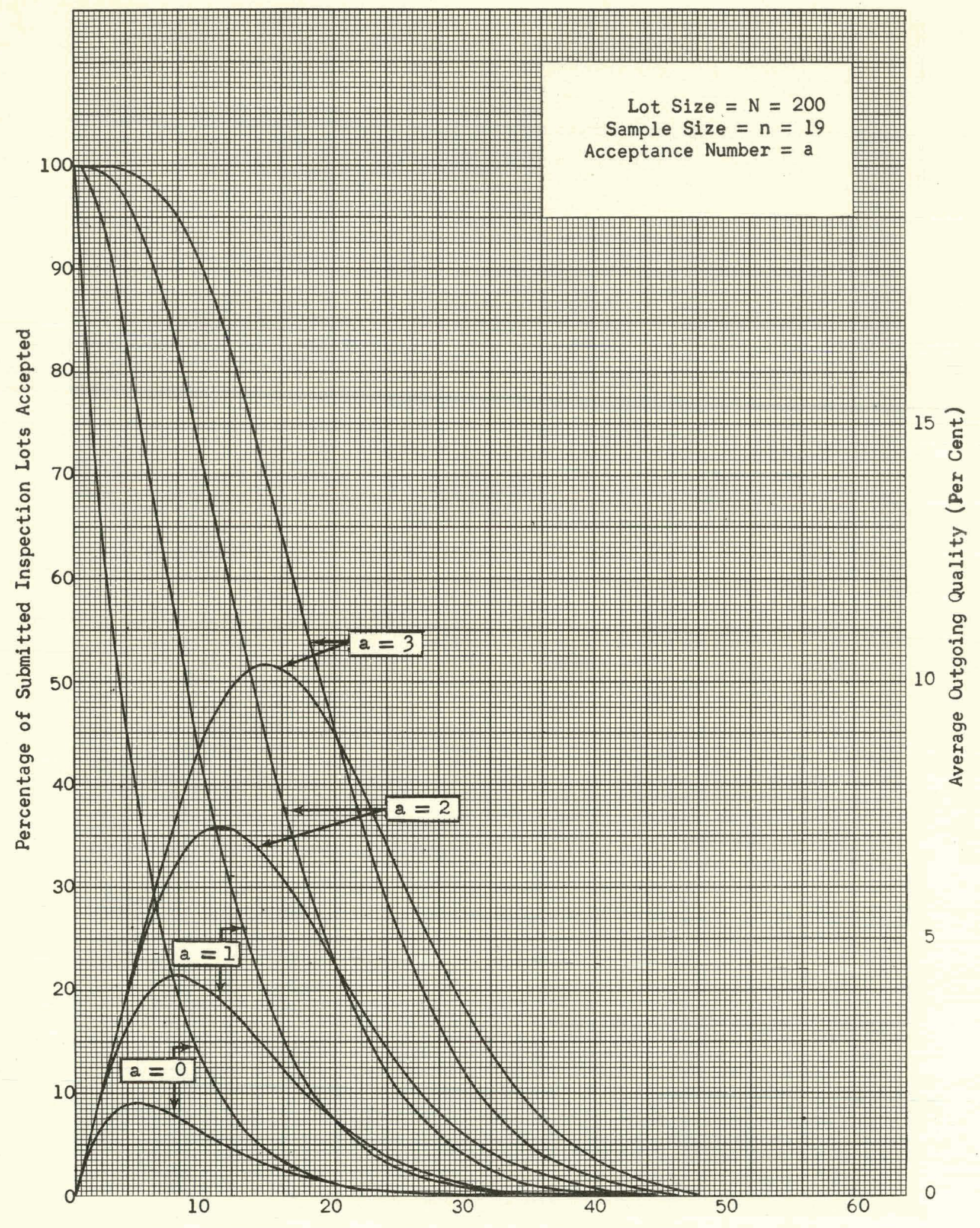

Percentage of Defective Items in Submitted Inspection Lots 


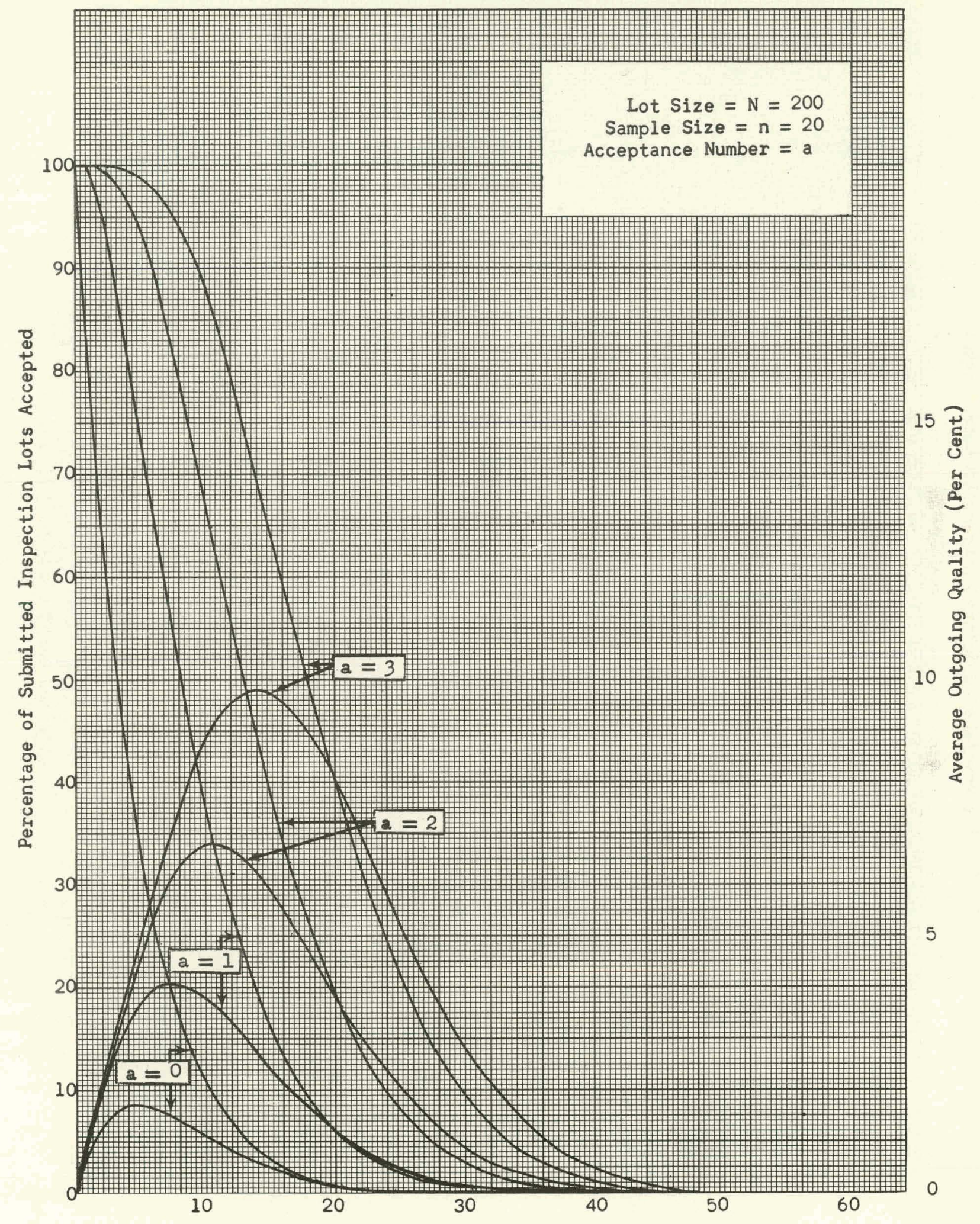

Percentage of Defective Items in Submitted Inspection Lots 


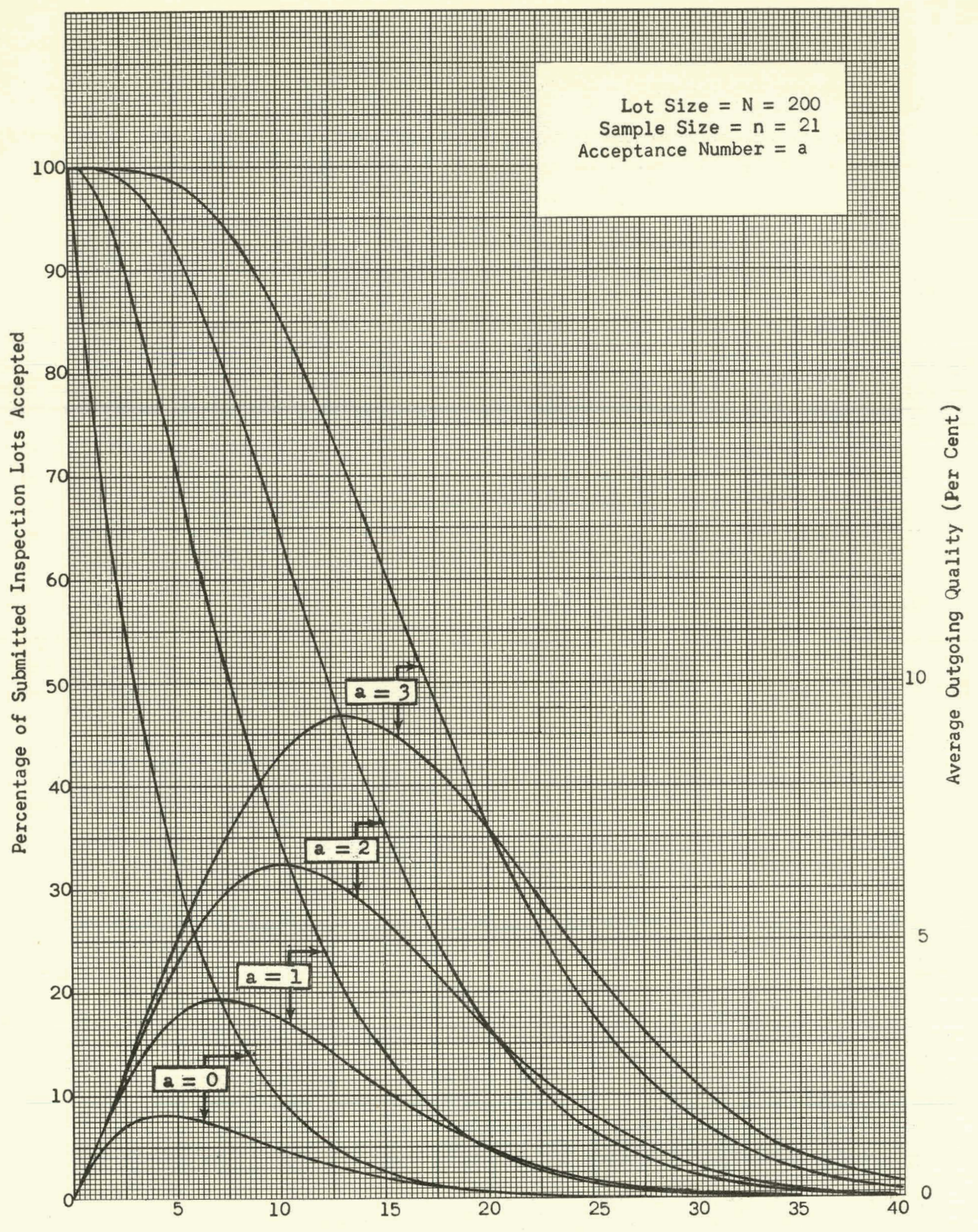

Percentage of Defective Items in Submitted Inspection Lots 


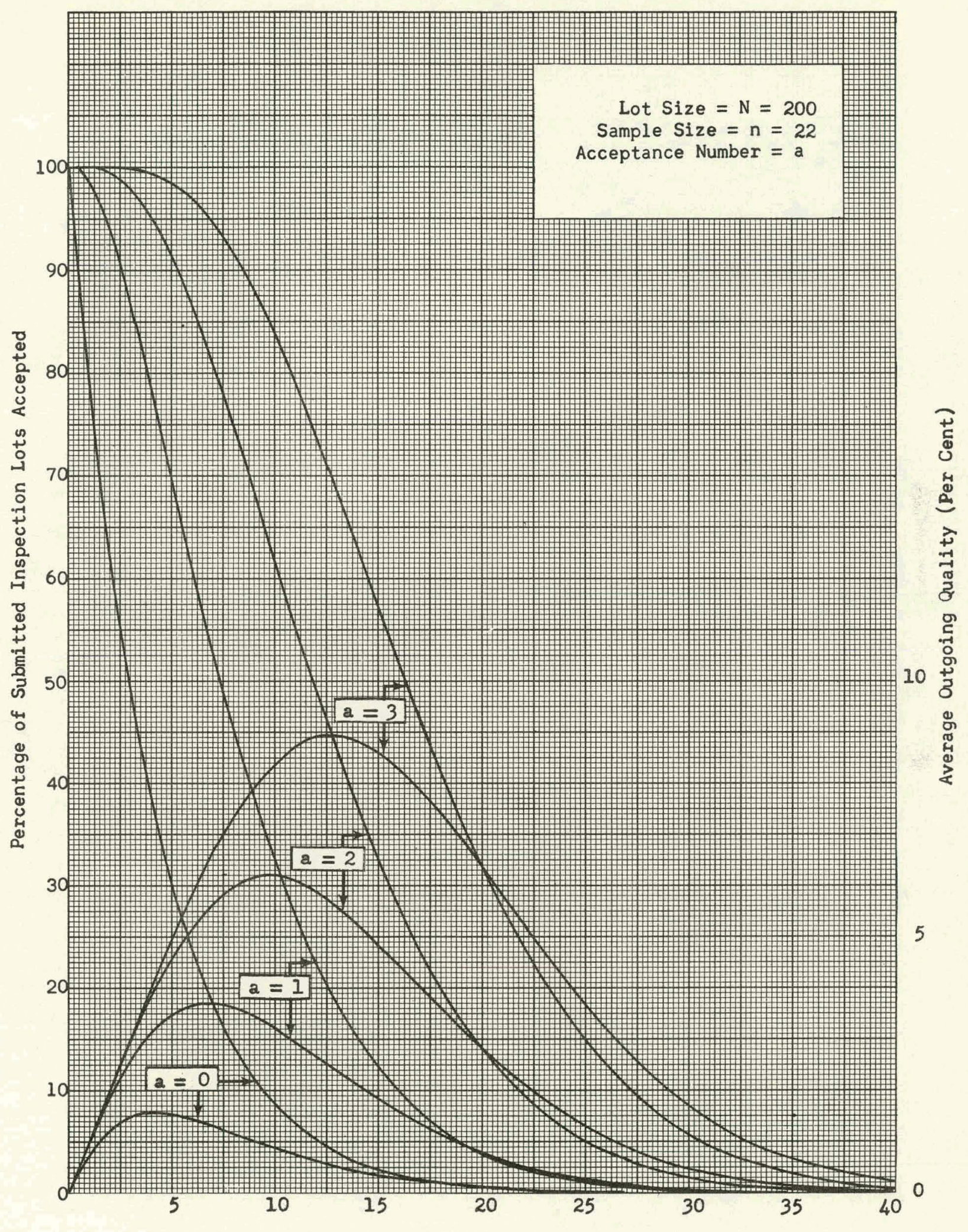

Percentage of Defective Items in Submitted Inspection Lots 


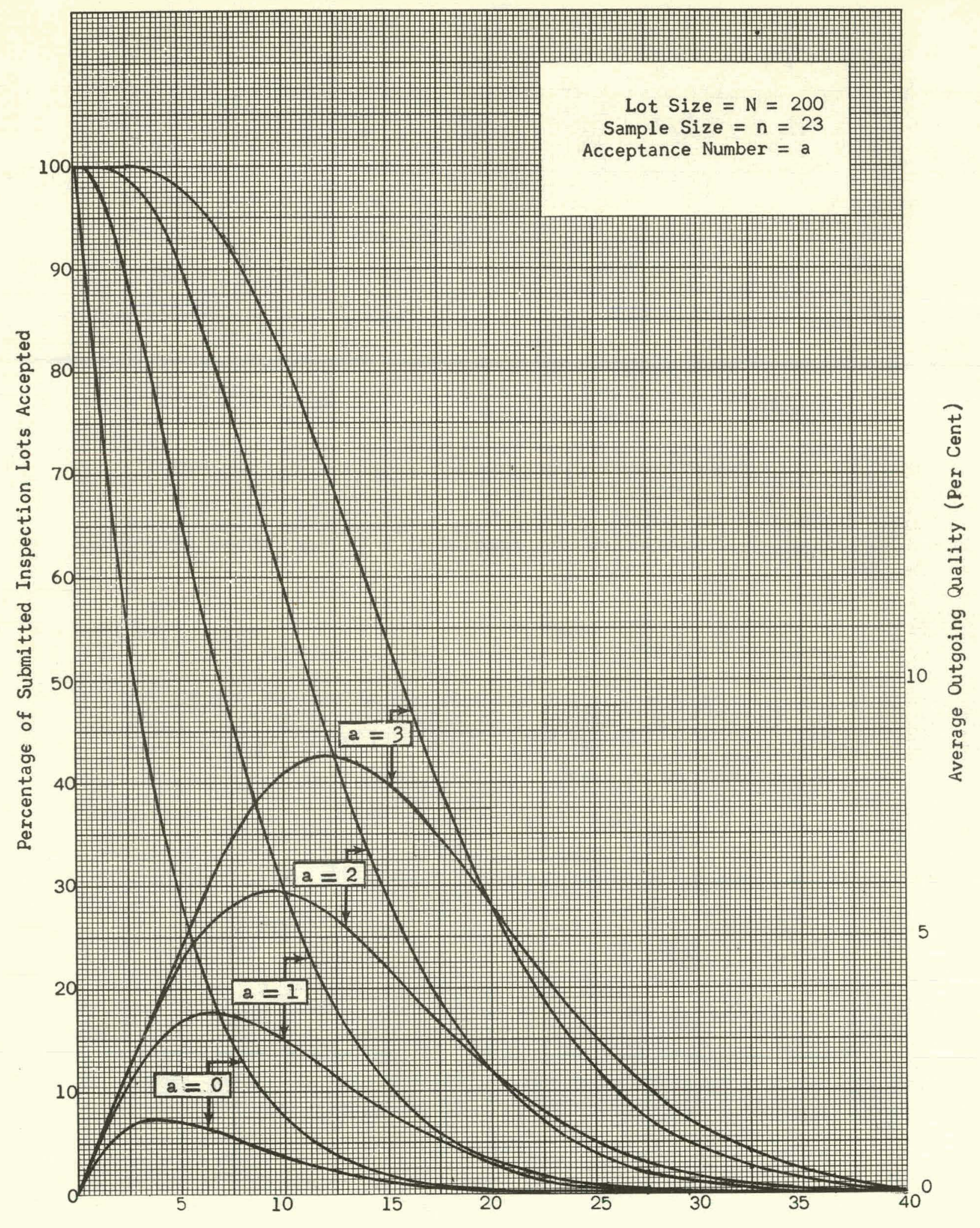

Percentage of Defective Items in Submitted Inspection Lots 


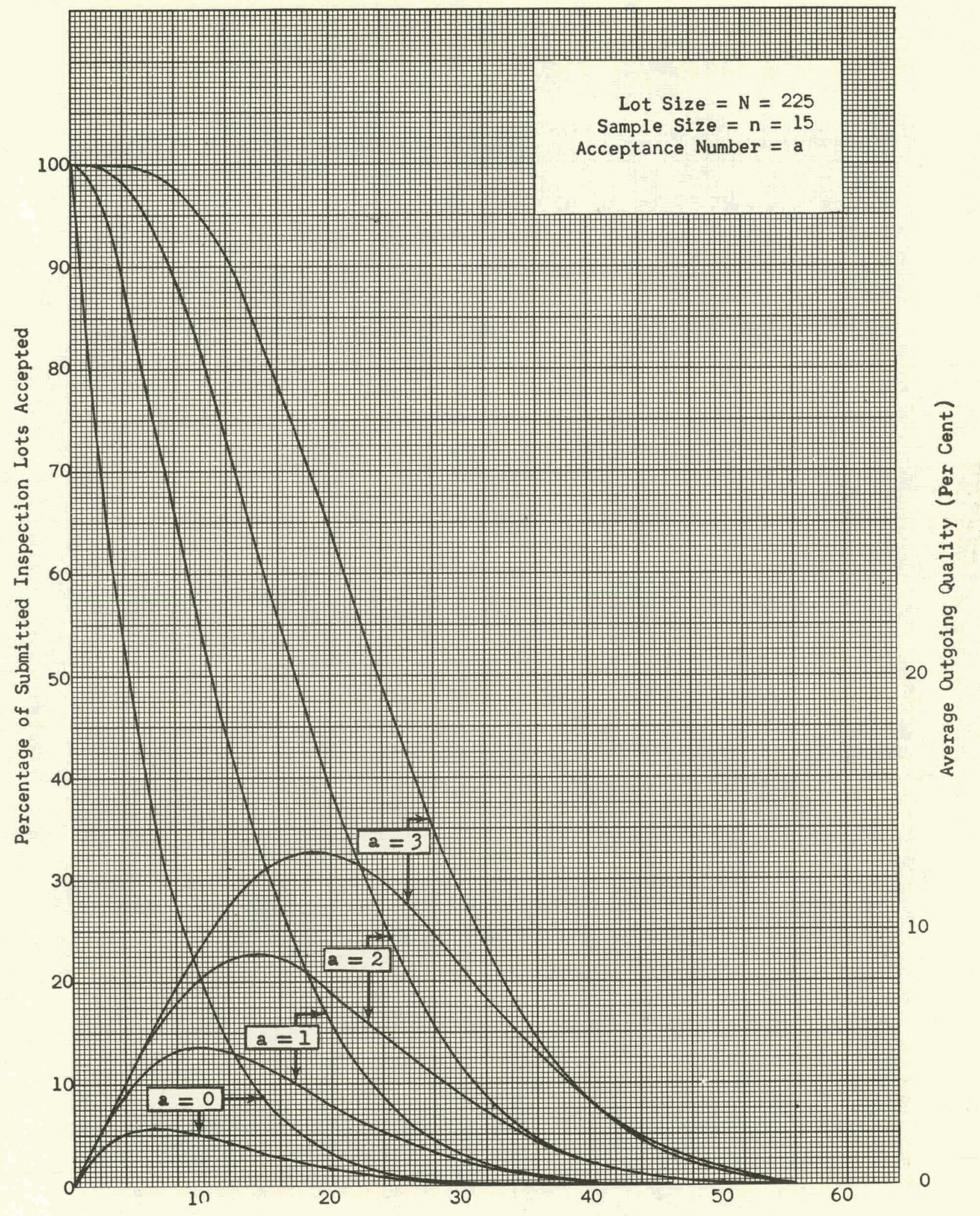

Percentage of Defective Items in Submitted Inspection Lots 


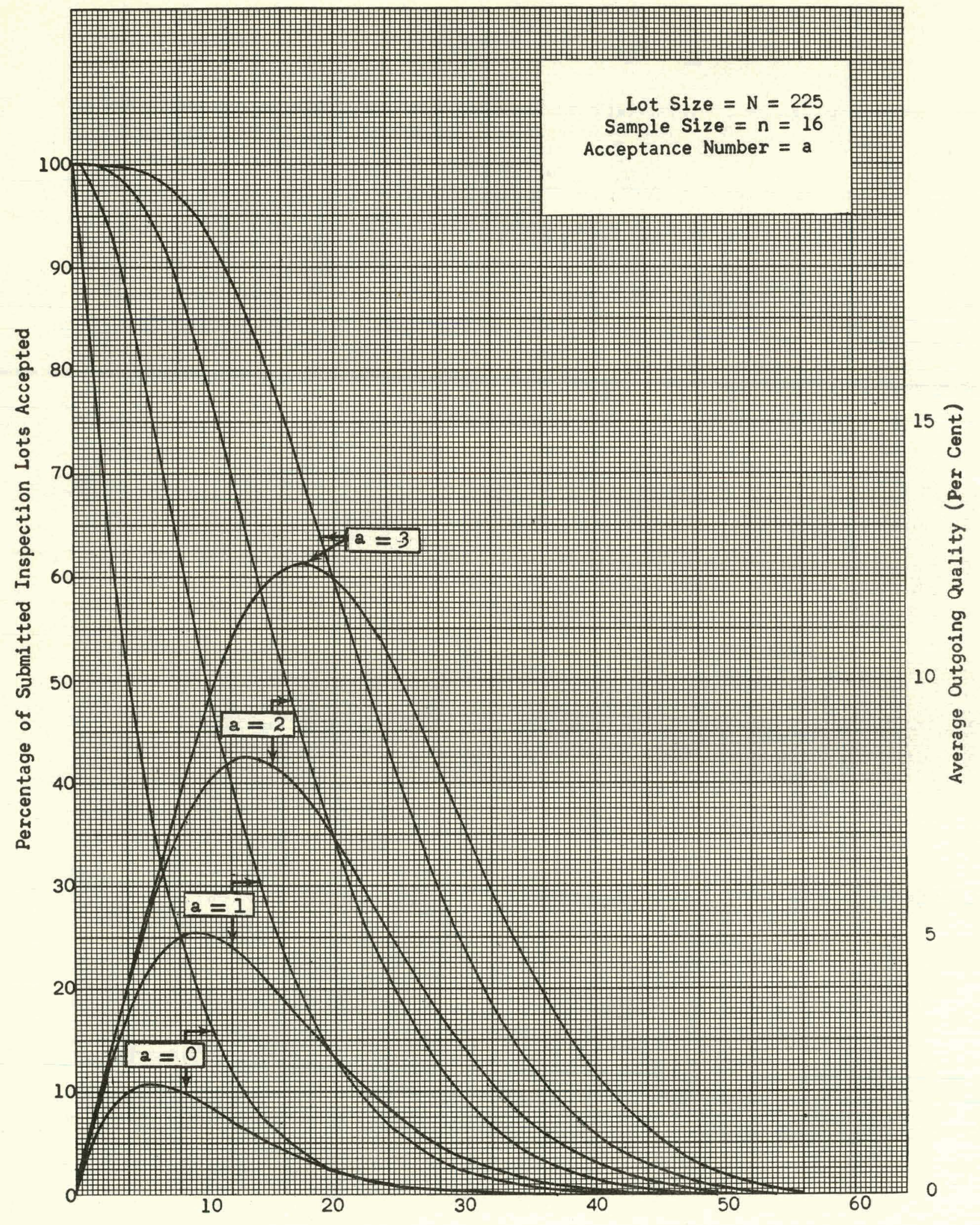

Percentage of Defective Items in Submitted Inspection Lots 


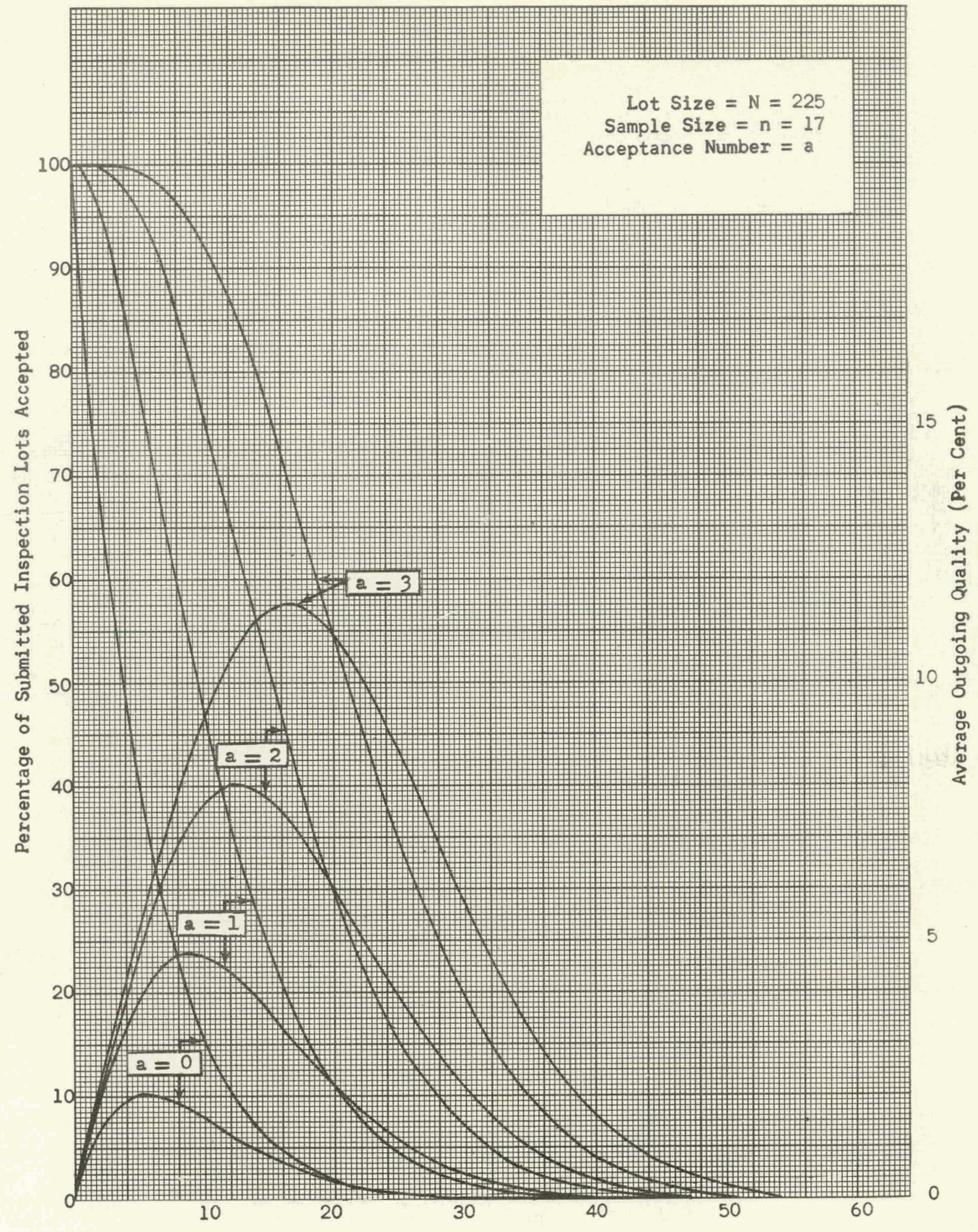

Percentage of Defective Items in Submitted Inspection Lots 


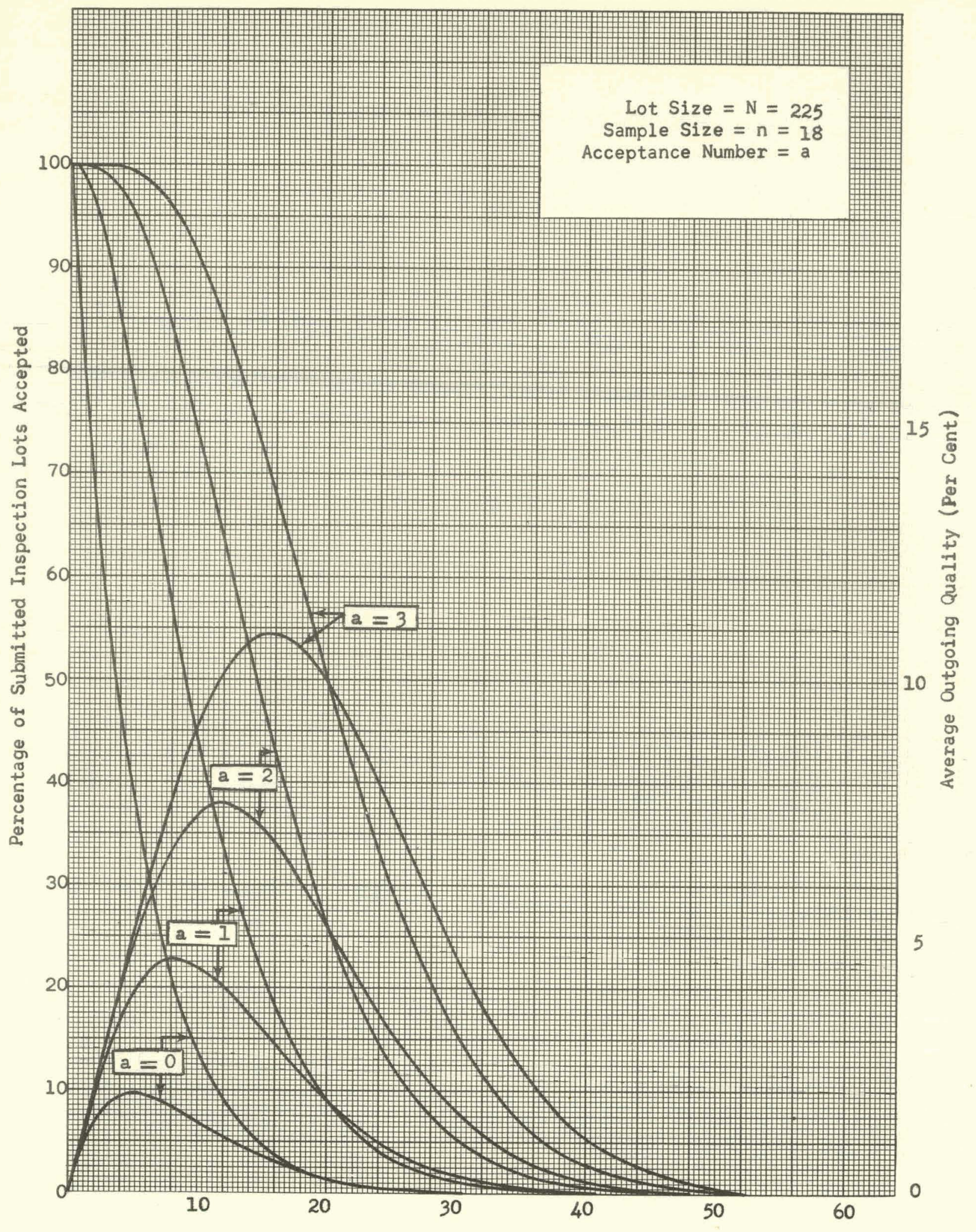

Percentage of Defective Items in Submitted Inspection Lots 


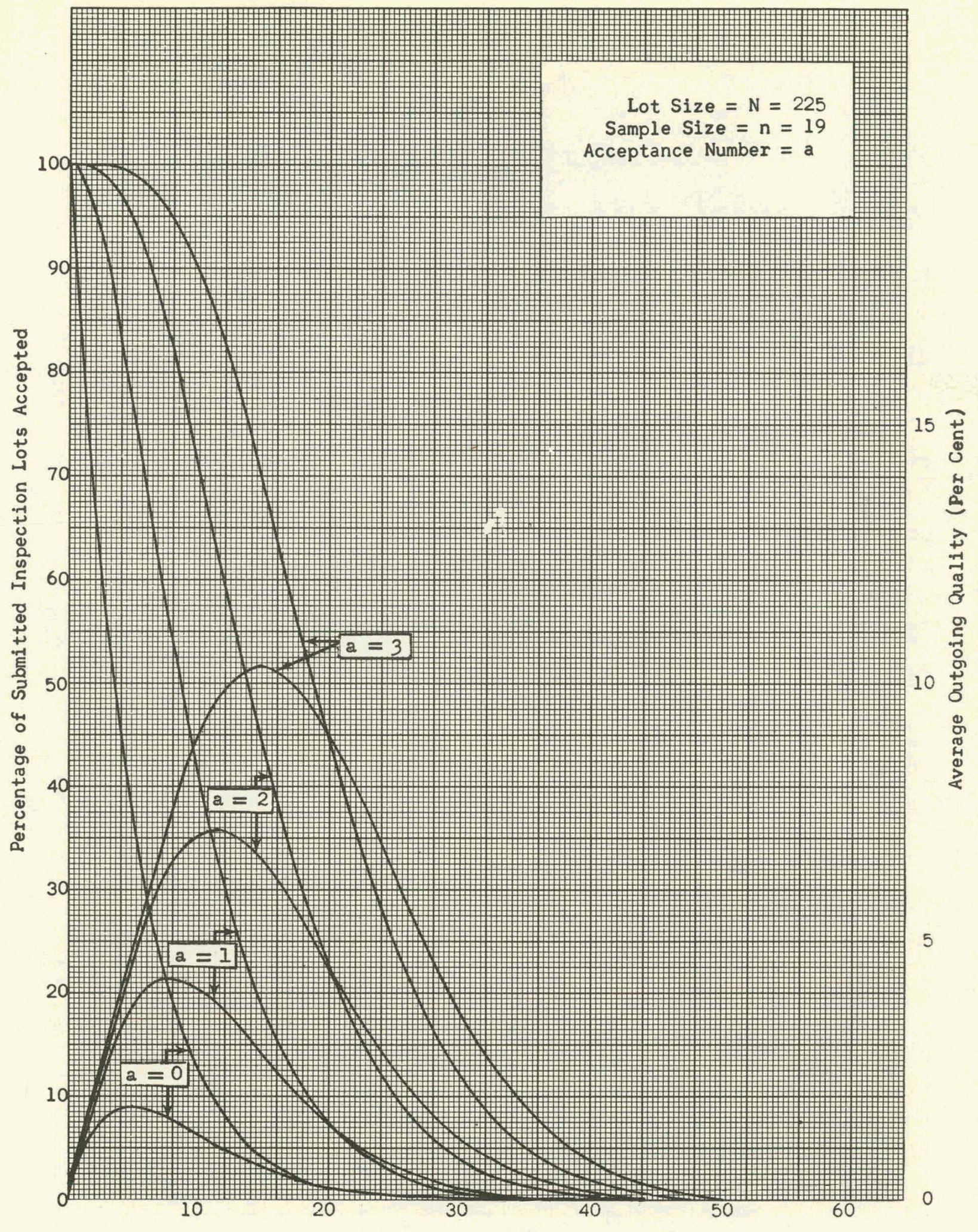

Percentage of Defective Items in Submitted Inspection Lots 


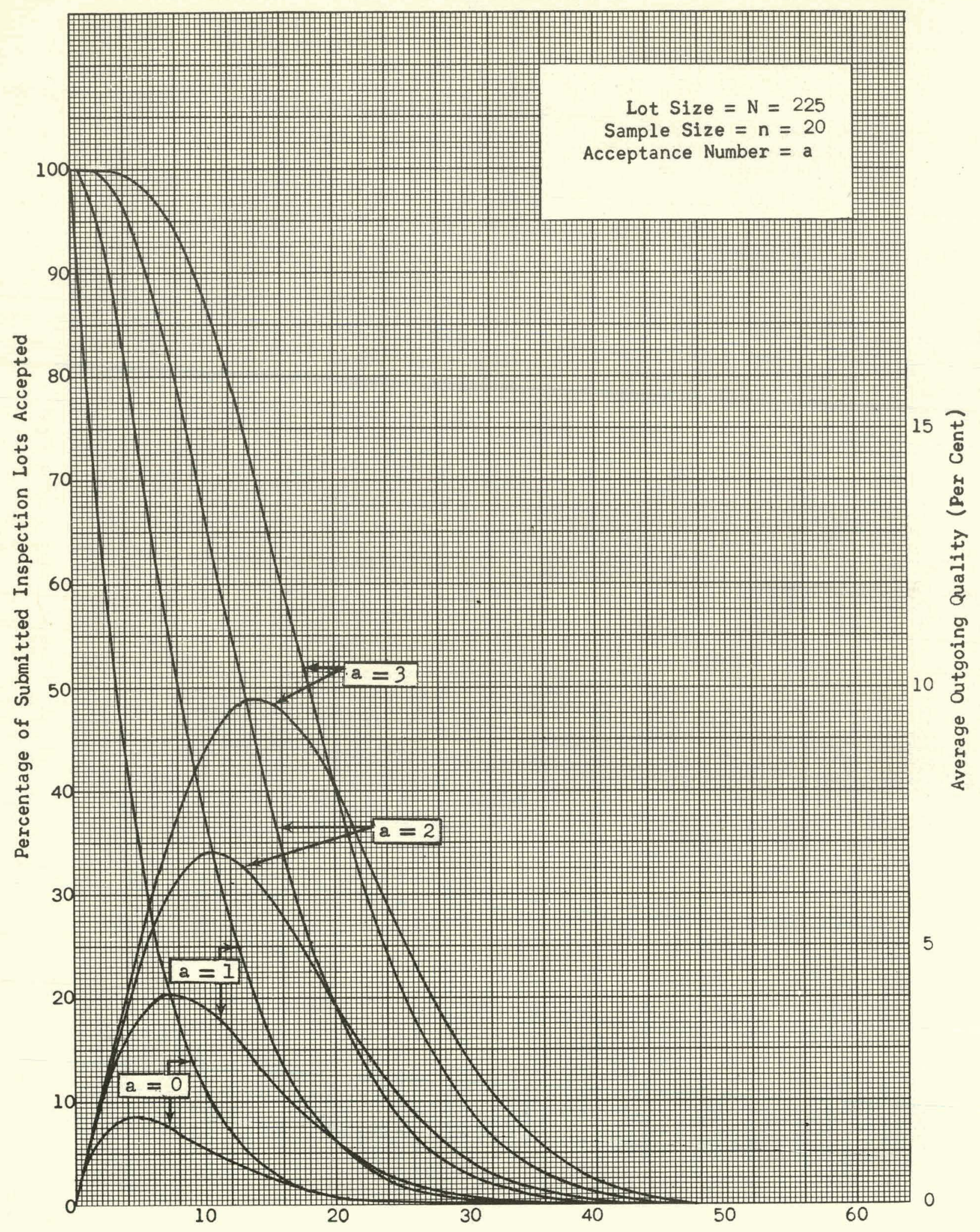

Percentage of Defective Items in Submitted Inspection Lots 


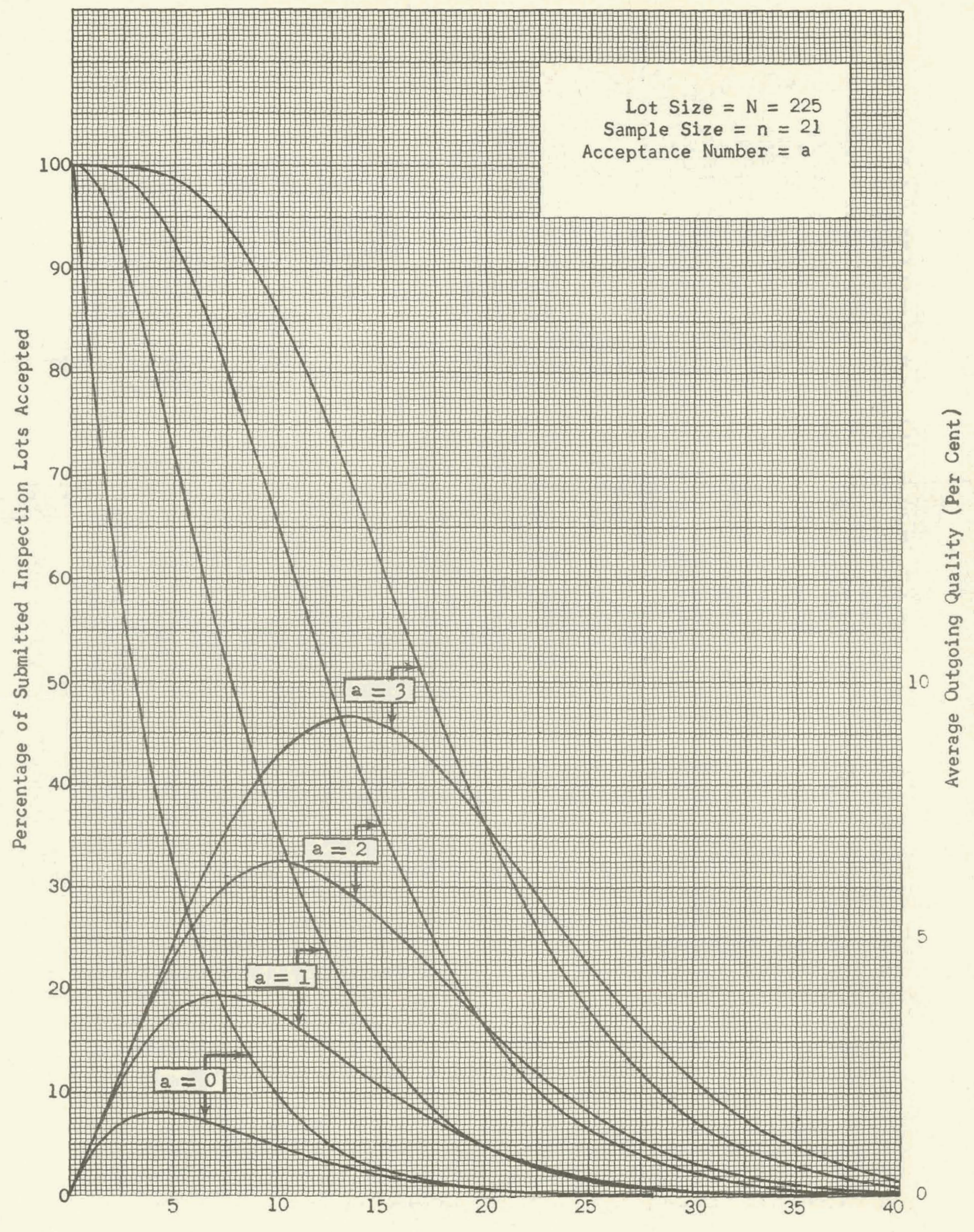

Percentage of Defective Items in Submitted Inspection Lots 


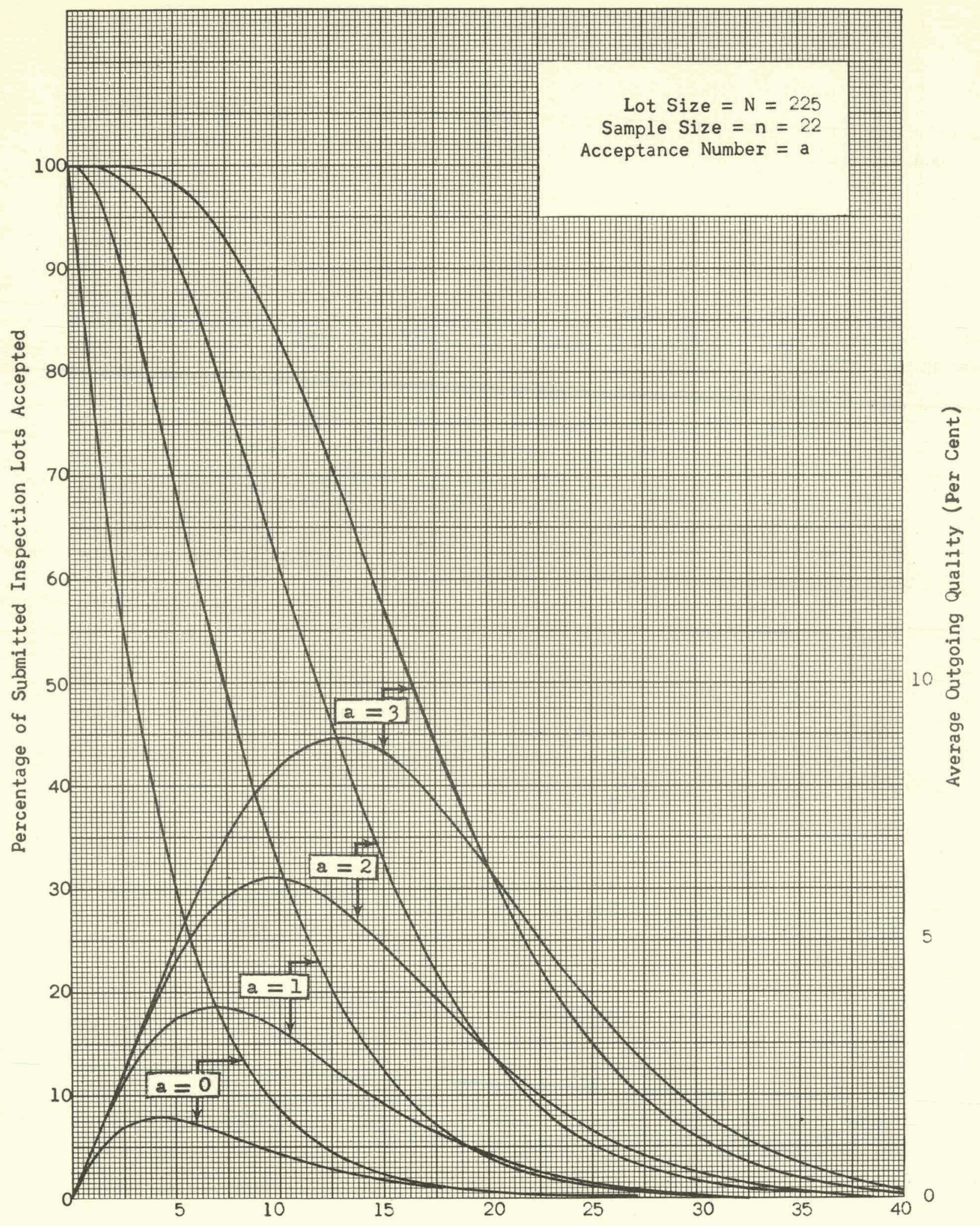

Percentage of Defective Items in Submitted Inspection Lots 


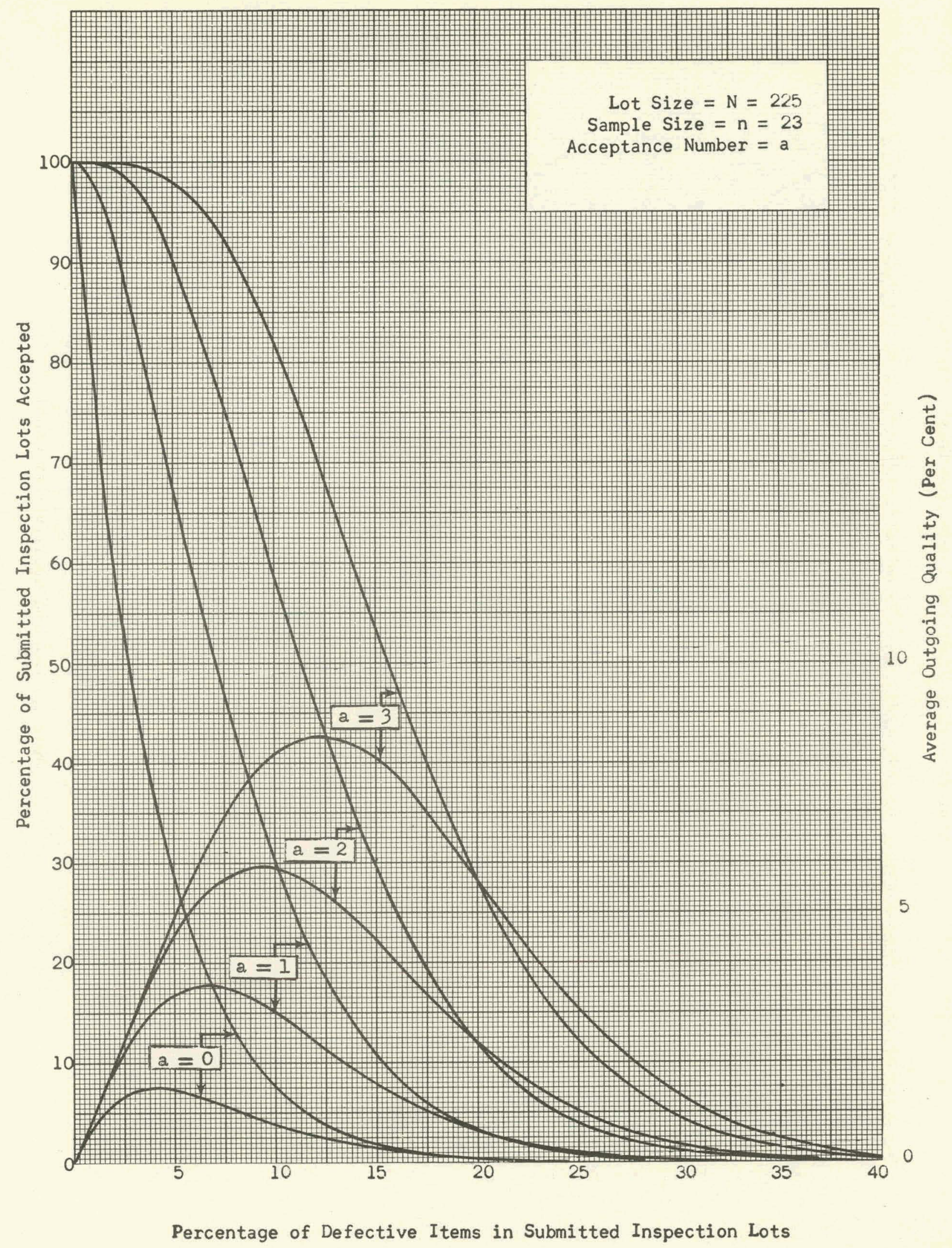




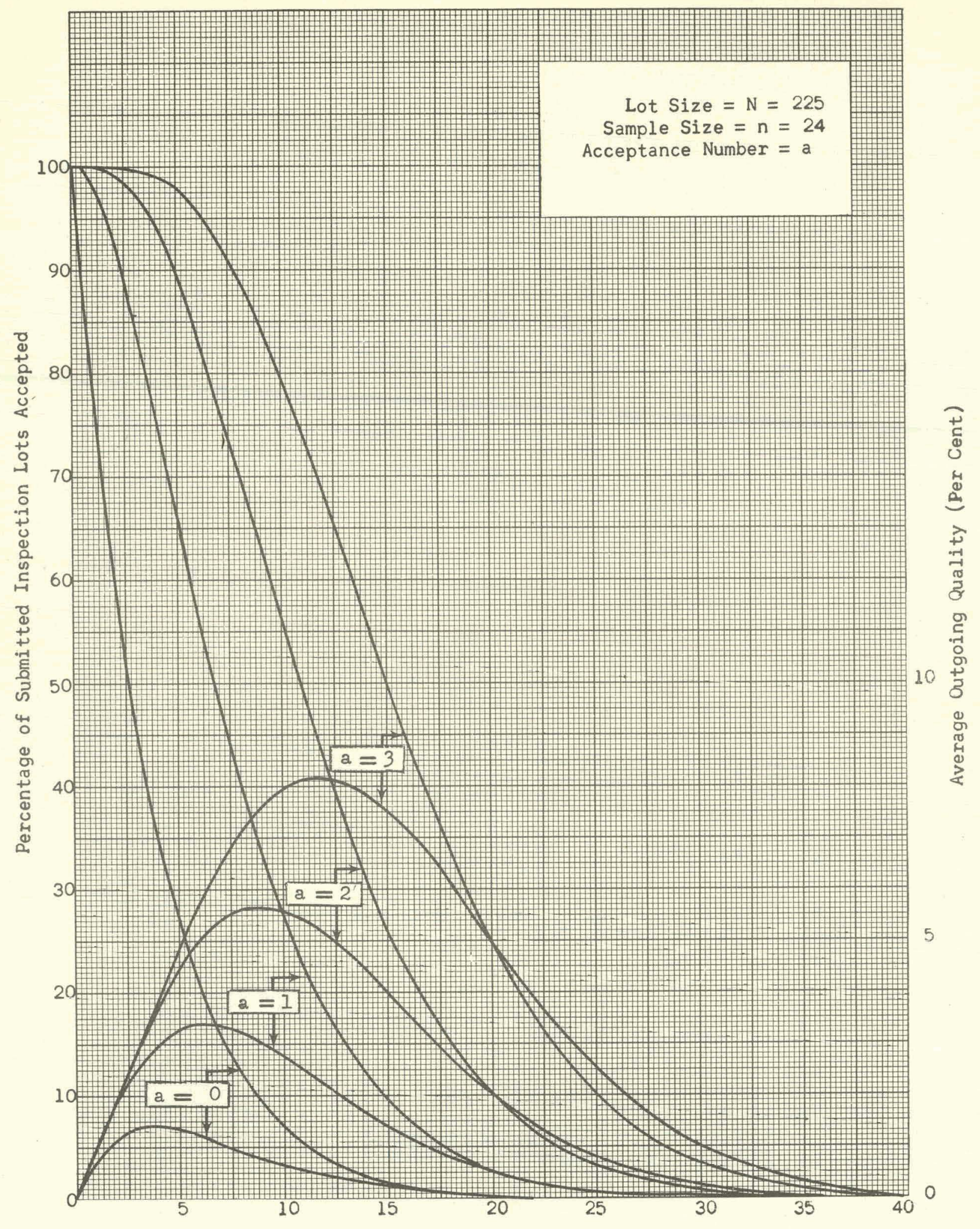

Percentage of Defective Items in Submitted Inspection Lots 